\title{
animals
}

\section{Horse Feeding \\ and Management}

Edited by

Markku Saastamoinen

Printed Edition of the Special Issue Published in Animals 
Horse Feeding and Management 



\section{Horse Feeding and Management}

Special Issue Editor

Markku Saastamoinen

MDPI • Basel • Beijing • Wuhan • Barcelona • Belgrade

\section{MDPI}


Special Issue Editor

Markku Saastamoinen

Natural Resources Institute

Finland (LUKE)

Finland

Editorial Office

MDPI

St. Alban-Anlage 66

4052 Basel, Switzerland

This is a reprint of articles from the Special Issue published online in the open access journal Animals (ISSN 2076-2615) from 2019 to 2020 (available at: https:/ / www.mdpi.com/journal/animals/special_ issues/horse_feeding_and_management).

For citation purposes, cite each article independently as indicated on the article page online and as indicated below:

LastName, A.A.; LastName, B.B.; LastName, C.C. Article Title. Journal Name Year, Article Number, Page Range.

ISBN 978-3-03928-552-5 (Pbk)

ISBN 978-3-03928-553-2 (PDF)

(C) 2020 by the authors. Articles in this book are Open Access and distributed under the Creative Commons Attribution (CC BY) license, which allows users to download, copy and build upon published articles, as long as the author and publisher are properly credited, which ensures maximum dissemination and a wider impact of our publications.

The book as a whole is distributed by MDPI under the terms and conditions of the Creative Commons license CC BY-NC-ND. 


\section{Contents}

About the Special Issue Editor $\ldots \ldots \ldots \ldots \ldots \ldots \ldots$ vii

Preface to "Horse Feeding and Management" $\ldots \ldots \ldots \ldots \ldots \ldots \ldots$ ix

Tayler L. Hansen, Elisabeth L. Chizek, Olivia K. Zugay, Jessica M. Miller, Jill M. Bobel, Jessie W. Chouinard, Angie M. Adkin, Leigh Ann Skurupey and Lori K. Warren

Digestibility and Retention Time of Coastal Bermudagrass (Cynodon dactylon) Hay by Horses Reprinted from: Animals 2019, 9, 1148, doi:10.3390/ani9121148 . . . . . . . . . . . . 1

Markku Saastamoinen and Susanna Särkijärvi

Effect of Linseed (Linum usitatissimum) Groats-Based Mixed Feed Supplements on Diet Nutrient Digestibility and Blood Parameters of Horses

Reprinted from: Animals 2020, 10, 272, doi:10.3390/ani10020272 . . . . . . . . . . . . 20

Markku Saastamoinen, Susanna Särkijärvi and Elisa Valtonen

The Effect of Diet Composition on the Digestibility and Fecal Excretion of Phosphorus in Horses:

A Potential Risk of P Leaching?

Reprinted from: Animals 2020, 10, 140, doi:10.3390/ani10010140 . . . . . . . . . . . . .

Joaquín Bull, Fernando Bas, Macarena Silva-Guzmán, Hope Helen Wentzel,

Juan Pablo Keim and Mónica Gandarillas

Characterization of Feeding, Sport Management, and Routine Care of the Chilean Corralero

Horse during Rodeo Season

Reprinted from: Animals 2019, 9, 697, doi:10.3390/ani9090697 . . . . . . . . . . . . . . 46

Malin Connysson, Marie Rhodin and Anna Jansson

Effects of Horse Housing System on Energy Balance during Post-Exercise Recovery

Reprinted from: Animals 2019, 9, 976, doi:10.3390/ani9110976 . . . . . . . . . . . . . .

Sara Ringmark, Anna Skarin and Anna Jansson

Impact of Year-Round Grazing by Horses on Pasture Nutrient Dynamics and the Correlation with Pasture Nutrient Content and Fecal Nutrient Composition

Reprinted from: Animals 2019, 9, 500, doi:10.3390/ani9080500

Dominique-Marie Votion, Anne-Christine François, Caroline Kruse, Benoit Renaud,

Arnaud Farinelle, Marie-Catherine Bouquieaux, Christel Marcillaud-Pitel and Pascal Gustin

Answers to the Frequently Asked Questions Regarding Horse Feeding and Management

Practices to Reduce the Risk of Atypical Myopathy

Reprinted from: Animals 2020, 10, 365, doi:10.3390/ani10020365 . . . . . . . . . . . . .

Katrin M. Lindroth, Astrid Johansen, Viveca Båverud, Johan Dicksved, Jan Erik Lindberg and Cecilia E. Müller

Differential Defecation of Solid and Liquid Phases in Horses-A Descriptive Survey

Reprinted from: Animals 2020, 10, 76, doi:10.3390/ani10010076 . . . . . . . . . . . . . . .

Katrina Merkies, Chloe Ready, Leanne Farkas and Abigail Hodder

Eye Blink Rates and Eyelid Twitches as a Non-Invasive Measure of Stress in the Domestic Horse

Reprinted from: Animals 2019, 9, 562, doi:10.3390/ani9080562 . . . . . . . . . . . . . 114 
Béke Nivelle, Liesbeth Vermeulen, Sanne Van Beirendonck, Jos Van Thielen and Bert Driessen

Horse Transport to Three South American Horse Slaughterhouses: A Descriptive Study

Reprinted from: Animals 2020, 10, 602, doi:10.3390/ani10040602 . . . . . . . . . . . . . 124

Nicoletta Miraglia, Elisabetta Salimei and Francesco Fantuz

Equine Milk Production and Valorization of Marginal Areas-A Review

Reprinted from: Animals 2020, 10, 353, doi:10.3390/ani10020353 . . . . . . . . . . . . . . 147

Agata Rzekeć, Céline Vial and Geneviève Bigot

Green Assets of Equines in the European Context of the Ecological Transition of Agriculture

Reprinted from: Animals 2020, 10, 106, doi:10.3390/ani10010106 . . . . . . . . . . . . . . 164 


\section{About the Special Issue Editor}

Markku Saastamoinen, Ph.D., Senior Scientist, graduated at the University of Helsinki in 1987 in Animal Science (animal nutrition and animal genetics) with a doctorial thesis 'Genetic and Environmental Parameter for Measures of Racing Performance in Standadrbred and Finnhorse Trotters' at the University of Helsinki in 1997. He is currently working as a senior scientist in Natural Resources Institute Finland (LUKE) on several topics related to horses and horse production, and as a lecturer in equine nutrition and management at the University of Helsinki. He has published scientific publications on equine nutrition, genetics, management exercise physiology, and equine economy. He has held several national and European positions in scientific and horse organizations and committees and was president of the Equine Workshop on Equine Nutrition (EWEN) as well as a secretary and vice president of the Horse Commission of the European Association of Animal Science (EAAP). 



\section{Preface to "Horse Feeding and Management"}

Horses perform variety of roles in our society, serving people in several ways. Thus, the links between equine health and good dietary treatment must be recognized to increase our understanding of the needs of the horse. Proper nutrition and feeding management are the main objectives to fulfil the ethological and physiological needs and to ensure the well-being and performance of horses. They influence the growth, reproduction, performance capacity, and health of the horse. Horse feeding is challenging for many horse owners as well as trainers and breeders. Many horses suffer from overweight as well as many diseases associated with nutrition. Other management issues, including stable and environmental conditions and feeding systems, have a major impact on the health and well-being of horses. Horses' management also influences their environment. In addition, there are many innovations in horse feeding and management. Large amounts of evidence- and science-based knowledge support good nutrition and management practices in horse husbandry. It is important to ensure these data are available to all stakeholders and people working in the horse industry. Consequently, the objective of this Special Issue and book is to publish research papers dealing with horse nutrition and management and the interrelations between management, nutrition, health, wellbeing, and environment to strengthen the knowledge about nutrition and management of all horse categories.

Markku Saastamoinen Special Issue Editor 

Article

\title{
Digestibility and Retention Time of Coastal Bermudagrass (Cynodon dactylon) Hay by Horses
}

\author{
Tayler L. Hansen, Elisabeth L. Chizek, Olivia K. Zugay, Jessica M. Miller, Jill M. Bobel, \\ Jessie W. Chouinard, Angie M. Adkin, Leigh Ann Skurupey and Lori K. Warren* \\ Department of Animal Sciences, University of Florida, Gainesville, FL 32611, USA; \\ tlhansen@cornell.edu (T.L.H.); creeksidefarm14@gmail.com (E.L.C.); ozugay@ufl.edu (O.K.Z.); \\ horsewhisperer1230@hotmail.com (J.M.M.); jbrides2@ufl.edu (J.M.B.); jessie23@ufl.edu (J.W.C.); \\ aadkin@ufl.edu (A.M.A.); leighann.skurupey@ndsu.edu (L.A.S.) \\ * Correspondence: lkwarren@ufl.edu
}

Received: 30 October 2019; Accepted: 13 December 2019; Published: 14 December 2019

Simple Summary: Longer retention of forages with increased fiber concentrations may be a compensatory digestive strategy in horses. We investigated the digestive characteristics of bermudagrass hay, a prominent warm-season grass in the southeast United States that has greater fiber concentrations than other common forages fed to horses. The morphological structure and photosynthetic pathway of warm-season grasses differ from cool-season grasses and legumes which may have important impacts on equine digestion and digesta transit through the gastrointestinal tract. The retention time of Coastal bermudagrass was longer than alfalfa or orchardgrass hay. The digestibility of Coastal bermudagrass decreased with increasing maturity, but the fiber digestibility of alfalfa and orchardgrass was similar to the earliest maturity of Coastal bermudagrass hay. The chemical composition of the plant cell wall influences diet digestibility and is a major difference between warm-season and cool-season forages. The increased retention time of Coastal bermudagrass allows for microbial fermentation to occur longer, adapting to more difficult-to-digest plant cell walls in warm-season forages. The decrease in diet digestibility when horses consume warm-season forages can be reduced by feeding early maturity forage, by harvesting hay at an earlier stage of growth or managing pastures in a vegetative state.

\begin{abstract}
Bermudagrass (Cynodon dactylon) and other warm-season grasses are known for their increased fiber concentrations and reduced digestibility relative to cool-season grasses and legumes. This study investigated the digestive characteristics and passage kinetics of three maturities of Coastal bermudagrass hay. A $5 \times 5$ Latin square design experiment was used to compare the digestion of five hays: alfalfa (Medicago sativa, ALF), orchardgrass (Dactylis glomerata, $\mathrm{ORCH}$ ), and Coastal bermudagrass harvested at 4 (CB 4), 6 (CB 6), and 8 weeks of regrowth (CB 8). Horses were fed cobalt-ethylenediaminetetraacetic acid (Co-EDTA) and ytterbium $(\mathrm{Yb})$ labeled neutral detergent fiber (NDF) before an 84 -h total fecal collection to determine digesta retention time. Dry matter digestibility was greatest for ALF (62.1\%) and least for CB $6(36.0 \%)$ and CB 8 diets $(36.8 \%$, SEM $=2.1 ; p<0.05)$. Mean retention time was longer $(p<0.05)$ for Coastal bermudagrass (particulate $31.3 \mathrm{~h}$, liquid $25.3 \mathrm{~h}$ ) compared with ORCH and ALF $(28.0 \mathrm{~h}, \mathrm{SEM}=0.88 \mathrm{~h} ; 20.7 \mathrm{~h}, \mathrm{SEM}=0.70 \mathrm{~h})$. Further evaluation of digesta passage kinetics through mathematical modeling indicated ALF had distinct parameters compared to the other diets. Differences in digestive variables between forage types are likely a consequence of fiber physiochemical properties, warranting further investigation on forage fiber and digestive health.
\end{abstract}

Keywords: alfalfa; equine; fiber; forage maturity; mathematical modeling; mean retention time; orchardgrass; rate of passage; warm-season grass 


\section{Introduction}

Bermudagrass (Cynodon dactylon) is one of the most prominent forages in the southeast United States; however, some horse owners and equine professionals assume that bermudagrass, particularly the Coastal variety, is a lower quality hay due to increased fiber concentrations. Furthermore, feeding Coastal bermudagrass hay in this region has been implicated as a cause of ileocecal impaction in horses [1]. The increased fiber concentrations of Coastal bermudagrass and fine, soft texture have been hypothesized to contribute to impaction [2], but greater fiber concentration is a common characteristic among warm-season grasses. Bermudagrass and other grasses common to subtropical and tropical climates (e.g., bahiagrass, millet, sorghum) possess a series of anatomical and biochemical modifications for C4 photosynthesis that distinguish them from C3 plants. The Kranz anatomy of C4 plants features tightly bundled mesophyll cells that form a ring around bundle-sheath cells. The proximity of mesophyll and bundle-sheath cells allows for carbon concentrating mechanisms in photosynthesis, reducing photorespiration in $\mathrm{C} 4$ plants. Plants using $\mathrm{C} 4$ carbon fixation are more efficient than $\mathrm{C} 3$ carbon fixation in areas of drought, high temperatures, and low nutrient inputs [3]. However, C4 plants tend to a have lower nutritive value via greater fiber concentrations that can lead to decreased animal performance [4].

Greater forage fiber concentrations have long been associated with decreased diet digestibility [5]. Forage digestibility by horses decreases by half a percentage unit for every one percentage unit increase in NDF concentration [6]. Using equine fecal inoculum, Lowman et al. [7] reported that time to reach total gas production took longer for oat (Avena sativa) straw and wheat (Triticum aestivum) straw compared with alfalfa (Medicago sativa) hay and grass haylage. Furthermore, the specific type of dietary fiber (insoluble vs. soluble) alters in vitro digestibility measurements [8]. Not only fiber concentration, but the specific composition of hemicellulose, cellulose, and lignin in the plant cell may alter digestion by horses.

The degradation of forage fiber in the equine gastrointestinal tract may be influenced by digesta rate of passage (ROP); however, a consistent relationship between fiber concentration and digesta mean retention time (MRT) has not been shown in horses. Low nutritional value forages have a longer retention time than high-quality legumes [9], but no difference in MRT was observed when horses were fed similar forage species differing in fiber concentration $[10,11]$. The influence of fiber concentration on digesta MRT may be confounded by factors such as the level of intake and feed particle size [12]. Furthermore, low-fermentable dietary fibers alter ROP through changes in digesta viscosity in the small intestine [13]. Such changes may not be detectable in total tract mean retention time (TTMRT) calculations.

Several mathematical models have been used to describe digesta passage in ruminants that improve understanding of passage kinetics by estimating retention time in the rumen from fecal marker excretion [14-16]. These models have been applied to equine fecal marker excretion with the hopes of increasing the understanding of digesta ROP in horses [10,11,17-20]. The models described by Dhanoa et al. [14] and Pond et al. [15] have been used most frequently to describe digesta passage in horses. The Dhanoa et al. [14] model is a mechanistic model based on first order kinetics. Digesta flows through an unspecified number of compartments with decreasing compartment retention times [14]. In contrast, the stochastic model described by Pond et al. [15] increases the passage rate of an age-dependent compartment to account for an increased probability of digesta leaving a compartment based on previous residence time in the compartment. These models have not been compared with the same data, due in part to the model equations failing to converge with experimental data collected from horses. With more advanced computer applications, a thorough investigation of model fit can be conducted while also exploring the effect of dietary characteristics on passage parameters in the horse.

We hypothesized that the greater hemicellulose concentration of Coastal bermudagrass would alter digestive characteristics. The objective of this study was to compare the digestibility and MRT of Coastal bermudagrass to alfalfa and orchardgrass (Dactylis glomerata) hays, which are other common forages fed to horses. Mean retention time was measured using liquid and particulate phase external 
markers, and fecal marker excretion was modeled using previously developed equations for marker excretion by ruminants [14,15]. We hypothesized that the use of mathematical modeling would provide a greater understanding of ROP variables than TTMRT alone. Differences in total tract MRT of Coastal bermudagrass compared with alfalfa and orchardgrass hay indicate fiber chemical composition alters digesta movement in the gastrointestinal tract of the horse. Longer digesta retention of Coastal bermudagrass may be an important compensation strategy to maximize the available nutrients from slowly degraded fibers in warm-season grasses.

\section{Materials and Methods}

All animal protocols were approved by the University of Florida Institutional Animal Care and Use Committee (201509618) under the FASS Guide for the Care and Use of Agricultural Animals in Research and Teaching [21]. This study took place from 1 July 2015 to 9 September 2015, in Gainesville, FL, USA. The mean temperature was $26.3^{\circ} \mathrm{C}$ and relative humidity was $88.5 \%$ during the study period.

Five mature Quarter Horse geldings ( $8 \pm 3$ years, $552 \pm 14$ kg, BCS $6.0 \pm 0.4$ [22], mean \pm SEM) housed at the University of Florida's Horse Teaching Unit in Gainesville, FL were used in this study. Before the start of the study, horses were fed Coastal bermudagrass hay or kept in warm-season grass pastures. Horses received routine vaccinations and anthelmintic treatment before entering the study. Farrier care was maintained during the study according to standard operating procedures of the Unit. During the study, horses were individually housed in $3.7 \mathrm{~m} \times 3.7 \mathrm{~m}$ stalls bedded with wood shaving and provided access to $7.4 \mathrm{~m} \times 18.3 \mathrm{~m}$ outdoor, grass-free paddocks with sand footing for $3 \mathrm{~h}$ each day for voluntary exercise.

Five hays (Table 1) were used to evaluate 5 forage-based diets (Table 2). Hay was fed at $1.6 \%$ body weight (BW) (dry matter (DM) basis). Alfalfa (ALF) and orchardgrass (ORCH) hays were purchased from a commercial hay dealer (Larson Farms; Ocala, FL). Coastal bermudagrass hays were harvested in Alachua, FL at 4 weeks (CB 4), 6 weeks (CB 6), and 8 weeks (CB 8) of regrowth under similar management conditions. The $\mathrm{CB} 4$ and $\mathrm{CB} 6$ were second cuttings, whereas the $\mathrm{CB} 8$ was a first cutting. Based on producer harvesting schedules and study timeline, 8 weeks of regrowth as a second cutting was not feasible for this study. The orchardgrass hay had a high electrolyte concentration, therefore, sodium chloride and potassium chloride were added to each diet to better balance electrolyte intake between diets. Horses were fed a vitamin/mineral pellet ( 0.1 to $0.125 \%$ BW, DM basis) during the evening meal to meet micronutrient requirements [23].

Diets were evaluated in a $5 \times 5$ Latin square design experiment. A standard $5 \times 5$ Latin square was randomly selected from Fisher and Yates [24]. Horses were randomly assigned to different rows and each period was considered a column. Each period lasted 14 days and consisted of a 10.5-day restricted intake phase when the ration was split into two equal-sized meals fed at 0730 and $1930 \mathrm{~h}$ (Table 2). On day 7, an 84-h total fecal collection that began during the evening meal was conducted to determine diet digestibility and retention time. As part of a companion study [25], horses had ad libitum access to hay for the remaining 3.5 days before the start of the next period.

Table 1. Nutrient composition of feedstuffs.

\begin{tabular}{|c|c|c|c|c|c|c|c|}
\hline Nutrient ${ }^{a}$ & Alfalfa & Orchardgrass & $\begin{array}{c}\text { Coastal } 4 \\
\text { Weeks }\end{array}$ & $\begin{array}{c}\text { Coastal } 6 \\
\text { Weeks }\end{array}$ & $\begin{array}{c}\text { Coastal } 8 \\
\text { Weeks }\end{array}$ & 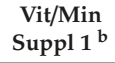 & $\begin{array}{l}\text { Vit/Min } \\
\text { Suppl } 2^{\text {C }}\end{array}$ \\
\hline DM, \% & 88.4 & 90.9 & 90.0 & 91.8 & 91.6 & 89.4 & 90.5 \\
\hline $\mathrm{DE}^{\mathrm{d}}, \mathrm{Mcal} / \mathrm{kg}$ & 2.50 & 2.09 & 1.95 & 1.90 & 1.85 & 2.76 & 3.31 \\
\hline $\mathrm{CP}, \%$ & 23.2 & 11.5 & 18.5 & 12.7 & 12.6 & 15.3 & 37.2 \\
\hline $\mathrm{NDF}, \%$ & 37.7 & 57.2 & 67.5 & 70.9 & 73.3 & 43.3 & 16.9 \\
\hline $\mathrm{ADF}, \%$ & 29.5 & 42.0 & 32.7 & 34.7 & 35.1 & 25.9 & 8.4 \\
\hline ADL, $\%$ & 8.3 & 2.8 & 4.6 & 5.0 & 6.0 & n.m. & n.m. \\
\hline Starch, \% & 1.3 & 0.2 & 1.6 & 1.6 & 2.5 & n.m. & n.m. \\
\hline ESC, \% & 5.9 & 9.6 & 4.3 & 4.4 & 4.4 & n.m. & n.m. \\
\hline WSC, \% & 6.3 & 12.5 & 3.6 & 4.3 & 4.8 & n.m. & n.m. \\
\hline
\end{tabular}


Table 1. Cont.

\begin{tabular}{|c|c|c|c|c|c|c|c|}
\hline Nutrient $^{a}$ & Alfalfa & Orchardgrass & $\begin{array}{c}\text { Coastal } 4 \\
\text { Weeks }\end{array}$ & $\begin{array}{c}\text { Coastal } 6 \\
\text { Weeks }\end{array}$ & $\begin{array}{c}\text { Coastal } 8 \\
\text { Weeks }\end{array}$ & $\begin{array}{l}\text { Vit/Min } \\
\text { Suppl } 1^{b}\end{array}$ & $\begin{array}{l}\text { Vit/Min } \\
\text { Suppl } 2^{\mathrm{C}}\end{array}$ \\
\hline $\mathrm{Ca}, \%$ & 1.58 & 0.32 & 0.57 & 0.39 & 0.38 & 1.31 & 3.12 \\
\hline $\mathrm{P}, \%$ & 0.24 & 0.23 & 0.30 & 0.27 & 0.18 & 1.78 & 1.19 \\
\hline $\mathrm{Na}, \%$ & 0.067 & 0.44 & 0.067 & 0.023 & 0.12 & 0.23 & 0.40 \\
\hline $\mathrm{K}, \%$ & 2.33 & 2.12 & 1.58 & 1.74 & 0.82 & 1.03 & 1.60 \\
\hline $\mathrm{Cl}, \%$ & 0.93 & 1.56 & 0.45 & 0.33 & 0.17 & 0.60 & 0.75 \\
\hline uNDFom, $\%$ e & 20.9 & 11.6 & 21.4 & 25.8 & 38.6 & n.m. & n.m. \\
\hline
\end{tabular}

${ }^{a}$ Nutrient composition of forages analyzed by NIRS at Dairy One Inc. (Ithaca, NY, USA). ${ }^{\mathrm{b}}$ Gro-n-Win alfa (Buckeye Nutrition, Dalton, OH, USA) analyzed by wet chemistry at Dairy One Inc. (Ithaca, NY, USA). ${ }^{c}$ Equalizer (Seminole Feed, Ocala, FL, USA) analyzed by wet chemistry at Dairy One Inc. (Ithaca, NY, USA). d Digestible energy calculated according to Pagan [26]. ${ }^{e}$ Undigestible NDF (ash-free) determined after 240-h in vitro incubation by Dairyland Laboratories (Arcadia, WI, USA). All values are on a 100\% DM basis except DM. n.m. not measured.

Table 2. Diet composition and nutrient intake of experimental diets ${ }^{1}$.

\begin{tabular}{|c|c|c|c|c|c|}
\hline Item & ALF & ORCH & CB 4 & CB 6 & CB 8 \\
\hline \multicolumn{6}{|l|}{ Ingredient, \% DMI } \\
\hline Alfalfa & 93.7 & & & & \\
\hline Orchardgrass & & 92.8 & & & \\
\hline Coastal Bermuda, 4 weeks & & & 91.8 & & \\
\hline Coastal Bermuda, 6 weeks & & & & 91.8 & \\
\hline Coastal Bermuda, 8 weeks & & & & & 91.4 \\
\hline Vit/Min Suppl $1^{a}$ & 5.9 & & & & \\
\hline Vit/Min Suppl $2^{\text {b }}$ & & 7.2 & 7.2 & 7.2 & 7.1 \\
\hline Sodium Chloride & 0.4 & & 0.3 & 0.4 & 0.2 \\
\hline Potassium Chloride & & & 0.7 & 0.6 & 1.3 \\
\hline \multicolumn{6}{|l|}{ Daily Intake } \\
\hline DM, \% BW & 1.71 & 1.73 & 1.74 & 1.74 & 1.75 \\
\hline $\mathrm{DE}^{\mathrm{c}}, \mathrm{Mcal} / \mathrm{kg} \mathrm{BW}$ & 0.043 & 0.038 & 0.035 & 0.35 & 0.034 \\
\hline $\mathrm{CP}, \mathrm{g} / \mathrm{kg} \mathrm{BW}$ & 3.87 & 2.31 & 3.43 & 2.50 & 2.48 \\
\hline NDF, g/kg BW & 6.47 & 9.36 & 11.01 & 11.56 & 11.94 \\
\hline $\mathrm{ADF}, \mathrm{g} / \mathrm{kg}$ BW & 4.98 & 6.83 & 5.34 & 5.65 & 5.72 \\
\hline $\mathrm{Ca}, \mathrm{mg} / \mathrm{kg}$ BW & 265.9 & 90.23 & 130.2 & 101.4 & 99.82 \\
\hline $\mathrm{P}, \mathrm{mg} / \mathrm{kg} \mathrm{BW}$ & 56.2 & 51.69 & 62.89 & 58.09 & 43.69 \\
\hline $\mathrm{K}, \mathrm{mg} / \mathrm{kg}$ BW & 383.1 & 359.2 & 332.8 & 348.4 & 261.2 \\
\hline $\mathrm{Na}, \mathrm{mg} / \mathrm{kg} \mathrm{BW}$ & 39.3 & 75.03 & 37.92 & 30.88 & 35.6 \\
\hline $\mathrm{Cl}, \mathrm{mg} / \mathrm{kg} \mathrm{BW}$ & 197.8 & 359.2 & 174.5 & 145.9 & 159.4 \\
\hline
\end{tabular}

\footnotetext{
${ }^{1}$ Abbreviations. ALF, alfalfa; ORCH, orchardgrass; CB 4, Coastal bermudagrass 4-weeks regrowth; CB 6, Coastal bermudagrass 6-weeks regrowth; $\mathrm{CB} 8$, Coastal bermudagrass 8-weeks regrowth. ${ }^{\text {a }}$ Gro-n-Win alfa (Buckeye Nutrition, Dalton, OH, USA). ${ }^{\mathrm{b}}$ Equalizer (Seminole Feeds, Ocala, FL, USA). ${ }^{\mathrm{c}}$ Digestible energy calculated according to Pagan [26].
}

External markers were prepared and used to determine digesta MRT for each gelding. A lithium salt of Co-EDTA was prepared according to the methods of Udén et al. [27] as a marker for the liquid phase of digesta. For the particulate marker, $\mathrm{Yb}$-acetate was bound to neutral detergent fiber residue according to Ringler and Lawrence [28]. Bermudagrass hay was chopped by a hammer mill until it passed through a $1.27-\mathrm{cm}$ screen and then boiled in neutral detergent solution for $1 \mathrm{~h}$ ( $60 \mathrm{~g}$ of bermudagrass hay per liter of neutral detergent solution). Neutral detergent fiber residue was labeled at a concentration of $100 \mathrm{~g}$ of NDF residue/L of $0.007 \mathrm{M} \mathrm{Yb}$ solution (prepared by dissolving $2.96 \mathrm{~g}$ of $\mathrm{Yb}$ (III) acetate tetrahydrate in $1 \mathrm{~L}$ of distilled water) [28]. The prepared Co-EDTA was 13.7\% Co (DM basis) and Yb-labeled NDF residue was $7304 \mathrm{mg} \mathrm{Yb/kg} \mathrm{DM.}$

On day 7 of each period, horses were fed $1.5 \mathrm{mg}$ of each marker per kilogram BW with the evening meal of vitamin/mineral pellets. Marker intake was monitored and spilled feed was immediately returned to the feed bucket to ensure complete marker consumption. On average, horses consumed the markers in $14.7 \mathrm{~min}$ (range 9 to $30 \mathrm{~min}$ ). 
Immediately before and during fecal collections, stalls were stripped of bedding and swept clean. All voided feces were collected directly from the floor of rubber-matted stalls. In order to minimize contamination of feces with hay, dirt, and other debris and to prevent the horse from stepping in the feces, stalls were checked for fresh excreta every $15 \mathrm{~min}$. Horses were removed from their stalls in 2 to 4-h intervals and temporarily placed in a stall bedded with pine shavings to allow horses to comfortably urinate. If a horse urinated in their primary stall, urine was removed with a wet-dry vacuum. Horses were hand-walked for two 15-min periods (06:00 and 20:00) each day during fecal collections.

Feces were compiled in 2-h intervals for the first 60-h following marker dosing and then in 4-h intervals from 60 to $84 \mathrm{~h}$ post marker dosing. Excreted feces were weighed and homogenized after each time interval with $10 \%$ of the feces retained for a $24-\mathrm{h}$ composite sample and a $200-\mathrm{g}$ subsample saved for marker concentration determination. Feces collected the first $12 \mathrm{~h}$ post marker dosing were only retained for marker concentration analysis, and feces collected from $12 \mathrm{~h}$ to $84 \mathrm{~h}$ post marker dosing were used for both marker concentration analysis and 24-h composite samples. During fecal collections, orts were collected prior to the next feeding. Orts were time-matched to 24-h fecal composites to determine diet digestibility. Fecal samples were stored at $-20^{\circ} \mathrm{C}$ until analysis.

Frozen fecal samples were thawed at $4{ }^{\circ} \mathrm{C}$ for $48 \mathrm{~h}$. Fecal samples, representative feed samples from each total fecal collection, and orts were dried in a $60^{\circ} \mathrm{C}$ forced air oven until achieving a constant weight. Samples were ground to pass a 1-mm screen using a Wiley Mill prior to laboratory analysis.

Twenty-four-hour fecal composite samples, representative feed samples, and orts were used to determine DM, organic matter (OM), NDF, and ADF digestibility (DMD, OMD, NDFD, ADFD, respectively). Samples were dried in triplicate at $60{ }^{\circ} \mathrm{C}$ until a constant weight and then ashed at 600 ${ }^{\circ} \mathrm{C}$ for $8 \mathrm{~h}$ to calculate $\mathrm{OM}$ concentration. Fiber concentrations were sequentially determined using an ANKOM 200 Fiber Analyzer [29]. Heat-stable $\alpha$-amylase was used in the NDF analysis of all samples. Digestibility was determined as ((Nutrient Intake - Nutrient Output)/Nutrient Intake $\times 100)$.

Marker concentrations were determined on fecal samples composited in 2- and 4-h intervals following marker dosing. Fecal samples were dried in triplicate in a $60{ }^{\circ} \mathrm{C}$ forced-air oven until a constant weight to determine DM concentration. A $0.500 \mathrm{~g}$ subsample was weighed and placed into a Teflon digestion vessel with $8 \mathrm{~mL}$ of $15.8 \mathrm{~N}$ nitric acid. Samples were sealed and digested for $15 \mathrm{~min}$ at $180{ }^{\circ} \mathrm{C}$ using a microwave-assisted acid digestion procedure (Anton-Paar, Ashland, VA, USA). Samples were allowed to cool and diluted to $25 \mathrm{~mL}$. Samples were centrifuged at $1050 \times \mathrm{g}$ for $15 \mathrm{~min}$ and the supernatant collected for determination of marker concentrations using inductively coupled plasma spectrometry (Perkin-Elmer, Inc., Shelton, CT, USA) [30,31]. The minimum element detection limit was $0.1 \mathrm{mg} / \mathrm{L}$. Marker recovery was calculated as (Marker Excreted/Marker Dosed $\times 100$ ).

Total tract MRT was calculated arithmetically according to Blaxter et al. [32] and Thielemans et al. [33]. Total tract MRT calculated according to Blaxter et al. [32] is

$$
\mathrm{MRT}=\frac{\sum m_{i} t_{i}}{\sum m_{i}}
$$

where $m_{i}=$ the amount of marker in the $i$ th sample $(\mathrm{g})$ and $t_{i}=$ time from dosage of the marker to the middle of the $i$ th sampling interval (h). The equation described by Thielemans et al. [33] uses the concentration of the marker in the sample and MRT is calculated as

$$
\text { MRT }=\frac{\sum t_{i} C_{i} \Delta t_{i}}{\sum C_{i} \Delta t_{i}}
$$

where $t_{i}=$ time from dosage of the marker to the middle of the $i$ th sampling interval (h), $C_{i}=$ concentration of marker in the $i$ th sample $(\mathrm{mg} / \mathrm{kg} \mathrm{DM})$, and $\Delta t_{i}=$ time interval between the middle of the $i$ th and $i$ th -1 sample $(\mathrm{h})$. 
Fecal marker excretion data were fit with compartment models described by Dhanoa et al. [14] and Pond et al. [15]. The multicompartment model derived by Dhanoa et al. [14] is a mechanistic model based on first order kinetics where marker concentration $(\mathrm{mg} / \mathrm{kg} \mathrm{DM})$ of the feces can be modeled as

$$
\text { Marker Concentration }=A e^{-k_{1} t} e^{-(\mathrm{N}-2) e^{-\Delta t}}
$$

where $A$ is a scaling parameter, $k_{1}=$ rate constant for the first compartment $\left(\mathrm{h}^{-1}\right), t=$ time from marker dosage (h), $\Delta=k_{2}-k_{1}$ where $k_{2}$ is the rate constant for the second compartment $\left(\mathrm{h}^{-1}\right.$, assuming $k_{2}>$ $k_{1}$ ), and $N=$ the number of exponentially distributed compartments. The rate constants do not change over time; therefore, the compartments are considered age-independent (the rate digesta leaves a compartment is not influenced by past residence time). The exponentially distributed compartments described by Dhanoa et al. [14] can represent multiple sub-compartments within a larger mixing compartment. The two-compartment model featuring a $\gamma$-distribution described by Pond et al. [15] was also fit to fecal marker excretion data $(\mathrm{mg} / \mathrm{kg} \mathrm{DM})$ as

$$
\text { Marker Concentration }=C_{2}\left[\delta^{\mathrm{n}} e^{-k_{2}(t)}-e^{-\lambda_{1} t} \sum_{i=1}^{\mathrm{n}} \frac{\delta^{i}\left(\lambda_{1} t\right)^{\mathrm{n}-i}}{(\mathrm{n}-i) !}\right]
$$

where $C_{2}=$ the initial concentration in the second compartment if the marker dose had been introduced into the compartment and instantaneously mixed, $\mathrm{n}=$ order of the $\gamma$-distribution in the first compartment, $k_{2}=$ rate parameter for exponentially distributed residence times $\left(\mathrm{h}^{-1}\right), t=$ time after dosing of marker $(\mathrm{h}), \lambda_{1}=$ rate parameter for $\gamma$-distributed residence times $\left(\mathrm{h}^{-1}\right)$, and $\delta=\lambda_{1} /\left(\lambda_{1}-\right.$ $k_{2}$ ). Time delay was incorporated into the Pond et al. [15] equation by substituting $\mathrm{t}$ for $\mathrm{t}-\mathrm{TT}$, where $t$ is the time from marker dosing $(\mathrm{h})$ and TT is transit time. Six orders of $\gamma$-distribution were analyzed $(\mathrm{n}=1$, 2, 3, 4, 5, 6) to test the G1G1, G2G1, G3G1, G4G1, G5G1, and G6G1 model described by Pond et al. [15]. If marker residence time is exponentially distributed $(n=1)$ in a compartment, the compartment is age-independent, indicating that the rate the marker leaves is not dependent on past residence time. However, if the ROP of a marker in a compartment changes over time, the compartment is considered age-dependent. Marker concentration in an age-dependent compartment can be modeled with a $\gamma$-distribution of order 2 or greater. Increasing the order of the $\gamma$-distribution alters the shape of the curve such that the emergence of marker from the compartment is slowed [15]. Curves were fit using nonlinear least squares methods in MATLAB (Version R2015a, Mathworks, Natick, MA, USA) with model parameter start values randomly assigned (Computer Code S1). Bounds for rate parameters were set between 0 and 1 .

Model parameters were used to determine total tract mean retention time (TTMRT) for each fitted equation to fecal marker excretion. For the Dhanoa et al. [14] model, TTMRT (h) was calculated as

$$
\mathrm{MRT}=\frac{1}{k_{1}}+\frac{1}{k_{2}}+\sum_{i=3}^{\mathrm{N}-1} \frac{1}{k_{2}+(i-2)\left(k_{2}-k_{1}\right)}, \quad k_{2}>k_{1}
$$

where $k_{1}$ and $k_{2}$ are rate parameters $\left(\mathrm{h}^{-1}\right)$ of the first and second compartments and $\mathrm{N}$ is the number of exponentially distributed compartments. The term $\sum_{i=3}^{\mathrm{N}-1} \frac{1}{k_{2}+(i-2)\left(k_{2}-k_{1}\right)}$ is said to represent the transit time (TT) of digesta markers or the time from dosing the marker to the first appearance of marker in the collected sample. Total tract MRT (h) for the Pond et al. [15] model was calculated as

$$
\mathrm{MRT}=\frac{\mathrm{n}}{\lambda_{1}}+\frac{1}{k_{2}}+\mathrm{TT}
$$

where $\lambda_{1}$ is the age-dependent compartment rate constant $\left(\mathrm{h}^{-1}\right), k_{2}$ is the age-independent compartment rate constant $\left(\mathrm{h}^{-1}\right), \mathrm{n}$ is the order of the $\gamma$-distribution, and TT is the transit time (h). The age-dependent compartment MRT $\left(\mathrm{CMRT}_{1}\right)$ was determined by $\mathrm{n} / \lambda_{1}$ and the age-independent compartment MRT 
$\left(\mathrm{CMRT}_{2}\right)$ was determined by $1 / k_{2}$. When $\mathrm{n}=1, \lambda_{1}$ is replaced by $k_{1}$, and $\mathrm{CMRT}_{1}$ is an age-independent compartment.

Unless otherwise noted, data are presented as means \pm SEM. Data were checked for normality using the Kolmogorov-Smirnov test and the Shapiro-Wilk test. Data were analyzed as a Latin square design using a mixed model ANOVA in SAS (v 3.8 SAS Studio, Cary, NC, USA). Fixed effects included dietary treatment and period, and the random effect was horse. The influence of feeding Coastal bermudagrass (CB 4, CB 6, and CB 8) compared with other hays (alfalfa and orchardgrass) on digestive variables was determined using contrasts. Statistically significant means were separated by Scheffe's method. Model derived TTMRT was compared to arithmetic calculations using both two one-sided tests of equivalence and regression analysis. For equivalence testing, the acceptable difference was $10 \%$. Statistical trends were defined as $p<0.1$ and differences at $p<0.05$.

\section{Results}

\subsection{Diet Digestibility}

One factor that affects digestibility measurements is feed refusal. Orts were collected during 26 of the 75 daily measurements of intake, most frequently when horses were fed the CB 8 diet. The mean weight of orts was $0.07 \mathrm{~kg}$ (DM basis). Ash concentration of hay orts ranged from $24.6 \%$ to $66.8 \%$, indicating contamination with sand from the environment. Thus, hay ort weight was corrected by multiplying ort weight by the ratio of ort ash concentration to forage ash concentration. Orts were analyzed for nutrient composition and subtracted from nutrient intake to correct for any feed not consumed by the horses.

Differences in fecal excretion were related to variations in diet digestibility. Horses fed Coastal bermudagrass hay diets defecated 1.4 times more frequently $(p<0.05)$ than when fed alfalfa hay (Table 3). Horses fed CB 6 and CB 8 excreted more feces $(p<0.05)$ than horses consuming ALF, ORCH, or CB 4. Dry matter and OM digestibilities were greatest $(p<0.05)$ for ALF, whereas a reduction in DMD and OMD was observed when horses were fed CB 6 and CB 8. There was a 32.0\% reduction $(p<0.05)$ in NDFD and a $47.1 \%$ decrease $(p<0.05)$ in ADFD digestibility for the CB 6 and CB 8 diets compared with the other diets.

Table 3. Fecal excretion and diet digestibility of five experimental diets ${ }^{1}(n=5)$.

\begin{tabular}{ccccccccc}
\hline Variable & ALF & ORCH & CB 4 & CB 6 & CB 8 & SEM & $\begin{array}{c}\text { Diet }^{2} \\
p \text {-Value }\end{array}$ & $\begin{array}{c}\text { Contrast }^{3} \\
p \text {-Value }\end{array}$ \\
\hline $\begin{array}{c}\text { Defecation } \\
\text { Frequency, times/d }\end{array}$ & $10.0^{\mathrm{c}}$ & $11.5^{\mathrm{b}, \mathrm{c}}$ & $14.1^{\mathrm{a}, \mathrm{b}}$ & $15.3^{\mathrm{a}}$ & $14.0^{\mathrm{a}, \mathrm{b}}$ & 0.5 & $<0.001$ & $<0.001$ \\
$\begin{array}{c}\text { Fecal Excretion, kg } \\
\text { DM/d }\end{array}$ & $3.55^{\mathrm{d}}$ & $4.41^{\mathrm{c}}$ & $5.04^{\mathrm{b}}$ & $5.84^{\mathrm{a}}$ & $5.87^{\mathrm{a}}$ & 0.20 & $<0.001$ & $<0.001$ \\
$\begin{array}{c}\text { Fecal DM, } \% \\
\text { Urination }\end{array}$ & $19.7^{2}$ & $20.9^{2}$ & 20.0 & 20.5 & 22.5 & 0.42 & 0.074 & 0.255 \\
$\begin{array}{c}\text { Frequency, times/d } \\
\text { Digestibility, } \%\end{array}$ & 10.6 & 10.6 & 8.7 & 8.3 & 10.7 & 0.58 & 0.324 & 0.161 \\
\hline DM & $62.1^{\mathrm{a}}$ & $51.2^{\mathrm{b}}$ & $47.2^{\mathrm{b}}$ & $36.0^{\mathrm{c}}$ & $36.8^{\mathrm{c}}$ & 2.1 & $<0.001$ & $<0.001$ \\
OM & $63.1^{\mathrm{a}}$ & $52.3^{\mathrm{b}}$ & $46.8^{\mathrm{c}}$ & $37.3^{\mathrm{d}}$ & $37.6^{\mathrm{d}}$ & 2.1 & $<0.001$ & $<0.001$ \\
NDF & $43.1^{\mathrm{a}}$ & $42.4^{\mathrm{a}}$ & $46.2^{\mathrm{a}}$ & $31.1^{\mathrm{b}}$ & $31.8^{\mathrm{b}}$ & 1.7 & $<0.001$ & $<0.001$ \\
ADF & $40.2^{\mathrm{a}}$ & $39.8^{\mathrm{a}}$ & $39.8^{\mathrm{a}}$ & $23.9^{\mathrm{b}}$ & $24.3^{\mathrm{b}}$ & 1.9 & $<0.001$ & $<0.001$ \\
\hline
\end{tabular}

${ }^{1}$ Abbreviations. ALF, alfalfa; ORCH, orchardgrass; CB 4, Coastal bermudagrass 4-weeks regrowth; CB 6, Coastal bermudagrass 6-weeks regrowth; $\mathrm{CB}$ 8, Coastal bermudagrass 8-weeks regrowth; SEM, standard error of the mean. ${ }^{2}$ Main effect of diet. ${ }^{3}$ Contrast between Coastal bermudagrass (CB 4, CB 6, CB 8) and other diets (ALF, ORCH). $\mathrm{a}, \mathrm{b}, \mathrm{c}, \mathrm{d}$ Means with unlike superscripts differ $(p<0.05)$ 


\subsection{Fecal Marker Excretion}

\subsubsection{Marker Excretion and Recovery}

Mean fecal marker excretion is presented in Figure 1. External marker concentrations were detected in feces between 5 to $13 \mathrm{~h}$ after feeding horses external markers. Element concentrations were below instrument detection limits by $60 \mathrm{~h}$ post marker dosing, thus, fecal samples were only analyzed for marker concentrations to $72 \mathrm{~h}$ post marker dosing. A pulsatile pattern was observed in some individual fecal marker excretion curves (Supplementary Figures S1-S5).
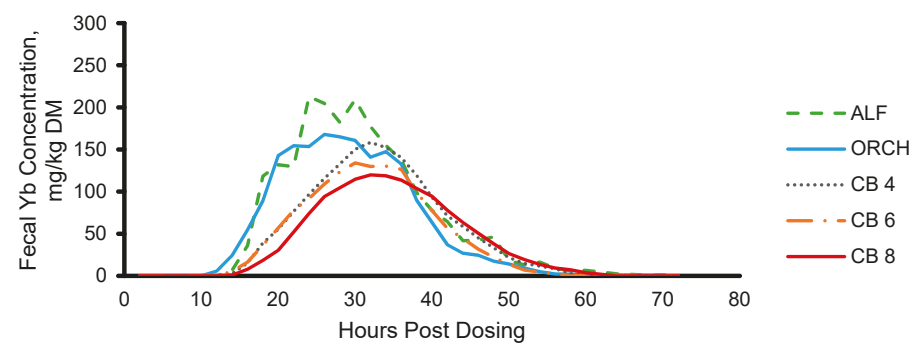

(a)
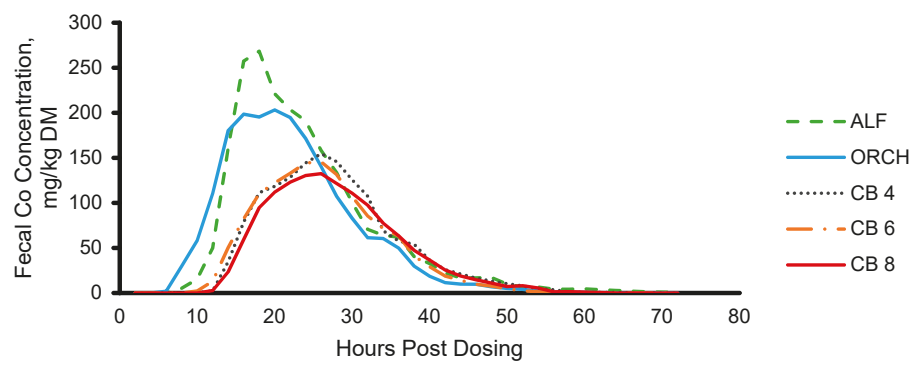

(b)

Figure 1. Two period moving average of fecal marker excretion of (a) $\mathrm{Yb}$ and (b) Co after dosing external markers (SEM = 12.4 and $13.2 \mathrm{mg} / \mathrm{kg}$ DM, respectively). Abbreviations. ALF, alfalfa; ORCH, orchardgrass; CB 4, Coastal bermudagrass 4-weeks regrowth; CB 6, Coastal bermudagrass 6-weeks regrowth; CB 8, Coastal bermudagrass 8-weeks regrowth.

Marker recovery ranged from 73.3 to $97.6 \%$ for $\mathrm{Yb}$ and 73.9 to $115 \%$ for Co. Particulate marker recovery did not differ by diet (Table 4$)$. Liquid marker recovery tended to differ among diets $(p=0.075)$ with mean Co recovery greatest in the ORCH diet and lowest in the CB 4 diet. Particulate and liquid marker recovery did not differ within a horse for each period.

Table 4. Particulate $(\mathrm{Yb})$ and liquid $(\mathrm{Co})$ marker recovery ${ }^{1}(n=5)$.

\begin{tabular}{ccccccccc}
\hline Variable & ALF & ORCH & CB 4 & CB 6 & CB 8 & SEM & $\begin{array}{c}\text { Diet }^{2} \\
p \text {-Value }\end{array}$ & $\begin{array}{c}\text { Contrast }^{3} \\
p \text {-Value }\end{array}$ \\
\hline $\begin{array}{c}\text { Particulate, \% } \\
\text { Liquid, \% }\end{array}$ & 80.6 & 86.3 & 85.5 & 82.5 & 85.0 & 1.44 & 0.549 & 0.948 \\
\hline
\end{tabular}

${ }^{1}$ Abbreviations. ALF, alfalfa; ORCH, orchardgrass; CB 4, Coastal bermudagrass 4-weeks regrowth; CB 6, Coastal bermudagrass 6-weeks regrowth; $C B$ 8, Coastal bermudagrass 8-weeks regrowth; SEM, standard error of the mean. ${ }^{2}$ Main effect of diet. ${ }^{3}$ Contrast between Coastal bermudagrass (CB 4, CB 6, CB 8) and other diets (ALF, ORCH). 


\subsubsection{Modeling Fecal Marker Excretion}

Seventy six percent of model equations fit fecal excretion data for each horse within a period using initial parameter ranges and start values defined in the program code. When the model did not converge using the code, model parameter ranges were adjusted using curve fitting software in MATLAB to obtain an acceptable fit (as indicated by the $\mathrm{R}^{2}$ value being non-negative).

Mean model result from all data is depicted for all equations in Figure 2. Mean model fit, parameter values, and retention time from fecal marker excretion of each observation are summarized in Table 5 . Model parameters were nonzero $(p<0.05)$ for $47 \%$ of the fitted equations. The scaling parameter was less than 0 for the G1G1 model. As the order of the $\gamma$-distribution increased for the equations described by Pond et al. [15], TT, CMRT 2 , and TTMRT decreased, whereas $\mathrm{CMRT}_{1}$ increased. The root mean square error (RMSE) ranged from 2.932 to 42.23 and 3.369 to 29.85 for particulate and liquid fecal marker excretion, respectively (Table 5). The model described by Dhanoa et al. [14] had the lowest RMSE and Akaike's information criterion (AIC) for the particulate and liquid phases of digesta. Among the six two-compartment $\gamma$-distributed equations described by Pond et al. [15], the G5G1 model best fit particulate marker excretion and the G4G1 equation best fit liquid marker excretion based on AIC values (Table 5). Because the AIC values increased once the order 5 and order $4 \gamma$-gamma distributions were fit to the particulate and liquid marker excretion, fitting marker excretion to the two-compartment model was terminated at the order $6 \gamma$-gamma distribution.
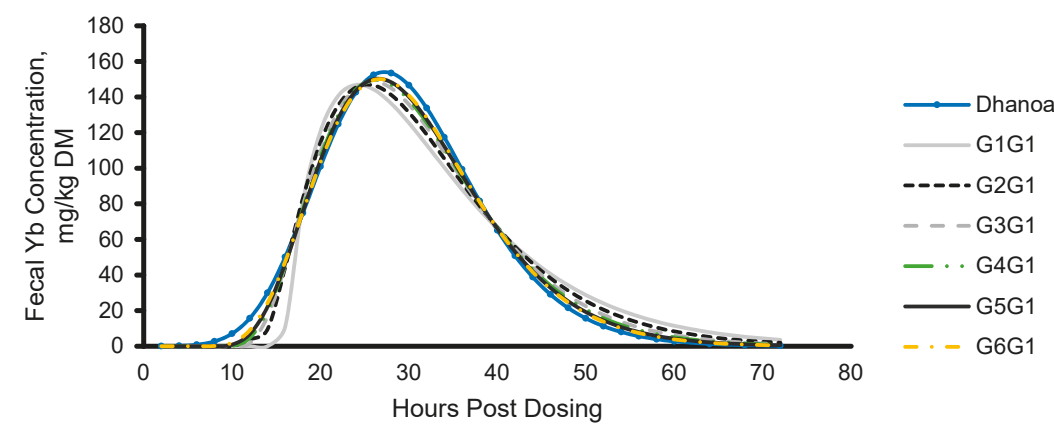

(a)
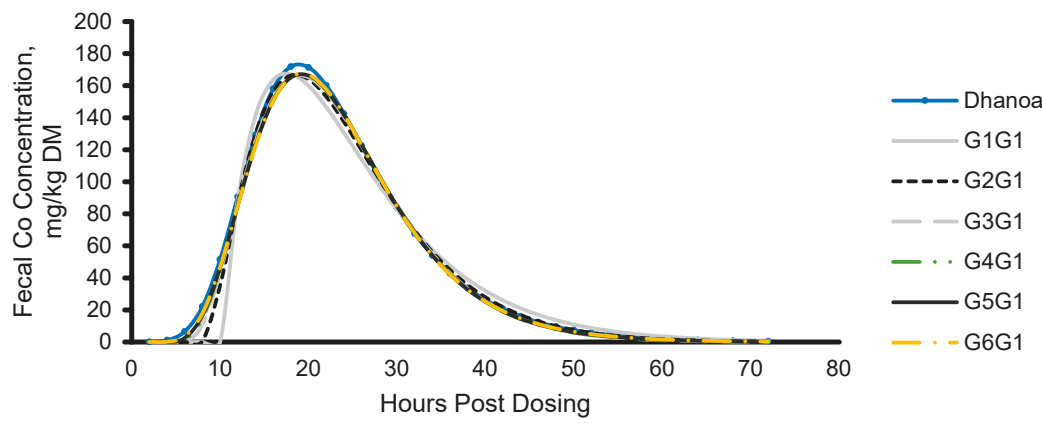

(b)

Figure 2. Model result derived from equations described by Dhanoa et al. [14] and Pond et al. [15] applied to all experimental data of (a) Yb and (b) Co after dosing external markers. Abbreviations. G1G1, first order two-compartment model; G2G1, second order two-compartment model; G3G1, third order two-compartment model; G4G1, fourth order two-compartment model; G5G1, fifth order two-compartment model; G6G1, sixth order two-compartment model according to Pond et al. [15]. 


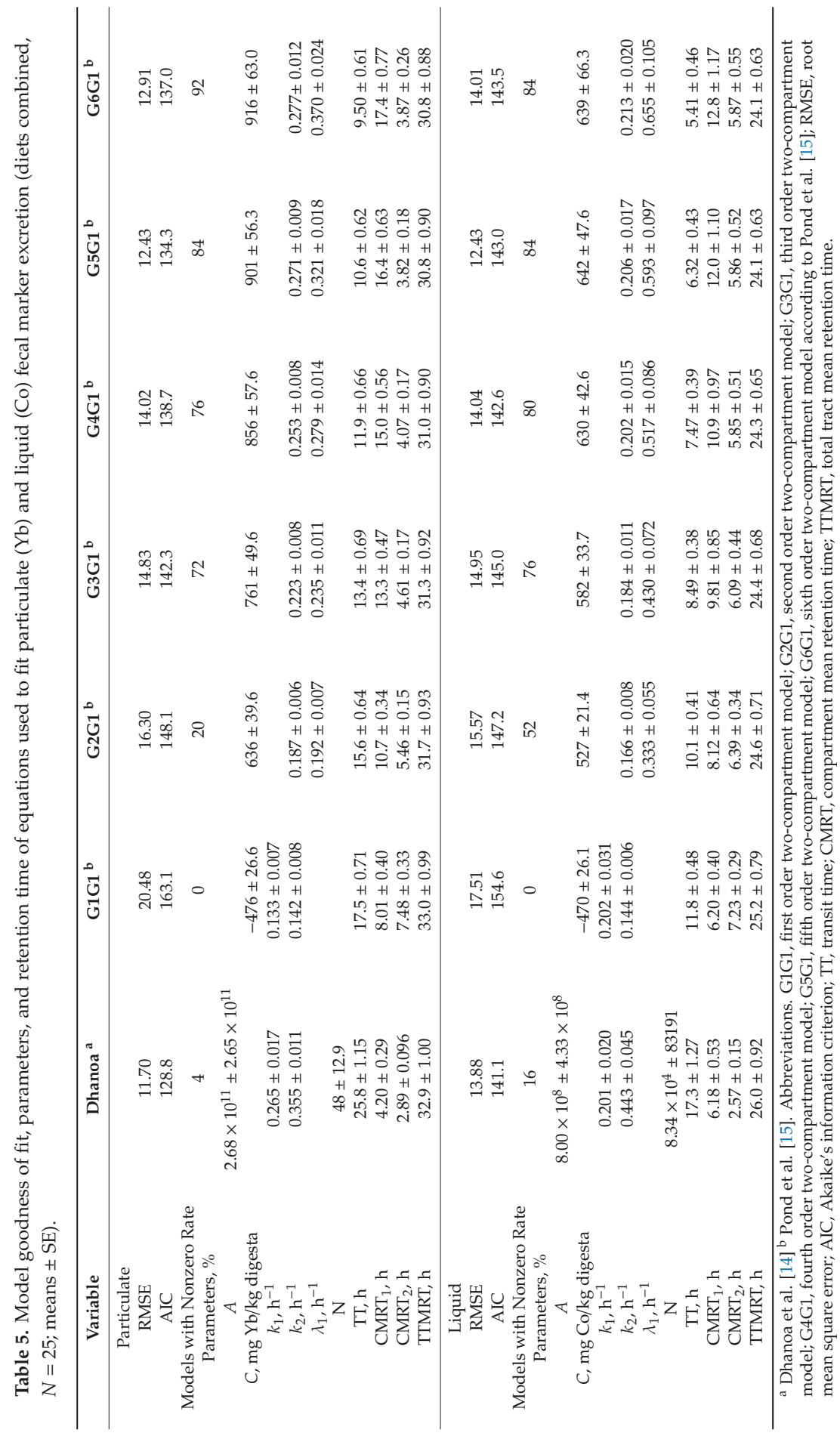




\subsection{Digesta Mean Retention Time}

\subsubsection{Mean Retention Time Calculated from Model Parameters}

The best fitting models to describe marker excretion were used to compare digesta ROP between diets. The Dhanoa et al. [14] and Pond et al. [15] G5G1 models were used to analyze particulate phase ROP. The Dhanoa et al. [14] and Pond et al. [15] G4G1 models were used to analyze liquid digesta ROP.

Particulate TTMRT differed by diet ( $p=0.020$ and $p=0.022$, respectively; Table 6) when Yb marker excretion was fit to both the Dhanoa et al. [14] and Pond et al. [15] G5G1 model. Rates of passage, $k_{1}$ and $k_{2}$, did not differ among diets when fecal excretion was fit to equations described by Dhanoa et al. [14]; however, $\mathrm{CMRT}_{1}$ tended to be longer $(p=0.084)$ when horses were fed ALF compared with CB 6. Transit time calculated according to Dhanoa et al. [14] tended to be longer $(p=0.074)$ in CB 8 than ALF. Modeling particulate fecal marker excretion using the G5G1 model [15], $\lambda_{1}$ tended to differ by diet ( $p=0.069)$ with $\lambda_{1}$ trending towards being quicker $(p=0.102)$ in ALF than CB 8. The other model parameters $k_{2}$ and TT did not differ by diet. Age-dependent compartment mean retention time $\left(\mathrm{CMRT}_{1}\right)$ was shorter $(p=0.014)$ in ALF than CB 8 and tended to be shorter $(p=0.065)$ than CB 4 . There was no difference in the age-independent compartment mean retention time $\left(\mathrm{CMRT}_{2}\right)$.

Table 6. Model parameters and compartment retention times for particulate (Yb) and liquid (Co) marker fecal excretion ${ }^{1}(n=5)$.

\begin{tabular}{|c|c|c|c|c|c|c|c|c|}
\hline Item & ALF & ORCH & CB 4 & CB 6 & CB 8 & SEM & $\begin{array}{c}\text { Diet }^{2} \\
p \text {-Value }\end{array}$ & $\begin{array}{c}\text { Contrast }^{3} \\
p \text {-Value }\end{array}$ \\
\hline \multicolumn{9}{|l|}{ Particulate } \\
\hline \multicolumn{9}{|l|}{ Dhanoa A } \\
\hline$A$ & $2.4 \times 10^{9}$ & $3.0 \times 10^{9}$ & $1.3 \times 10^{12}$ & $3.1 \times 10^{9}$ & $3.5 \times 10^{9}$ & $4.3 \times 10^{8}$ & & \\
\hline$k_{1}, \mathrm{~h}^{-1}$ & 0.210 & 0.287 & 0.248 & 0.294 & 0.259 & 0.0536 & 0.223 & 0.239 \\
\hline$k_{2}, \mathrm{~h}^{-1}$ & 0.357 & 0.380 & 0.336 & 0.372 & 0.328 & 0.0450 & 0.338 & 0.312 \\
\hline $\mathrm{N}$ & 107 & 34 & 29 & 36 & 33 & 83191 & 0.179 & 0.054 \\
\hline TT, h & $22.0^{y}$ & $23.5^{x, y}$ & $27.9^{x, y}$ & $26.9^{x, y}$ & $28.7^{x}$ & 1.27 & 0.035 & 0.004 \\
\hline $\mathrm{CMRT}_{1}, \mathrm{~h}$ & $5.59^{x}$ & $3.77^{x, y}$ & $3.82^{x, y}$ & $3.63 \mathrm{y}$ & $4.17^{x, y}$ & 0.532 & 0.049 & 0.051 \\
\hline $\mathrm{CMRT}_{2}, \mathrm{~h}$ & 2.92 & 2.68 & 3.03 & 2.70 & 3.12 & 0.148 & 0.303 & 0.479 \\
\hline TTMRT, h & $30.5^{y}$ & $30.0^{y}$ & $34.7^{x, y}$ & $33.2^{x, y}$ & $35.9^{x}$ & 0.921 & 0.020 & 0.003 \\
\hline \multicolumn{9}{|l|}{ G5G1 ${ }^{B}$} \\
\hline $\begin{array}{c}\mathrm{C}, \mathrm{mg} \mathrm{Yb} / \mathrm{kg} \\
\text { digesta }\end{array}$ & 1134 & 1007 & 906 & 780 & 681 & 56.3 & & \\
\hline$\lambda_{1}, \mathrm{~h}^{-1}$ & 0.396 & 0.342 & 0.277 & 0.319 & 0.272 & 0.018 & 0.069 & 0.014 \\
\hline$k_{2}, \mathrm{~h}^{-1}$ & 0.249 & 0.279 & 0.280 & 0.274 & 0.272 & 0.009 & 0.751 & 0.489 \\
\hline $\mathrm{TT}, \mathrm{h}$ & 11.4 & 9.02 & 10.3 & 11.1 & 11.4 & 0.616 & 0.362 & 0.948 \\
\hline $\mathrm{CMRT}_{1}, \mathrm{~h}$ & $13.6^{\mathrm{b}, \mathrm{y}}$ & $15.4^{\mathrm{a}, \mathrm{b}}$ & $18.2^{\mathrm{a}, \mathrm{b}, \mathrm{x}}$ & $16.1^{\mathrm{a}, \mathrm{b}}$ & $18.5^{\mathrm{a}}$ & 0.634 & 0.008 & 0.002 \\
\hline $\mathrm{CMRT}_{2}, \mathrm{~h}$ & 4.47 & 3.64 & 3.59 & 3.71 & 3.71 & 0.182 & 0.508 & 0.218 \\
\hline TTMRT, h & $29.5^{a, b}$ & $28.1^{b}$ & $32.1^{a, b}$ & $30.9^{a, b}$ & $33.6^{a}$ & 0.900 & 0.022 & 0.007 \\
\hline \multicolumn{9}{|l|}{ Liquid } \\
\hline \multicolumn{9}{|l|}{ Dhanoa ${ }^{A}$} \\
\hline A & 1919 & $3.0 \times 10^{9}$ & $1.5 \times 10^{9}$ & $1.3 \times 10^{9}$ & $9.8 \times 10^{7}$ & $2.7 \times 10^{11}$ & & \\
\hline$k_{1}, \mathrm{~h}^{-1}$ & $0.106^{x}$ & 0.234 & 0.145 & $0.111^{\mathrm{y}}$ & 0.120 & 0.0165 & 0.042 & 0.023 \\
\hline$k_{2}, \mathrm{~h}^{-1}$ & $0.708^{x}$ & 0.440 & 0.373 & 0.376 & $0.320 \mathrm{y}$ & 0.0108 & 0.042 & 0.016 \\
\hline N & $4.2 \times 10^{5}$ & 50 & 49 & 33 & 31.2 & 13 & 0.661 & 0.075 \\
\hline TT, h & $11.3^{b}$ & $13.6^{a, b}$ & $19.9^{\mathrm{a}}$ & $20.7^{\mathrm{a}}$ & $20.7^{\mathrm{a}}$ & 1.14 & 0.005 & $<0.001$ \\
\hline $\mathrm{CMRT}_{1}, \mathrm{~h}$ & $9.52^{\mathrm{a}}$ & $6.14^{b}$ & $5.57^{\mathrm{b}}$ & $4.0^{\mathrm{b}}$ & $5.58^{\mathrm{b}}$ & 0.291 & $<0.001$ & $<0.001$ \\
\hline $\mathrm{CMRT}_{2}, \mathrm{~h}$ & $1.75^{b}$ & $2.48^{a, b}$ & $2.75^{\mathrm{a}, \mathrm{b}}$ & $2.70^{a, b}$ & $3.17^{\mathrm{a}}$ & 0.096 & 0.009 & 0.005 \\
\hline TTMRT, h & $22.6^{c, z}$ & $22.3^{b, c, y, z}$ & $28.2^{a, b, x, y}$ & $27.5^{\mathrm{a}, \mathrm{b}, \mathrm{c}, \mathrm{x}}$ & $29.5^{a}$ & 1.00 & 0.002 & $<0.001$ \\
\hline
\end{tabular}


Table 6. Cont.

\begin{tabular}{|c|c|c|c|c|c|c|c|c|}
\hline Item & ALF & ORCH & CB 4 & CB 6 & CВ 8 & SEM & $\begin{array}{c}\text { Diet }^{2} \\
p \text {-Value }\end{array}$ & $\begin{array}{r}\text { Contrast }^{3} \\
p \text {-Value }\end{array}$ \\
\hline \multicolumn{9}{|l|}{$\mathrm{G}^{\prime G} 1^{\mathrm{B}}$} \\
\hline $\begin{array}{c}\mathrm{C}, \mathrm{mg} \mathrm{Yb} / \mathrm{kg} \\
\text { digesta }\end{array}$ & 465 & 801 & 614 & 704 & 565 & 43 & & \\
\hline$\lambda_{1}, \mathrm{~h}^{-1}$ & $1.095^{\mathrm{a}, \mathrm{x}}$ & $0.491^{a, b, y}$ & $0.359^{b}$ & $0.329^{b}$ & $0.310^{\mathrm{b}}$ & 0.0856 & 0.002 & 0.001 \\
\hline$k_{2}, \mathrm{~h}^{-1}$ & $0.107^{b, y}$ & $0.216^{a, b, x}$ & $0.203^{a, b}$ & $0.247^{\mathrm{a}}$ & $0.236^{a, b, x}$ & 0.0152 & 0.010 & 0.012 \\
\hline TT, h & $8.42^{x}$ & $5.45^{\mathrm{y}}$ & 8.15 & 7.34 & 8.00 & 0.391 & 0.042 & 0.194 \\
\hline $\mathrm{CMRT}_{1}, \mathrm{~h}$ & $4.71^{\mathrm{b}}$ & $10.3^{\mathrm{a}}$ & $12.6^{\mathrm{a}}$ & $13.4^{\mathrm{a}}$ & $13.6^{\mathrm{a}}$ & 0.973 & $<0.001$ & $<0.001$ \\
\hline $\mathrm{CMRT}_{2}, \mathrm{~h}$ & $9.44^{\mathrm{a}}$ & $5.32^{b}$ & $5.61^{b}$ & $4.20^{\mathrm{b}}$ & $4.69^{b}$ & 0.513 & 0.001 & 0.002 \\
\hline TTMRT, h & $22.6^{\mathrm{b}, \mathrm{c}}$ & $21.0^{\mathrm{c}}$ & $26.4^{\mathrm{a}}$ & $25.0^{\mathrm{a}, \mathrm{b}}$ & $26.3^{a}$ & 0.650 & $<0.001$ & $<0.001$ \\
\hline
\end{tabular}

${ }^{1}$ Abbreviations. ALF, alfalfa; ORCH, orchardgrass; CB 4, Coastal bermudagrass 4-weeks regrowth; CB 6, Coastal bermudagrass 6-weeks regrowth; CB 8, Coastal bermudagrass 8-weeks regrowth; SEM, standard error of the mean; RMSE, root mean square error; AIC, Akaike's information criterion; TT, transit time; CMRT, compartment mean retention time; TTMRT, total tract mean retention time. ${ }^{2}$ Main effect of diet. ${ }^{3}$ Contrast between Coastall bermudagrass (CB 4, CB 6, CB 8) and other diets (ALF, ORCH). ${ }^{A}$ Dhanoa et al. [14]. ${ }^{B}$ Pond et al. [15]. ${ }^{a, b, c}$ Means with unlike superscripts differ $(p<0.05)$. ${ }^{x, y, z}$ Means with unlike superscripts tend to differ $(p<0.1)$

\subsubsection{Arithmetically Calculated Mean Retention Time}

Arithmetically calculated particulate digesta MRT (Table 7) using the equation described by Blaxter et al. [32] was longer $(p=0.019)$ than when calculated according to Thielemans et al. [33], but the mean difference was only $0.2 \mathrm{~h}(30.0 \pm 0.88 \mathrm{vs} .29 .8 \pm 0.88 \mathrm{~h})$. Th method of calculation did not affect liquid MRT ( $23.4 \pm 0.70$ vs. $23.5 \pm 0.67 \mathrm{~h})$. For both equations, particulate MRT was longer $(p<0.001)$ than liquid MRT.

Particulate MRT differed by diet $(p<0.001)$ and was longer $(p<0.05)$ when horses were fed CB 8 compared with ORCH (Table 7). Liquid MRT differed by diet $(p<0.001)$. Horses fed ORCH had a shorter $(p<0.01)$ liquid MRT than when fed the Coastal bermudagrass diets. Liquid MRT differed $(p<0.011)$ between horses fed ALF compared with CB 4 and CB 8 and tended to be shorter $(p<0.079)$ than horses fed the CB 6 diet.

Table 7. Mean retention time (h) of particulate digesta measured with Yb-NDF and Co-EDTA external markers ${ }^{1}(n=5)$.

\begin{tabular}{ccccccccc}
\hline Equation & ALF & ORCH & CB 4 & CB 6 & CB 8 & SEM & $\begin{array}{c}\text { Diet }^{2} \\
p \text {-Value }\end{array}$ & $\begin{array}{c}\text { Contrast }^{3} \\
p \text {-Value }\end{array}$ \\
\hline Blaxter et al. [32] & & & & & & & & \\
$\quad$ Particulate & $29.2^{\mathrm{a}, \mathrm{b}}$ & $26.9^{\mathrm{b}}$ & $31.1^{\mathrm{a}, \mathrm{b}}$ & $30.0^{\mathrm{a}, \mathrm{b}}$ & $32.7^{\mathrm{a}}$ & 0.88 & 0.010 & 0.006 \\
$\quad$ Liquid & $21.3^{\mathrm{b}, \mathrm{c}, \mathrm{y}}$ & $20.1^{\mathrm{c}}$ & $25.7^{\mathrm{a}}$ & $24.3^{\mathrm{a}, \mathrm{b}, \mathrm{x}}$ & $25.9^{\mathrm{a}}$ & 0.70 & $<0.001$ & $<0.001$ \\
$\begin{array}{c}\text { Thielemans et al. [33] } \\
\quad\end{array}$ & & & & & & & \\
$\quad \begin{array}{c}\text { Particulate } \\
\text { Liquid }\end{array}$ & $28.9^{\mathrm{a}, \mathrm{b}}$ & $27.0^{\mathrm{b}}$ & $30.4^{\mathrm{a}, \mathrm{b}}$ & $29.6^{\mathrm{a}, \mathrm{b}}$ & $32.6^{\mathrm{a}}$ & 0.88 & 0.010 & 0.008 \\
& $21.2^{\mathrm{b}, \mathrm{c}, \mathrm{y}}$ & $20.6^{\mathrm{c}}$ & $25.4^{\mathrm{a}}$ & $24.1^{\mathrm{a}, \mathrm{b}, \mathrm{x}}$ & $25.9^{\mathrm{a}}$ & 0.67 & $<0.001$ & $<0.001$ \\
\hline
\end{tabular}

${ }^{1}$ Abbreviations. ALF, alfalfa; ORCH, orchardgrass; CB 4, Coastal bermudagrass 4-weeks regrowth; CB 6, Coastal bermudagrass 6-weeks regrowth; $\mathrm{CB} 8$, Coastal bermudagrass 8-weeks regrowth; SEM, standard error of the mean.

${ }^{2}$ Main effect of diet. ${ }^{3}$ Contrast between Coastal bermudagrass (CB 4, CB 6, CB 8) and other diets (ALF, ORCH). ${ }^{a, b, c}$

Means with unlike superscripts differ $(p<0.05)$. ${ }^{x, y}$ Means with unlike superscripts tend to differ $(p<0.10)$.

\subsubsection{Comparing Model-Derived and Arithmetically Calculated Mean Retention Time}

The mean retention times calculated from Dhanoa et al. [14] and Pond et al. [15] model parameters were compared with arithmetically calculated MRT using two one-sided test of equivalence (TOST) with a $10 \%$ difference and regression analysis. Model-derived TTMRT was similar to $(p<0.05)$ MRT calculated according to the equation described by Blaxter et al. [32] or Thielemans et al. [33] for the G2G1, G3G1, G4G1, G5G1 models for the particulate phase of digesta. For the liquid phase of digesta, models described by Pond et al. [15] were similar to $(p<0.05)$ arithmetic MRT, but TTMRT calculated according to Dhanoa et al. [14] was over $2 \mathrm{~h}$ shorter than arithmetic MRT. 
Arithmetically calculated MRT and model-derived TTMRT are plotted in Figure 3. For the particulate phase of digesta (Figure 2a), the equation relating TTMRT to MRT according to Blaxter et al. [32] was MRT $=0.7929 x+3.903\left(\right.$ RMSE $\left.=1.980 ; \mathrm{r}^{2}=0.8071 ; p<0.001\right)$ for TTMRT calculated according to Dhanoa et al. [14] and MRT $=0.9737 \mathrm{x}-0.05589\left(\mathrm{RMSE}=0.6256 ; \mathrm{r}^{2}=0.9807\right.$; $p<0.001$ ) when TTMRT according to the G5G1 model described by Pond et al. [15]. When MRT was calculated according to Thielemans et al. [33], MRT $=0.7935 x+3.680\left(\right.$ RMSE $=1.960 ; r^{2}=0.8105$; $p<0.001$ ) for TTMRT calculated according to Dhanoa et al. [14] and MRT $=0.9743 x-0.2772$ $\left(\right.$ RMSE $\left.=0.5592 ; \mathrm{r}^{2}=0.9846 ; p<0.001\right)$ when TTMRT according to the G5G1 model described by Pond et al. [15]. For the liquid phase of digesta (Figure 2b), the equation relating TTMRT to MRT according to Blaxter et al. [32] was MRT $=0.6329 \mathrm{x}+6.956\left(\mathrm{RMSE}=2.017 ; \mathrm{r}^{2}=0.6852 ; p<0.001\right)$ for TTMRT calculated according to Dhanoa et al. [14] and the $y$-intercept differed ( $p=0.007)$ from zero. Mean retention time calculated according to Blaxter et al. [14] was related to TTMRT calculated according to the G4G1 model described by Pond et al. [15] as MRT $=1.064 x-2.408($ RMSE $=0.6661$; $\left.\mathrm{r}^{2}=0.9657 ; p<0.001\right)$ and the $\mathrm{y}$-intercept differed $(p=0.028)$ from zero. When TTMRT was calculated according to Thielemans et al. [33], MRT $=0.5326 \mathrm{x}+9.984\left(\mathrm{RMSE}=2.565 ; \mathrm{r}^{2}=0.4879 ; p<0.001\right)$ for TTMRT calculated according to Dhanoa et al. [14] and MRT $=0.8692 x+2.748(\mathrm{RMSE}=2.129$; $\left.\mathrm{r}^{2}=0.6474 ; p<0.001\right)$ when TTMRT according to the G4G1 model described by Pond et al. [15]. For the regression equation relating TTMRT from the G4G1 model to MRT calculated according to Thielemans et al. [33], the $y$-intercept differed from zero $(p=0.003)$.

Blaxter

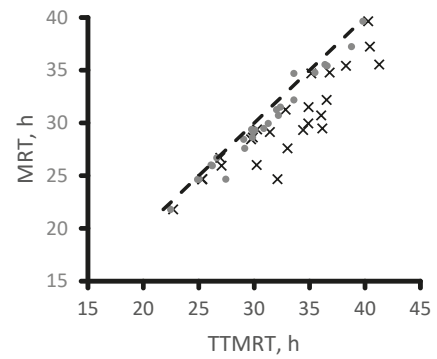

(a)

Blaxter

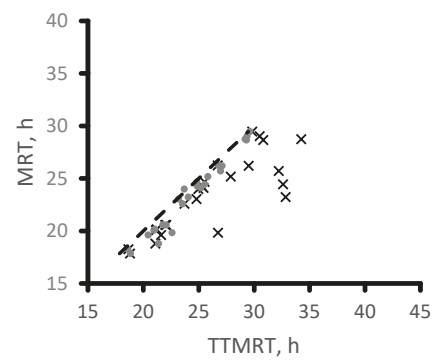

Thielemans
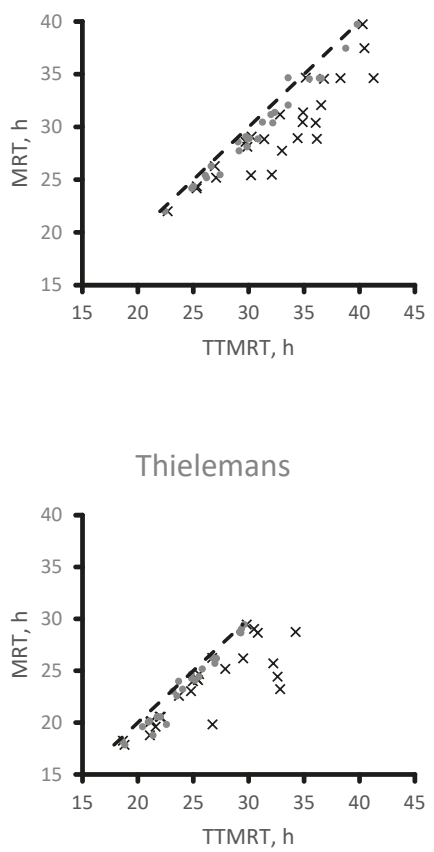

(b)

Figure 3. Comparison of arithmetically calculated mean retention time (MRT) calculated according to Blaxter et al. [32] and Thielemans et al. [33] compared with total tract mean retention time (TTMRT) calculated according to Dhanoa et al. [14] $(\times)$ and the best fitting two-compartment model described by Pond et al. [15] (•) for the particulate (a) and liquid (b) phase of digesta. The 1 to 1 line is denoted by the dashed line. 


\section{Discussion}

Increasing the retention time of Coastal bermudagrass may be an important digestive strategy in horses to adapt to the more difficult-to-digest fiber particles of warm-season grasses. Greater retention time of highly fibrous, warm-season forages allows for a lengthened exposure of digesta to microbial degradation. Forage fiber composition may also influence digesta passage rate within the gastrointestinal tract, as observed when mathematically modeling fecal marker excretion when horses were fed alfalfa hay, which has an increased concentration of pectin compared to grasses.

Forage type affected DMD, with the greatest digestibility observed when horses were fed alfalfa. Several other studies have reported greater digestibility of legume hays than cool-season or warm-season grass hays [34-40]. The DMD of alfalfa hay in this study falls within the 54-66\% range of alfalfa hay DMD reported in the literature [34-40]. Chemically, legume forages have greater protein and pectin concentrations and decreased insoluble fibers, allowing for a faster rate of digestion [41]. Legumes also contain a greater proportion of more easily digested mesophyll cells compared to grasses. The accumulation of lignin in alfalfa cell walls occurs primarily in alfalfa stems, whereas lignin accumulates in both grass stems and leaves during maturity [42,43]. Thus, there is a greater extent of cell wall digestion of alfalfa leaves compared to grasses [44].

Longer intervals of growth before harvest increased Coastal bermudagrass fiber and lignin concentrations in hay and resulted in reduced dry matter, organic matter, and fiber digestibilities. The internal girder structure of $\mathrm{C} 4$ forages firmly links the epidermis to vascular bundles, reducing the rate of digestion $[45,46]$. Akin et al. [47] reported that even typically highly digestible plant mesophyll cells were only partially degraded with increasing plant maturity in bermudagrass samples. The reported digestibility of Coastal bermudagrass hay ranges from $41-53 \%[34,35,48-50]$. Although the DMD of CB 4 fell within the reported range, the CB 6 and CB 8 had reduced digestibility compared with reported values. Because fiber concentration is negatively correlated with digestibility [6], the comparatively low digestibility of $\mathrm{CB} 6$ and $\mathrm{CB} 8$ to other published data is surprising as the Coastal bermudagrass used in those studies often had a greater detergent fiber concentration than the hays utilized in the current study [34,48-50]. Although the Coastal bermudagrass harvested at four weeks regrowth had greater NDF and hemicellulose concentrations than orchardgrass and alfalfa hays, fiber digestibility was similar. However, a reduction in NDFD and ADFD was observed in the CB 6 and CB 8 diets. Phenolic compounds and hemicellulose composition changes with increasing plant cell maturity $[47,51,52]$ likely leading to the decreased digestibility of Coastal bermudagrass harvested at longer intervals of growth. The results of the current study indicate that differences beyond plant fiber concentration, such as hemicellulose composition and lignin concentration also affect the digestibility of Coastal bermudagrass hay.

One strategy to adapt to the lower digestibility of high fiber C4 grasses such as Coastal bermudagrass is for the digesta retention time to increase. Other high fiber forages, such as oat straw, have also been reported to have increased MRT in equines [9]. Longer exposure to microbial fermentation in the equine hindgut can increase cell wall digestibility and could compensate for a slower rate of degradation of fibers in warm-season grasses $[46,53,54]$. This selective retention of Coastal bermudagrass hay in the gastrointestinal tract (GIT) may be due to differences in the particle size of digesta, rate of intake, or changes in GIT motility. How fiber affects gastrointestinal transit is not clearly understood in horses, people, or other mammals. One theory is that the fiber can trap water in the gastrointestinal tract, altering the way bacteria and solutes interact in the GIT [55]. In addition to luminal contents, gut motility is also driven by a range of neurohormones. Peptide YY (PYY) and glucagon-like peptide-1 (GLP-1) are important neurohormones regulating colonic motility [56], and the secretion of PYY and GLP-1 increases with the addition of fiber to diets [57,58]. Gut motility, neurotransmitters, and digesta characteristics warrant future investigation for potential mechanisms of regulating digesta transit in horses.

Differences in ROP were identified between forage types that were not apparent in TTMRT, indicating that mathematically modeling fecal marker excretion can advance the study of digesta 
passage in horses. Alfalfa ROP parameters derived from Dhanoa et al. [14] and Pond et al. [15] differed from other diets, indicating differences in digesta passage kinetics for a legume hay compared to grasses. For the particulate phase of digesta, $\lambda_{1}$ was quicker and $\mathrm{CMRT}_{1}$ shorter in ALF than CB 8 , even though no total tract differences were determined when TTMRT was calculated according to the G5G1 model. When particulate $\mathrm{CMRT}_{1}$ was calculated according to Dhanoa et al. [14], $\mathrm{CMRT}_{1}$ was longer in ALF compared with CB 6, a result also not reflected in TTMRT. When the liquid phase of digesta was modeled according to the G4G1 model, the age-dependent compartment ( $\left.\mathrm{CMRT}_{1}\right)$ was shorter than the age-independent compartment when horses were fed alfalfa. In contrast, all the grass forages had longer age-dependent CMRT than age-independent CMRT. Alfalfa and other legumes have higher pectin (a soluble fiber) concentrations compared to grasses. Soluble fiber has been shown to increase retention time in the small intestine and delay gastric emptying in other species $[59,60]$. The effect of fiber type on digesta ROP in the horse may be better elucidated using mathematical models than total tract MRT.

In the current study, compartment models described by both Dhanoa et al. [14] and Pond et al. [15] adequately fit equine marker excretion using non-linear least squares methods by modifying model parameter start values and bounds of rate parameters. Both one- and two-compartment models have been used in the recent literature, with the best fitting model depending on the study. Equations described by both Dhanoa et al. [14] and Pond et al. [15] have failed to produce a solution of acceptable model fit due to lack of convergence between experimental data and the model $[10,19,61]$. However, computing power and collaboration with computer scientists and modelers can greatly reduce the likelihood of models failing to converge with experimental data. Future studies incorporating mathematical modeling into digesta ROP studies will help to identify the best ways to describe digesta passage in the equine GIT.

Although using the equation described by Dhanoa et al. [14] resulted in an improved fit compared with the Pond et al. [15] models based on AIC values, TTMRT from the best fitting Pond et al. [15] models were more similar to arithmetically calculated MRT. The mathematical basis of these two models differ. The equation described by Dhanoa et al. [14] represents an unspecified number of exponentially distributed compartments, whereas the Pond et al. [15] equations used in the current study represented two distinct compartments plus transit time. The first two compartments in the Dhanoa et al. [14] model ( $\mathrm{CMRT}_{1}$ and $\left.\mathrm{CMRT}_{2}\right)$ have the longest retention time, and the remaining compartments are summed to determine transit time. Transit time is often defined as the amount of time from marker dosing to the first appearance of marker in the feces, but Ellis et al. [62] described transit time in the Dhanoa et al. [14] model as the sum of time in the remaining system of mixing compartments. The difference in transit time definition may be part of the discrepancy between transit time calculated from the different model equations. Additionally, the Dhanoa et al. [14] model may represent a set of exponentially distributed compartments that are within a larger mixing structure. The lack of agreement between arithmetic MRT and TTMRT calculated by the Dhanoa et al. [14] model may be explained by these differences.

The use of mathematical models could be further enhanced if theoretical compartments could be correlated to anatomical sections of the GIT. Moore-Colyer et al. [10] hypothesized that the two compartments of the Pond et al. [15] model represented the large colon for the age-dependent compartment and the cecum for the age-independent compartment because retention time in the colon is longer than the retention time in the cecum [63]. Transit time was hypothesized to represent residence time in the remaining structures of the GIT (i.e., stomach and small intestine). In a previous study using similar methodology, modeling fecal marker excretion when horses were fed mainly forage diets resulted in a CMRT similar to MRT in the cecum and colon [64,65]. However, Murray et al. [19] rejected the hypothesis that the age-dependent compartment was the colon because they observed a longer retention time in the age-independent compartment. The longer retention time of the age-independent compartment by Murray et al. [19] may be due to the diet (alfalfa and sugar beet pulp, which are high in soluble fiber), as observed in this study. Thus, diet may have a greater influence on compartment 
mean retention time than connections with anatomical compartments. Overall, mathematical models show promise to describe passage kinetics in horses, but the physiological relevance of compartment retention times remains unclear.

\section{Conclusions}

In conclusion, the horse appears to adopt a digestive strategy to decrease the rate of passage of digesta when fed warm-season grass forages. Increasing the retention time allows for fiber particles with greater hemicellulose and lignin concentrations to be exposed to microbial fermentation longer. Because warm-season forages have slower rates of degradation, this change in retention time allows the horse to maximize potential nutrients obtained from the diet. Using mathematical models further characterized differences in digesta ROP between forages which were not apparent when evaluating total tract MRT alone. Minor discrepancies between models and arithmetically calculated MRT were observed and should be resolved for future use. Nonetheless, mathematical modeling should be incorporated into future equine nutrition research to expand knowledge on digesta passage and equine science in general.

Supplementary Materials: The following are available online at http://www.mdpi.com/2076-2615/9/12/1148/s1, Computer Code S1: Matlab Model Fit; Supplementary Figures S1-S5: Individual Horse Marker Excretion Within Diet.

Author Contributions: Conceptualization, L.K.W., T.L.H., and E.L.C.; methodology, L.K.W., T.L.H., and E.L.C.; validation, L.K.W., and T.L.H.; formal analysis, T.L.H.; investigation, T.L.H., E.L.C., O.K.Z., J.M.M., J.M.B., L.A.S., J.W.C., A.M.A. and L.K.W.; resources, L.K.W.; writing—original draft preparation, T.L.H.; writing-review and editing, L.K.W., T.L.H.

Funding: This research received no external funding.

Acknowledgments: Seminole Feed Inc. (Ocala, FL, USA) provided a vitamin, mineral, protein pellet to feed in this study. The authors are grateful for the staff and students at the University of Florida/Institute of Food and Agricultural Sciences Horse Teaching Unit to complete this study. The authors would like to thank K. Bissinger, K. Bush, S. Chewing, M. Di-Lernia, B. Eubanks, T. Fraguela, J. Gerbert, K. Irvine, A. Mesa, N. Oliver, H. Miller, V. Robbins, D. Van Camp for animal care, sample collection, and laboratory assistance. J. Bauman, B. d'Angelo, and N. Wilkinson were an essential team for marker analysis on fecal samples. We additionally would like to acknowledge the thoughtful discussion provided by J. Brendemuhl, A.L. Fowler, T.J. Hackmann, and L. Sollenberger about this data.

Conflicts of Interest: The authors declare no conflict of interest.

\section{References}

1. Little, D.; Blikslager, A.T. Factors associated with development of ileal impaction in horses with surgical colic: 78 cases (1986-2000). Equine Vet. J. 2002, 34, 464-468. [CrossRef]

2. Blikslager, A.T. Colic prevention to avoid colic surgery: A surgeon's perspective. J. Equine Vet. Sci. 2019, 76, 1-5. [CrossRef]

3. Moore, K.J.; Boote, K.J.; Sanderson, M.A. Physiology and developmental morphology. In Warm-Season $\left(C_{4}\right)$ Grasses; Moser, L.E., Burson, B.L., Sollenberger, L.E., Eds.; ASA/CSSA/SSSA: Madison, WI, USA, 2014; pp. 179-216.

4. Sollenberger, L.E.; Vanzant, E.S. Interrelationships among forage nutritive value and quantity and individual animal performance. Crop Sci. 2011, 51, 420-432. [CrossRef]

5. Rohweder, D.A.; Barnes, R.F.; Jorgensen, N. Proposed hay grading standards based on laboratory analyses for evaluating quality. J. Anim. Sci. 1978, 47, 747-759. [CrossRef]

6. Hansen, T.L.; Lawrence, L.M. Composition factors predicting forage digestibility by horses. J. Equine Vet. Sci. 2017, 58, 97-102. [CrossRef]

7. Lowman, R.S.; Theodorou, M.K.; Hyslop, J.J.; Dhanoa, M.S.; Cuddeford, D. Evaulation of an in vitro batch culture technique for estimating the in vivo digestibility and digestible energy content of equine feeds using equine faeces as the source of microbial inoculum. Anim. Feed Sci. Technol. 1999, 80, 11-27. [CrossRef] 
8. Sunvold, G.D.; Hussein, H.S.; Fahey, G.C., Jr.; Merchen, N.R.; Reinhart, G.A. In vitro fermentation of cellulose, beet pulp, citrus pulp, and citrus pectin using fecal inoculum from cats, dogs, horses, humans, and pigs and ruminal fluid from cattle. J. Anim. Sci. 1995, 73, 3639-3648. [CrossRef]

9. Pearson, R.A.; Archibald, R.F.; Muirhead, R.H. The effect of forage quality and level of feeding on digestibility and gastrointestinal transit time of oat straw and alfalfa given to ponies and donkeys. Br. J. Nutr. 2001, 85, 599-606. [CrossRef]

10. Moore-Colyer, M.J.S.; Morrow, H.J.; Longland, A.C. Mathematical modelling of digesta passage rate, mean retention time and in vivo apparent digestibility of two different lengths of hay and big-bale grass silage in ponies. Br. J. Nutr. 2003, 90, 109-118. [CrossRef]

11. Miyaji, M.; Ueda, K.; Hata, H.; Kondo, S. Effects of quality and physical form of hay on mean retention time of digesta and total tract digestibility in horses. Anim. Feed Sci. Technol. 2011, 165, 61-67. [CrossRef]

12. Van Weyenberg, S.; Sales, J.; Janssens, G.P.J. Passage rate of digesta through the equine gastrointestinal tract: A review. Livest. Sci. 2006, 99, 3-12. [CrossRef]

13. Hooda, S.; Metzler-Zebeli, B.U.; Vasanthan, T.; Zijlstra, R.T. Effects of viscosity and fermentability of dietary fibre on nutrient digestibility and digesta characteristics in ileal-cannulated grower pigs. Br. J. Nutr. 2011, 106, 664-674. [CrossRef]

14. Dhanoa, M.S.; Siddons, R.C.; France, J.; Gale, D.L. A multicompartmental model to describe marker excretion patterns in ruminant faeces. Br. J. Nutr. 1985, 53, 663-671. [CrossRef]

15. Pond, K.R.; Ellis, W.C.; Matis, J.H.; Ferreiro, H.M.; Sutton, J.D. Compartment models for estimating attributes of digesta flow in cattle. Br. J. Nutr. 1988, 60, 571-595. [CrossRef]

16. Grovum, W.L.; Williams, V.J. Rate of passage of digesta in sheep. 4. Passage of marker through the alimentary tract and the biological relevance of rate-constants derived from the changes in concentration of marker in faeces. Br. J. Nutr. 1973, 30, 313-329. [CrossRef]

17. Austbø, D.; Volden, H. Influence of passage model and caecal cannulation on estimated passage kinetics of roughage and concentrate in the gastrointestinal tract of horses. Livest. Sci. 2006, 100, 33-43. [CrossRef]

18. Miyaji, M.; Ueda, K.; Hata, H.; Kondo, S. Effect of grass hay intake on fiber digestion and digesta retention time in the hindgut of horses. J. Anim. Sci. 2014, 92, 1574-1581. [CrossRef]

19. Murray, J.A.M.D.; Sanderson, R.; Longland, A.C.; Moore-Colyer, M.J.S.; Hastie, P.M.; Dunnett, C. Assessment of mathematical models to describe the rate of passage of enzyme-treated or sugar beet pulp-substituted lucerne silage in equids. Anim. Feed Sci. Technol. 2009, 154, 228-240. [CrossRef]

20. Rosenfeld, I.; Austbo, D.; Volden, H. Models for estimating digesta passage kinetics in the gastrointestinal tract of the horse. J. Anim. Sci. 2006, 84, 3321-3328. [CrossRef]

21. Federation of Animal Science Societies (FASS). Guide for the Care and Use of Agricultural Animals in Research and Teaching, 3rd ed.; FASS: Champaign, IL, USA, 2010.

22. Henneke, D.R.; Potter, G.D.; Kreider, J.L.; Yeates, B.F. Relationship between condition score, physical measurements and body fat percentage in mares. Equine Vet. J. 1983, 15, 371-372. [CrossRef]

23. NRC. Nutrient Requirements of Horses: Sixth Revised Edition; The National Academies Press: Washington, DC, USA, 2007; p. 360.

24. Fisher, R.A.; Yates, F. Statistical Tables for Biological, Agricultural and Medical Research; Oliver \& Boyd Ltd.: London, UK, 1963; p. 146.

25. Chizek, E.L. Comparison of Feed Intake Behavior between Warm- and Cool-Season Forages Offered to Horses. Master's Thesis, University of Florida, Gainesville, FL, USA, 2016.

26. Pagan, J. Nutrient digestibility in horses. In Advances in Equine Nutrition; Kentucky Equine Research, Inc.: Versailles, KY, USA, 1998; pp. 77-83.

27. Udén, P.; Colucci, P.E.; Van Soest, P.J. Investigation of chromium, cerium and cobalt as markers in digesta rate of passage studies. J. Sci. Food Agric. 1980, 31, 625-632. [CrossRef]

28. Ringler, J.E.; Lawrence, L.M. Development of a method to label forages used in passage rate studies in the horse. J. Equine Vet. Sci. 2009, 29, 389-390. [CrossRef]

29. ANKOM Technology. Analytical Methods Fiber Analyzer A200. Available online: https://www.ankom.com/ analytical-methods-support/fiber-analyzer-a200 (accessed on 20 January 2015).

30. EPA. Method 3052: Microwave Assisted Acid Digestion of Siliceous and Organically Based Matrices; EPA: Washington, DC, USA, 1996. 
31. EPA. Method 200.7: Determination of Metals and Trace Elements in Water and Wastes by Inductively Coupled Plasma-Atomic Emmision Spectometry; EPA: Washington, DC, USA, 1994.

32. Blaxter, K.L.; Graham, N.M.; Wainman, F.W. Some observations on the digestibility of food by sheep, and on related problems. Br. J. Nutr. 1956, 10, 69-91. [CrossRef]

33. Thielemans, M.-F.; Francois, E.; Bodart, C.; Thewis, A. Gastrointestinal transit in the pig: Measurement using radioactive lanthanides and comparison with sheep. Ann. Biol. Anim. Biochim. Biophys. 1978, 18, 237-247. [CrossRef]

34. Sturgeon, L.S.; Baker, L.A.; Pipkin, J.L.; Haliburton, J.C.; Chirase, N.K. The digestibility and mineral availability of Matua, Bermuda grass, and alfalfa hay in mature horses. J. Equine Vet. Sci. 2000, 20, 45-48. [CrossRef]

35. Eckert, J.V.; Myer, R.O.; Warren, L.K.; Brendemuhl, J.H. Digestibility and nutrient retention of perennial peanut and bermudagrass hays for mature horses. J. Anim. Sci. 2010, 88, 2055-2061. [CrossRef]

36. Earing, J.E.; Cassill, B.D.; Hayes, S.H.; Vanzant, E.S.; Lawrence, L.M. Comparison of in vitro digestibility estimates using the DaisyII incubator with in vivo digestibility estimates in horses. J. Anim. Sci. 2010, 88, 3954-3963. [CrossRef]

37. Cymbaluk, N.; Christensen, D. Nutrient utilization of pelleted and unpelleted forages by ponies. Can. J. Anim. Sci. 1986, 66, 237-244. [CrossRef]

38. Cymbaluk, N.F. Comparison of forage digestion by cattle and horses. Can. J. Anim. Sci. 1990, 70, 601-610. [CrossRef]

39. Potts, L.; Hinkson, J.; Graham, B.; Löest, C.; Turner, J. Nitrogen retention and nutrient digestibility in geldings fed grass hay, alfalfa hay, or alfalfa cubes. J. Equine Vet. Sci. 2010, 30, 330-333. [CrossRef]

40. Crozier, J.A.; Allen, V.G.; Jack, N.E.; Fontenot, J.P.; Cochran, M.A. Digestibility, apparent mineral absorption, and voluntary intake by horses fed alfalfa, tall fescue, and caucasian bluestem. J. Anim. Sci. 1997, 75, 1651-1658. [CrossRef] [PubMed]

41. Smith, L.W.; Goering, H.K.; Gordon, C.H. Relationships of forage compositions with rates of cell wall digestion and indigestibility of cell walls. J. Dairy Sci. 1972, 55, 1140-1147. [CrossRef]

42. Albrecht, K.A.; Wedin, W.F.; Buxton, D.R. Cell-wall composition and digestibility of alfalfa stems and leaves. Crop Sci. 1987, 27, 735-741. [CrossRef]

43. Griffin, J.L.; Jung, G.A. Leaf and stem forage quality of big bluestem and switchgrass. Agron. J. 1983, 75, 723-726. [CrossRef]

44. Bourquin, L.D.; Fahey, G.C., Jr. Ruminal digestion and glycosyl linkage patterns of cell wall components from leaf and stem fractions of alfalfa, orchardgrass, and wheat straw. J. Anim. Sci. 1994, 72, 1362-1374. [CrossRef] [PubMed]

45. Wilson, J.R.; Akin, D.E.; McLeod, M.N.; Minson, D.J. Particle size reduction of the leaves of a tropical and a temperate grass by cattle. II. Relation of anatomical structure to the process of leaf breakdown through chewing and digestion. Grass Forage Sci. 1989, 44, 65-75. [CrossRef]

46. Hastert, A.A.; Owensby, C.E.; Harbers, L.H. Rumen microbial degradation of Indiangrass and big bluestem leaf blades. J. Anim. Sci. 1983, 57, 1626-1636. [CrossRef]

47. Akin, D.E.; Robinson, E.L.; Barton, F.E.; Himmelsbach, D.S. Changes with maturity in anatomy, histochemistry, chemistry, and tissue digestibility of bermudagrass plant parts. J. Agric. Food Chem. 1977, 25, 179-186. [CrossRef]

48. Lieb, S.; Ott, E.A.; French, E.C. Digestible nutrients and voluntary intake of rhizomes peanut, alfalfa, bermudagrass and bahiagrass by equine. In Proceedings of the Thirteenth Equine Nutrition and Physiology Symposium, Gainesville, FL, USA, 21-23 January 1993; pp. 98-99.

49. Lieb, S.; Mislevy, P. Comparative intake and nutrient digestibility of three grass forages: Florakirk and Tifton 85 bermudagrasses and Florona stargrass to Coastal bermudagrass fed to horses. In Proceedings of the Seventeenth Equine Nutrition and Physiology Symposium, Lexington, KY, USA, 31 May-2 June 2001; pp. 390-391.

50. LaCasha, P.A.; Brady, H.A.; Allen, V.G.; Richardson, C.R.; Pond, K.R. Voluntary intake, digestibility, and subsequent selection of Matua bromegrass, coastal bermudagrass, and alfalfa hays by yearling horses. J. Anim. Sci. 1999, 77, 2766-2773. [CrossRef]

51. Akin, D.E.; Hartley, R.D. UV Absorption microspectrophotometry and digestibility of cell types of bermudagrass internodes at different stages of maturity. J. Sci. Food Agric. 1992, 59, 437-447. [CrossRef] 
52. De Ruiter, J.M.; Burns, J.C.; Timothy, D.H. Hemicellulosic cell wall carbohydrate monomer composition in Panicum amarum, P. amarulum and P virgatum accessions. J. Sci. Food Agric. 1992, 60, 297-307. [CrossRef]

53. Koller, B.L.; Hintz, H.F.; Robertson, J.B.; Van Soest, P.J. Comparative cell wall and dry matter digestion in the cecum of the pony and the rumen of the cow using in vitro and nylon bag techniques. J. Anim. Sci. 1978, 47, 209-215. [CrossRef]

54. Coblentz, W.K.; Fritz, J.O.; Fick, W.H.; Cochran, R.C.; Shirley, J.E. In situ dry matter, nitrogen, and fiber degradation of alfalfa, red clover, and eastern gamagrass at four maturities. J. Dairy Sci. 1998, 81, 150-161. [CrossRef]

55. Eastwood, M.A.; Kay, R.M. An hypothesis for the action of dietary fiber along the gastrointestinal tract. Am. J. Clin. Nutr. 1979, 32, 364-367. [CrossRef]

56. Wen, J.; Phillips, S.F.; Sarr, M.G.; Kost, L.J.; Holst, J.J. PYY and GLP-1 contribute to feedback inhibition from the canine ileum and colon. Am. J. Physiol. 1995, 269, G945-G952. [CrossRef]

57. Reimer, R.A.; McBurney, M.I. Dietary fiber modulates intestinal proglucagon messenger ribonucleic acid and postprandial secretion of glucagon-like peptide-1 and insulin in rats. Endocrinology 1996, 137, 3948-3956. [CrossRef]

58. Cani, P.D.; Lecourt, E.; Dewulf, E.M.; Sohet, F.M.; Pachikian, B.D.; Naslain, D.; De Backer, F.; Neyrinck, A.M.; Delzenne, N.M. Gut microbiota fermentation of prebiotics increases satietogenic and incretin gut peptide production with consequences for appetite sensation and glucose response after a meal. Am. J. Clin. Nutr. 2009, 90, 1236-1243. [CrossRef]

59. Jenkins, D.J.; Wolever, T.M.; Leeds, A.R.; Gassull, M.A.; Haisman, P.; Dilawari, J.; Goff, D.V.; Metz, G.L.; Alberti, K.G. Dietary fibres, fibre analogues, and glucose tolerance: Importance of viscosity. Br. Med. J. 1978, 1, 1392-1394. [CrossRef]

60. Schwartz, S.E.; Levine, R.A.; Singh, A.; Scheidecker, J.R.; Track, N.S. Sustained pectin ingestion delays gastric emptying. Gastroenterology 1982, 83, 812-817.

61. Jensen, R.B.; Austbo, D.; Bach Knudsen, K.E.; Tauson, A.H. The effect of dietary carbohydrate composition on apparent total tract digestibility, feed mean retention time, nitrogen and water balance in horses. Animal 2014, 8, 1788-1796. [CrossRef]

62. Ellis, W.C.; Matis, J.H.; Hill, T.M.; Murphy, M.R. Methodology for Estimating Digestion and Passage Kinetics of Forages. In Forage Quality, Evaluation, and Utilization; Fahey, G.C., Ed.; American Society of Agronomy, Crop Science Society of America, Soil Science Society of America: Madison, WI, USA, 1994; pp. 682-756.

63. Argenzio, R.A.; Lowe, J.E.; Pickard, D.W.; Stevens, C.E. Digesta passage and water exchange in the equine large intestine. Am. J. Physiol. 1974, 226, 1035-1042. [CrossRef] [PubMed]

64. Miyaji, M.; Ueda, K.; Nakatsuji, H.; Tomioka, T.; Kobayashi, Y.; Hata, H.; Kondo, S. Mean retention time of digesta in the different segments of the equine hindgut. Anim. Sci. J. 2008, 79, 89-96. [CrossRef]

65. Hansen, T.L. Modeling Digestibility and Rate of Passage in Horses. Master's Thesis, University of Kentucky, Lexington, KY, USA, 2014.

(C) 2019 by the authors. Licensee MDPI, Basel, Switzerland. This article is an open access article distributed under the terms and conditions of the Creative Commons Attribution (CC BY) license (http://creativecommons.org/licenses/by/4.0/). 


\title{
Effect of Linseed (Linum usitatissimum) Groats-Based Mixed Feed Supplements on Diet Nutrient Digestibility and Blood Parameters of Horses
}

\author{
Markku Saastamoinen * and Susanna Särkijärvi \\ Production Systems, Natural Resources Institute Finland (Luke), FI-31600 Jokioinen, Finland; \\ susanna.sarkijarvi@luke.fi \\ * Correspondence: markku.saastamoinen@luke.fi
}

Received: 28 January 2020; Accepted: 7 February 2020; Published: 10 February 2020

Simple Summary: In this study, the effect of linseed groat-based fibrous feed supplements on diet digestibility was studied. In addition, possible detrimental health effects due to continuous feeding of such supplemental feeds containing linseed were examined by evaluating blood parameters. The supplemented diets had statistically significantly higher digestibility of crude protein compared to the control diet. In addition, the digestibility of fat (ether extract) was higher in the supplemented diets than in the basal feeding. There were no statistically significant differences or trends in the blood parameters between the treatments. It is concluded that linseed by-products (linseed groats $0.8 \mathrm{~g} / \mathrm{kg} \mathrm{BW} / \mathrm{d}$ ) combined with other fibre sources can be safely used, for example, in feeding strategies replacing grains in the horses' rations in order to reduce the intake of starch.

\begin{abstract}
Linseed (Linum usitatissimum) and its by-products are common supplements used in equine diets and are claimed to have beneficial health effects. In this study, the effect of linseed groat-based fibrous feed supplements on diet digestibility was studied. Also, possible detrimental health effects due to continuous feeding of supplemental feeds containing linseed were examined by evaluating blood parameters. The experimental design was arranged as two balanced $3 \times 3$ Latin Squares. The horses were individually fed at the maintenance energy level, the forage-to-concentrate ratio being 70:30, with three diets: (A) Control diet consisting of dried hay and whole oats; (B) Control diet + Feed 1 ; and (C) Control diet + Feed 2. Feed 1 contained 70\% of linseed groats, $15 \%$ dried carrot, $10 \%$ dried garlic and 5\% molasses. Feed 2 contained $65 \%$ linseed groats, 15\% molassed sugar-beet pulp, 10\% dried garlic, $5 \%$ dried carrot and $5 \%$ molasses. Digestibility data were obtained by using chromium mordanted straw as an indigestible external marker for the estimation of apparent digestibility. Blood samples were collected from the jugular vein at the end of each feeding period to evaluate the possible effects of the supplemented diets B and C on the health of the horses. Diets B and C had a higher digestibility of crude protein compared to the control diet $\mathrm{A}(p<0.05)$. In addition, the digestibility of ether extract was higher in the supplemented diets than in the basal feeding $(p<0.01)$. There were no statistically significant differences or trends $(p>0.05)$ in the blood parameters between the treatments. It is concluded that linseed groat-based supplements (offering approximately $6.3 \%-6.7 \%$ linseed groats in the diet's dry matter (DM), or $0.8 \mathrm{~g} / \mathrm{kg} \mathrm{BW} / \mathrm{d})$, and feed containing soluble fibre sources (sugar-beet pulp, dehydrated carrot), improved the crude protein and fat digestibility of hay-oats diets of horses, and can be used, for example, in feeding strategies replacing grains in the horse rations in order to reduce the intake of starch without any adverse effects on the blood parameters and health of the horses.
\end{abstract}

Keywords: feeding; haematology; flax seed; fibre 


\section{Introduction}

Linseed (Linum usitatissimum) or by-products (groats, cakes, meals) of linseed oil pressing have been used in human and animal nutrition for decades because they are believed to have numerous beneficial effects, many times without any scientific evidence. The "basic" horse nutrition literature in different countries [1-3] has recommended the feeding of linseed in various amounts for a long time as a supplemental feed to promote gut and skin health as well as coat quality. Thus, linseed products are commonly used in equine diets $[4,5]$. However, there is a knowledge gap on the nutritional and health effects of feeding linseed products to horses, because scientific research about this is scarce. For example, proper and safe supplementation levels are not given or known.

Linseed meal is high in crude fibre, acid detergent fibre (ADF) and neutral detergent fibre (NDF) [6]. Pectins and other dietary fibres of linseed have been proved to promote the health of the gastrointestinal tract in humans and dogs (e.g., [7,8]). The hull fraction (outer seed coat) contains $2 \%-7 \%$ polysaccharide mucilage $[6,9]$. Mucilage is readily water dispersible and forms a viscous slime, which is believed to have positive effects on the stomach and gut [10]. Further, in our preliminary study [11], linseed-based feed enhanced sand removal from the digestive tract of the horses.

Linseed oil is a good source of valuable fatty acids (omega-3) [12]. Groats and meal from cold-pressing may have an oil content of up to $20 \%$ [13]. Thus, linseed can be viewed as a cost-effective and economical way to boost omega-3 fatty acids in the feed [14]. In one study [15], a significant improvement in a skin test response to Culicoides spp. was reported due to linseed supplementation. Improved hair coat and skin condition scores have also been obtained in dogs after one month of linseed supplementation [16]. Horses have low fatty acid elongation activity, which is important for the inflammatory response, and there is speculation that linseed as a source of omega-3 PUFA may decrease signs of laminitis by inhibiting inflammatory mediators [17]. In a quite recent study [18], increased concentrations of red blood cells, haemoglobin and haematocrit, as well as improved n-3 fatty acid profiles, were reported as a result of linseed oil supplementation. Vineyard et al. [19] found that supplementing horses with milled linseed resulted in pronounced early inflammatory responses to phytohaemagglutinin injections. Both studies also showed increased fatty acid contents of red blood cell membranes. In addition, fats are an important source of energy for horses [20] and can be applied to reduce the starch content of the diet. However, the ether extract digestibility of linseed observed for horses was lower compared to oats and bran [21].

Linseed by-products are rich in protein [6], but a comparison of linseed meal to blended milk products showed that the growth and feed/gain were much better for milk products, the main reason being their better lysine content [22]. Linseed by-products have not been successfully used as protein sources in chicks either [23]. Instead, conflicting results on the effects on growth and health have been reported for pigs $[24,25]$.

Consequently, there are several reasons for the interest in including linseed meal or oily linseed by-products in horse diets by horse owners [5]. However, linseed is known to contain compounds that may be toxic or have anti-nutritive properties $[6,26]$, when the enzyme linase releases cyanide from the glycoside and diclucosides of the seeds [27]. Cyanide levels in linseed are below the level hazardous to humans [6], but there is some concern about the possibility of cyanide poisoning in horses, which are fed linseed [3]. However, intoxications or studies on this matter and where the daily intakes are given have not been reported in horses.

Williams and Lamprecht [28] reviewed studies where linseed oil has been fed to horses, but the feeding of linseed by-products has rarely been the subject of controlled studies with horses, or any other species for that matter. In addition, data regarding the effects (beneficial or detrimental) on diet digestibility and/or animal health when large amounts are fed is scarce. Instead of this, rather small amounts (only 50-120 g/d) are recommended to horse diets [2]. Science-based levels are not given, but recently Lindinger [29] concluded in his article in a veterinary science journal, based on a trade blog [4]), that the highest recommended amount for horses is 454 grams/d (1 pound). Neither research data exists regarding feeds in which linseed is combined with botanically diverse fibre sources. 
Therefore, the objectives of this study were to: (1) investigate the effect of two linseed groat-based mixed feed supplements containing other fibrous ingredients on diet digestibility; (2) evaluate the possible detrimental health effects due to continuous feeding of linseed groats supplements in terms of blood parameters. The hypothesis was that there will be no detrimental effects due to the linseed supplementation on the diet digestibility and the haematological values of the horses. The results can be applied in the practical feeding of horses, or by the feed industry utilising linseed groats as a feed ingredient.

\section{Materials and Methods}

\subsection{Horses and their Management}

The influence of two linseed-based feed supplements on diet digestibility was examined with six Finnhorse mares (5-14 years; mean initial BW 636 kg, s.d. 37.8 kg), owned by MTT Agrifood Research Finland (currently Natural Resources Institute Luke). The experiment was conducted in the facilities of Luke. The experimental horses were individually housed in stalls $(3 \times 3 \mathrm{~m})$ with peat as bedding. The horses had free access to water and a salt block and they were de-wormed before the experiment, and dental care and vaccinations had also been carried out regularly prior to the experiment. During the experiment, they were freely exercised daily in outdoor paddocks for four hours, and one hour by riding at a slow walk, to fulfil their needs of exercise and ensure their wellbeing.

The experimental design was arranged as two balanced $3 \times 3$ Latin Squares. Each experimental period consisted of 21 days: 16 days of adaptation to the new diet followed by a five-day period of collecting representative spot faecal samples. The BW (electronic animal scale Lahden Vaaka/Lahti Precision Ltd., Lahti, Finland) of the horses was monitored after each collection period to control possible changes and to adjust the individual energy intakes if necessary.

In animal handling and sample collection, the European Union recommendation directives (1999/275/EU) and national animal welfare and ethical legislation set by the Ministry of Agriculture and Forestry of Finland were followed carefully. The experimental procedures were evaluated and approved by The Animal Care Committee of MTT (Permit 9/2001) before the study was started.

\subsection{Experimental Feeds and Feeding}

The horses were randomly allotted to three dietary treatments: (A) Control diet consisting of dried hay dominated by timothy grass and whole oats; (B) Control diet + Feed 1; and (C) Control diet + Feed 2. Feed 1 contained $70 \%$ of linseed groats, $15 \%$ dried carrot, $10 \%$ dried garlic and $5 \%$ molasses. Feed 2 contained 65\% linseed groats, 15\% molassed sugar-beet pulp, 10\% dried garlic, 5\% dried carrot and $5 \%$ molasses. The hay and oats for this experiment were produced by Luke. Feed 1 and Feed 2 were manufactured in a single batch for this experiment by a Finnish medical and food factory (Neomed Ltd., Somero, Finland) and were in granulated form (granulated in $70-80{ }^{\circ} \mathrm{C}$ heat for 5 to $6 \mathrm{~min}$ ). The linseed groats in the experimental feeds were by-products of cold-pressing of linseed oil with an average fat (oil) content of $20 \%$. The other raw materials were included in the experimental feeds in order to improve the palatability as well as owing to their technological properties [30]. They are also common supplemental feeds included in horse diets. The average chemical composition of the feeds is presented in Table 1 .

The horses were individually fed at the maintenance energy level according to the Finnish Feed Tables and Feeding Recommendations [13], the forage-to-concentrate ratio being 70:30. Each experimental feed ration was formulated and adjusted to be as isocaloric and isonitrogenous as possible. The average daily allowances of hay, oat and experimental feeds in each dietary treatment are presented in Table 2. About $8 \%$ of the oats was substituted with the experimental feeds in the treatments B and C. 
Table 1. Average chemical composition of the experimental feeds ( $\mathrm{g} / \mathrm{kg}$ dry matter).

\begin{tabular}{ccccc}
\hline Composition & Hay & Oats & Feed 1 & Feed 2 \\
\hline Dry matter g kg ${ }^{-1}$ & 870.7 & 883.1 & 905.2 & 885.4 \\
Organic matter & 934.7 & 971.4 & 930.6 & 924.3 \\
Crude protein & 95.0 & 112.8 & 211.5 & 209.8 \\
Ether extract & 15.6 & 61.0 & 185.7 & 172.7 \\
NDF & 687.7 & 263.3 & 183.3 & 228.0 \\
Crude fibre & 339.0 & 89.0 & 96.0 & 105.3 \\
Ash & 63.5 & 28.6 & 69.4 & 75.7 \\
NFE & 485.1 & 708.6 & 437.5 & 436.5 \\
ME MJ/kg DM & 9.10 & 12.6 & 14.3 & 13.9 \\
NDF $=$ neutral detergent fibre; NFE = nitrogen free extract; ME = metabolisable energy.
\end{tabular}

Table 2. Daily allowances of hay, oats and experimental feeds (Feed 1 or Feed 2) fed in each dietary treatment (DM kg/day) (with ranges).

\begin{tabular}{cccc}
\hline Feed & Diet A (Control) & Diet B (Feed 1) & Diet C (Feed 2) \\
\hline \multirow{2}{*}{ Hay } & 5.89 & 5.44 & 5.43 \\
& $(5.66-6.36)$ & $(5.22-5.92)$ & $(5.22-5.75)$ \\
Oats & 1.85 & 1.74 & 1.74 \\
& $(1.80-2.12)$ & $(1.68-1.89)$ & $(1.68-1.84)$ \\
Experimental feed & - & 0.757 & 0.745 \\
& & $(0.710-0.780)$ & $(0.730-0.750)$ \\
\hline
\end{tabular}

The change in rations between periods was made gradually during the first five days of the adaptation period. Feeds were offered in equal meal sizes three times a day at 06:30, 12:30 and 17:30. The grain ration was given about $30 \mathrm{~min}$ after the hay ration. The experimental feeds (Feeds 1 and 2) were aimed to be fed at a level of approximately $10 \%$ of the total dry matter (DM) intake, the average daily portion being $765 \mathrm{~g} \mathrm{DM}$ /horse divided into three equal portions that were fed separately after the intake of oats. They were soaked in warm water $\left(45-50{ }^{\circ} \mathrm{C}\right)$ before feeding to ensure their palatability. Mineral intakes were balanced with a commercial vitamin-mineral mixture (Suomen Rehu Ltd., Seinäjoki, Finland).

\subsection{Feed and Faeces Sampling}

Digestibility data were obtained by using chromium mordanted straw (68 mg Cr/g DM) with a daily dose of $1.6 \mathrm{~g} / \mathrm{kg}$ feed DM as an indigestible external marker for the estimation of apparent digestibility. The chromium mordanted straw was prepared according to Udèn et al. [31]. The chromium dosage was calculated separately for every feed portion and served on the top of the concentrate three times a day, as described in detail by Särkijärvi and Saastamoinen [32]. Samples of hay and oats were collected for analysis over the last seven days of each period, and stored until the end of the five-day collection period. Faecal grab samples (500 g) were taken from each horse twice a day after the morning and mid-day feeding, during the five-day collection period. Samples were collected from the floor of the pen from a freshly produced pile. Daily faecal samples were stored at $-24{ }^{\circ} \mathrm{C}$ until mixed, sub-sampled and dried (at $100{ }^{\circ} \mathrm{C}$ for $1 \mathrm{~h}+$ at $60^{\circ} \mathrm{C}$ for $72 \mathrm{~h}$ ) for laboratory analysis [32]. 
Feed and faeces samples were analysed in the feed laboratory of Luke (Luke Laboratories, Jokioinen, Finland) for dry matter (DM), organic matter (OM), neutral detergent fibre (NDF), crude fibre $(\mathrm{CF})$, crude protein $(\mathrm{CP})$, ether extract (EE) and ash with standard wet chemical methods as described by Särkijärvi et al. [33]. The nitrogen-free extract (NFE) was calculated: (100-CP-CF-EE-ash). The digestible CP $(\mathrm{DCP})$ was calculated: $\mathrm{DCP}(\mathrm{g} / \mathrm{kg} \mathrm{DM})=\mathrm{CP}(\mathrm{g} / \mathrm{kg} \mathrm{DM}) \times \mathrm{CP}$ digestibility $(\mathrm{g} / \mathrm{kg} \mathrm{CP}) / 1000$, where the CP digestibility was taken from the Finnish Feed Tables and Feeding Recommendations [11]. The metabolisable energy value (ME) was calculated according to the British energy evaluation system [34].

\subsection{Blood Sampling}

Blood samples were collected at the end of each period to evaluate the possible effects of the diets on the health of the horses. The samples $(2 \times 10 \mathrm{~mL})$ were collected $90 \mathrm{~min}$ after the morning meal from the jugular vein to heparinised blood collection tubes, and centrifuged. The blood analysis consisted of the contents of red blood cells (RBC), white blood cells (WBC), haemoglobin (Hb), haematocrit (HcT), and fibrinogen, as well as liver enzymes alanine aminotransferase (ALT) and $\gamma$-glutamyltransferase (GT), to indicate possible detrimental effects of linseed (cyanogenic glucosides) on the liver. All samples were analysed in the clinical laboratory of Luke.

\subsection{Statistical Analysis}

The data were analysed with a linear mixed model using the MIXED procedure of the SAS system using the REML estimation method. The following statistical model was applied:

$$
\mathrm{Y}_{\mathrm{ijk}}=\mu+\mathrm{a}_{\mathrm{i}}+\mathrm{t}_{\mathrm{j}}+\mathrm{p}(\mathrm{sq})_{\mathrm{k}}+\varepsilon_{\mathrm{ijk}}
$$

where $Y_{i j k}$ is the observation, $\mu$ is the overall mean, $a_{i}$ is the random effect of $i$ th animal $(i=1, \ldots 6), t_{j}$ is the fixed effect of $\mathrm{jth}$ dietary treatment $(\mathrm{j}=1, \ldots 3), \mathrm{p}(\mathrm{sq})_{\mathrm{k}}$ is the fixed effect of kth period within the square $(\mathrm{k}=1, \ldots 3)$ and $\varepsilon_{\mathrm{ijk}}$ is the normally distributed error with a mean of 0 and the variance $\delta^{2}$. Residuals were tested for normality. The differences were tested with Tukey's test, and the level of significance was set at the $5 \%$ level.

\section{Results}

\subsection{Feed and Nutrient Intakes}

The palatability of all the diets was good and there were no feed refusals. There were only very minor changes ( $\pm 0.8-2.2 \%$ between the measurements) in the body weights of the horses during the study. Diet intake was isocaloric and isonitrogenous between study periods (all diets combined; Table 3), but the intakes differed between the diets (Table 4). The average intakes of fat (EE) and CP of the supplemented horses (Diets B and C) were $58.0 \%$ and $14.1 \%$ higher than in the control group. Concerning ME, CF and NDF intakes, the differences were much smaller with $+2.0 \%,-4.0 \%$ and $-4.5 \%$, respectively.

Table 3. Average daily ME, CP and DM intakes ( \pm s.d.) for each period.

\begin{tabular}{cccc}
\hline Intake & Period I & Period II & Period III \\
\hline ME MJ & $80.3 \pm 4.8$ & $81.8 \pm 3.9$ & $80.1 \pm 3.2$ \\
CP g & $832.4 \pm 68.9$ & $850.4 \pm 73.1$ & $835.2 \pm 50.6$ \\
DM kg & $7.86 \pm 0.37$ & $7.98 \pm 0.29$ & $7.86 \pm 0.31$ \\
\hline ME = metabolisable energy; $\mathrm{CP}=$ crude protein; $\mathrm{DM}=$ dry matter.
\end{tabular}

The proportions of linseed groats (on a DM basis) in diets B and C were $6.7 \%$ and $6.3 \%$, respectively. On the BW basis, the intakes of linseed groats were approximately $0.8 \mathrm{~g} \mathrm{DM} / \mathrm{kg} \mathrm{BW} / \mathrm{d}$. 


\subsection{Diet Digestibility}

The supplementation of the experimental feeds improved only the digestibilities of total diet fat (ether extract, EE) and crude protein (CP) $(p=0.0012$ and 0.0182 , respectively) compared to the control diet (Table 5). In addition, the digestibility of ash (minerals) seemed to be numerically (but not statistically, $p=0.2093$ ) somewhat higher in the supplemented diets than in the control diet. None of the digestibility values differed between the supplemental diets (Diet B versus Diet C) $(p$-values $=0.47-0.80)$.

Table 4. Average daily dry matter, metabolisable energy and nutrient intakes ( \pm s.d.) in each dietary treatment.

\begin{tabular}{cccc}
\hline Intake & Diet A (Control) & Diet B (Feed 1) & Diet C (Feed 2) \\
\hline DM kg & $7.77 \pm 0.39$ & $7.94 \pm 0.28$ & $7.91 \pm 0.27$ \\
ME MJ & $77.3 \pm 3.9$ & $82.9 \pm 3.0$ & $81.5 \pm 2.6$ \\
EE g & $206.4 \pm 10.8$ & $332.8 \pm 9.7$ & $318.9 \pm 6.5$ \\
CP g & $763.9 \pm 40.2$ & $877.5 \pm 29.6$ & $867.3 \pm 26.5$ \\
DCP g & $518.5 \pm 26.5$ & $618.2 \pm 18.2$ & $612.0 \pm 23.2$ \\
NDF g & $4556.3 \pm 209.1$ & $4338.6 \pm 156.8$ & $4358.9 \pm 166.6$ \\
CF & $2164.8 \pm 108.0$ & $2072.0 \pm 74.4$ & $2073.9 \pm 83.0$ \\
\hline
\end{tabular}

$\mathrm{DM}=$ dry matter; $\mathrm{ME}=$ metabolisable energy; $\mathrm{EE}=$ ether extract (fat); $\mathrm{DCP}=$ digestible crude protein; $\mathrm{CP}=$ crude protein; $\mathrm{NDF}=$ neural detergent fibre; $\mathrm{CF}=$ crude fibre.

Table 5. Average apparent digestibility coefficients (\%) and standard deviations (s.d.) for the total diet nutrients in the control and experimental diets.

\begin{tabular}{ccccc}
\hline \multirow{2}{*}{ Composition } & Diet A (Control) & Diet B & Diet C & $p$ Value \\
\cline { 3 - 5 } & & (Feed 1) & (Feed 2) & (B and C vs. Control Diet) \\
\hline Dry matter & $54.8(5.29)$ & $55.3(2.54)$ & $57.0(3.96)$ & 0.5065 \\
Organic matter & $56.9(5.05)$ & $57.2(3.24)$ & $58.9(3.92)$ & 0.5710 \\
Crude protein & $61.4(6.20)$ & $64.0(4.46)$ & $65.7(5.83)$ & 0.0182 \\
Ether extract & $56.2(7.99)$ & $68.0(5.02)$ & $68.8(5.46)$ & 0.0012 \\
NDF & $47.2(6.01)$ & $47.8(4.17)$ & $47.9(4.16)$ & 0.8139 \\
Crude fibre & $44.6(5.27)$ & $43.9(4.45)$ & $46.3(4.87)$ & 0.8484 \\
Ash & $19.7(20.08)$ & $25.1(8.74)$ & $27.4(10.68)$ & 0.2093 \\
NFE & $62.8(5.09)$ & $62.0(2.83)$ & $63.5(3.32)$ & 0.9601 \\
\hline
\end{tabular}

$\mathrm{NDF}=$ neutral detergent fibre; NFE = nitrogen free extract.

\subsection{Blood Parameters}

There were no statistically significant differences or trends $(p>0.05)$ in the blood parameters between the diets (Table 6). The variation in the blood parameters (except ALT) was largest when the diet $\mathrm{C}$ was fed to the horses. $\gamma$-glutamyltransferase (GT) activity was numerically (but not statistically) somewhat higher, and the ALT activity lower, in the linseed supplemented diets. The average number of WBC and concentration of fibrinogen were also numerically higher in linseed supplemented horses but were within the reference values as well. Compared to the other horses, one horse had an exceptionally high GT activity (23-37 U/1), and another individual a low ALT activity (2.0 U/1) during the study period. The $\mathrm{Hb}$ and $\mathrm{RBC}$ values in all horses were low. 
Table 6. Average values of blood parameters and standard deviations (s.d.) for the horses in the control and experimental diets.

\begin{tabular}{ccccc}
\hline Blood Parameters & Diet A (Control) & $\begin{array}{c}\text { Diet B } \\
\text { (Feed 1) }\end{array}$ & $\begin{array}{c}\text { Diet C } \\
\text { (Feed 2) }\end{array}$ & $\begin{array}{c}\text { Reference Values } \\
{[35,36]}\end{array}$ \\
\hline Glutamyltransferase, U/l & $17.0(4.46)$ & $19.7(6.66)$ & $18.0(7.10)$ & $10-70$ \\
Alanine aminotransferase, U/1 & $6.33(2.02)$ & $5.67(2.57)$ & $5.83(1.95)$ & $5-45$ \\
Haemoglobin, g/l & $127.7(7.27)$ & $124.2(5.64)$ & $126.0(11.03)$ & $120-155$ \\
Haematocrit, $\%$ & $34.7(2.15)$ & $34.3(1.88)$ & $34.4(3.51)$ & $34-43$ \\
Red blood cells, $\times 10^{12} / 1$ & $6.99(0.55)$ & $6.86(0.55)$ & $6.92(0.89)$ & $7.0-9.0$ \\
White blood cells, $\times 10^{9} / 1$ & $7.35(1.02)$ & $7.25(0.69)$ & $7.23(1.72)$ & $4.6-9.5$ \\
Fibrinogen, $\mathrm{g} / 1$ & $2.67(0.28)$ & $2.78(0.25)$ & $2.86(0.34)$ & $1.2-4.0$ \\
\hline
\end{tabular}

None of the differences between the groups were statistically significant (all $p>0.05$; $p$-values $0.6-1.0$ ).

\section{Discussion}

\subsection{Feed and Nutrient Intakes}

Maintaining BW showed that the feeding level used equalled the energy needs [11] of the horses. By period, intakes were isocaloric and isonitrogenous. However, the average fat (EE) intake of the supplemental diets (B and $\mathrm{C}$ ) was more than 1.5-fold greater compared to the control diet, and the $\mathrm{CP}$ was $14.1 \%$ higher. In contrast, the differences were minor for energy and fibre components.

The palatability of the studied supplemental feeds was good. In our earlier unpublished study, we observed that the palatability of plain linseed groats was not good when fed in large (more than $6 \%$ in DM) portions. Delobel et al. [37] found no effects of flaxseed oil supplementation on diet palatability in horses. The other ingredients (sugar-beet pulp, carrot and molasses) of the linseed supplements fed in the present study likely improved the palatability of the supplemental feeds. Because of the $10 \%$ content of dried garlic in the supplemented diets, the horses had to ingest approximately $120 \mathrm{mg} / \mathrm{kg}$ BW dried garlic, which has been reported to be within the safe limits of garlic intake given by The National Academies [38].

\subsection{Diet Digestibility}

The improved digestibilities of dietary CP and EE when the supplemental feeds were fed is most likely due to the high concentrations and intakes of those nutrients in the feeds, and is supported by previous studies for CP $[32,39,40]$ and EE [21,41]. In addition, Reitnour and Salsbury [42] found that the caecal administration of linseed meal increased the digestibility of total diet protein. There is, however, no evidence that fat and protein of linseed groats are more digestible than those of the control diet. The improvements may also be partly attributed to the dilution of endogenous faecal nitrogen and fat at higher intakes, which enhances their apparent digestibility [41,43-46].

Supplementing the diets with the experimental feeds caused a minor decrease in the NDF and $\mathrm{CP}$ intakes. The supplemental feeds contained properly digestible fibre sources, carrot and molassed sugar-beet pulp. Both of those ingredients are rich in dietary fibre of a soluble form, and have approximately the same amount of $\mathrm{CF}$, but the NDF content of sugar-beet pulp is approximately two times that of carrot [30,47]. Sugar-beet pulp containing a lot of soluble and highly fermentable fibre [48] has been reported to be well utilised by horses [49-51]. No data on the digestibility of carrot is available. In addition, Snel et al. [52] (in their review of studies with different animal species) and Dongowski et al. [53] (in rats) have reported that the dietary fibre in sugar-beet pulp may have a prebiotic effect on intestinal flora improving the microbial activity and, thus, the digestibility. Murray et al. [54] reported in horses that sugar-beet pulp enhanced total diet digestibility fed together with forages. In addition, Lindberg and Palmgren Karlsson [44] explained their results with a positive effect of soluble and fermentable fibre in horses when sugar-beet pulp and fat was added to horse diets. As a potentially contributing factor, Clauss et al. [55] reported that nutrient supply to gut bacteria is the major digestive constraint in horses. 
Because the experimental feeds contained many ingredients (being combinations of botanically diverse fibrous feeds), comparisons with previous studies including different diet compositions, and where linseed or variety of its by-products was used, are difficult. It is likely that the other components have their influences too, and that there are confounding and synergistic effects of the diet ingredients. Reitnour and Salsbury [42] found that the caecal administration of linseed meal decreased diet DM digestibility. In our unpublished study, we found that the supplementation of plain linseed groats from $0 \%$ to $10 \%$ (in the diet $\mathrm{DM}$ ) gradually decreased the digestibility of the diet nutrients. This has also been reported in dogs [8], and may be due to the poor digestibility of linseed husks and the mucilage content of the hull. Linseed meal is also high in lignin [48], and most of the dietary fibre in linseed meal is in an insoluble form [8]. These findings are supported by Takagi et al. [21] (intakes were not given) who reported very low (21.8) digestibility for the crude fibre of linseed in horses. In one study, the inclusion of extruded linseed ( $20 \%$ in DM) in the diets of horses decreased the digestibility of nutrients compared to hay-only and hay/wheat bran diets [56]. In agreements with the results of the present study, Smolders et al. [57] found increased digestibility values of the diet nutrients when horses were fed compound feed containing $(16 \%)$ linseed expeller plus more digestible ingredients (cereals). In the present study, the intake of linseed groats was $6.3 \%-6.7 \%$ in DM, and when combined with digestible fibre sources, also improved the diet's digestibility. Inconsistency of the results between studies is likely due to the different methods and processing of adding linseed or by-products, and different compositions of the diets.

Concerning other animal species, low levels ( $8 \%-10 \%$ in the feed) of linseed meal in pig feed may improve digestibility and growth rate, but $12 \%$ inclusion caused adverse effects [58]. Sled dogs can utilise up to $4.2 \%$ linseed cake as a source of fibre without severe reductions in nutrient digestibility or feed consumption [8]. In dairy cows, linseed supplementation improved total tract nutrient utilisation without any adverse effects on ruminal fermentation [59].

Regarding the method applied in determining digestibility, Palmgren Karlsson [60] suggested that chromium mordanted fibre could be an alternative to the administration of chromium, but may result in underestimated digestibility values. In Särkijärvi et al. [33], however, chromium mordanted silage gave quite precise digestibility values in horses (of a similar breed, gender and age as in this study).

\subsection{Haematology Parameters}

The serum concentrations of the liver enzymes alanine aminotransferase (ALT) and $\gamma$-glutamyltransferase (GT) were within the reference values of Finnhorses, but close to their lower limit [61]. Elevated ALT and GT values might have indicated possible detrimental effects of linseed (cyanogenic glucosides) on the liver. Additionally, the average number of WBC and concentration of fibrinogen were within the reference values. It can be concluded that there were no inflammatory reactions in the bodies of the horses due to the diet. The large variation in the haematology parameters when the Feed 2 diet was fed to the horses was likely due to the small number of horses used in this study.

$\mathrm{The} \mathrm{Hb}, \mathrm{HcT}$ and $\mathrm{RBC}$ values in all horses were low and close to the lower limit of the reference values of Finnhorses $[61,62]$ regardless of the feeding group. The generally low $\mathrm{Hb}$ might be a result of the low feeding and exercise intensity of the horses [63].

Based on the blood analyses, we concluded that no adverse health effects in horses were caused from the supplementation of the diet with linseed groat-based feeds (offering approximately $6.3 \%-6.7 \%$ linseed groats in the diet DM or $0.8 \mathrm{~g} / \mathrm{kg} \mathrm{BW} / \mathrm{d}$ ) during the nine-week experimental period. This is supported by Vineyard et al. [19] who fed milled flaxseed for 70 days without any health problems.

No negative effects on health or performance of sport horses were found when linseed cake (990 g/d) was fed for 60 days [62], which agreed with O'Neil et al. [15] who observed no negative side effects when milled flaxseed was fed $(1 \mathrm{~g} / \mathrm{kg} \mathrm{BW})$. The latter researchers concluded that stomach acid can inactivate enzymes within the seeds, which are required to interact with glycosides to form cyanide. Most glycosidases have a pH-optimum of around 7, so in herbivores with acid digestion, e.g., 
horses, they are usually inactivated [26]. In pigs, Batterham et al. [24] report lighter kidneys, pancreas and spleens for those animals given linseed, but no effects on the weight of livers were observed. They concluded that this may be a result of the anti-nutritional factors of linseed. Mazza and Oomah [26] concluded that most herbivores excrete the unhydrolysed cyanogenic compounds without harm to the animal.

The content of the anti-nutritive compounds in seeds depends on the cultivar, location and year of production, with the cultivar having the most significant effect $[6,26]$. The current and new L. usitatissimum varieties for human nutrition are rather low in toxic and detrimental compounds [26], as were the cultivars used in the present study (Neomed Ltd., Somero, Finland). According to Abraham et al. [63], in case of missing or inactivated glucosidase, the hazard potential (to humans) is low. Boiling is usually recommended to remove the potentially toxic cyanide components, and heat processing of linseed reduces its content of cyanogenic glycosides. Thus, in the present study, both the manufacturing process in the temperatures of $75-80^{\circ} \mathrm{C}$, and soaking into $45-50^{\circ} \mathrm{C}$ water before feeding, might also have decreased the content of possible harmful compounds of the linseed groats $[6,26]$. In addition, $\mathrm{HCN}$ content is reduced when linseed is mixed with several ingredients and when the product is pelleted [64] as in the present study.

\section{Conclusions}

Linseed groat-based supplements (offering approximately $6.3 \%-6.7 \%$ linseed groats in the diet $\mathrm{DM}$ or $0.8 \mathrm{~g} / \mathrm{kg} \mathrm{BW} / \mathrm{d}$ ), and containing soluble fibre sources (sugar-beet pulp, dehydrated carrot), improved the crude protein and fat digestibility of hay/oats diets of horses, and had no effects on fibre digestibility. No adverse or anti-nutritional effects were observed on the availability of any component of the diet or the haematologic parameters and health of the horses. Linseed by-products combined with other fibre sources can be used, for example, in feeding strategies replacing grains in the horse rations in order to reduce the intake of starch. There is a need to investigate the synergetic and confounding effects of diet ingredients of different sources, especially botanically diverse fibrous feeds.

Author Contributions: M.S. and S.S. contributed methodology, investigation and data curation; S.S. contributed formal analysis and data analyzing; M.S. contributed resource, writing-original draft preparation, supervision and project administration. All authors have read and agreed to the published version of the manuscript.

Funding: This research was carried out by an independent governmental research institute and partly $(30 \%)$ funded by Neomed Ltd.

Conflicts of Interest: The authors declare no conflict of interest. The funder had no role in the design of the study; in the collection, analyses, or interpretation of data; in the writing of the manuscript, or in the decision to publish the results.

\section{References}

1. Cunha, T.J. Horse Feeding and Nutrition, 2nd ed.; Academic Press Inc.: San Diego, CA, USA, 1991.

2. Meyer, H. Pferdefütterung, 3rd ed.; Blackwell Wissenschafts-Verlag: Berlin, Germany; Wien, Austria, 1995.

3. Frape, D. Equine Nutrition and Feeding, 3rd ed.; John Wiley \& Sons: Bodmin, UK, 2008.

4. Janickie, K.M. 5 Facts of About Flax. The Horse.com. Available online: https://thehorse.com/149473/5-factsabout-flax (accessed on 15 July 2019).

5. Christopherson, K. Tha Facts on Flax - the Value of Flaxsees in Your Horse's Diet. Equine Wellness Magazine.com. Available online: https://equinewellnessmagazine.com (accessed on 15 July 2019).

6. Wanasundra, P.K.J.P.D.; Shadidi, S. Process-induced compositiona cganges of flaxseed. In Process-Induced Chemical Changes in Food; Plenum Press: New York, NY, USA, 1998; pp. 307-325.

7. Reinhart, G.A.; Moxley, R.A.; Clemens, E.T. Source of dietary fiber and its effects on colonic microstructure, function and histopathology of beagle dogs. J. Nutr. 1994, 124, 2701S-2703S. [CrossRef] [PubMed]

8. Kempe, R.; Saastamoinen, M. Effect of linseed cake supplementation on digestibility and faecal and haematological parameters in dogs. J. Anim. Physiol. Nutr. 2007, 91, 319-325. [CrossRef] [PubMed]

9. Bhatty, R.S.; Cherdkiatgumchai, P. Compositional analysis of laboratory-prepared and commercial samples of linseed meal and hulls isolated from flax. J. Am. Oil Chem. Soc. 1990, 67, 79-84. [CrossRef] 
10. Bhatty, R.S. Physiochemical properties of roller-milled barley bran and flour. Cereal Chem. 1993, 70, 397-402.

11. Särkijärvi, S.; Hyyppä, S.; Saastamoinen, M. Effect of linseed based feed supplementation on sand excretion in horses. In The Impact of Nutrition on the Health and Welfare of Horses; Wageningen Academic Publishers: Wageningen, The Netherlands, 2010; pp. 266-268.

12. Cunnane, S.C.; Ganguli, S.; Menard, C.; Liede, A.C.; Hamadeh, M.J.; Chen, Z.-Y.; Wolever, T.M.S.; Jenkins, D.A. High- $\alpha$-linolenic acid flaxseed (Linum ussitatissimum L.); some nutritional properties in humans. Br. J. Nutr. 1993, 69, 443-453. [CrossRef]

13. Luke. Finnish Feed Tables and Feeding Recommendations; Natural Resources Institute Finland: Helsinki, Finland, 2015. Available online: http://urn.fi/URN:ISBN:978-952-326-054-2 (accessed on 18 December 2019).

14. Elghandour, M.M.Y.; Reddy, P.R.; Salem, A.Z.M.; Reddy, P.P.R.; Hyder, I.; Barbabosa-Pliego, A.; Yasawini, D. Plant bioactives and extracts as feed additives in Horse nutrition. J. Equine Vet. Sci. 2018, 69, 66-77. [CrossRef]

15. O'Neil, W.; McKee, S.; Clarke, A.F. Flaxseed (Linum usitatissimum) supplementation associated with reduced skin test lesional area in horses with Culicoides hypersensitivity. Can. J. Vet. Res. 2002, 66, 272-277.

16. Rees, C.; Bauer, J.; Burkholder, W.; Kennis, R.; Dunbar, B.; Bigley, K. Effects of dietary flaxseed and sunflower seed supplementation on normal canine serum polyunsaturated fatty acids and skin and hair coat condition scores. Vet. Dermat. 2001, 12,111-117. [CrossRef]

17. Tinworth, K.D.; Harris, P.A.; Sillence, M.N.; Noble, G.K. Potential treatments for insulin resistance in the horse: A comparative multi-species review. Vet. J. 2010, 186, 282-291. [CrossRef]

18. Patoux, S.; Istasse, L. Incorporation of sunflower oil or linseed oil in equine compound feedstuff: 1 Effects on haematology and fatty acid profiles in the blood cells membranes. J. Anim. Physiol. Anim. Nutr. 2016, 100, 828-835. [CrossRef]

19. Vineyard, K.R.; Warren, L.K.; Kivipelto, J. Effect of dietary omega-3 fatty acid source on plasma and red blood cell membrane composition and immune function in yearling horses. J. Anim. Sci. 2010, 88, $248-257$. [CrossRef]

20. Harking, J.D.; Morris, G.S.; Tulley, R.T.; Nelson, A.G.; Kamerling, S.G. Effect of added dietary fat on racing performance in thoroughbred horses. J. Equine Vet. Sci. 1992, 12, 123-129. [CrossRef]

21. Takagi, H.; Hashimoto, Y.; Yonemochi, C.; Ishibashi, T.; Asai, Y.; Watanabe, R. Digestibility of cereals, oil meals, brans and hays in thoroughbreds. J. Equine Sci. 2003, 14, 119-124. [CrossRef]

22. Hintz, H.F.; Schryver, H.F.; Lowe, J.E. Comparison of a blend of milk products and linseed meal as protein supplements for young growing horses. J. Anim. Sci. 1971, 33, 1274-1277. [CrossRef]

23. Treviño, J.; Rodríguez, M.L.; Ortiz, L.T.; Rebolé, A.; Alzueta, C. Protein quality of linseed for growing broiler chicks. Anim. Feed Sci. Technol. 2000, 84, 155-166. [CrossRef]

24. Batterham, E.S.; Andersen, L.M.; Baigent, D.R.; Green, A.G. Evaluation of meals from Linola ${ }^{\mathrm{TM}}$ Loe-linolenic acid linseed and conventional linseed as protein sources for growing pigs. Anim. Feed Sci. Technol. 1991, 35, 181-190. [CrossRef]

25. Romans, J.R.; Johnson, R.C.; Wulf, D.M.; Libal, G.W.; Costello, W.J. Effects of ground flaxseed in swine diets on pig performance and on physical and sensory characteristics and omega-3 fatty acid content of pork: I. Dietary level of flaxseed. J. Anim. Sci. 1995, 73, 1982-1986. [CrossRef]

26. Mazza, G.; Oomah, D.B. Flaxseed dietary fibre and cyanogens. In Flaxseed in Human Nutrition; American Oil Chemists' Society: Champaign, IL, USA, 1995; pp. 56-81.

27. Oomah, B.D.; Mazza, G.; Kenaschuk, E. Cyanogenic compounds in flaxseeds. J. Agric. Food Chem. 1992, 40, 1346-1348. [CrossRef]

28. Williams, C.A.; Lamprecht, E.D. Some commonly fed herbs and other functional foods in equine nutrition: A review. Vet. J. 2008, 178, 21-31.

29. Lindinger, M. Ground flaxseed-How safe is it for companion animals and for us? Vet. Sci. Res. 2019, 1, 35-40. [CrossRef]

30. Sharma, K.D.; Karki, S.; Thakur, N.S.; Attri, S. Chemical composition, functional properties and processing of carrot - a review. J. Food Sci. Technol. 2012, 49, 22-32. [CrossRef]

31. Uden, P.; Colucci, P.E.; Van Soest, P.J. Investigation of chromium, cerium and cobalt as digesta flow markers in rate of passage studies. J. Food Agric. Sci. 1980, 31, 625-632. [CrossRef]

32. Särkijärvi, S.; Saastamoinen, M. Feeding value of various processed oat grains in equine diets. Livest. Sci. 2006, 100, 3-9. [CrossRef] 
33. Särkijärvi, S.; Sormunen-Cristian, R.; Heikkilä, T.; Rinne, M.; Saastamoinen, M. Effect of grass species and cutting time on in vivo digestibility of silage by horses and sheep. Livest. Sci. 2012, 144, 230-239. [CrossRef]

34. MAFF. Energy Allowances and Feeding Systems for Ruminants; Reference Book 433; Ministry of Agriculture, Fisheries and Food (MAFF), Her Majesty's Stationary Office: London, UK, 1984.

35. Movet. 2018. Available online: www.movet.fi. (accessed on 15 November 2019).

36. Pösö, A.R.; Soveri, T.; Oksanen, H.E. The effect of exercise on blood parameters in Standardbred and Finnish-bred horses. Acta Vet. Scand. 1983, 24, 170-184.

37. Delobel, A.; Fabry, C.; Schoonheere, N.; Istasse, L.; Hornick, J.L. Linseed oil supplementation in diet for horses: Effects on palatability and digestibility. Livest. Sci. 2008, 116, 15-21. [CrossRef]

38. The National Academies. Safety of Dietary Supplements for Horses, Dogs and Cats; The National Academies Press: Washington, DC, USA, 2008.

39. Gibbs, P.G.; Potter, G.D.; Schelling, G.T.; Kreider, J.L.; Boyd, C.L. Digestion of hay protein in different segments of the equine digestive tract. J. Anim. Sci. 1988, 66, 400-406. [CrossRef]

40. Ragnarsson, S.; Lindberg, J.-E. Nutritional value of timothy haylage in Icelandic horses. Livest. Sci. 2008, 113, 2020-2028. [CrossRef]

41. Lindberg, J.E.; Essen-Gustavsson, B.; Dahlborn, K.; Gottlieb-Vedi, M.; Jansson, A. Exercise response, metabolism at rest and digestibility in athlete horses fed high-fat oats. Equine Vet. J. Suppl. 2006, 36, 626-630. [CrossRef]

42. Reitnour, C.M.; Salsbury, R.L. Digestion and utilization of cecally infused protein by the equine. J. Anim. Sci. 1972, 35, 1190-1193. [CrossRef]

43. Julen, T.R.; Potter, G.D.; Greene, L.W.; Scott, G.G. Adaptation to a fat-supplemented diet by cutting horses. J. Vet. Sci. 1995, 15, 436-441. [CrossRef]

44. Lindberg, J.E.; Palmgren Karlsson, C. Effect of partial replacement of oats with sugar beet pulp and maize oil on nutrient utilisation in horses. Equine Vet. J. 2001, 33, 585-590. [CrossRef] [PubMed]

45. McCann, J.S.; Meacham, T.N.; Fontenot, J.P. Energy utilization and blood traits of ponies fed fat-supplemented diets. J. Anim. Sci. 1987, 65, 1019-1026. [CrossRef] [PubMed]

46. Farley, E.B.; Potter, G.D.; Gibbs, P.G.; Schumacher, J.; Murray-Gerzik, M. Digestion of soybean meal protein in the equine small and large intestine at various levels of intake. J. Equine Vet. Sci. 1995, 15, 391-397. [CrossRef]

47. Fadel, J.G.; DePeters, E.J.; Arosemena, A. Composition and digestibility of beet pulp with and without molasses and dried using three methods. Anim. Feed Sci. Technol. 2000, 85, 121-129. [CrossRef]

48. Bach Knudsen, K.E. Carbohydrate and lignin contents of plant materials used in animal feeding. Anim. Feed Sci. Technol. 1997, 67, 319-338. [CrossRef]

49. Lindberg, J.E.; Jacobsson, K.G. Effects of barley and sugar-beet pulp on digestibility, purine excretion and blood parameters in horses. Pferdeheilkunde Sonderausgabe 1992, 12, 116-118.

50. Hyslop, J.J.; Jessop, N.S.; Stefansdottir, G.J.; Cudderford, D. Comparative degradation in situ of four concentrate feeds in the caecum of ponies and the rumen of deters. In Proceedings of the 15th Equine Nutrition and Physiology Symposium, Ft. Worth, TX, USA, 28-31 May 1997; pp. 116-117.

51. Palmgren Karlsson, C.; Jansson, A.; Essén-Gustavsson, B.; Lindberg, J.-E. Effect of molassed sugar beet pulp on nutrient utilisation and metabolic parameters during exercise. Equine Vet. J. Suppl. 2002, 34, 44-49. [CrossRef]

52. Snel, J.; Harmsen, H.J.M.; van der Wielen, P.W.J.J.; Williams, B.A. Dietary strategies to influence the gastrointestinal microflora of young animals, and its potential to improve intestinal health. In Nutrition and Health of the Gastrointestinal Tract; Wageningen Academic Publisher: Wageningen, The Netherlands, 2002; pp. 37-69.

53. Dongowski, G.; Plass, R.; Bleyl, D. Biochemical parameters of rats fed dietary fibre preparation from sugar-beet pulp. Zeits. Lebensm. Unters. Forsc. 1998, 206, 393-398. [CrossRef]

54. Murray, J.-A.M.D.; Longland, A.; Hastie, P.M.; Moore-Colyer, M.; Dunnett, C. The nutritive value of sugar beet pulp-substituted Lucerne for equids. Anim. Feed Sci. Technol. 2008, 140, 110-124. [CrossRef]

55. Clauss, M.; Schiele, K.; Ortmann, S.; Fritz, J.; Codron, D.; Hummel, J.; Kienzle, E. The effect of very low food intake on digestive physiology and forage digestibility in horses. J. Anim. Physiol. Anim. Nutr. 2014, 98, 107-118. [CrossRef] 
56. De Marco, M.; Miraglia, N.; Peiretti, P.G.; Bergero, D. Apparent digestibility of wheat bran and extruded flax in horses determined from the total collection of feces and acid-insoluble as ash an internal marker. Animal 2011, 6, 227-231. [CrossRef]

57. Smolders, E.A.A.; Steg, A.; Hindle, V.A. Organic matter digestibility in horses and its prediction. Netherl. J. Agric. Sci. 1990, 38, 435-447.

58. Bell, J.M.; Keith, M.O. Nutritional evaluation of linseed meals from flax with yellow or brown hulls, using mice and pigs. Anim. Feed Sci. Technol. 1993, 43, 1-18. [CrossRef]

59. Gonthier, C.; Mustafa, A.F.; Berthiaume, R.; Petit, H.V.; Martineau, R.; Quellet, D.R. Effects of feeding micronized and extruded flaxseed on ruminal fermentation and nutrient utilization by dairy cows. J. Dairy Sci. 2004, 87, 1854-1863. [CrossRef]

60. Palmgren Karlsson, C. Nutrient utilization in horses-Effect of oat replacement on ration digestibility and metabolic parameters. Doctoral Thesis, Swedish University of Agricultural Sciences, Uppsala, Sweden, 2001.

61. Laboratory Diagnosis for Sport Horses; Lindner, A. (Ed.) Wageningen Pers: Wageningen, The Netherlands, 1998.

62. Świstowska, A.; Kuleta, Z.; Stopyra, A.; Minakowski, D.; Tomczyński, R. The use of linseed cake in sport horse nutrition. Annales Universitatis Marie-Curie-Skłodowska, Sectio DD, Medicina Veterinaria 2006, 61, 103-114.

63. Abraham, K.; Buhrke, T.; Lampen, A. Bioavailability of cyanide after consumption of a single meal foods containing high levels of cyanogenic glycosides: A crossover study in humans. Arch. Toxicol. 2015, 90, 559-574. [CrossRef]

64. Feng, D.; Shen, Y.; Chavez, E.D. Effectiveness of different processing methods in reducing hydrogen cyanide content of flaxseed. J. Sci. Food Agric. 2003, 83, 836-841. [CrossRef]

(C) 2020 by the authors. Licensee MDPI, Basel, Switzerland. This article is an open access article distributed under the terms and conditions of the Creative Commons Attribution (CC BY) license (http://creativecommons.org/licenses/by/4.0/). 


\title{
Article \\ The Effect of Diet Composition on the Digestibility and Fecal Excretion of Phosphorus in Horses: A Potential Risk of P Leaching?
}

\author{
Markku Saastamoinen ${ }^{1, *}$, Susanna Särkijärvi ${ }^{1}$ and Elisa Valtonen ${ }^{2}$ \\ 1 Production Systems, Natural Resources Institute Finland (Luke), FI-31600 Jokioinen, Finland; \\ susanna.särkijärvi@luke.fi \\ 2 Department of Animal Science, University of Helsinki, FI-00790 Helsinki, Finland; \\ elisa.mj.valtonen@gmail.com \\ * Correspondence: markku.saastamoinen@luke.fi
}

Received: 30 October 2019; Accepted: 12 January 2020; Published: 15 January 2020

Simple Summary: This study aimed to examine phosphorus utilization and excretion in feces when typical feeds and forage-based diets are fed. The hypothesis was that feeding regimes might influence phosphorus digestibility and excretion in feces, and therefore the environmental impact of horse husbandry. We also studied the nutrient digestibilities of the diets, as well as the proportion of the soluble fraction of $\mathrm{P}$ of the total phosphorus. Horse dung may pose a potential risk of $\mathrm{P}$ run-off into the environment if not properly managed. Supplementation with inorganic $P$ should be controlled in the diets of mature horses in light work to decrease the excretion of $\mathrm{P}$ in feces.

\begin{abstract}
The main horse phosphorus excretion pathway is through the dung. Phosphorus originating from animal dung and manure has harmful environmental effects on waters. The number of horses has increased in many countries, and several studies have pointed that leaching of $\mathrm{P}$ from horse paddocks and pastures are hotspots for high P leaching losses. The hypothesis was that feeding regimes might influence phosphorus digestibility and excretion in feces, and therefore the environmental impact of horse husbandry. A digestibility experiment was conducted with six horses fed six forage-based diets to study phosphorus utilization and excretion in feces. The study method was a total collection of feces. The experimental design was arranged as an unbalanced $6 \times 4$ Latin Squares. Phosphorus intake increased with an increasing concentrate intake. All studied diets resulted in a positive $\mathrm{P}$ balance and, the P retention differed from zero in all except the only-hay diet, in which the intake was lower compared to the other diets. The digestibility of $\mathrm{P}$ varied from 2.7 to $11.1 \%$, and supplementing forage-diets with concentrates slightly improved P digestibility $(p=0.024)$, as it also improved the digestibilities of crude protein $(p=0.002)$ and organic matter $(p=0.077)$. The horses excreted an average of $20.9 \pm 1.4 \mathrm{~g} / \mathrm{d} \mathrm{P}$ in feces. Excretion was smallest $(20.0 \mathrm{~g})$ in horses on a hay-only diet $(p=$ 0.021 ). The average daily phosphorus excretion resulted in $7.6 \mathrm{~kg} P$ per year. The soluble $P$ part of the total $\mathrm{P}$ in feces accounted for about $88 \%$ of the $\mathrm{P}$ excreted in feces, and is vulnerable to runoff losses and may leach into waters. Thus, horse dung may pose a potential risk of $\mathrm{P}$ leaching into the environment if not properly managed, and is not less harmful to the environment than that from other farm animals. Supplementation with inorganic P should be controlled in the diets of mature horses in light work to decrease the excretion of $\mathrm{P}$ in feces.
\end{abstract}

Keywords: environment; horse nutrition; phosphorus loss; phosphorus supplementation; phosphorus retention 


\section{Introduction}

Macro-mineral phosphorus plays an important role in bone formation as a constituent of phosphoproteins, phospholipids, and nucleic acids, and in energy and fat metabolism [1-3]. In animals, $80-85 \%$ of phosphorus is stored in the bones and teeth, and the remainder in soft tissues and body fluids [3]. In the skeleton, phosphorus forms hydroxyapatite with calcium. In growing animals, the need for phosphorus is greater than in adult animals, since developing bones require more phosphorus than already developed bones in adult animals [4].

Phosphorus deficiency is found throughout the world in areas with soil poor in phosphorus. Deficiency symptoms include, but are not limited to, rice disease, osteomalacia, nervous system symptoms, stiff joints, muscle weakness, poor fertility, impaired ovarian function and consequent irregular rotation, poor growth in juvenile animals, and impaired weight gain in adult animals [1]. To avoid these detrimental effects of phosphorus malnutrition and ensure efficient intake, phosphorus is usually routinely supplemented in horses' diets.

Phosphorus absorption is influenced by the intake, source, and composition of the feed ration [5]. In adult horses, which mainly eat roughage, absorption efficiency is $35 \%$, and in lactating mares and growing horses it is $45 \%$ as their diets are often supplemented by larger amounts of concentrates [1]. There may be some improvement in phosphorus absorption as the need for phosphorus increases, for example, through exercise or when the phosphorus content of the diet increases [6]. Fowler et al. [7] concluded that yearlings can utilize organic $\mathrm{P}$ as well as mature horses.

The main site of the gastrointestinal tract of phosphorus absorption in horses is the dorsal colon, but some phosphorus is also absorbed from the small intestine [8,9]. Fowler et al. [7] suggested that degradation either occurs after the site of $\mathrm{P}$ absorption, or liberated $\mathrm{P}$ is recycled back into the gastrointestinal tract.

The main phosphorus excretion pathway is through the dung. The phosphorus content of feces is directly proportional to the phosphorus content of the diet [10]. Especially in a diet rich in forage, the horse often gets too much supplemented phosphorus to meet its needs, and excess $\mathrm{P}$ is excreted from the body in the feces [11]. A very low proportion (about 1\%) of the phosphorus is excreted in the urine $[8,10,12]$, and is thus usually ignored in studies dealing with P digestibility. In the gastrointestinal tract, endogenous phosphorus secretion occurs in the small intestine and in the cecum $[8,13]$. Endogenous phosphorus secretion is due to the presence of phosphorus compounds in gastrointestinal fluids such as saliva and gastric, pancreatic, and biliary fluids $[8,14]$.

The digestibility of phosphorus is influenced by its form and amount in feed, and its interaction with other feed components and minerals, e.g., Ca and Ca:P ratio [1,15]. Cereals are good sources of phosphorus [3], but a significant proportion of the phosphorus in cereals is bound to phytic acid, which is poorly digestible in monogastric animals [16]. However, the horse is able to digest phytate phosphorus $[7,17,18]$. The content of phosphorus in grasses approximately equates to that in cereals (about $3 \mathrm{~g} / \mathrm{kg} \mathrm{DM}$ ), but the phosphorus content of grasses is significantly influenced by the age of the crop at the time of harvest $[19,20]$. Mineral supplements usually contain inorganic forms of phosphorus like monocalcium phosphate, dicalcium phosphate, or phosphorite as phosphorus sources [4].

Phosphorus and nitrogen originating from animal manure are the main environmental and water pollutants from agriculture. There is imbalance of $\mathrm{N}$ and $\mathrm{P}$ in the manure, and $\mathrm{P}$ is considered more harmful, because when it is in excess of crop requirements, soil becomes saturated resulting in $\mathrm{P}$ runoff [21]. Because the number of horses has increased in many countries, and horses are kept in paddocks and pastures there is risk of $\mathrm{P}$ leaching to the environment also from horse husbandry. In addition, horse manure is widely utilized in agriculture. However, the NRC [1] considers horse feces to be less risky to the environment compared to that from other farm animals because it assumes that horse manure contains less water-soluble phosphorus, prone to runoff. However, later studies have pointed that leaching of $\mathrm{P}$ from horse paddocks and pastures are hotspots for high $\mathrm{P}$ leaching losses [22-25]. 
In general, dietary strategies have been developed for many animal species to effectively reduce the total $\mathrm{P}$ concentration in manure. As we were interested in the possible detrimental environmental impact of horses, we studied phosphorus utilization and excretion in feces applying typical feeds and forage-based diets fulfilling the current $P$-intake recommendations [1,19]. We also studied the nutrient digestibilities of the diets, as well as the proportion of the soluble fraction of $\mathrm{P}$ of the total phosphorus. The hypothesis was that feeding regimes might influence phosphorus digestibility and excretion in feces, and therefore the environmental impact of horse husbandry.

\section{Materials and Methods}

A digestibility experiment was conducted with six forage-based diets typically fed to horses in Finland. The study was conducted at the facilities of the Natural Resources Institute Finland (Luke) in Southwest Finland. In animal handling and sample collection, the European Union recommendation directives (2010/63/EU) and national animal welfare and ethical legislation set by the Ministry of Agriculture and Forestry of Finland were followed carefully. The experimental procedures were evaluated and approved by the national ethical committee for animal experiments (https://www.avi.fi/web/avi/elainkoelautakunta-ella) (ESAVI/8331/04.10.07/2013).

\subsection{Horses and their Management}

Six adult Finnhorse mares (5-13 years; initial BW $552 \pm 32$ kg, mean BCS $6=$ moderately fleshy) owned by Luke were used in the study. All the experimental horses had the same managing and feeding history before the trial. The horses were individually housed in stalls $(3 \mathrm{~m} \times 3 \mathrm{~m})$ with peat as bedding. The horses were de-wormed before the experiment. Dental care and vaccinations had been carried out regularly prior to the experiment. The horses were freely exercised daily in groups in outdoor paddocks (with sand grounds) for 2-4 h, except during the collection period, when they were led in walk by a rope in the stable corridors (consisting of two connected $32 \mathrm{~m}$ long corridors with concrete and asphalt floors) for $15 \mathrm{~min}$. In the paddocks, the horses had masks to prevent sand eating.

The study method was a total collection of feces. The experimental design was arranged as an unbalanced $6 \times 4$ Latin Squares. The study consisted of six treatments and four 21-day periods. Each period started with a five-day feed change period followed by 12 days of adaptation to the new diet, and four-day period of collecting feces samples. During the collection period, the peat bedding was changed to rubber mats. The body weight (BW) (electronic animal scale Lahden Vaaka/Lahti Precision Ltd., Lahti, Finland) and body condition score (BCS) [26] of the horses was monitored after each collection period.

\subsection{Experimental Feeds and Feeding}

The diets were formulated and adjusted to be as isocaloric as possible. The horses were individually fed at a level of $65-75 \mathrm{~g} \mathrm{DM} \mathrm{kg}^{-1} \mathrm{~W}^{0.75}$, corresponding to the feeding and energy level recommended in light work in accordance with the Finnish Feed Tables and Feeding Recommendations [19]. The regularly obtained BCS and BW were used to control their possible changes, and the individual energy intakes were adjusted if necessary. The horses were fed three times per day (at 6:00 a.m., 12:00 noon and 6:00 p.m.), except in the mornings of blood sampling days, when the forages were fed at 7:30 and concentrates at 8:00 o'clock.

The diets were (dry matter basis) (A) hay 100\%; (B) haylage 100\%; (C) hay $80 \%$ + whole oats $20 \%$; (D) hay $65 \%$ + whole oats $35 \%$; (E) hay $80 \%$ + commercial pelleted complete feed $20 \%$ (Lantmännen, Malmö, Sweden) and (F) hay $65 \%$ + commercial pelleted complete feed $35 \%$. All diets except those including the complete feed were balanced with a mineral mixture $(\mathrm{Ca}: \mathrm{P}=3.57)$ in which $\mathrm{P}$ was in the form of monocalcium phosphate (Vilomix Ltd., Paimio, Finland) according to the P and Ca needs of the horses. The complete feed (the added $\mathrm{P}$ was in the form of monocalcium phosphate, Ca:P 1.43) covered the mineral requirements of the horses. Forages were fed from special hay-boxes to avoid dropping, and the concentrates were fed from feed mangers. Free water was available from float valve drinkers. 
The dried hay was produced by a local farmer in Ypäjä $\left(60^{\circ} 48^{\prime} 34^{\prime \prime} \mathrm{N}, 23^{\circ} 16^{\prime} 35^{\prime \prime} \mathrm{E}\right)$. The haylage (Prohay Ltd., Punkalaidun, Finland, $61^{\circ} 06^{\prime} 40^{\prime \prime} \mathrm{N}, 23^{\circ} 06^{\prime} 20^{\prime \prime} \mathrm{E}$ ) was packed in $20 \mathrm{~kg}$ air tight plastic packages and purchased from the producer. The oats were produced by Luke.

Feed samples were collected daily and stored at $-20{ }^{\circ} \mathrm{C}$ until analysis. The samples were analyzed at the Luke Laboratories (Jokioinen, Finland) for dry matter (DM), crude protein (CP), NDF, ADF, crude fiber (CF), and ash with standard wet chemical methods e.g., [27], as well as for P and Ca content using the method by Huang and Schulte [28]. The chemical composition of the feeds is presented in Table 1.

Table 1. Average chemical composition $(\mathrm{g} / \mathrm{kg} \mathrm{DM})$ and energy value (ME MJ/kg DM) of the experimental feeds.

\begin{tabular}{cccccc}
\hline Composition & Hay & Haylage & Oats & Complete Feed & Mineral Mixture $^{\mathbf{1}}$ \\
\hline Dry matter & 83.6 & 59.4 & 86.1 & 86.9 & 96.0 \\
Crude protein & 82.1 & 122.5 & 107.0 & 124.4 & \\
Crude fiber & 318.7 & 326.7 & 103.9 & 113.5 & \\
NDF & 596.0 & 615.0 & 260.5 & 305.4 & \\
ADF & 317.5 & 326.6 & 104.3 & 123.3 & 737.8 \\
Ash & 62.3 & 67.6 & 32.2 & 74.0 & 156.4 \\
Calcium & 2.4 & 2.9 & 0.5 & 7.0 & 45.0 \\
Magnesium & 1.2 & 1.3 & 1.3 & 4.2 & 43.6 \\
Phosphorus & 2.2 & 2.7 & 3.6 & 4.9 & \\
Energy ME & 9.7 & 9.6 & 12.0 & 11.0 & \\
\hline
\end{tabular}

$\mathrm{NDF}=$ neutral detergent fiber; $\mathrm{ADF}=$ acid detergent fiber; ${ }^{1}$ Inorganic mineral sources: monocalcium phosphate, limestone meal, magnesium oxide; $\mathrm{ME}=$ metabolisable energy.

\subsection{Feces Sampling and Analysis}

Feces were collected for four days (Monday-Friday). Before the start of the collection period, the peat bedding was removed from the boxes and replaced with rubber mats. The feces collected overnight (every day at 9:00 a.m.) was thoroughly mixed and weighed, and a representative sample was taken. Partial samples were pooled throughout the collection period and stored at $-20^{\circ} \mathrm{C}$. The daily amount of sampled feces was $12 \%$ of the total daily amount collected. Feces that were entangled with foreign substances such as urine were defined as waste. The amount of waste feces was weighed but not utilized in the analysis.

Fecal samples were analyzed at the Luke Laboratories for dry matter (DM), nitrogen, NDF, ADF, $\mathrm{CF}$ ash as well as total and (water) soluble P content. Nitrogen was analyzed with the Khjeldal method (AOAC-984.13) using Foss Khjeltec 2400 analyzer (Foss Analytical AB, Höganäs, Sweden), and the $\mathrm{CP}$ content was calculated as $6.25 \times \mathrm{N}$. NDF and ADF were analyzed with ANKOM 220 fiber analyzer (ANKOM Technology, Macedon, NY, USA) using $25 \mu$ m nylon bags [29,30]. Total P was analyzed spectrometrically (ICP-OES, Thermo Jarrel Ash Iris advantage, Franklin, MA, USA). The proportion of soluble $\mathrm{P}$ (phospahte- $\mathrm{P}, \mathrm{PO}_{4}-\mathrm{P}$ ) was analyzed from 1:60 water extracts using a continuous photometric flow analyzer (Aquakem 250, Thermo Fisher Scientific Inc., Vantaa, Finland) as described by Keskinen et al. [31]. Because only a very low proportion (about 1\%) of the phosphorus is excreted in the urine $[8,10,12]$, urine was not collected in this experiment.

\subsection{Blood Samples and Analysis}

Blood samples were collected 90 min after the morning meal every Wednesday during the collection period. A blood sample was drawn from the jugular vein into two sample tubes $(2 \times 10 \mathrm{~mL})$. The samples were analyzed for inorganic $P$ and Ca photometrically using wavelengths $660 \mathrm{~nm}$ and $340 \mathrm{~nm}$, respectively. The analyses were performed in a clinical authorized laboratory (Ellab Ltd., Ypäjä, Finland). 


\subsection{Statistical Analysis}

Differences in digestibility, as well as intake, excretion and retention parameters between the diets were statistically analyzed using the SAS (SAS 9.3, 2008) GLM procedure (SAS Institue, Cary, NC, USA) applying the following statistical model:

$$
Y_{i j k}=\mu_{i j k}+a_{i}+p_{j}+d_{k}+e_{i j k}
$$

where $\mu_{\mathrm{ijk}}$ is the overall mean, $a_{i}$ is the random effect of the animal $(i=1 \ldots 6), p_{j}$ is the fixed effect of the period $(j=1 \ldots 4), d_{k}$ is the fixed effect of the diet $(k=1 \ldots 6)$, and $e_{i j k}$ is the normally distributed error with a mean of 0 and variance $\delta^{2}$. The differences between the diets were tested with orthogonal contrasts: (1) B vs. A and C-F; (2) A vs. C-F; (3) C and D vs. E and F; (4) C vs. E and D vs. F; and (5) the interactions between the type of concentrate and concentrate level C and D vs. E and F, C vs. E, and D vs. F. Concerning the retention values, it was also tested if they differ from zero.

Differences in the proportion of soluble P of the excreted P were not studied because the diets were composed of different ingredients containing various sources of P (inorganic and organic sources, phytate P) that were not analyzed.

\section{Results}

\subsection{Feed and Nutrient Intakes}

The feed, energy and nutrient intakes for each diet are presented in Table 2. The DM intake was smallest in horses eating only haylage $(p<0.001)$, but same time they had the largest CP intake $(p<0.001)$. Concerning the concentrate supplemented diets (hay + oats or complete feed), the concentrate level did not affect the DM intake. The horses maintained their BW and BCS during the experiment (mean initial BW $=552 \pm 32 \mathrm{~kg}$, mean final BW $=558 \pm 32 \mathrm{~kg}$ ).

Table 2. Mean daily energy (MJ ME), dry matter (g) and nutrient intakes (g) for the experimental diets.

\begin{tabular}{|c|c|c|c|c|c|c|c|c|c|c|c|c|}
\hline \multirow{2}{*}{$\begin{array}{c}\text { Diet } \\
\text { Forage }\end{array}$} & \multirow{2}{*}{$\begin{array}{c}\text { A } \\
\text { Hay }\end{array}$} & \multirow{2}{*}{$\begin{array}{c}\text { B } \\
\text { Haylage }\end{array}$} & \multirow{2}{*}{$\begin{array}{c}\text { C } \\
\text { Hay }\end{array}$} & \multirow{2}{*}{$\begin{array}{c}\text { D } \\
\text { Hay }\end{array}$} & \multirow{2}{*}{$\begin{array}{c}\text { E } \\
\text { Hay }\end{array}$} & \multirow{2}{*}{$\begin{array}{c}F \\
\text { Hay }\end{array}$} & \multirow{2}{*}{$\begin{array}{c}\text { Pooled } \\
\text { SEM }\end{array}$} & \multicolumn{5}{|c|}{ Statistical Significance ( $p$-Values) } \\
\hline & & & & & & & & $\begin{array}{c}\text { Haylage } \\
\text { vs. Others }\end{array}$ & $\begin{array}{c}\text { Hay vs. } \\
\text { Cons }\end{array}$ & $\begin{array}{l}\text { Oats vs. } \\
\text { Comp }\end{array}$ & ConL & $\begin{array}{c}\text { ConT } \times \\
\text { ConL }\end{array}$ \\
\hline ME & 74.3 & 73.3 & 79.1 & 82.6 & 77.6 & 78.7 & 0.4 & $<0.001$ & $<0.001$ & $<0.001$ & $<0.001$ & 0.009 \\
\hline $\mathrm{DM}$ & 7536 & 6702 & 7568 & 7734 & 7601 & 7595 & 17.0 & $<0.001$ & 0.038 & 0.037 & 0.439 & 0.338 \\
\hline $\mathrm{OM}$ & 6981 & 6186 & 7148 & 7250 & 7081 & 7075 & 47.3 & $<0.001$ & 0.033 & 0.027 & 0.368 & 0.272 \\
\hline NDF & 4427 & 4060 & 3992 & 3647 & 4073 & 3753 & 33.9 & 0.055 & $<0.001$ & 0.018 & $<0.001$ & 0.715 \\
\hline $\mathrm{ADF}$ & 2361 & 2155 & 2076 & 1845 & 2109 & 1891 & 18.8 & $<0.001$ & $<0.001$ & 0.058 & $<0.001$ & 0.746 \\
\hline Ash & 556 & 516 & 510 & 485 & 519 & 521 & 17.0 & 0.901 & 0.033 & 0.202 & 0.519 & 0.446 \\
\hline
\end{tabular}

$\mathrm{ME}=$ metabolisable energy $\mathrm{MJ} /$ day $; \mathrm{DM}=$ dry matter; $\mathrm{OM}=$ organic matter; $\mathrm{CP}=$ crude protein $; \mathrm{CF}=$ crude fiber; $\mathrm{NDF}=$ neutral detergent fiber; $\mathrm{ADF}=$ acid detergent fiber; $\mathrm{O}=$ Oats; $\mathrm{C}=$ Complete feed; $\mathrm{ConL}=$ Concentrate level ( 20 or $35 \%$ of oats $\mathrm{O}$ or complete feed $\mathrm{C})$; ConS = Concentrate supplementation; ConT = concentrate type (oats/complete feed); Comp = complete feed.

\subsection{Intake, Fecal Excretion and Digestibility of Phosphorus}

The average P intake was $22.0 \pm 2.0 \mathrm{~g} / \mathrm{d}$. The P intake increased with an increasing concentrate intake (Table 3). Horses ingesting oats had larger daily intake of P (22.8-24.8 g) compared to those fed with the complete feed $(20.9-24.1 \mathrm{~g})(p<0.001)$ and horses fed with hay only had smaller intakes than horses supplemented with concentrates (20.6 vs. 20.9-24.8 g) ( $p<0.001)$. Horses fed with haylage had somewhat smaller P intake than those who ate hay $(p=0.036)$. 
Table 3. Daily intake (g), fecal excretion (g), digestibility (\%) and retention $(\mathrm{g})$ of phosphorus $(\mathrm{P})$.

\begin{tabular}{|c|c|c|c|c|c|c|c|c|c|c|c|c|}
\hline \multirow[b]{2}{*}{ Diet/Forage } & \multirow{2}{*}{$\begin{array}{c}\text { A } \\
\text { Hay }\end{array}$} & \multirow{2}{*}{$\begin{array}{c}\text { B } \\
\text { Haylage }\end{array}$} & \multirow{2}{*}{$\begin{array}{c}\text { C } \\
\text { Hay }\end{array}$} & \multirow{2}{*}{$\begin{array}{c}\text { D } \\
\text { Hay }\end{array}$} & \multirow{2}{*}{$\begin{array}{c}\text { E } \\
\text { Hay }\end{array}$} & \multirow{2}{*}{$\begin{array}{c}F \\
\text { Hay }\end{array}$} & \multirow[b]{2}{*}{$\begin{array}{c}\text { Pooled } \\
\text { SEM }\end{array}$} & \multicolumn{5}{|c|}{ Statistical Significance ( $p$-Values) } \\
\hline & & & & & & & & $\begin{array}{c}\text { Haylage } \\
\text { vs. } \\
\text { Others }\end{array}$ & $\begin{array}{c}\text { Hay } \\
\text { vs.ConS }\end{array}$ & $\begin{array}{c}\text { Oats } \\
\text { vs.Comp }\end{array}$ & ConL & $\begin{array}{c}\text { ConT } \\
\times \\
\text { ConL }\end{array}$ \\
\hline ConL & 0 & 0 & $\mathrm{O} 20$ & $\mathrm{O} 35$ & $\mathrm{C} 20$ & C35 & & & & & & \\
\hline Intake P & 20.6 & 22.1 & 22.8 & 24.8 & 20.9 & 24.1 & 0.21 & 0.036 & $<0.001$ & $<0.001$ & $<0.001$ & 0.027 \\
\hline Excretion $\mathrm{P}$ & 20.0 & 20.2 & 21.5 & 22.1 & 19.9 & 21.5 & 0.42 & 0.125 & 0.021 & 0.025 & 0.033 & 0.251 \\
\hline
\end{tabular}

$\mathrm{O}=$ oats; $\mathrm{C}=$ complete feed; ConL = concentrate level $(20$ or $35 \%$ of oats $\mathrm{O}$ or complete feed $\mathrm{C})$; ConS = concentrate supplementation; ConT = concentrate type (oats/complete feed); Comp = complete feed.

The average daily quantity of dung was $15.6 \pm 2.5 \mathrm{~kg} /$ horse. The horses excreted an average of $20.9 \pm 1.4 \mathrm{~g} / \mathrm{d}$ P in feces. Excretion was smallest $(20.0 \mathrm{~g})$ in horses on a hay-only diet $(p=0.021)$ (Table 3). Horses supplemented with oats excreted somewhat more P (21.5-22.1 vs. 19.9-21.5 g) than those supplemented with the complete feed $(p<0.025)$, and the excretion increased with increasing concentrate intake $(p=0.033)$.

The horses were on a positive $\mathrm{P}$ balance in all diets (Table 3). The retention of $\mathrm{P}$ was largest in the diet $\mathrm{D}$ (with the highest complete feed level) being $2.8 \mathrm{~g} / \mathrm{d}$. The retention values were different from zero for the diets $\mathrm{B}(p=0.002), \mathrm{C}(p=0.05), \mathrm{D}(p<0.001), \mathrm{E}(p=0.08)$, and $\mathrm{F}(p=0.002)$. The P retention increased $(p=0.0145)$ with the increasing concentrate level. Feeding concentrates slightly improved $\mathrm{P}$ digestibility $(p=0.024)$. The amount of water-soluble phosphorus of the P excreted in feces was $18.3 \pm$ $2.5 \mathrm{~g} / \mathrm{d}$, on average. This corresponds to $87.6 \%$ of the $\mathrm{P}$ in feces.

\subsection{Intake, Fecal Excretion and Digestibility of Calcium and Magnesium}

The intake of calcium was largest in the horses fed with haylage only ( $p>0.001)$ (Table 4). Ingestion of concentrates decreased Ca intake, depending on type of concentrate fed. $\mathrm{Mg}$ intake was smallest in the horses on a haylage-only diet. The intake increased when concentrates were fed. The increase was largest with complete feed (interaction $p<0.001$ ).

Table 4. Daily intake (g), excretion (g) and digestibility (\%) of calcium (Ca) and magnesium (Mg).

\begin{tabular}{|c|c|c|c|c|c|c|c|c|c|c|c|c|}
\hline \multirow[b]{2}{*}{ Diet/Forage } & \multirow{2}{*}{$\begin{array}{c}\text { A } \\
\text { Hay }\end{array}$} & \multirow{2}{*}{$\begin{array}{c}\text { B } \\
\text { Haylage }\end{array}$} & \multirow{2}{*}{$\frac{C}{\text { Hay }}$} & \multirow{2}{*}{$\begin{array}{c}\text { D } \\
\text { Hay }\end{array}$} & \multirow{2}{*}{$\begin{array}{c}\mathrm{E} \\
\text { Hay }\end{array}$} & \multirow{2}{*}{$\begin{array}{c}\text { F } \\
\text { Hay }\end{array}$} & \multirow{2}{*}{$\begin{array}{c}\text { Pooled } \\
\text { SEM }\end{array}$} & \multicolumn{5}{|c|}{ Statistical Significance ( $p$-Values) } \\
\hline & & & & & & & & $\begin{array}{c}\text { Haylage } \\
\text { vs. Others }\end{array}$ & $\begin{array}{c}\text { Hay vs. } \\
\text { ConS }\end{array}$ & $\begin{array}{l}\text { Oats vs. } \\
\text { Comp }\end{array}$ & ConL & $\begin{array}{c}\text { ConT } \times \\
\text { Con } L\end{array}$ \\
\hline ConL & 0 & 0 & $\mathrm{O} 20$ & $\mathrm{O} 35$ & $\mathrm{C} 20$ & $\mathrm{C} 35$ & & & & & & \\
\hline \multicolumn{13}{|l|}{ Intake } \\
\hline $\mathrm{Ca}$ & 32.6 & 34.2 & 29.6 & 28.3 & 24.7 & 30.4 & 0.45 & $<0.001$ & $<0.001$ & 0.010 & 0.001 & $<0.001$ \\
\hline $\mathrm{Mg}$ & 9.31 & 8.71 & 9.25 & 9.74 & 13.9 & 17.3 & 0.26 & $<0.001$ & $<0.001$ & $<0.001$ & $<0.001$ & $<0.001$ \\
\hline \multicolumn{13}{|l|}{ Excretion } \\
\hline $\mathrm{Ca}$ & 19.1 & 17.7 & 17.5 & 17.8 & 19.4 & 20.2 & 0.98 & 0.330 & 0.757 & 0.048 & 0.610 & 0.797 \\
\hline $\mathrm{Mg}$ & 10.4 & 10.1 & 10.1 & 10.4 & 10.6 & 12.9 & 0.28 & 0.030 & 0.107 & $<0.001$ & 0.002 & 0.006 \\
\hline \multicolumn{13}{|l|}{ Digestibility } \\
\hline $\mathrm{Ca}$ & 41.6 & 47.1 & 29.3 & 38.1 & 22.6 & 31.7 & 7.10 & 0.096 & 0.187 & 0.371 & 0.265 & 0.987 \\
\hline $\mathrm{Mg}$ & -13.1 & -19.0 & -9.0 & -7.0 & 23.4 & 25.3 & 4.73 & 0.001 & 0.002 & $<0.001$ & 0.702 & 0.993 \\
\hline
\end{tabular}

$\mathrm{O}=$ Oats; $\mathrm{C}=$ Complete feed; ConL $=$ Concentrate level $(20$ or $35 \%$ of oats $\mathrm{O}$ or complete feed C); ConS = Concentrate supplementation; ConT $=$ concentrate type (oats/complete feed); Comp = complete feed.

Concerning the excretion of minerals, horses on the haylage-only diet excreted somewhat less $\mathrm{Mg}$ than fed with hay only $(p=0.03)$. Comparing the concentrates, horses supplemented with complete feed excreted more both $\mathrm{Ca}$ and $\mathrm{Mg}$ than those supplemented with oats $(p=0.048$ and $p<0.001$, respectively). The digestibility of $\mathrm{Ca}$ did not differ between the diets. Concerning $\mathrm{Mg}$, digestibility was lowest in the haylage-only diet, and lower when oats was fed compared with feeding the complete feed. The variation in Mg digestibility values was large (Table 4). 


\subsection{Digestibility of the Diet Nutrients}

The dry matter digestibility of the haylage-only diet was lower compared with the other diets $(p<0.001)$ (Table 5). Supplementing the forage diets with concentrates improved the digestibilities of crude protein $(p=0.002)$ and organic matter $(p=0.077)$ but the concentrate level fed did not affect the digestibility of the fiber fractions. The CP digestibility of the haylage-only diet was better $(p=0.009)$ compared to the other diets. Correspondingly, the CP digestibility of the hay-only diet was the lowest $(p=0.004)$.

Table 5. Apparent digestibility coefficients (\%) of the diet nutrients.

\begin{tabular}{|c|c|c|c|c|c|c|c|c|c|c|c|c|}
\hline \multirow[b]{2}{*}{ Diet/Forage } & \multirow{2}{*}{$\begin{array}{c}\text { A } \\
\text { Hay }\end{array}$} & \multirow{2}{*}{$\frac{\text { B }}{\text { Haylage }}$} & \multirow{2}{*}{$\frac{C}{\text { Hay }}$} & \multirow{2}{*}{$\begin{array}{c}\text { D } \\
\text { Hay }\end{array}$} & \multirow{2}{*}{$\begin{array}{c}\text { E } \\
\text { Hay }\end{array}$} & \multirow{2}{*}{$\begin{array}{c}\text { F } \\
\text { Hay }\end{array}$} & \multirow{2}{*}{$\begin{array}{c}\text { Pooled } \\
\text { SEM }\end{array}$} & \multicolumn{5}{|c|}{ Statistical Significance ( $p$-Values) } \\
\hline & & & & & & & & $\begin{array}{c}\text { Haylage } \\
\text { vs. Others }\end{array}$ & $\begin{array}{c}\text { Hay vs. } \\
\text { ConS }\end{array}$ & $\begin{array}{l}\text { Oats vs. } \\
\text { Comp }\end{array}$ & ConL & $\begin{array}{c}\text { ConT } \times \\
\text { ConL }\end{array}$ \\
\hline ConL & 0 & 0 & $\mathrm{O} 20$ & O35 & $\mathrm{C} 20$ & $\mathrm{C} 35$ & & & & & & \\
\hline $\mathrm{DM}$ & 55.0 & 49.9 & 56.6 & 59.3 & 57.5 & 60.1 & 1.33 & $<0.001$ & 0.046 & 0.543 & 0.090 & 0.998 \\
\hline Ash & 38.4 & 31.6 & 29.8 & 29.6 & 34.9 & 37.7 & 2.73 & 0.437 & 0.105 & 0.033 & 0.666 & 0.591 \\
\hline OM & 56.3 & 51.4 & 58.5 & 61.3 & 59.1 & 61.8 & 1.29 & $<0.001$ & 0.023 & 0.699 & 0.077 & 0.972 \\
\hline $\mathrm{CP}$ & 50.9 & 63.6 & 51.7 & 61.8 & 57.3 & 63.6 & 1.83 & 0.009 & 0.004 & 0.066 & 0.002 & 0.310 \\
\hline $\mathrm{CF}$ & 49.5 & 45.7 & 46.1 & 43.0 & 49.6 & 56.5 & 2.61 & 0.685 & 0.291 & 0.206 & 0.294 & 0.997 \\
\hline NDF & 49.5 & 46.3 & 46.3 & 42.5 & 49.0 & 47.5 & 2.44 & 0.811 & 0.278 & 0.144 & 0.334 & 0.635 \\
\hline $\mathrm{ADF}$ & 47.2 & 41.6 & 41.7 & 41.4 & 45.5 & 40.5 & 3.40 & 0.668 & 0.224 & 0.669 & 0.488 & 0.497 \\
\hline
\end{tabular}

$\mathrm{DM}=$ dry matter; $\mathrm{OM}=$ organic matter; $\mathrm{CP}=$ crude protein $\mathrm{CF}=$ crude fiber; $\mathrm{NDF}=$ neutral detergent fiber; $\mathrm{ADF}=$ acid detergent fiber. $\mathrm{O}=$ Oats; $\mathrm{C}=$ Complete feed; $\mathrm{ConL}=$ Concentrate level $(\%) ; \mathrm{ConS}=$ Concentrate supplementation; ConT = concentrate type (oats/complete feed); Comp = complete feed.

\subsection{Blood Concentrates of $\mathrm{P}$ and $\mathrm{Ca}$}

The between diet variation of the blood serum $\mathrm{P}$ and Ca concentrations was small. The average blood serum P concentration was $1.16 \pm 0.04 \mathrm{mmol} / \mathrm{L}$. Comparing concentrate types, the concentration was larger when oats was fed than when the complete feed was fed ( $1.21 \mathrm{vs} .1 .13 \mathrm{mmol} / \mathrm{L})(p<0.031)$. The mean blood Ca concentration of the horses was $3.14 \pm 0.04 \mathrm{mmol} / \mathrm{L}$. It was larger when the horses were on a hay-only diet compared with the diets containing concentrates (3.22 vs. $3.12 \mathrm{mmol} / \mathrm{L})$ $(p<0.001)$.

\section{Discussion}

The main goal of this experiment was to find the differences between the diets for P utilization, rather than the actual values for specific diets. Because studying digestibilities of other nutrients was only a secondary aim of this study, the results are discussed only briefly.

\subsection{Feed Values and Nutrient Intakes}

The feed values corresponded to the analyzed values presented for Finnish forages produced for horses [32], the hay being of "medium nutritional quality" and the haylage of "high nutritional quality". Concerning oats, the CP content was lower than that presented in the Finnish Feed Tables and Feeding Recommendations (10.4. vs. 12-13\%) [19]. The NDF, ADF, and CF values were also lower than the values presented for average Finnish oats [19]. The P, Ca, and $\mathrm{Mg}$ content of the forages and oats was lower than the values presented for hays and haylages [19]. The mineral content was also clearly lower than reported for Norwegian and Swedish haylage samples collected from horse farms [20].

The nutrient intakes naturally varied because of the differences in the composition of the feeds and actual intakes, although the individual diets were initially formulated and balanced to correspond the needs of each horse [19] and be as isocaloric as possible. The smaller DM intake of the horses in the haylage-only diet resulted from restriction of haylage intake because of its high CP content. This led naturally also to smaller energy (ME) intake. In addition, the size of the horse affected the individual daily portion such that larger horses had larger portions. The horses maintained their BW and BCS during the experiment, indicating that the feeds, feeding regime, and intakes applied covered the nutritional requirements of the horses (energy and protein) in the course of the experimental period 
The mean daily energy intake of 77.5 MJ ME/d during the course of the experiment agreed with the recommendation for horses in light work [19].

\subsection{Intake, Fecal Excretion and Digestibility of Phosphorus}

The differences in the P intake between the diets were due to the differences in the feeds and diet compositions, but the forms of $\mathrm{P}$ were not analyzed. P concentrations in oats and complete feed were higher than in the forages. In addition, the oat supplemented diets were balanced for minerals ( $\mathrm{P}$ and Ca) with a mineral supplement mixture which also increased the P intake. The intakes of $\mathrm{P}$ were in accordance with the current recommendations [1,19], except on the highest concentrate levels where they exceeded the recommendations.

The excretion of phosphorus observed here was within the ranges presented in the literature $[7,12,18,33,34]$. P excretion is linearly related to its intake, and the intake increases with the increasing concentrate ingestion $[10,12,33]$. Van Doorn et al. [35] concluded that horses can regulate P digesting and thus $\mathrm{P}$ balance. The extra $\mathrm{P}$ can be excreted in the feces.

In the present study, the digestibility of $\mathrm{P}$ in adult horses varied from 2.7 to $11.1 \%$, improving with an increased concentrate intake. This is well in line with the results of van Doorn et al. [18] for adult horses (2.4-15.4\%). However, higher values (4.2-28.7\%) have also been reported $[15,34,36]$ for adult horses (with a range between 4 and 25 years). In many studies the digestibilities show impaired values with increasing age. The largest digestibilities (37-42\%) have been reported for young horses (8-months-olds), but they decline quickly (to 2.0-7.7\%) when the horses are between one and two years old [7,12]. Elzinga et al. [36] reported digestibility of $4.2 \%$ for aged (19-28 years) horses. P digestibility is therefore influenced by the age of the horse. In this study, the horses were between 5 and 13 years old, and P digestibility seems to accord well with previous studies when the age of the horses is considered. In previous studies, higher values have also been reported when hay + concentrates were fed e.g., [6,7,15,18,34,35] compared with forage-only diets [12,28]. The digestibility of P may also improve somewhat with increasing P intake [6]. Furthermore, digestibility is affected by the components (feeds) of the diet [1].

Diets with the highest concentrate levels (35\% oats or complete feed) had better digestibility compared to the other diets. All diets resulted in a positive $\mathrm{P}$ balance and the $\mathrm{P}$ retention differed from zero in all except the only-hay diet, in which the intake was lower compared to the other diets. According to previous studies $[10,18]$, the P retention increased with P intake in adult animals. The $P$ retention values observed in our study were smaller (less than half) than reported for adult (appr. 6-year-olds) Standardbred horses [18] fed mixed hay + concentrate diets, but in the same time, the intakes were also correspondingly smaller. According to that study, the reasons for the P retention in adult horses are not known. However, Buchholz-Bryant [37] reported a higher P retention in mature horses (7 to 11 year old) at rest compared to exercised horses. In the present study the horses were only freely exercised daily in outdoor paddocks for $2-4 \mathrm{~h}$, and during the collection period, they were walked manually in the stable corridors for $15 \mathrm{~min}$ In the study of Van Doorn et al. [18], the horses were given 1-h walk on a treadmill, and during the collection period they walked manually for $10 \mathrm{~min}$ indicating rather light work level. Thus, the light work load of the horses may be one reason for the $\mathrm{P}$ retention in our study. In addition, because phosphorus is stored in many body tissues and fluids [1-3], some P can be accumulated to these, too. The retention values presented here includes also the urine $\mathrm{P}$, because urine was not collected and analyzed for $\mathrm{P}$. This was done, because according to studies $[8,10,12]$, only a very low proportion (about $1 \%$ ) of the phosphorus is excreted in the urine.

The Ca:P ratio of the feed or diet affects not only the digestibility of phosphorus but also the digestibility of calcium [15]. A high calcium intake can impair phosphorus digestibility at a Ca:P ratio of 2.58 or more [1,18]. However, the dietary Ca:P ratios in the current study were much lower, 1.14-1.58. Concerning fecal Ca:P ratios, Böswald et al. [38] found that in horses (and other large hindgut fermenters), the fecal Ca:P ratio is lower than the dietary Ca:P ratio. The present study was in accordance with this, the mean fecal ratios ranging from 0.80 to 0.95 . 


\subsection{Intake, Fecal Excretion and Digestibility of Calcium and Magnesium}

Calcium and magnesium intakes also differed between the diets because of the differences in the mineral content of the feeds. The intakes of Ca and $\mathrm{Mg}$ agreed with the recommendations $[1,19]$, with the exception that $\mathrm{Mg}$ intake was above the recommended values when complete feed was fed. Intakes of $\mathrm{Ca}$ from the concentrates were small. Oats was low in $\mathrm{Ca}$, and the increased proportion of oats and decreased proportion of forage in the diet resulted in a decline in Ca intake. Concerning the intakes of $\mathrm{Mg}$, the larger $\mathrm{Mg}$ content of the complete feed compared to that of oats explains the differences in $\mathrm{Mg}$ intake.

The excretion of $\mathrm{Ca}$ in the present study was smaller than reported in the literature e.g., [7,18] because the intake was smaller. It is also likely that different Ca sources have an influence. The Mg excretion agreed with previous studies $[7,18]$.

The amounts of excreted $\mathrm{Ca}$ and $\mathrm{Mg}$ in feces are related to intakes [39,40], but no effect of intake was observed by Nielsen et al. [33]. Meyer et al. [41,42] reported that diets containing more roughage resulted in a higher renal excretion of $\mathrm{Ca}$ and $\mathrm{Mg}$.

The observed digestibilities of Ca not differing between the diets agreed with the literature values $[2,7,18,35]$. Van Doorn et al. [18] have reported that high amounts of $\mathrm{P}$ and phytate $\mathrm{P}$ may decrease $\mathrm{Ca}$ digestibility. The larger excretion of $\mathrm{Mg}$ compared with its intake in all diets, except those including the complete feed, explains, the poor $\mathrm{Mg}$ digestibility in these diets. The digestibility of $\mathrm{Mg}$ has been reported to be largely varying, and negative values have also been reported [2,7,18,35], as in the present study. Because $\mathrm{Ca}$ and $\mathrm{Mg}$ are excreted in large quantities in urine $[9,40]$, the observed digestibilities here may be underestimated.

\subsection{Digestibility of the Diet Nutrients}

It is very likely that the lower DM digestibility of the haylage-only diet was due to its larger fiber content (NDF, ADF, CF) compared to the other diets. The better CP digestibility of the haylage-only diet was due to its larger CP content, and correspondingly, the poor CP digestibility of the hay-only diet was due to its low CP content. These results are supported for example by Särkijärvi and Saastamoinen [27] and Ragnarsson and Lindberg [43,44]. The positive effect of including concentrates in the forage diets agrees with previous studies, being e.g., due to the lower NDF content of the diet e.g., [45,46]. The NDF content also explains the digestibility value differences between the forage diets. The digestibility values observed in the present study are comparable with those reported previously for Finnhorses of the same age e.g., $[27,47]$.

\subsection{Blood Concentrates of $\mathrm{P}$ and $\mathrm{Ca}$}

The blood phosphorus levels are affected by phosphorus intake [48,49], which may explain why blood levels were highest in the horses whose diets were supplemented with oats. Greiwe-Crandell et al. [50] suggested that mares fed an all-forage diet marginal or low in phosphorus may mobilize $\mathrm{P}$ from bone.

The blood Ca concentration was largest in the horses on the hay-only diet. Meyer et al. [42] reported higher plasma Ca levels for forage fed horses than concentrate fed horses. Some other studies, however, pointed out that the blood Ca concentration does not depend on the Ca intake [48,49]. Regarding all diets, the average blood serum $\mathrm{Ca}$ and $\mathrm{P}$ concentrations were within the normal ranges used for Finnhorses (https://www.movet.fi/laboratoriokasikirja/). To maintain physiologic Ca and P blood levels, mammals can absorb them from the gastrointestinal tract or change their bone turnover [38].

\subsection{Impact of Horse Diets on P Leaching}

The daily quantity of dung produced by the horses was in line with the literature values [7,51,52], depending, however, on diet and feed intake. The average daily phosphorus excretion of about $21 \mathrm{~g}$ in feces in this study, when typical diets and current recommendations [1,19] were applied, resulted in 
$7.6 \mathrm{~kg} \mathrm{P}$ per year. If the $\mathrm{P}$ is not properly absorbed in stable beddings, or if the dung in paddocks is altered by rain and water from melting snow, $\mathrm{P}$ in feces and manure may present an environmental risk when leaching into waters.

The soluble $\mathrm{P}$ part of the total $\mathrm{P}$ in feces available for the utilization of plants accounted for about $88 \%$ of the P excreted in feces in this study. Ögren et al. [12] reported a proportion of $80 \%$ of soluble $\mathrm{P}$. The $\mathrm{P}$ that is unavailable is vulnerable to runoff losses. According to Chapuis-Lardy et al. [53], excess dietary $\mathrm{P}$ is excreted in feces in water-soluble forms. Dougherty et al. [54] pointed out that around $90 \%$ of $\mathrm{P}$ losses occurred in water-soluble form. The leaching P from the dung of horses is mainly inorganic [55]. Consequently, the argument of the NRC [1] that horse manure is less harmful to the environment compared with that from other farm animals because of its low proportion of water-soluble $\mathrm{P}$, is not correct in the light of the results of this and previous studies.

It is possible that the composition of the diet affects the solubility of $\mathrm{P}$, as reported for dairy cows and pigs [56,57]. However, in this study it was irrelevant to compare the diets because of their composition, i.e., the inclusion of various $P$ sources in the same diet. Further studies can be suggested to be carried out concerning this issue also in horses. Ögren et al. [12] concluded that soluble P has a strong positive relationship to $\mathrm{P}$ intake in horses.

As P loss is linearly related to its intake in various animal species $[12,53,58]$, it is impossible to conclude how polluting horse industry is compared with other forms of animal production. However, in the study of Ögren et al. [12], the high proportion of inorganic P in horse feces indicated that $\mathrm{P}$ overfeeding of horses might be more harmful to the environment than P overfeeding of dairy cows. Previously, several other authors have also reported that horse paddocks may pose a high risk of extensive $P$ loss $[22-25,55,59]$. Regular removal of dung from paddocks is recommended to minimize this risk $[25,55,60,61]$. How often this should be done naturally depends on the time the horses spend in the paddocks and livestock density/ha. Phosphorus sorbing materials (e.g., Fe containing) [22,59], filtering materials (geotextile-gravel) [61], or organic (bedding) materials [62] can also be used on paddock surfaces to reduce leaching loss.

Ögren et al. [12] concluded that an increase in the P requirement for growing horses is not justified. The present study shows that it is unnecessary to supplement the diets of mature horses, especially those in light work, with inorganic phosphorus, when the diets are supplemented with concentrates. According to Fowler et al. [7], the organic P in feeds may fulfill the needs of horses in light work, and no supplementation with inorganic $\mathrm{P}$ is needed. Balancing the diets for $\mathrm{P}$ intake can be estimated to save both money and environment in dairy production [63]. There may also be economic motives to catch the $\mathrm{P}$ in feces and absorb it in bedding materials, because the use of horse manure may reduce fertilizing costs. When horse manure is composted, its nutrients can be recycled and utilized [31], which reduces the use of inorganic fertilizers.

In addition, optimizing the proportions of the diet components, for example by supplementing the forage diets with concentrates, may improve the digestibility of phosphorus. However, it is necessary to analyze the feeds for the mineral concentrations because of the large variation $[20,32,64]$. In complete feeds for horses, $\mathrm{P}$ (and other mineral) concentrations are usually formulated to cover the requirements of an "average horse" when "medium-quality" forages are fed. They thus do not take into account the true mineral concentrations in the other components of the diet. This may result in over- or undernutrition in practical feeding. As in this study, they also contain the added P in inorganic form. In addition, when increasing the proportion of concentrates in the daily ration, the possible detrimental effects of starch [65] have to be considered. In the present study, the concentrate levels fed were not very large, and the diets were based on forages.

\section{Conclusions}

Horse dung may pose a potential risk of $\mathrm{P}$ leaching into the environment, and is not less harmful to the environment than that from other farm animals if not properly managed, because most of the $\mathrm{P}$ in feces is in soluble form. Supplementation with inorganic P should be controlled in the diets of 
adult horses in light work to decrease the excretion of $\mathrm{P}$ in feces. Supplementing forage diets with concentrates may improve the digestibility of phosphorus and, thus, improves the availability of $\mathrm{P}$ to horses. More research especially into cost effective feeding strategies and their applications for horses is essential, e.g., concerning diet composition and ingredients, to reduce horse industry's harmful impacts on and risks to water quality.

Author Contributions: M.S. and S.S. contributed methodology and investigation; S.S. contributed formal analysis; M.S. contributed resource, writing-original draft preparation, supervision; E.V. contributed experimental part and investigation, and data analyzing. All authors have read and agreed to the published version of the manuscript.

Funding: This research was funded by Finnish Ministry of the Environment (YM 126/481/2012).

Conflicts of Interest: The authors declare no conflict of interest. The funders had no role in the design of the study; in the collection, analyses, or interpretation of data; in the writing of the manuscript, or in the decision to publish the results.

\section{References}

1. NRC. Nutrient Requirements of Horses, 6th ed.; National Research Council of the National Academies: Washington, DC, USA, 2007.

2. Lavin, T.E.; Nielsen, B.D.; Zingsheim, J.N.; O'Connor-Robison, C.I.; Link, J.E.; Hill, G.M.; Shelton, J. Effects of phytase supplementation in mature horses fed alfalfa hay and pelleted concentrate diets. J. Anim. Sci. 2013, 91, 1719-1727. [CrossRef] [PubMed]

3. McDonald, P.; Edwards, R.A.; Greenhalgh, J.F.D.; Morgan, C.A.; Sincliar, L.A.; Wilkinson, R.G. Animal Nutrition, 7th ed.; Pearson Education Limited: Harlow, UK, 2011.

4. Ammermann, C.B.; Baker, D.P.; Lewis, A.J. Bioavailability of Nutrients for Animals: Amino Acids, Minerals, Vitamins; Academic Press: San Diego, CA, USA, 1995.

5. Geor, R.J.; Harris, P.A.; Coenen, M. Equine Applied and Clinical Nutrition: Health, Welfare and Performance, 1st ed.; Saunders/Elsevier: Edinburgh, UK, 2013.

6. van Doorn, D.A.; Everts, H.; Wouterse, H.; Homan, S.; Beynen, A.C. Influence of high phosphorus intake on salivary and plasma concentrations, and urinary phosphorus excretion in mature ponies. J. Anim. Physiol. Anim. Nutr. 2011, 95, 154-160. [CrossRef] [PubMed]

7. Fowler, A.; Hansen, T.; Strasinger, L.; Davis, B.; Harlow, B.E.; Lawrence, L. Phosphorus digestibility and phytate degredation by yearlings and mature horse. J. Anim. Sci. 2015, 93, 5735-5742. [CrossRef] [PubMed]

8. Schryver, H.F.; Hintz, H.F.; Craig, P.H.; Hogue, D.E.; Lowe, J.E. Site of phosphorus absorption from intestine of the horse. J. Nutr. 1972, 102, 143-147. [CrossRef] [PubMed]

9. Schryver, H.F.; Hintz, H.F.; Lowe, J.E. Calcium and phosphorus in the nutrition of the horse. Cornell Vet. 1974, 64, 493-514. [PubMed]

10. Schryver, H.F.; Hintz, H.F.; Craig, P.H. Phosphorus metabolism in ponies fed varying levels of phosphorus. J. Nutr. 1971, 101, 1257-1263. [CrossRef]

11. Fowler, A.; Strasinger, L.; Hansen, T.; Davis, B.; Hayes, S.; Lawrence, L. The availability of dietary phosphorus to long yearlings and mature horses. J. Equine Vet. Sci. 2013, 33, 342-343. [CrossRef]

12. Ögren, G.; Holtenius, K.; Jansson, A. Phosphorus balance and fecal losses in growing Standardbred horses in training fed forage-only diets. J. Anim. Sci. 2013, 91, 2749-2755. [CrossRef]

13. Cehak, A. In vitro studies on intestinal calcium and phosphate transport in horses. Comp. Biochem. Physiol. Part A 2012, 161, 259-264. [CrossRef]

14. Pagan, J.D. Nutrient digestibility in horses. In Advances in Equine Nutrition; Pagan, J., Ed.; Nottingham University Press: Nottingham, UK, 1998; pp. 77-83.

15. Wilson, J.A.; Babb, C.W.; Prince, R.H. Protein and mineral digestibility of three pelleted equine feeds and subsequent nitrogen and phosphorus waste excretion. Prof. Anim. Sci. 2006, 22, 341-345. [CrossRef]

16. Warren, L.; Weir, J.; Harris, P.; Kivipelto, J. Effect of total phosphorus and phytate -phosphorus intake on phosphorus digestibility in horses. J. Equine Vet. Sci. 2013, 33, 352. [CrossRef]

17. Hainze, M.T.M.; Muntifering, R.B.; Wood, C.W.; McCall, C.A.; Wood, B.H. Faecal phosphorus excretion from horses fed typical diets with and without added phytase. Anim. Feed Sci. Technol. 2004, 117, 265-279. [CrossRef] 
18. van Doorn, D.; Everts, H.; Wouterse, H.; Beynen, A.C. The apparent digestibility of phytate phosphorus and the influence of supplemental phytase in horses. J. Anim. Sci. 2004, 82, 1756-1763. [CrossRef] [PubMed]

19. Luke. Finnish Feed Tables and Feeding Recommendations; Natural Resources Institute Finland; Available online: http://urn.fi/URN:ISBN:978-952-326-054-2 (accessed on 21 November 2019).

20. Zhao, X.; Müller, C.E. Macro and micromineral content of wrapped forages for horses. Grass For. Sci. 2015, 71, 195-207. [CrossRef]

21. Knowlton, K.F.; Radcliffe, J.S.; Novak, C.L.; Emmerson, D.A. Animal management to reduce phosphorus losses to the environment. J. Anim. Sci. 2004, 82, E173-E195. [CrossRef] [PubMed]

22. Uusi-Kämppä, J.; Närvänen, A.; Kaseva, J.; Jansson, H. Phosphorus and faecal bacteria in runoff from horse paddocks and their mitigation by the addition of P-sorbing materials. Agr. Food Sci. 2012, 21, 247-259. [CrossRef]

23. Parvage, M.M.; Kirchmann, H.; Kynkäänniemi, P.; Ulén, B. Impact of horse grazing and feeding on phosphorus concentrations in soil and drainage water. Soil Use Manag. 2011, 27, 367-375. [CrossRef]

24. Parvage, M.M.; Ulén, B.; Kirchmann, H. A survey of soil phosphorus (P) and nitrogen (N) in Swedish horse paddocks. Agric. Ecos. Environ. 2013, 178, 1-9. [CrossRef]

25. Parvage, M.M.; Ulén, B.; Kirchmann, H. Are horse paddocks threating water quality through exess loading of nutrients. J. Environ. Manag. 2015, 147, 306-313. [CrossRef]

26. Henneke, R.R.; Potter, G.D.; Kreider, J.L.; Yeates, B.F. Relationship between condition score, physical measurements and body fat percentage in mares. Equine Vet. J. 1983, 14, 371-372. [CrossRef]

27. Särkijärvi, S.; Saastamoinen, M. Feeding value of various processed oat grains in equine diets. Livest. Sci. 2006, 100, 3-9. [CrossRef]

28. Huang, C.Y.L.; Schulte, E.E. Digestion of plant tissue for analysis by ICP Emission Spectroscopy. Commun. Soil Sci. Plant Anal. 1985, 16, 943-958. [CrossRef]

29. Robertson, J.; Van Soest, P. The detergent system of analysis and its application to human foods. Anal. Diet. Fiber Food. 1981, 3, 123.

30. Van Soest, P.J.; Robertson, J.B.; Lewis, B.A. Methods for dietary fiber, neutral detergent fiber, and nonstarch polysaccharides in relation to animal nutrition. J. Dairy Sci. 1991, 74, 3583-3597. [CrossRef]

31. Keskinen, R.; Saastamoinen, M.; Nikama, J.; Särkijärvi, S.; Myllymäki, M.; Salo, T.; Uusi-Kämppä, J. Recycling nutrients from horse manure: effects of bedding type and its compostability. Agric. Food Sci. 2017, 26, 68-79. [CrossRef]

32. Saastamoinen, M.T.; Hellämäki, M. Forage analyses as a base of feeding of horses. In Forages and Grazing in Horse Nutrition; Saastamoinen, M., Fradinho, M.J., Santos, A.S., Miraglia, N., Eds.; Wageningen Academic Publishers: Cambridge, MA, USA, 2012; pp. 304-314.

33. Pösö, A.R.; Soveri, T.; Oksanen, H.E. The effect of exercise on blood parameters in Standardbred and Finnish-bred horses. Acta Vet. Scand. 1983, 24, 170-184. [PubMed]

34. Patterson, D.P.; Cooper, S.R.; Freeman, D.W.; Teeter, R.G. Effects of varying levels of phytase supplementation on dry matter and phosphorus digestibility in horses fed common textured ration. J. Equine Vet. Sci. 2002, 22, 456-459. [CrossRef]

35. van Doorn, D.; van der Spek, M.E.; Everts, H.; Wouterse, H.; Beynen, A.C. The influence of calcium intake on phosphorus digestibility in mature ponies. J. Anim. Physiol. Anim. Nutr. 2004, 88, 412. [CrossRef]

36. Elzinga, S.; Nielsen, B.D.; Schott, H.C.; Rapson, J.; Robinson, C.I.; McCutcheon, J.; Harris, P.A.; Geor, R. Comparison of nutrient digestibilitys between adult and aged horses. J. Equine Vet. Sci. 2014, 34, 1164-1169. [CrossRef]

37. Buchholz-Bryant, M.A.; Baker, L.A.; Pipkin, J.L.; Mansell, B.J.; Haliburton, J.C.; Bachman, R.C. The effect of calcium and phosphorus supplementation, inactivity, and subsequent aerobic training on mineral balance in young, mature, and aged horses. J. Equine Vet. Sci. 2001, 21, 71-77. [CrossRef]

38. Böswald, L.F.; Dobenecker, B.; Clauss, M.; Kienzle, E. A comparative meta-analysis on the relationship of faecal calcium and phosphorus excretion in mammals. J. Anim. Physiol. Anim. Nutr. 2018, 102, 370-379. [CrossRef] [PubMed]

39. Schryver, H.F.; Craig, P.H.; Hintz, H.F. Calcium metabolism in ponies fed varying levels of calcium. J. Nutr. 1970, 100, 955-964. [CrossRef]

40. Hintz, H.F.; Schryver, H.F. magnesium metabolism in the horse. J. Anim. Sci. 1972, 35, 755-759. [CrossRef] [PubMed] 
41. Meyer, H.; Heilemann, M.; Perez Noriega, H.; Gomda, Y. Postprandiale renale Ausscheidung von Calcium, Magnesium und Phosphorus bei ruhenden und arbeitenden Pferden. In Advances in Animal Physiology and Animal Nutrition; Contributions to water and mineral metabolism of the horse; Springer: Berlin/Heidelberg, Germany, 1990; pp. 78-85.

42. Meyer, H.; Stadermann, B.; Schnurpel, B.; Nehring, T. The influence of type of diet (roughage or concentrate) on the plasma level, renal excretion, and apparent digestibility of calcium and magnesium in resting and exercising horses. J. Equine Vet. Sci. 1992, 12, 233-239. [CrossRef]

43. Ragnarsson, S.; Lindberg, J.E. Nutritional value of timothy haylage in Icelandic horses. Livest. Sci. 2008, 113, 202-208. [CrossRef]

44. Ragnarsson, S.; Lindberg, J.E. Nutritional value of mixed grass haylage in Icelandic horses. Livest. Sci. 2010, 131, 83-87. [CrossRef]

45. Martin Rosset, W.; Vermorel, M.; Doreau, M.; Tisserand, J.L.; Andrieu, J. The French horse feed evaluation systems and recommended allowances for energy and protein. Livest. Prod. Sci. 1994, 40, 37-56. [CrossRef]

46. Palmgren Karlsson, C.; Lindberg, J.E.; Rundgren, M. Associative effects on total tract digestibility in horses fed different ratios of grass hay and whole oats. Livest. Prod. Sci. 2000, 65, 143-153. [CrossRef]

47. Särkijärvi, S.; Sormunen-Cristian, R.; Heikkilä, T.; Rinne, M.; Saastamoinen, M. Effect of grass species and cutting time on in vivo digestibility of silage by horses and sheep. Livest. Sci. 2012, 144, 230-239. [CrossRef]

48. Breidenbach, A.; Schlumbohm, C.; Harmeyr, J. Pecularities of vitamin D andof the calcium and phosphate homeostatic system in horses. Vet. Res. 1998, 29, 173-186.

49. van Doorn, D.A.; Schaafstra, F.J.; Wouterse, H.; Everts, H.; Estepa, J.C.; Aguilera-Tejero, E.; Beynen, A.C. Repeated measurements of $\mathrm{P}$ retention in ponies fed rations with various Ca: P ratios. J. Anim. Sci. 2014, 92, 4981-4990. [CrossRef] [PubMed]

50. Greiwe-Crandell, K.M.; Morrow, G.A.; Kronfeld, D.S. Phosphorus and selenium depletion in Thoroughbred mares and weanlings. Pferdeheilkunde, Sonderausgabe 1. Europäissche Konferenz über die Ernährung des Pferdes 1992, 77-80.

51. Jansson, A.; Dahlborn, K. Effects of feeding frequency and voluntary salt intake on fluid and electrolyte regulation in athletic horses. J. Appl. Physiol. 1999, 86, 1610-1616. [CrossRef] [PubMed]

52. Wartell, B.A.; Krumins, J.A.; Kang, K.; Schwab, B.J.; Fennell, D. Methane production from horse manure and stall waste with softwood bedding. Bioresour. Technol. 2012, 112, 42-50. [CrossRef] [PubMed]

53. Chapuis-Lardy, L.; Fiorini, J.; Toth, J.; Dou, Z. Phosphorus concentration and solubility in dairy feces: Variability and affecting factors. J. Dairy Sci. 2004, 87, 4334-4341. [CrossRef]

54. Dougherty, W.J.; Nicholls, P.J.; Milham, P.J.; Havilah, E.J.; Lawrie, R.A. Phosphorus Fertilizer and Grazing Management Effects on Phosphorus in Runoff from Dairy Pastures. J. Environ. Qual. 2008, 37, 417-428. [CrossRef]

55. Keskinen, R.; Nikama, J.; Närvänen, A.; Uusi-Kämppä, J.; Särkijärvi, S.; Saastamoinen, M. Reducing nutrient runoff from horse paddocks by removal of dung. In Proceedings of the Equi-Meeting Infrastructures Horses and Equestrian Facilities, Le Lion d' Angers, France, 6-7 October 2014; pp. 60-65.

56. Kebreab, E.; Shah, M.A.; Beever, D.E.; Humphries, D.J.; Sutton, J.D.; France, J.; Mueller-Harvey, I. Effects of contrasting forage diets on phosphorus utilisation in lactating dairy cows. Livest. Prod. Sci. 2005, 93, 125-135. [CrossRef]

57. Maguire, R.O.; Dou, Z.; Sims, T.; Brake, J.; Joern, B.C. Dietary strategies for reduced phosphorus excretion and improved water quality. J. Environ. Qual. 2005, 34, 2093-2103. [CrossRef]

58. Dou, Z.; Knowlton, K.F.; Kohn, R.A.; Wu, Z.; Satter, L.D.; Zhang, G.; Toth, J.D.; Ferguson, J.D. Phosphorus characteristics of dairy feces affected by diets. J. Environ. Qual. 2002, 31, 2058-2065. [CrossRef]

59. Närvänen, A.; Jansson, H.; Uusi-Kämppä, J.; Jansson, H.; Perälä, P. Phosphorus load from equine critical source areas and its reduction using ferric sulphate. Boreal. Environ. Res. 2008, 13, 266-274.

60. Airaksinen, S.; Heiskanen, M.-L.; Heinonen, H. Contamination of surface run-off water and soil in two horse paddocks. Bioresour. Technol. 2007, 98, 1762-1766. [CrossRef] [PubMed]

61. von Wachenfelt, H.E. A field test of all-weather surfaces for horse paddocks. J. Food Sci. Eng. 2016, 6, $197-211$. [CrossRef]

62. Parvage, M.M.; Ulén, B.; Kirchmann, H. Can organic materials reduce nutrient leaching from manure-rich paddock soils? J. Eneviron. Qual. 2017, 46, 105-112. [CrossRef] [PubMed] 
63. Kebreab, E.; Odongo, B.W.; McBride, B.W.; Hanigan, M.D.; France, J. Phosphorus Utilization and Environmental and Economic Implications of Reducing Phosphorus Pollution from Ontario Dairy Cows. J. Dairy Sci. 2008, 91, 241-246. [CrossRef]

64. Uotila, R.; Thuneberg, T.; Saastamoinen, M. The usage of forage analyses in optimizing horse nutrition in Finland. In Forages and Grazing in Horse Nutrition; Saastamoinen, M., Fradinho, M.J., Santos, A.S., Miraglia, N., Eds.; Wageningen Academic Publishers: Cambridge, MA, USA, 2012; pp. 331-334.

65. Julliand, V.; Grimm, P. The impact of diet on the hindgut microbiome. J. Equine Vet. Sci. 2017, 52, $23-28$. [CrossRef]

(C) 2020 by the authors. Licensee MDPI, Basel, Switzerland. This article is an open access article distributed under the terms and conditions of the Creative Commons Attribution (CC BY) license (http://creativecommons.org/licenses/by/4.0/). 


\title{
Characterization of Feeding, Sport Management, and Routine Care of the Chilean Corralero Horse during Rodeo Season
}

\author{
Joaquín Bull ${ }^{1}$, Fernando Bas ${ }^{1}$, Macarena Silva-Guzmán ${ }^{2}$, Hope Helen Wentzel ${ }^{3}$, \\ Juan Pablo Keim ${ }^{4}$ and Mónica Gandarillas ${ }^{1,4, *}$ \\ 1 Departamento de Ciencias Animales, Facultad de Agronomía e Ingeniería Forestal, Pontificia Universidad \\ Católica de Chile, Avda. Vicuña Mackenna 4860, Santiago 7820436, Chile; jabull@uc.cl (J.B.); fbas@uc.cl (F.B.) \\ 2 Private statistical consultant, Guardia Vieja 441, Santiago 7510318, Chile; maca.silva.guzman@gmail.com \\ 3 Escuela de Graduados, Facultad de Ciencias Agrarias, Universidad Austral de Chile, Valdivia 5110566, Chile; \\ hope.wentzel@alumnos.uach.cl \\ 4 Instituto de Producción Animal, Facultad de Ciencias Agrarias, Universidad Austral de Chile, \\ Independencia 641, Valdivia 5110566, Chile; juan.keim@uach.cl \\ * Correspondence: monica.gandarillas@uach.cl
}

Received: 1 August 2019; Accepted: 11 September 2019; Published: 17 September 2019

Simple Summary: The Chilean corralero horse holds great cultural importance due to its use in Chilean rodeo, the national sport. However, information regarding this breed is sparse, especially husbandry, feeding, and training recommendations, which could present challenges for their proper care. A survey of horse farms in several regions from central to southern Chile was conducted in order to document current management of the Chilean corralero horses which participated in the 2014-2015 Chilean Rodeo Federation season. In the survey, horse owners and trainers were asked about horse gender and size, daily routine, exercise and competition regimen, and feeding practices. All horses in the study were kept in stalls for at least $12 \mathrm{~h}$ daily and spent the rest of the day either tied or loose in pens or paddocks. Horses were in moderate- to high-intensity exercise programs, with workouts six days/week and two rodeos per month. Feeding practices varied greatly among farms but most horses received forage (alfalfa or grass hay) and an energy feed (oats, corn, or concentrate), while protein and lipid supplements were less common. The goal of this characterization of current management of the Chilean corralero horse is to contribute to information available about this breed to improve husbandry practices.

\begin{abstract}
The aim of this study was to characterize the routine care, training, feeding, and nutritional management of Chilean corralero horses that participated in the rodeos of the Chilean Rodeo Federation. Forty-nine horse farms between the Metropolitan ( $33^{\circ} 26^{\prime} 16^{\prime \prime}$ south (S) $70^{\circ} 39^{\prime} 01^{\prime \prime}$ west $(\mathrm{W})$ ) and Los Lagos Regions $\left(41^{\circ} 28^{\prime} 18^{\prime \prime} \mathrm{S} 72^{\circ} 56^{\prime} 12^{\prime \prime} \mathrm{W}\right)$, were visited and a survey was conducted on the management and feeding of the Chilean horse. Of the horses which participated in at least one official rodeo in the 2014-2015 season, 275 horses were included in the study. The survey consisted of five questions about general data on the property and the respondent, four questions on the animal characteristics, five questions about where the horses were kept during the day, seven questions to characterize the amount of exercise done by the horse, and 18 questions about feeding practices; additionally, the amount of feed offered was weighed. All horses in this study were in training and kept in their stall for at least $12 \mathrm{~h}$ and remained tied or loose for the rest of the day. The intensity of daily exercise of the rodeo Chilean horse could be classified as moderate to heavy and consisted of being worked six days/week and participating in two rodeos/month. Ninety-eight percent of respondents had watering devices in the stables. The diet of the Chilean corralero horse during the training season is based on forages, mainly alfalfa hay, plus oats as an additional energy source. Protein supplements such as oil seed by-products are used less frequently. A wide variation was
\end{abstract}


observed in the diets and quantities of feed offered, which suggests that the feeding management of these individuals is not formulated according to their requirements.

Keywords: Chilean corralero horse; rodeo; feeding practices

\section{Introduction}

Horses served humans for centuries as a source of food, as well as for military, agricultural labor, and sport purposes [1]. The International Federation for Equestrian Sports (FEI) recognizes eight disciplines for competition (dressage, jumping, vaulting, endurance, reining, combined driving, eventing, and para-equestrian). Nevertheless, there are several other widely known equestrian sport competitions worldwide, such as polo and racing.

In Chile, "rodeo" was declared the national sport in 1962 (Decree 269 of the National Council of Sports), when it became part of the Olympic Committee of Chile [2]. This sport is one of the culturally rich activities that take place in the Chilean countryside. It symbolizes traditional cattle-working and is part of the traditional folklife with its own customs [2,3]. After football (soccer), rodeo is the second most popular sport in Chile due to its massive following and because it became an important cultural symbol throughout national history.

The breeding aim for the Chilean corralero horse is to produce a horse that is suitable and functional for saddle and stock work, as well as practicing rodeo [4].

The rodeo is performed in an oval-shaped area and consists of a pair of riders (each rider is called a "huaso") and their horses ("collera") running half laps around the arena while working a steer and attempting to pin it against a large 12-m cushion ("quincha"). Horses run a total of approximately $400 \mathrm{~m}$ at $6.95 \mathrm{~m} / \mathrm{s}$ in each round of the competition [5]. The rodeo is highly regulated by the Chilean Rodeo Federation, and there are 311 officially registered arenas throughout the national territory [6], with 350 competitions per season, which begins in August each year and ends with the national championship in April of the following year.

Despite the national importance of rodeo, there is little information available and easily accessible about the Chilean corralero horse, specifically related to equine numbers, competing animals, feeding type, and routine management. Moreover, unlike other equestrian sports like show-jumping [7], racing [8], and three-day eventing [9], there is no known characterization of feeding management and schedule or dietary ingredients. Since competition horses may develop nutritional and digestive problems such as gastric ulcers, decreased appetite, and weight loss [10], it is important to establish feeding practices of sport horses undergoing hard work. Considering that the rodeo sport season lasts eight months every year, with some horses competing every weekend or every other weekend, a properly designed training routine and sound feeding management is crucial. Moreover, since the Chilean corralero horse is considered a small horse (height at the withers 99.86-136.4 cm) and huasos weigh an average of $80.78+10.02 \mathrm{~kg}$, some of these horses may be overburdened [5], thus requiring additional energy.

The lack of information on Chilean corralero horses also makes it difficult for breeders, trainers, riders, veterinarians, and owners to develop management and feeding standards. Therefore, this work seeks to contribute with relevant information on diet composition and feed ingredients utilized daily in the diet of Chilean corralero horses actively participating in the national sport. Hence, the objective of this study was to characterize the feeding and nutritional management, routine care, and training of Chilean corralero horses that participate in the rodeos of the Chilean Rodeo Federation. 


\section{Materials and Methods}

\subsection{Animals}

The target population for this study was healthy Chilean corralero horses that participated in the 2014-2015 season of the Chilean national rodeo competition and that were in training at the time of the visit. The data to identify individuals that participated during that season were provided by the Chilean Rodeo Federation.

The horses' owners were contacted by telephone or e-mail to request their participation in the study, and an interview was scheduled if they were willing to participate. As a result, a personal visit was carried out between October and December of 2015 to 49 farms ( 275 horses) located between the Metropolitan and the Los Lagos regions ( $33^{\circ} 26^{\prime} 16^{\prime \prime}$ south (S), $70^{\circ} 39^{\prime} 1^{\prime \prime}$ west $(\mathrm{W})$ to $\left.41^{\circ} 28^{\prime} 18^{\prime \prime} \mathrm{S}, 72^{\circ} 56^{\prime} 12^{\prime \prime} \mathrm{W}\right)$. Farms were located in the following regions: Metropolitan $(n=5)$, Valparaiso $(n=3)$, O'Higgins $(n=6)$ Maule $(n=5)$, Bío-Bío $(n=10)$, Araucanía $(n=8)$, Los Ríos $(n=5)$, and Los Lagos $(n=7)$.

\subsection{Survey Design}

The interview consisted of a questionnaire with five questions regarding general farm and respondent information (farm name, location, farm administrator, position, date of the visit), three questions to characterize the animal (registration number, sex, date of birth), five questions about housing conditions and activity (hours spent within the stall, outdoor pen, paddock, and tied), and four questions characterizing the type and amount of daily exercise of the horse (minutes spent walking, trotting, cantering, and in the "bumping activity", on a weekly and daily basis). "Bumping" (topeo) is when the horse performs lateral canter half-passes while maintaining contact at a $45^{\circ}$ angle between the horse's chest and the steer's body, using a lateral movement to push slightly on the steer and maintain him at a $45^{\circ}$ angle to the horse's body.

The questionnaire also included 18 questions about nutritional management with regard to feeding (feed ingredient type, feeding frequency, and schedule), water availability and source (automatic drinker, water bucket, etc.), access to pasture, hay type, grains, protein supplements, other commercial concentrate or byproduct, minerals, oils, if feedstuffs were moisturized, nutritional advisor, and other information (de-wormer type and frequency, incidence of colic and laminitis per year).

The daily amount of each ingredient offered was weighed with a digital scale. The girth and scapula-ischial length (SIL) were measured using a measuring tape to estimate live body weight, using the formula of Carroll and Huntington [11], where

$$
\text { weight }(\mathrm{kg})=\left(\operatorname{girth}\left(\mathrm{cm}^{2}\right) \times \operatorname{SIL}(\mathrm{cm})\right) / 11,877 \text {. }
$$

The girth corresponds to the thoracic perimeter $(\mathrm{cm})$ and was measured by wrapping a 3-m flexible measuring tape around the girth, just behind the withers, of each horse. The scapula-ischial length (SIL) corresponds to the length from scapula (point of the shoulder) to ischial tuberosity (point of the buttock) in centimeters [12].

The unique registration number and date of birth of the horses were obtained from the owners or the animal's registration certificate.

\subsection{Statistical Analyses}

Data obtained from the surveys were consolidated in an Excel spreadsheet and reported as a descriptive analysis (average \pm standard deviation, frequency, average, minimum, maximum). One-way ANOVA between horses was conducted to determine significant differences among treatments, and a Tukey honestly significant difference (HSD) test was performed whenever there were significant differences. Significance was declared with a $p$-value lower than 0.05 . Pearson correlations were performed between feedstuffs (hay, corn, oats) utilized and incidence of colic and laminitis. The Pearson 
correlation was performed among different exercises types (walk, trot, canter). Data were processed using Statistica V 7.0.

\section{Results}

Measurements were collected from 275 horses located on 49 farms, and general characterizations about gender, age, and physical characteristics are presented in Table 1 . The evaluated farms had geldings, mares, and stallions, which respectively accounted for $30.6 \%, 32.7 \%$, and $36.7 \%$ of the entire sampled population. The average age per horse was $9.9 \pm 2.6$ years old. Geldings in this survey were older than mares and stallions $(p<0.05)$.

Table 1. Characterization of horses included in the survey, concerning gender, age, and estimated weight calculated from the girth and scapula-ischial length (SIL).

\begin{tabular}{ccccccc}
\hline \multicolumn{7}{c}{ Parameter } \\
\hline Gender & $N$ & $\%$ & $\begin{array}{c}\text { Age (Years) } \\
\text { (Mean } \pm \text { SD) }\end{array}$ & $\begin{array}{c}\text { Estimated } \\
\text { Weight (kg) } \\
\text { (Mean } \pm \text { SD) }\end{array}$ & $\begin{array}{c}\text { Girth (cm) } \\
\text { (Mean } \pm \text { SD) }\end{array}$ & $\begin{array}{c}\text { SIL (cm) } \\
\text { (Mean } \pm \text { SD) }\end{array}$ \\
\hline Geldings & 84 & 30.6 & $10.9 \pm 2.4^{\mathrm{a}}$ & $379.3 \pm 27.9^{\mathrm{b}}$ & $166.4 \pm 4.3^{\mathrm{b}}$ & $150.6 \pm 5.1^{\mathrm{b}}$ \\
Mares & 90 & 32.7 & $9.7 \pm 2.6^{\mathrm{b}}$ & $394.2 \pm 23.8^{\mathrm{a}}$ & $168.3 \pm 3.7^{\mathrm{a}}$ & $153.1 \pm 5.7^{\mathrm{a}}$ \\
Stallions & 101 & 36.7 & $9.4 \pm 2.6^{\mathrm{b}}$ & $377.8 \pm 25.8^{\mathrm{b}}$ & $165.5 \pm 4.4^{\mathrm{b}}$ & $151.7 \pm 4.9^{\mathrm{ab}}$ \\
All & 275 & 100.0 & $9.9 \pm 2.6^{\circ}$ & $383.7 \pm 26.8$ & $166.7 \pm 4.3$ & $151.8 \pm 5.3$ \\
\hline \multicolumn{7}{c}{ a,b Values within a column with different superscript letters differ significantly at $p \leq 0.05}$.
\end{tabular}

The estimated weight of mares was greater than males (geldings and stallions) $(p<0.05)$, but there was no significant difference between gelding and stallions. When all horses were considered, the average estimated weight was $383.7 \pm 26.8 \mathrm{~kg}$. The averages of girth and SIL per horse were $166.7 \pm 4.3 \mathrm{~cm}$ and $151.8 \pm 5.3 \mathrm{~cm}$, respectively, with mares having a larger girth compared to stallions and geldings $(p<0.05)$ and a larger SIL compared to geldings $(p<0.05)$.

Routine care did not follow a common pattern among farms; however, all horses were kept in individual stalls during the night and for part of the day. Eighty-six horses $(31.3 \%)$ spent the entire day in stalls. Of the rest, 163 horses spend part of the day tied, 24 in pens, and two in paddocks (Table 2).

Table 2. Routine management of Chilean corralero horses.

\begin{tabular}{ccccc}
\hline \multirow{2}{*}{ Hours/Day } & \multicolumn{4}{c}{ Number and Percentage of Horses } \\
\cline { 2 - 5 } & Stalls & Tied & Pens & Paddock \\
\hline $0-5$ & 0 & $17(6.2 \%)^{\ddagger}$ & 0 & 0 \\
$6-10$ & 0 & $2(0.7 \%)^{\dagger}$ & 0 & 0 \\
$11-15$ & 172 & $144(52.4 \%)$ & $24(8.7 \%)$ & $2(0.7 \%)^{+}$ \\
$15-19$ & $(62.5 \%)$ & + & + & 0 \\
$20-24$ & $17(6.2 \%)$ & 0 & 0 & 0 \\
\hline \multirow{2}{*}{ Total } & $86(31.3 \%)$ & 0 & 0 & $2(0.7 \%)$
\end{tabular}

${ }^{+}$Animals that spent less than $15 \mathrm{~h}$ in a stall; ${ }^{\ddagger}$ animals that spent within 15 to $19 \mathrm{~h}$ in a stall.

The sport and exercise management routine of the Chilean corralero horses is presented in Table 3.

Each farm studied had a unique routine for each of their horses. On average, horses trotted for $8.6 \pm 6.6 \mathrm{~min} /$ day and cantered for $22.3 \pm 6.1 \mathrm{~min} /$ day. All farms utilized bumping as an exercise, usually for durations of between 10 and $20 \mathrm{~min}$ and two times/week. Lunging was not a common practice among trainers; only $6.5 \%$ of horse were lunged for more than $15 \mathrm{~min}$. A Pearson correlation $(r=-0.44)$ was detected between trot and canter exercises, indicating that the time spent on one of the two exercises is 
inversely correlated to the other. There was no correlation detected between exercise routine and number of rodeos annually. The average number of rodeos during the season was $8.6 \pm 4.7$ per horse; $20(41.0 \%), 16$ $(33.0 \%)$, and five $(10.0 \%)$ farms participated in two, three, and four rodeos per month, respectively. Eight farms participated in one or fewer than one rodeo per month during the 2014-2015 season.

Table 3. Exercise routine (minutes/workout) of Chilean corralero horses.

\begin{tabular}{|c|c|c|c|c|c|}
\hline & Trot & Canter & Lunge & Bumping ${ }^{+}$ & Tournaments/Season \\
\hline $\mathrm{N}$ & 275 & 275 & 275 & 275 & \\
\hline Mean & 8.6 & 22.3 & 2.5 & 16.3 & \\
\hline SD & 6.6 & 6.1 & 8.7 & 6.4 & \\
\hline \multicolumn{6}{|c|}{ Time spent per activity (minutes/workout) } \\
\hline $0-15$ & 78.5 & 6.9 & 93.5 & 37.8 & \\
\hline $15-30$ & 20.4 & 61.8 & 2.5 & 54.2 & \\
\hline $30-45$ & 1.1 & 31.3 & 3.3 & 8.0 & \\
\hline$>45$ & 0 & 0.0 & 0.7 & 0.0 & \\
\hline \multicolumn{6}{|c|}{ Activity (days per week): trot/canter/lunge } \\
\hline Mean & & & & 2.4 & 8.6 \\
\hline SD & & & & 0.7 & 4.7 \\
\hline
\end{tabular}

\footnotetext{
${ }^{+}$Bumping refers to the exercise in which the horse performs lateral canter half-passes while maintaining contact at
} a $45^{\circ}$ angle between the horse's chest and the steer's body.

Feeding and nutritional management of the Chilean corralero horse during the rodeo season is summarized in Table 4 . Results showed that $81.1 \%$ of the horses were fed twice daily (morning and noon/night), and $18.9 \%$ received three meals (morning, noon and afternoon/evening). The horses that had two rations per day ate during the morning and night (212 horses from 37 farms) or noon and night (11 horses from two farms). None of the horses surveyed had access to pasture.

Table 4. Feedstuffs by type and quantity that were offered to every horse on a daily basis, as fed.

\begin{tabular}{|c|c|c|c|c|c|c|}
\hline & Horses N (\%) & Farms N & Daily feed allowance & SD & Max & Min \\
\hline \multicolumn{7}{|l|}{ Forages $(\mathrm{kg} / \mathrm{d})$} \\
\hline Alfalfa hay & $122(44.4)$ & 22 & 8.8 & 2.3 & 19.1 & 4.9 \\
\hline Grass hay & $67(24.3)$ & 13 & 9.2 & 1.7 & 14.3 & 5.6 \\
\hline Alfalfa cubes and/or pellets & $64(23.3)$ & 8 & 8.6 & 0.9 & 11.3 & 7.1 \\
\hline \multirow[t]{2}{*}{ Mix } & $22(8.0)$ & 6 & 10.7 & 2.6 & 15.7 & 7.0 \\
\hline & 275 & 49 & & & & \\
\hline \multicolumn{7}{|l|}{ Cereal grains $(\mathrm{kg} / \mathrm{d})$} \\
\hline Oats & $57(77.0)$ & 14 & 2.6 & 1.6 & 6.4 & 0.6 \\
\hline \multirow[t]{2}{*}{ Corn } & $17(33.0)$ & 4 & 1.3 & 1.3 & 3.6 & 0.2 \\
\hline & 74 & 18 & & & & \\
\hline \multicolumn{7}{|l|}{ Wheat by-products (kg/d) } \\
\hline Wheat bran & $93(60.4)$ & 19 & 1.9 & 1.2 & 5.3 & 0.5 \\
\hline \multirow[t]{2}{*}{ Wheat middlings } & $61(39.6)$ & 11 & 2.4 & 1.3 & 6.0 & 0.7 \\
\hline & 154 & 30 & & & & \\
\hline \multicolumn{7}{|l|}{ Oilseed by-products (kg/d) } \\
\hline Soybean meal & $54(90.0)$ & 10 & 0.8 & 0.4 & 0.9 & 0.1 \\
\hline \multirow[t]{2}{*}{ Canola meal } & $6(10.0)$ & 1 & 0.9 & 0.0 & 0.9 & 0.9 \\
\hline & 60 & 11 & & & & \\
\hline \multicolumn{7}{|l|}{ Comercial concentrate $(\mathrm{kg} / \mathrm{d})$} \\
\hline Locally produced & $75(83.3)$ & 17 & 2.3 & 2.1 & 9.0 & 0.6 \\
\hline \multirow[t]{2}{*}{ Imported } & $15(16.6)$ & 4 & 2.0 & 1.3 & 3.8 & 0.5 \\
\hline & 90 & 21 & & & & \\
\hline \multicolumn{7}{|l|}{ Oils (ml/d) } \\
\hline None & 226 & 39 & 0 & & & \\
\hline Corn oil & 2 & 1 & $200^{+}$ & & & \\
\hline
\end{tabular}


Table 4. Cont.

\begin{tabular}{|c|c|c|c|c|c|c|}
\hline & Horses N (\%) & Farms N & Daily feed allowance & SD & Max & Min \\
\hline Sunflower oil & 9 & 1 & 45 & & & \\
\hline Olive oil & 2 & 1 & 50 & & & \\
\hline Linseed oil & 26 & 4 & 60 & & & \\
\hline Soybean oil & 5 & 1 & 40 & & & \\
\hline Fish oil & 5 & 1 & 30 & & & \\
\hline \multicolumn{7}{|l|}{ Minerals blocks } \\
\hline No addition & 94 & $17(34.7 \%)$ & & & & \\
\hline Addition & 181 & $32(65.3 \%)$ & & & & \\
\hline \multicolumn{7}{|l|}{ Suplements (any kind) } \\
\hline No addition & 53 & $12(24.5 \%)$ & & & & \\
\hline Addition & 222 & $37(75.5 \%)$ & & & & \\
\hline
\end{tabular}

A total of 265 horses were fed hay. Each studied farm used more than one hay type to feed their horses. The average amount of hay offered per horse was $9.0 \pm 1.9 \mathrm{~kg} /$ day as fed. Alfalfa hay was the most commonly used forage, followed by a pasture hay and alfalfa cubes/pellets. Twenty-seven percent of horses received some type of cereal grains. Oats were the most commonly used grain, followed by corn which was offered fine, ground, or rolled.

Wheat milling by-products were also part of the feed used, where $61.2 \%$ of the farms used middlings or bran. The delivered amount of wheat bran ranged from $0.5 \mathrm{~kg} /$ day to $5.3 \mathrm{~kg} / \mathrm{day}$, whereas wheat middlings were offered at a range of 0.7 to $6.0 \mathrm{~kg} /$ day.

A total of 38 farms (77.6\% of farms surveyed) did not use oilseed by-products (soybean and canola meal) to feed any of their horses. Eleven farms utilized oilseed by-products in their ration, and only one fed all their horses with oilseed by-products.

Commercial concentrates (based on mixtures of different energetic ingredients such as oats, corn, soybean meal, molasses, wheat middling, and vegetable oils) were used in the Chilean corralero horse diets, with $42.9 \%$ (21 of the 49 ) of the owners including $2.2 \pm 2.0 \mathrm{~kg}$ daily. Mineral premix and vitamins were used in 181 horses from 32 of the studied farms, whereas 93 horses from 16 farms were not fed supplements. Finally, only 41 horses from 10 farms were fed different oils or fats, with linseed oil being the most popular.

One hundred and ninety-seven horses from 27 farms were dewormed between two and six times per year.

Of 275 horses, 149 horses (54.2\%) did not suffer colic during the previous year, whereas $47(17.1 \%)$ and nine $(3.3 \%)$ horses suffered colic one or two times during the year before, respectively. There was a negative correlation $(r=-0.72)$ between the numbers of colic episodes that the horses suffered per year and the amount of hay (other than alfalfa hay) offered, whereas the number of colic episodes that the horses suffered per year was positively correlated with corn grain $(r=0.6)$ and wheat middlings $(r=0.7)$.

Around $63 \%$ did not suffer laminitis disease the previous year, and $12 \%$ suffered laminitis during that period. The remaining interviewees did not know the answer. A negative correlation $(r=-0.72)$ between the incidence of laminitis and the amount of hay was observed.

\section{Discussion}

Unfortunately, there is little scientific literature describing the characteristics of the Chilean corralero horse. In 1950, Denhardt [13] described the horse as a muscular, strongly built animal, with a broad chest and a good distance between its shoulders. Years later, a review of morphological characteristics of this breed during the rodeo sport season was reported by García et al. [14]. The girth of the Chilean corralero horse usually ranges between 162 and $182 \mathrm{~cm}$ for males and 164 and $184 \mathrm{~cm}$ for females [15]. In this study, the girth data fell within these ranges. Mares had a larger girth 
$(168.3 \pm 3.7 \mathrm{~cm})$ than both stallions $(165.5 \pm 4.4 \mathrm{~cm})$ and geldings $(166.4 \pm 4.3 \mathrm{~cm})$, which was similar to the values obtained by García et al. [14], who reported $170.3 \pm 7.1 \mathrm{~cm}$ for females and $168.8 \pm 5.3$ and $169.6 \pm 6.4$ for stallions and geldings, respectively. However, there is no established reference parameter for the scapula-ischial length (SIL) of this breed. In this study, the average SIL for mares was $153.1 \pm 5.7 \mathrm{~cm}$, while it was $150.6 \pm 5.1 \mathrm{~cm}$ for geldings and $151.7 \pm 4.9 \mathrm{~cm}$ for stallions. In the case of García et al. [14], mares had an SIL of $147.9 \pm 6.3 \mathrm{~cm}$, geldings had an SIL of $148.2 \pm 7.9 \mathrm{~cm}$, and stallions were shorter at a length of $145.6 \pm 6.4 \mathrm{~cm}$.

In this study, the wither height was not measured but information obtained from the study of Muñoz et al. [5] showed that the standard height of the withers of the breed established at 138-148 cm [15]. The morphological characteristics mentioned above indicate that Chilean corralero horse is considered a small horse. To estimate the average liveweight, the formula proposed by Carroll and Huntington [11] was used, and the estimated weight of the surveyed horses was $383.66+26.8 \mathrm{~kg}$. Mares had the greatest estimated average weight of $394.16 \pm 23.8$, followed by geldings and stallions, with average weights of $379.34 \pm 27.9$ and $377.8 \pm 25.8$, respectively. The standard of the Chilean corralero horse establishes that mares are $2 \mathrm{~cm}$ longer in SIL than males due to their reproductive anatomy [16]. Several other studies about morphometric measurements of the Chilean horse are available for further information [5].

Stabling is a common practice in sport horse management and is part of the evolution of the horse throughout history, as it changed from being utilized primarily for agricultural and military purposes to use in sports and leisure [17]. This trend to confine the animal allows for a better control of the daily routine, feed intake, reproduction, and health management, among other benefits. To our best knowledge, there is limited information about Chilean corralero horse breeding and management, even during the reproductive or training phases. This research was conducted focusing on the sport phase of those horses exclusively focused on rodeo training. In the rodeo, as in any other equine sport discipline, horses are kept within single stalls which limit locomotion, making horse care easier and more economical [18]. However, the restricted motion and the lack of freedom to express characteristic behaviors may lead to stress and vices [19]. Upon the results of this study, it is clear from the routine handling management questions of Chilean corralero horses that $100 \%$ of the horses spent some time of the day within the stall (Table 2), usually more than $12 \mathrm{~h}$ a day. Another large percentage (59.3\%) of the horses spent between a few hours to up to half of their day tied. Only a small percentage of the horses were left free in pens $(8.7 \%)$ or paddocks $(0.7 \%)$. These extensive confinement periods correspond to abnormal behavior and vices in the Chilean corralero horse and, according to Muñoz et al. [20], 10\% of the horses studied exhibited these behaviors. Prolonged stabling can result in several undesirable behaviors such as "cribbing" (biting hard, often wooden surfaces, frequently swallowing air in the act) which can generate small fractures (less than $5 \mathrm{~mm}$ ) in the horses' teeth [21].

Daily exercise routines of the Chilean corralero horse were quite variable among farms. It seems that every trainer and/or owner managed their horses without following a common pattern within the discipline. Overall, Chilean corralero horses exercised six days per week, and the daily exercise consisted of walking, trotting, cantering, and bumping. Total daily exercise lasted $49.6 \pm 27.8 \mathrm{~min}$. The NRC [22] categorizes exercise as light, moderate, heavy, and very heavy for horses, depending on the mean heart rate, description, and types of event. In this case, the Chilean corralero horse training can best be categorized as heavy exercise, since, on average, the horse worked $4-5 \mathrm{~h} /$ week, during which time the activity was composed of $30 \%$ walk, 50-65\% trot or canter, and $5 \%$ canter, jumping, or other skill. In this case, since there are no data on mean heart rate, bumping may be considered similar to jumping or cantering [22].

Horses are non-ruminant herbivores with an enormous capacity to digest and obtain energy from fibrous ingredients [23]. However, they have a small stomach ( $8 \%$ of the total gastrointestinal tract volume) and, thus, must eat small quantities many times throughout the day. In free-ranging conditions, horses spend between 16 and $20 \mathrm{~h}$ per day grazing and, thus, in nature, can consume small amounts of feed throughout the day [24]. Nevertheless, for practical reasons, owners of confined horses may not be able to simulate this feeding delivery [25]. Feeding frequency affects horse health 
and, thus, performance. In this study, a major portion of the animals surveyed $(81.1 \%)$ were fed twice a day, whilst the remaining $18.9 \%$ were fed three times per day, which is within the recommendations for feeding horses to avoid colic [26]. Furthermore, the number of meals provided for the horses in this study was the same as the number of meals reported in a survey study of show-jumping horses [7], horses in the United Kingdom (UK) with high energy requirements [17], but differed from eventing horses [9] and racehorses [27], which received between one and five meals per day.

With regard to the type and amount of feed offered, this study found a wide variation in the diets and quantities of food offered, which suggests that the feeding management of these individuals is not formulated according to their requirements but rather according to the managers' personal criteria. All horses surveyed had access to some kind of forage in concordance with recommendations by the NRC [22]. An average of $9.0 \mathrm{~kg} /$ horse (2.3\% live bodyweight, "bwt") of either alfalfa hay and/or pasture hay was offered daily; however, the exact amount varied greatly, between 5.6 and $19.1 \mathrm{~kg} / \mathrm{horse}$ (as fed). More recently published recommendations for horses with high energy requirements indicate that hay intake should be $20 \mathrm{~g}$ dry matter (DM)/kg bwt/day [25]. Considering a $400 \mathrm{~kg}$ bwt for the Chilean corralero horse, the minimum forage intake should be $8 \mathrm{~kg}$ of DM daily. In contrast to high fiber feeding, 59\% of the sampled horses received grains (oats or corn) and/or a commercial concentrate (locally produced or imported). These energetic ingredients were offered from 2.6, 1.3, 2.3, and $2.0 \mathrm{~kg}$ per day as fed for oats, corn, local, and imported commercial concentrate, respectively (Table 4). The average grain or concentrate offered was $2.1 \mathrm{~kg} /$ horse daily, which represents $0.5 \%$ of the horse liveweight. This value is in accordance with the recommendations of Owens [28] and the NRC [22]. Wheat by-products (wheat middlings and wheat bran) were also offered to horses as part of the daily diet as a replacement or partial replacement of energetic feedstuffs. The average offered was $2.1 \mathrm{~kg} /$ horse; nevertheless, the NRC [22] lists both by-products as concentrates (3.2 and $3.4 \mathrm{Mcal} \mathrm{DE} / \mathrm{kg}$, respectively) even although both are considerably higher in fiber than corn (ADF 15.5 and $12.1 \%$ respectively, compared to $3.4 \%$ ADF in corn) but similar to oat ADF content (13.5\%). As the partial or total replacement of grain with wheat by-products did not follow a common pattern among farms, it is suggested that every owner follows their own criteria when establishing feeding practices for the Chilean corralero horse. Finally, when compared to the $400 \mathrm{~kg}$ bwt horses from the NRC tables [22], Chilean corralero horses are fed $2.8 \%$ of their bwt, which is slightly greater than the recommendation for horses in heavy exercise. It is worth noting that NRC recommendations do not account for breed-type behavior. Chilean corralero horses have a nervous and alert temperament which may increase the average energy requirements compared with a regular 400-kg horse [29]. Rosselot et al. [29] found that Chilean corralero horses tend to demonstrate proactive avoidance behaviors when presented with a challenge in a handling test; thus, this increased activity in response to environmental stressors could also impact nutrient requirements. Another factor that must be considered is the total rider and saddle weight that the horse supports on its back during competition and daily training. Muñoz et al. [5] conducted a study to determine the weight supported by Chilean corralero horses during a rodeo competition. The estimated back load maximum capacity of these Chilean corralero horses was $115.0 \pm 6.1 \mathrm{~kg}$, and the riders weighed on average $80.8 \mathrm{~kg}$ with a saddle weight of $11.6 \mathrm{~kg}$; therefore, while the horse is not overloaded, the weight of the rider and saddle corresponds to $25 \%$ of the horse's weight and, thus, has a lesser impact on its relative energy expenditure (25.7 Mcal/d DE) as compared to other sports with a lower rider/horse weight ratio such as show jumping and endurance, where the sum of weights for riders and saddle represents approximately $15 \%$ of the horses' weight and the energy requirements.

In terms of nutrition, the use of fats and oils was not common, with just $17.8 \%$ of horses fed with some oil source. The amount varied greatly but averaged 30-60 mL/day. In general, corn oil was preferred for horse feeding since it was proven that, among vegetable and animal oils, it is the most used and accepted [30]. In contrast, mineral supplementation and the use of other additives/supplements are common practice within the industry. Sixty-five percent of horses were supplemented with mineral 
blocks, and 75.5\% were given some supplement (liver protectors, vitamins premix, creatine sources, and joint supplements, among others).

In this study, colic events were negatively correlated to hay consumption and positively correlated to grain and wheat middling intake. Colic is a complex multifactorial condition and it has some association with feeds and feeding [31]. Grain overloading and, thus, high-starch diets along with low-fiber diets may predispose horses to colic [32]. In this study, grains were included in the diet with a high variation: $2.6 \pm 1.6 \mathrm{~kg} /$ day of oats on average, ranging from $0.6-6.4 \mathrm{~kg} /$ day and $1.3 \pm 1.3 \mathrm{~kg} / \mathrm{day}$ of corn ranging from 0.2 to $3.6 \mathrm{~kg} /$ day. As mentioned before, the recommended amount of grain offered to a horse daily is $500 \mathrm{~g} / 100 \mathrm{~kg}$ of liveweight. Thus, the Chilean corralero horse (400 kg liveweight) is expected to consume $2.0 \mathrm{~kg}$ of grains to supply the energy requirements (20-25 Mcal/d DE) according to NRC guidelines [22]. This recommendation comes from the limited ability of the enzymes in the horses' small intestine to digest starch from cereal grains. When grain, which is high in starch, is overfed, part of the carbohydrates mentioned above are incompletely digested and escape absorption in the small intestine, traveling to the large intestine and promoting a disruption in the microbial population, leading to abnormal $\mathrm{pH}$ conditions which compromise intestine health [32]. These alterations may increase the risk of colic, laminitis, and other pathologies.

A characterization of the animal and its routine care was carried out through this study. This information complements all physics hypsometry studies that were done. To reach a better understanding of this breed's nutritional requirements, more data should be taken in situ, such as time dedicated to working in each activity, as well as heart rate, blood metabolites, and other physiological variables.

Chilean legislation for animal welfare only establishes that owners should provide adequate feeding and healthcare to their animals, regardless the animal species. Therefore, the results of this study may provide information which could be considered when creating or enforcing legislation regarding horse care and training.

\section{Conclusions}

The average Chilean corralero horse spends approximately $12 \mathrm{~h}$ daily within a stall, and spends its remaining hours tied, loose in a pen, and/or training. The horse's workload can be classified as moderate to heavy intensity according to the NRC [22], and includes six workouts weekly (walk/trot/canter) with two bumping workouts per week and two competitions per month.

During the training season, the diet of the Chilean corralero horse is based on forages, mainly alfalfa hay, plus oats as an additional energy source. Protein supplements such as oilseed by-products are used less frequently.

Additional studies are required to provide further information on nutritional requirements, feeding management, and exercise in order to improve the raising and management of this breed.

Author Contributions: Conceptualization, J.P.K. and M.G.; data curation, J.B., M.S.-G., and J.P.K.; funding acquisition, F.B. and M.G.; investigation, J.B., J.P.K., and M.G.; methodology, J.P.K. and M.G.; project administration, J.B., J.P.K., and M.G.; resources, F.B.; software, M.S.-G.; supervision, M.G.; validation, M.S.-G.; visualization, M.S.-G. and H.H.W.; writing-original draft, J.B. and M.G.; writing-review and editing, F.B., H.H.W., and J.P.K.

Funding: This research received no external funding. The Animal Sciences Department of the Facultad de Agronomía e Ingeniería Forestal de la Pontificia Universidad Católica de Chile funded minor expenses related to the investigation.

Conflicts of Interest: The authors declare no conflicts of interest.

\section{References}

1. Siegel, M. UC Davis School of Veterinary Medicine Book of Horses: A Complete Medical Reference Guide for Horses and Foals; Harper Collins Publishers: New York, NY, USA, 1996; pp. 3-17.

2. Pérez, R.; García, M.; Cabezas, I.; Guzmán, R.; Merino, V.; Valenzuela, S.; Gonzalez, C. Actividad física y cambios cardiovasculares y bioquímicos del caballo chileno a la competencia de rodeo. Arch. Med. Vet. 1997, 29, 221-234. [CrossRef] 
3. Tadich, T.A.; Araya, O.; Solar, F.; Ansoleaga, N.; Nicol, C.J. Description of the responses of some blood constituents to rodeo exercise in Chilean Creole horses. J. Equine Vet. Sci. 2013, 33, 174-181. [CrossRef]

4. Hendricks, B.L. International Encyclopedia of Horse Breeds; University of Oklahoma Press: Norman, OK, USA, 2007; pp. 121-122.

5. Muñoz, L.; Ortiz, D.; Ortiz, R.; Cabezas, I.; Briones, M. Determination of the back load in horses used for Chilean rodeo and comparison with the estimated back load maximum capacity, in accordance with the Beltrán formula (1954). Arch. Med. Vet. 2012, 44, 285-289. [CrossRef]

6. Arancibia, F.; Molina, E. “Cultura y Tiempo Libre” Informe Anual 2005. Instituto Nacional de Estadística. 2005. Available online: https://www.ine.cl/docs/default-source/sociales/cultura/cultura-y-tiempo-libre-2005. pdf?sfvrsn=6 (accessed on 13 April 2018).

7. Brunner, J.; Liesegang, A.; Weiss, S.; Wichert, B. Feeding practice and influence on selected blood parameters in show jumping horses competing in Switzerland. J. Anim. Physiol. Anim. Nutr. 2015, 99, 684-691. [CrossRef] [PubMed]

8. Frape, D. Equine Nutrition and Feeding, 2nd ed.; Blackwell Science: Oxford, UK, 1998; pp. 300-365.

9. Brunner, J.; Wichert, B.; Burger, D.; von Peinen, K.; Liesegang, A. A survey on the feeding of eventing horses during competition. J. Anim. Physiol. Anim. Nutr. 2012, 96, 878-884. [CrossRef] [PubMed]

10. Leahy, E.B.; Burk, A.O.; Green, E.A.; Williams, C.A. Nutrition-associated problems facing elite level three-day eventing horses. Equine Vet. J. 2010, 42, 370-374. [CrossRef] [PubMed]

11. Carroll, C.L.; Huntington, P.J. Body condition scoring and weight estimation of horses. Equine Vet. J. 1988, 20, 41-45. [CrossRef] [PubMed]

12. McKiernan, B. Estimating a Horse's Weight. Primefact 494. New South Wales Department of Primary Industries, NSW, Australia. 2007. Available online: http://www.dpi.nsw.gov.au/_data/assets/pdf_file/0008/ 109988/estimating-a-horses-weight.pdf (accessed on 1 October 2017).

13. Denhardt, R.M. The Chilean Horse. Agric. Hist. 2010, 24, 161-165.

14. García, M.; Cabezas, I.; Guzmán, R.; Valenzuela, S.; Merino, V.; Pérez, R. Características hipométricas, peso corporal y capacidad de carga del caballo fina sangre chileno en rodeo. Avan. Cs. Vet. 1997, 12, 45-51. [CrossRef]

15. Porte, E. El Nuevo estándar del caballo chileno. Rev. Fed. Rodeo Chil. Asoc. Criads. Cab. Chil. 1978, 30, 16-20.

16. Porte, E. Crecimiento y desarrollo del caballo chileno. Av. Prod. Anim. 2000, 25, 167-174.

17. Harris, P.A. Review of equine feeding and stable management practices in the UK concentrating on the last decade of the 20th century. Equine Vet. J. 1999, 28, 46-54. [CrossRef]

18. Werhahn, H.; Hessel, E.F.; Van den Weghe, H.F.A. Competition Horses Housed in Single Stalls (II): Effects of Free Exercise on the Behavior in the Stable, the Behavior during Training, and the Degree of Stress. J. Equine Vet. Sci. 2012, 32, 22-31. [CrossRef]

19. McGreevy, P.D.; Cripps, P.J.; French, N.P.; Green, L.E.; Nicol, C.J. Management factors associated with stereotypic and redirected behaviour in the thoroughbred horse. Equine Vet. J. 1995, 27, 82-83. [CrossRef]

20. Muñoz, L.; Torres, J.; Sepúlveda, O.; Rehhof, C.; Ortiz, R. Frequency of stereotyped abnormal behaviour in stabled Chilean horses. Arch. Med. Vet. 2009, 41, 73-76.

21. Muñoz, L.; Vidal, F.; Sepúlveda, O.; Ortiz, O.; Rehhof, C. Dental pathologies in incisors, canines and first premolar in adult Chilean horses. Arch. Med. Vet. 2010, 42, 85-90.

22. NRC. Nutrient Requirements of Horses, 6th Revised Edition; National Research Council of the National Academies: Washington, DC, USA, 2007; pp. 22-27.

23. Hintz, H.F.; Cymbaluk, N.F. Nutrition of the horse. Annu. Rev. Nutr. 1994, 14, 243-267. [CrossRef] [PubMed]

24. Keiper, R.R. Behavior: Social structure. Vet. Clin. N. Am. Equine Pract. 1986, 2, 465-483. [CrossRef]

25. Harris, P.; Dunnett, C. Nutritional tips for veterinarians. Equine Vet. Educ. 2018, 30, 486-496. [CrossRef]

26. Reeves, M.J.; Salman, N.D.; Smith, G. Risk factors for equine acute abdominal disease (colic): Results from a multi-center case-control study. Prev. Vet. Med. 1996, 26, 285-301. [CrossRef]

27. Williamson, A.; Rogers, C.W.; Firth, E.C. A survey of feeding, management and faecal pH of Thoroughbred racehorses in the North Island of New Zealand. N. Z. Vet. J. 2007, 55, 337-341. [CrossRef] [PubMed]

28. Owens, E. Sport horse nutrition-An Australian perspective. In Advances in Equine Nutrition III.; Pagan, J., Geor, R.J., Eds.; Nottingham University Press: Nottingham, UK, 2005; pp. 185-192.

29. Rosselot, P.; Mendonça, T.; González, I.; Tadich, T. Behavioral and Physiological Differences between Working Horses and Chilean Rodeo Horses in a Handling Test. Animals 2019, 9, 397. [CrossRef] [PubMed] 
30. Dunnet, C.E. Dietary lipid form and function. In Advances in Equine Nutrition III; Pagan, J.D., Ed.; Nottingham University Press: Thrumpton, UK, 2005; pp. 37-54.

31. White, N.A. Colic prevalence, risk factors and prevention. In Advances in Equine Nutrition IV; Pagan, J.D., Ed.; Nottingham University Press: Thrumpton, UK, 2009; pp. 313-326.

32. Durham, A.E. The role of nutrition in colic. Vet. Clin. N. Am. Equine Pract. 2009, 25, 67-78. [CrossRef] [PubMed]

(C) 2019 by the authors. Licensee MDPI, Basel, Switzerland. This article is an open access article distributed under the terms and conditions of the Creative Commons Attribution (CC BY) license (http://creativecommons.org/licenses/by/4.0/). 


\title{
Effects of Horse Housing System on Energy Balance during Post-Exercise Recovery
}

\author{
Malin Connysson ${ }^{1, *}$, Marie Rhodin ${ }^{2}$ and Anna Jansson ${ }^{2}$ \\ 1 Wången National Center for Education in Trotting, Vången 110, S-835 93 Alsen, Sweden \\ 2 Department of Anatomy, Physiology and Biochemistry, Swedish University of Agricultural Sciences, \\ SE-75007 Uppsala, Sweden; marie.rhodin@slu.se (M.R.); anna.jansson@slu.se (A.R.) \\ * Correspondence: malin.connysson@wangen.se; Tel.: +46-(0)640-17431
}

Received: 29 October 2019; Accepted: 8 November 2019; Published: 14 November 2019

Simple Summary: Horse management aims to keep horses healthy and ensure good performance and animal welfare. Many horses are currently kept in individual box stalls indoors, a housing system that limits free movement, exploration, and social interaction, and may also subject horses to lower air quality. The alternative is a free-range housing system where horses are kept in groups outdoors. Anecdotal information indicates concerns among sports horse trainers that lack of rest in such systems delays recovery and impairs performance. This study examined whether recovery after competition-like exercise in Standardbred trotters was affected by housing system. The results showed that a free-range housing system did not delay recovery in Standardbred trotters, and in fact had positive effects on appetite and recovery of energy balance.

\begin{abstract}
This study examined the effects of two housing systems (free-range and box stalls) on recovery of energy balance after competition-like exercise in Standardbred horses. Eight adult geldings (mean age 11 years) were used. The study had a change-over design, with the box stall (BOX) and free-range group housing (FreeR) treatments each run for 21 days. The horses were fed forage ad libitum and performed two similar race-like exercise tests (ET), on day 7 and day 14 in each treatment. Forage intake was recorded during the last 6-7 days in each period. Blood samples were collected before, during, and until $44 \mathrm{~h}$ after ET. Voluntary forage intake (measured in groups with four horses in each group) was higher in FreeR horses than BOX horses (FreeR: 48, BOX: 39, standard error of the mean (SEM) $1.7 \mathrm{~kg}(p=0.003)$ ). Plasma non-esterified fatty acids (NEFA) was lower at $20-44 \mathrm{~h}$ of recovery than before in FreeR horses $(p=0.022)$, but not in BOX horses. Housing did not affect exercise heart rate, plasma lactate, plasma urea, or total plasma protein concentration. Thus the free-range housing system hastened recovery in Standardbred trotters, contradicting anecdotal claims that it delays recovery. The free-range housing also had positive effects on appetite and recovery of energy balance.
\end{abstract}

Keywords: NEFA; Standardbred trotters; feed intake

\section{Introduction}

Many horses are currently housed in individual box stalls in stables [1-4]. Box stalls facilitate supervision, individual feeding and grooming of the horses, but obviously limit their scope for free movement, exploration and social interaction. An alternative is a modern housing system where horses are kept in groups in paddocks with shelters and lying areas and with individual feeding controlled by transponders. Anecdotal information indicates concerns among sports horse trainers that lack of rest in such systems delays recovery and impairs competition performance. However, unpublished data [5] indicate that picky-eater Standardbred trotters kept in a group housing system have better body condition than when housed in box stalls, indicating better appetite and higher feed intake. 
Environmental factors such as space allowance, group size and feeder characteristics have been shown to affect feed intake in pigs [6]. Little is known about how physical environment affects feed intake in horses. Keeping horses in groups may affect eating; which has been shown to be highly synchronized in group-housed horses $[7,8]$.

In the short term, recovery involves decreasing muscle temperature, compensating for oxygen debt, and regulating acid-base balance. In the longer term, it also involves energy replenishment, fluid balance recovery, and tissue re-synthesis. Energy balance can be monitored by measuring body weight, energy expenditure (using heart rate), body condition score (BCS), and substrate usage (non-esterified fatty acids (NEFA) and urea). NEFA, originating from lipolysis of adipose tissue, have been widely shown to increase in ponies and horses during periods of insufficient energy intake [9-13]. When amino acids are used as energy substrate there is a degradation that starts with deamination, where the amino group is removed and converted into ammonia. Ammonia released by this process is removed from the body by forming urea in the liver.

This study examined whether recovery of energy balance after competition-like exercise in Standardbred horses fed ad libitum was affected by housing system. Two different systems were compared: free-range group housing (FreeR) and an individual box-stall housing system (BOX) in which activity in groups was possible for only $4-5 \mathrm{~h} /$ day. The hypothesis was that free-range housing hastens recovery compared with box stall housing.

\section{Materials and Methods}

Umeå local ethics committee approved the study (A 54-13) and it was performed in compliance with European Union directives on animal experiments (2010/63/EU; European Union, 2010) and with laws (Swedish Constitution, 1988:534) and regulations (Swedish Board of Agriculture Constitution, 2012:26) governing experiments on live animals in Sweden.

\subsection{Horses and Management}

Eight adult Standardbred geldings in training (mean age 11 years, range 9-13 years) were used. The study was performed during May-June 2015 and all horses had raced during the period 2005-2015 and had average earnings of 146,553 SEK (range 26,500-495,798 SEK). Mean bodyweight at the beginning of the trial was $509 \mathrm{~kg}$ (range 410-562 kg). The horses were trained under the supervision of professional trainers (licensed by the Swedish Trotting Association) according to a training program similar to that used by Swedish trotting trainers [14].

\subsection{Experimental Design}

The horses were randomly allocated to two groups of four and kept in the box stall (BOX) or free-range group housing system (FreeR) for 21 days, followed by a complete change-over to the other treatment. Between treatments, the horses had a three-day transition period in the new housing system. All horses performed two similar exercise tests (ET), on day 7 (ET1) and day 14 (ET2) in each treatment period. On days 3,11 , and 18 of each treatment, the horses were exercised on a track (5000 m warm-up, $3000 \mathrm{~m}$ at a speed of $11.1 \mathrm{~m} / \mathrm{s})$.

The horses in treatment BOX were housed individually in $3 \mathrm{~m} \times 3 \mathrm{~m}$ boxes with wood shavings and were let out into a sand paddock $\left(2000 \mathrm{~m}^{2}\right)$ together with the other horses in their group for $4-5 \mathrm{~h}$ every day. In the boxes, the horses had ad libitum access to water in buckets. The horses in treatment FreeR were kept together in a group housing area that consisted of a paved paddock $\left(3200 \mathrm{~m}^{2}\right)$ with a shelter with rubber matting and automatic feeding stations. They were offered water ad libitum in water barrels. 


\subsection{Diet}

In treatment BOX, the horses were fed forage ad libitum in their stall, but no feed was offered during the paddock stay. Feed was offered four times per day $(07.00,12.30,17.00$, and $20.00 \mathrm{~h})$ and there had to be left-overs at every meal to provide ad libitum access.

In treatment FreeR, the horses were fed from automatic feeding stations that recognized the individuals by transponders. With this technique, feed allowance was regulated by time and all horses had access to the feeding station for more time than they used it (free access). All horses but one had $400 \mathrm{~min}$ eating time/day, while in one horse the access was $500 \mathrm{~min} /$ day to ensure free access.

The same forage was used in both housing systems, a haylage (dry matter (DM) 78\%, 11.2 MJ metabolizable energy (ME)/kg DM, 14.3\% crude protein (CP), calcium (Ca) $5.6 \mathrm{~g} / \mathrm{kg} \mathrm{DM}$, phosphorus (P) $2.2 \mathrm{~g} / \mathrm{kg} \mathrm{DM}$, and magnesium $(\mathrm{Mg}) 1.7 \mathrm{~g} / \mathrm{kg} \mathrm{DM})$. The horses were also given $0.5 \mathrm{~kg}$ concentrate (Krafft Sport, Malmö, Sweden (12 MJ ME/kg, 11\% CP)) and $80 \mathrm{~g}$ mineral and vitamin supplement (Krafft Miner Vit, Malmö, Sweden) (Ca 55 g/kg, P 65 g/kg, Mg 60 g/kg, salt (NaCl) 125 g/kg, copper (Cu) $900 \mathrm{mg} / \mathrm{kg}$, selenium (Se) $15 \mathrm{mg} / \mathrm{kg}$, vitamin A 100,000 IU/kg, vitamin D3 10,000 IU/kg, and vitamin E $5000 \mathrm{mg} / \mathrm{kg}$ ) every day. In the BOX system this was fed once a day, while in FreeR the automatic feed station divided the total allowance equally between every hour of the day.

The horses were offered ad libitum access to salt blocks during the whole study and they also had extra salt mixed with beet pulp after the exercise on days 3, 11, and 18 ( $250 \mathrm{~g}$ beet pulp and $20 \mathrm{~g} \mathrm{NaCl}$ ).

\subsection{Exercise Test}

On the day of the exercise test (ET), the horses were transported $50 \mathrm{~km}$ to an official 1000-m oval, banked, gravel racetrack (Östersunds race track, Sweden). The horses performed the ET in groups of four, two from each treatment. The same driver drove the same horse in a harness race sulky on all test occasions and the horses raced in the same group at the same time on all occasions. The ET started with a warm-up consisting of $4000 \mathrm{~m}$ slow trot $(6.3-6.7 \mathrm{~m} / \mathrm{s})$ and $500 \mathrm{~m}$ trot $(10 \mathrm{~m} / \mathrm{s})$. After the warm-up, the horses walked the track for $10 \mathrm{~min}$. They then trotted $2140 \mathrm{~m}$ in the same race field position, at 11.8-12.2 m/s for the first $1640 \mathrm{~m}$ and as fast as they could (free positioning) for the last $500 \mathrm{~m}$. This was followed by a cool-down of $1000 \mathrm{~m}$ slow trot $(6.3-6.7 \mathrm{~m} / \mathrm{s})$. Approximately one hour after crossing the finish line in the ET, the horses were transported back home, and three hours after the ET they were put back into their housing system.

\subsection{Measurements, Sampling, and Analysis}

The horses were weighed on a scale (Tru-test E2000S2, Auckland, New Zealand) every morning. Body weight measurements on the day before ET day and on the morning of ET day were used as "Rest" values for bodyweight. Rectal temperature was measured every day, at $07.00 \mathrm{~h}$. Before and after each experimental period, the body condition score (BCS) of all horses was evaluated as specified by Henneke et al. [15]. During days 15-22 (in period 1) and days 14-19 (in period 2), forage intake was measured by weighing the allowance and left-overs. In treatment FreeR, the horses were fed forage from two feeding stations (four feeding places) and intake had to be measured for the whole group. Mean ambient temperature on ET days and the three following days was $8.4{ }^{\circ} \mathrm{C}$ (range $1.3-9.8^{\circ} \mathrm{C}$ ).

During ET days, blood samples were collected via a catheter inserted in vena jugularis after local cutaneous anesthesia (Tapin (lidocaine $25 \mathrm{mg} / \mathrm{g}$, prilocaine $25 \mathrm{mg} / \mathrm{g}$ ), Orifarm Generics, Stockholm, Sweden). The catheter was inserted approximately one hour before the first blood sampling. Blood samples were collected in 6-mL lithium-heparinized tubes (102 IU) and kept on ice until centrifuging $\left(10 \mathrm{~min}, 920 \times \mathrm{g}, 18^{\circ} \mathrm{C}\right)$, after which the plasma was frozen $\left(-20^{\circ} \mathrm{C}\right)$. Blood samples were collected at rest in the stable (Rest), at the racetrack 1 min after the finish line (FL) and after 10, 180, 240, 300, 360, and $420 \mathrm{~min}$ of recovery. At 20 and $44 \mathrm{~h}$ after the ET, blood samples were collected by venipuncture from the jugular vein. 
Total plasma protein concentration (TPP) was measured in all plasma samples using a handheld refractometer (Atago, Tokyo, Japan). Plasma lactate concentration was analyzed in samples Rest, FL and after 10, 180, and $420 \mathrm{~min}$ of recovery, using an enzymatic (L-lactate dehydrogenase and glutamate-pyruvate transaminase) and spectrophotometric method (Boehringer Mannheim/R-Biopharm, Darmstadt, Germany), with intraassay coefficient of variation (CV) $2.2 \%$ in this study. Plasma NEFA concentration was analyzed in samples taken at Rest, FL, and after 10, 180, 240, and $420 \mathrm{~min}$ of recovery and also after 20 and $44 \mathrm{~h}$, by quantitative determination using an enzymatic colorimetric method (Wako Chemicals GmbH, Neuss, Germany), with intraassay CV $1.8 \%$ in this study. Plasma urea concentration was analyzed with a spectrophotometric method (Urea Assay Kit, Cell Biolabs Inc., San Diego, CA, USA), with intraassay CV 1.3\% in this study.

Heart rate was continuously recorded during the race and up to $420 \mathrm{~min}$ of recovery using a heart rate recorder (Polar CS600X Polar Electro, Kempele, Finland) and the data were analyzed using Polar ProTrainer 5 Equine Edition Software (Polar Electro, Kempele, Finland). Mean recovery heart rate was calculated using recordings from $270-410 \mathrm{~min}$ of recovery.

\subsection{Statistical Analysis}

Analysis of variance was performed with the MIXED procedure in SAS (version 9.4; SAS Institute Inc., Cary, NC, USA), using an autoregressive (AR(1)) structure. Plasma sample results were pooled into recovery 3-7 h (180-420 $\mathrm{min})$, and recovery 20-44 h (22 h and $44 \mathrm{~h})$. Statistical analysis was performed with a statistical model including fixed effects of housing, sample, and the interaction between them. The model for an observed variable of horse i in housing j, sample k, was:

$$
Y_{i j k}=\mu+\eta_{i}+\pi_{j}+\gamma_{k}+(\pi \gamma)_{i k}+e_{i j k}
$$

where $\mu$ is the overall mean, $\eta_{i}$ is the effect of horse, $\pi_{j}$ is the effect of housing, $\gamma_{k}$ is the effect of sample, $(\pi \gamma)_{\mathrm{ik}}$ is the effect of the interaction between housing and sample, and $\mathrm{e}_{\mathrm{ijk}}$ is the random error. The random part included horse, horse $\times$ housing, and period. Observations within each horse $\times$ period $\times$ housing combination were modeled as repeated measurements. For urea, race had a significant effect and was included in the model.

Forage intake, bodyweight, BCS, heart rate, and velocity data were analyzed by a statistical model including fixed effects (housing, period, and the interaction between housing and period). The model for an observed variable of horse i in period $\mathrm{j}$, in housing $\mathrm{k}$ was:

$$
Y_{i j k}=\mu+\eta_{i}+\pi_{j}+\gamma_{k}+(\pi \gamma)_{i k}+e_{i j k}
$$

where $\mu$ is the overall mean, $\eta_{i}$ is the effect of horse, $\pi_{j}$ is the effect of housing, $\gamma_{k}$ is the effect of sample, $(\pi \gamma)_{\mathrm{ik}}$ is the effect of the interaction between housing and sample, and $\mathrm{e}_{\mathrm{ijk}}$ is the random error. The random part included horse and horse $\times$ housing. Observations within each horse were modeled as repeated measurements.

Post-hoc comparisons were adjusted for multiplicity using the Bonferroni method. Values are presented as least square means (LSM) with the standard error of the mean (SEM) in a parenthesis. Differences were considered statistically significant at $p<0.05$.

\section{Results}

One of the horses was excluded due to a hoof crack, although it showed no clinical signs of pain. Training and ET were still performed with that horse and it was included in feed intake measurements, since these were done by group. Group forage intake was higher in treatment FreeR than treatment BOX (FreeR: 48 (1.7), BOX: 39 (1.7) kg ( $p=0.003)$ ) and the mean bodyweight during the whole treatment periods (21 days) tended to be higher in FreeR horses than in BOX horses (FreeR: 505 (13), BOX: 500 (13) $\mathrm{kg}(p=0.07))$. There was no difference in BCS between the housing systems (FreeR: $4.8(0.4)$, BOX: $4.7(0.4)(p=0.93))$. 


\subsection{Rest}

Body weight was higher in FreeR horses than BOX horses at Rest (morning day before ET + morning before ET) (Table 1). Housing did not affect plasma NEFA, urea, or TPP concentration on the morning before ET (Tables 1 and 2).

Table 1. Body weight and total plasma protein in Standardbred horses kept in free-range group housing (FreeR) or box housing (BOX). SEM = standard error of the mean.

\begin{tabular}{ccccccc}
\hline Variable & Sample & FreeR & SEM & BOX & SEM & $p$-Value \\
\hline Body weight $(\mathrm{kg})$ & Rest & 509 & 13 & 504 & 13 & 0.038 \\
& 20-44 h recovery & $504^{\mathrm{a}}$ & 13 & $498^{\mathrm{a}}$ & 13 & 0.020 \\
\hline Total plasma protein $(\mathrm{g} / \mathrm{L})$ & & & & & \\
& Rest & 59.5 & 0.8 & 60.4 & 0.8 & 0.996 \\
& Finish line & $73.5^{\mathrm{a}}$ & 0.8 & $74.3^{\mathrm{a}}$ & 0.8 & 1.000 \\
& 10 min recovery & $67.0^{\mathrm{a}}$ & 0.8 & $67.4^{\mathrm{a}}$ & 0.8 & 1.000 \\
& 3-7 h recovery & 61.0 & 0.8 & $62.3^{\mathrm{a}}$ & 0.8 & 0.405 \\
& 20-44 h recovery & $61.8^{\mathrm{a}}$ & 0.8 & $62.6^{\mathrm{a}}$ & 0.8 & 1.000 \\
\hline
\end{tabular}

a Significantly different $(p<0.05)$ from Rest.

Table 2. Plasma concentrations of non-esterified fatty acids (NEFA), urea and lactate in Standardbred horses kept in free-range group housing (FreeR) or box housing (BOX). SEM = standard error of the mean.

\begin{tabular}{ccccccc}
\hline Variable & Sample & FreeR & SEM & BOX & SEM & $p$-Value \\
\hline Plasma NEFA (mmol/L) & Rest & 0.26 & 0.04 & 0.21 & 0.04 & 1.000 \\
& Finish line & 0.33 & 0.04 & $0.34^{\text {a }}$ & 0.04 & 1.000 \\
& 10 min recovery & $0.54^{\text {a }}$ & 0.04 & $0.55^{\text {a }}$ & 0.04 & 1.000 \\
& 3-7 h recovery & 0.24 & 0.04 & 0.22 & 0.04 & 1.000 \\
& 20-44 h recovery & $0.16^{\text {a }}$ & 0.04 & 0.25 & 0.04 & 0.019 \\
\hline Plasma urea $(\mathrm{mmol} / \mathrm{L})$ & Rest & 5.0 & 0.3 & 4.6 & 0.3 & 0.481 \\
& Finish line & 5.1 & 0.3 & $4.9^{\mathrm{b}}$ & 0.3 & 1.000 \\
& 10 min recovery & 5.2 & 0.3 & $4.9^{\mathrm{a}}$ & 0.3 & 0.818 \\
& 3-7 h recovery & $5.6^{\mathrm{a}}$ & 0.3 & $5.3^{\mathrm{a}}$ & 0.3 & 0.718 \\
& 20-44 h recovery & 4.8 & 0.3 & 4.7 & 0.3 & 1.000 \\
\hline Plasma lactate $(\mathrm{mmol} / \mathrm{L})$ & Rest & 0.9 & 0.8 & 1.3 & 0.8 & 1.000 \\
& Finish line & $20.8^{\mathrm{a}}$ & 0.8 & $20.6^{\mathrm{a}}$ & 0.8 & 1.000 \\
& 10 min recovery & $16.0^{\mathrm{a}}$ & 0.8 & $16.0^{\mathrm{a}}$ & 0.8 & 1.000 \\
& 3-7 h recovery & 1.0 & 0.7 & 1.1 & 0.7 & 1.000 \\
\hline
\end{tabular}

${ }^{a}$ Significantly different $(p<0.05)$ from Rest. ${ }^{\mathrm{b}}$ Tendency for significant difference $(p \leq 0.09)$ from Rest.

\subsection{Finish Line and 10 min Recovery}

Housing system did not affect peak heart rate (FreeR: 224 (2), BOX: 221 (2) beats/min), plasma lactate concentration (Table 2), or velocity during the simulated race (FreeR: $12.0(0.1)$, BOX: $12.0(0.1) \mathrm{m} / \mathrm{s}$ ).

Plasma lactate concentrations and TPP were higher than Rest values at the finish line and after 10 min of recovery during both FreeR and BOX (Tables 1 and 2). Plasma NEFA concentrations were higher than Rest values at 10 min of recovery during both FreeR and BOX, and for BOX treatment also at the finish line (Table 2). Plasma urea concentrations were higher than Rest values at the finish line (tendency $p=0.071$ ) and after 10 min of recovery during BOX treatment (Table 2). There was no effect 
of FreeR compared with BOX on plasma NEFA, urea, or TPP concentration at finish line or after 10 min of recovery (Tables 1 and 2).

\subsection{Short-Term Recovery (3-7 h)}

As mentioned, heart rate, plasma lactate, NEFA, urea, and TPP concentrations all increased from rest to race, and therefore recovery was necessary. There was a tendency during 3-7 h recovery for higher heart rate in FreeR horses compared with BOX horses (47 (1) vs. 43 (2) beats/min; $p=0.100$ ) (Figure 1). The different housing systems did not significantly affect plasma lactate, plasma NEFA, urea, or TPP concentration during 3-7 h recovery (Tables 1 and 2). During short-term recovery, plasma urea concentrations were greater than the Rest values (Table 2). During short-term recovery, TPP were higher than the Rest values during BOX housing (Table 1).

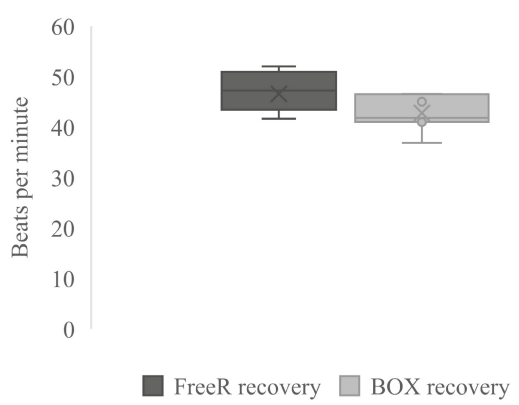

Figure 1. Box-plot of 3-7 h recovery heart rates in Standardbred horses kept in free-range group housing (FreeR) or box housing (BOX).

\subsection{Long-Term Recovery (20-44h)}

Body weight did not return to the Rest values during long-term recovery (Table 1). Plasma NEFA returned to the Rest value during 20-44 h of recovery in BOX horses, while in FreeR horses it not only returned to the Rest value but fell below it (Table 2). Plasma NEFA was lower in FreeR horses than in BOX horses during 20-44 h of recovery (Table 2) and bodyweight was higher in FreeR horses than in BOX horses during this period (Table 1). Housing system had no significant effect on plasma urea or TPP concentration during 20-44 h of recovery (Tables 1 and 2). Plasma TPP concentration during 20-44 h of recovery was significantly higher than the Rest value (Table 1).

\section{Discussion}

In this study, there was little or no difference in short-term (3-7 h) metabolic recovery in horses kept in the free-range and box stall housing systems evaluated. In fact, the results indicated that in the long-term perspective, the free-range system may be beneficial. The lack of differences in NEFA, urea, and TPP responses during short-term recovery indicates that water and feed intake were similar in the two housing systems during the first hours after ET. During long-term recovery, the NEFA levels were very low in FreeR horses, even lower than before the ET. This indicates quick and efficient recovery of energy balance by horses in this housing system, an indication supported by the higher daily feed consumption observed in the FreeR housing system. The hormone insulin plays an important role in regulating lipolysis in adipose tissue, as increased insulin concentration results in decreased lipolysis and thereby decreased release of NEFA. An increased insulin response in FreeR (due to higher feed intake) may have lowered the NEFA response but the response may also have been influenced by different feeding intervals in the housing systems. Low post-exercise appetite has been observed in athletic horses (box-housed) and is suggested to be associated with the hormone's active ghrelin, adiponectin, and leptin, and/or gastric ulcers [16,17]. Low BCS and periods of low appetite are conditions seen in some horses during periods of intense training and racing, and our results indicate 
that a group housing system might counteract these problems. Our findings indicate that physical environment is important for feed intake in horses, as reported earlier for pigs [6]. The lower feed intake in box-housed horses could have been due to the daily $4-5 \mathrm{~h}$ without feed in the paddock, but that is close to the time span without eating observed in wild-living horses and was probably compensated for by increased feed intake. Compensatory increases in feed consumption after a period of feed restriction have been reported in ponies [18].

Although plasma NEFA concentrations indicated that energy balance was restored in the horses, bodyweight was still not back to resting values at $44 \mathrm{~h}$ of recovery. In French Trotters, the post racing decrease in bodyweight is reported to be on average $9.4 \mathrm{~kg}$ (range $0-26 \mathrm{~kg}$ ) and bodyweight requires on average 3.3 days to recover [19]. An exercise-induced decrease in body weight also seems to be affected by whether the horses are transported [20]. It has been suggested that sweat losses are responsible for $90 \%$ of post-exercise weight losses [21], which are therefore not affected by energy balance but by water and electrolyte intake. Since total plasma protein concentrations remained elevated from resting values at the end of the study period, it is likely that the horses did not recover fluid balance within $44 \mathrm{~h}$. The salt intake in the present study might have been too low to compensate for losses, since salt blocks have been shown to be an inadequate sole source of salt for athletic horses [22] and the extra salt offered $(20 \mathrm{~g})$ to the horses on the day after ET might not have been sufficient.

There were no differences in plasma lactate responses between the housing systems, which was probably due to events in the immediate recovery period after exercise (i.e., $1000 \mathrm{~m}$ slow-down trot, walk, and road transport back home) being the same in both treatments. It has been shown previously that, during the first $30 \mathrm{~min}$ after intense exercise, lactate removal can be increased two-fold by light exercise [23]. Interestingly, there was no significant difference in HR between the housing treatments during short-term recovery indicating that energy expenditure was similar in this period [24]. In both systems, HR seemed to be slightly higher than earlier observed [25] in box-stalled Standardbred horses at night (36-40 bpm vs. 43-47 bpm in our study). We expected HR to be higher when horses were kept in group housing compared to box housing, due to more physical activity (walking around). Earlier studies have shown that physical activity in stabled or partly stabled horses is lower than in horses housed in free-range systems [26]. In addition, keeping horses in groups in paddocks seems to increase physical activity compared with keeping them in individual paddocks [27]. In BOX horses, an elevation of $\mathrm{HR}$ from expected levels at rest is difficult to explain and accordingly also the lack of difference in HR between treatments. One possible reason for the lack of difference in HR is because HR was elevated in BOX horses due to horses being more alert, excited, or stressed in this system (by people and horses moving around in the stable). This assumption contradicts anecdotal claims that horses kept in a free-range group housing system are less relaxed than stabled horses.

\section{Conclusions}

This study found that a free-range housing system hastened recovery in Standardbred trotters, rather than delaying it as suggested by anecdotal claims. The free-range housing system also had positive effects on appetite and recovery of energy balance.

Author Contributions: Conceptualization, M.C. and A.J.; data curation, M.C., M.R., and A.J.; formal analysis, M.C. and M.R.; funding acquisition, A.J.; investigation, M.C.; methodology, M.C. and A.J.; project administration, M.C.; resources, M.C. and A.J.; supervision, M.R. and A.J.; validation, M.C., M.R., and A.J.; writing-original draft, M.C., M.R., and A.J.; writing-review and editing, M.C., M.R., and A.J.

Funding: This research was funded by the Swedish-Norwegian Foundation for Equine Research (Stiftelsen Hästforskning) grant number H-16-47-194 and HIT (Hinrichs Innovation and Technology) Active Stable. Horses and facilities were provided by Wången National Centre for Education in Trotting.

Acknowledgments: Thanks also to Ulf Hedenström, Lars-Åke Svärdfeldt, Sara Sandqvist, Emma Folkesson, and the students at Wången for assistance during the study.

Conflicts of Interest: The authors declare no conflict of interest. The funders had no role in the design of the study; in the collection, analyses, or interpretation of data; in the writing of the manuscript; or in the decision to publish the results. 


\section{References}

1. Bachmann, I.; Stauffacher, M. Haltung und nutzung von pferden in der schweiz: Eine repräsentative erfassung des status quo. Schweizer Archiv für Tierheilkunde 2002, 144, 331-347. [CrossRef] [PubMed]

2. Petersen, S.; Tolle, K.H.; Blobel, K.; Grabner, A.; Krieter, J. Evaluation of horse keeping in Schleswig-Holstein. Züchtungskunde 2006, 78, 207-217.

3. Henderson, A.J.Z. Don't fence me in: Managing psychological well being for elite performance horses. J. Appl. Anim. Welf. Sci. 2007, 10, 309-329. [CrossRef] [PubMed]

4. Hotchkiss, J.W.; Reid, S.W.J.; Christley, R.M. A survey of horse owners in Great Britain regarding horses in their care. Part 1: Horse demographic characteristics and management. Equine Vet. J. 2007, 39, $294-300$. [CrossRef] [PubMed]

5. Connysson, M. (Wången National Center for Education in Trotting, Alsen, Sweden). Personal communication, 2017.

6. Li, Q.; Patience, J.F. Factors involved in the regulation of feed and energy intake of pigs. Anim. Feed Sci. Technol. 2017, 233, 22-33. [CrossRef]

7. Nicol, C.J.; Badnell-Waters, A.J.; Bice, R.; Kelland, A.; Wilson, A.D.; Harris, P.A. The effects of diet and weaning method on the behaviour of young horses. Appl. Anim. Behav. Sci. 2005, 95, 205-221. [CrossRef]

8. Sweeting, M.P.; Houpt, C.E.; Houpt, K.A. Social facilitation of feeding and time budgets in stabled ponies. J. Anim. Sci. 1985, 60, 369-374. [CrossRef] [PubMed]

9. Baetz, A.L.; Pearson, J.E. Blood constituent changes in fasted ponies. Am. J. Vet. Res. 1972, 33, 1941-1946. [PubMed]

10. Rose, R.J.; Sampson, D. Changes in certain metabolic parameters in horses associated with food deprivation and endurance exercise. Res. Vet. Sci. 1982, 32, 198-202. [CrossRef]

11. Sticker, L.S.; Thompson, D.L.; Fernandez, J.M.; Bunting, L.D.; DePew, C.L. Dietary protein and(or) energy restriction in mares: Plasma growth hormone, IGF-I, prolactin, cortisol, and thyroid hormone responses to feeding, glucose, and epinephrine. J. Anim. Sci. 1995, 73, 1424-1432. [CrossRef] [PubMed]

12. Christensen, R.A.; Malinowski, K.; Massenzio, A.M.; Hafs, H.D.; Scanes, C.G. Acute effects of short-term feed deprivation and refeeding on circulating concentrations of metabolites, insulin-like growth factor i, insulin-like growth factor binding proteins, somatotropin, and thyroid hormones in adult geldings. J. Anim. Sci. 1997, 75, 1351-1358. [CrossRef] [PubMed]

13. Connysson, M.; Essén-Gustavsson, B.; Lindberg, J.E.; Jansson, A. Effects of feed deprivation on standardbred horses fed a forage-only diet and a 50:50 forage-oats diet. Equine Vet. J. 2010, 42, 335-340. [CrossRef] [PubMed]

14. Ringmark, S. A Forage-Only Diet and Reduced High Intensity Training Distance in Standardbred Horses. Ph.D Thesis, Swedish University of Agricultural Sciences, Uppsala, Sweden, 2014.

15. Henneke, D.R.; Potter, G.D.; Kreider, J.L.; Yeates, B.F. Relationship between condition score, physical measurements and body fat percentage in mares. Equine Vet. J. 1983, 15, 371-372. [CrossRef] [PubMed]

16. Gordon, M.E.; McKeever, K.H.; Bokman, S.; Betros, C.L.; Manso-Filho, H.; Liburt, N.; Streltsova, J. Interval exercise alters feed intake as well as leptin and ghrelin concentrations in standardbred mares. Equine Vet. J. 2006, 38, 596-605. [CrossRef] [PubMed]

17. Gordon, M.E.; McKeever, K.H.; Betros, C.L.; Manso Filho, H.C. Plasma leptin, ghrelin and adiponectin concentrations in young fit racehorses versus mature unfit standardbreds. Vet. J. 2007, 173, 91-100. [CrossRef] [PubMed]

18. Glunk, E.C.; Pratt-Phillips, S.E.; Siciliano, P.D. Effect of restricted pasture access on pasture dry matter intake rate, dietary energy intake, and fecal $\mathrm{pH}$ in horses. J. Equine Vet. Sci. 2013, 33, 421-426. [CrossRef]

19. Leleu, C.; Miot, M.; Rallet, N. Mailliot Pivan Race-induced weight loss and its recovery time in Trotters: Factors of variation. In Proceedings of the 10th International Conference on Equine Exercise Physiology, Lorne, Australia, 12-16 November 2018.

20. Connysson, M.; Muhonen, S.; Jansson, A. Road transport and diet affect metabolic response to exercise in horses. J. Anim. Sci. 2017, 95, 4869-4879. [CrossRef] [PubMed]

21. Carlson, G.P. Haematology and body fluids in the equine athlete: A review. In Equine Exercise Physiology, 2 ed.; Gillespie, J.R., Robinson, N.E., Eds.; ICEEP Publications: Davis, CA, USA, 1987; pp. 393-425.

22. Jansson, A.; Dahlborn, A. Effects of feeding frequency and voluntary salt intake on fluid and electrolyte regulation in athletic horses. J. Appl. Phys. 1999, 86, 1610-1616. [CrossRef] [PubMed] 
23. Marlin, D.J.; Harris, R.C.; Harman, J.C.; Snow, D.H. Influence of post-exercise activity on rates of muscle and blood lactate disappearance in the Thoroughbred horse. In Equine Exercise Physiology, 2 ed.; Gillespie, J.R., Robinson, N.E., Eds.; ICEEP Publications: Davis, CA, USA, 1987; pp. 686-700.

24. NRC. Nutrient Requirements of Horses, 6th ed.; The National Academies Press: Washington, DC, USA, 2007; p. 24.

25. Ringmark, S.; Lindholm, A.; Hedenström, U.; Lindinger, M.; Dahlborn, K.; Kvart, C.; Jansson, A. Reduced high intensity training distance had no effect on VLa4 but attenuated heart rate response in 2-3-year-old Standardbred horses. Acta Vet. Scand. 2015, 57, 17-30. [CrossRef] [PubMed]

26. Chaplin, S.J.; Gretgrix, L. Effect of housing conditions on activity and lying behaviour of horses. Animal 2010, 4, 792-795. [CrossRef] [PubMed]

27. Jørgensen, G.H.M.; Bøe, K.E. Individual paddocks versus social enclosure for horses. In Horse Behavior and Welfare; European Federation of Animal Science No. 122; Wageningen Academic Publishers: Wageningen, The Netherlands, 2007.

(C) 2019 by the authors. Licensee MDPI, Basel, Switzerland. This article is an open access article distributed under the terms and conditions of the Creative Commons Attribution (CC BY) license (http://creativecommons.org/licenses/by/4.0/). 
Article

\title{
Impact of Year-Round Grazing by Horses on Pasture Nutrient Dynamics and the Correlation with Pasture Nutrient Content and Fecal Nutrient Composition
}

\author{
Sara Ringmark ${ }^{1, *}$, Anna Skarin ${ }^{2}$ and Anna Jansson ${ }^{1}$ \\ 1 Department of Anatomy, Physiology and Biochemistry, Swedish University of Agricultural Sciences, \\ SE-75007 Uppsala, Sweden \\ 2 Department of Animal Nutrition and Management, Swedish University of Agricultural Sciences, \\ SE-75007 Uppsala, Sweden \\ * Correspondence: sara.ringmark@slu.se; Tel.: +46-18-671422
}

Received: 26 June 2019; Accepted: 19 July 2019; Published: 29 July 2019

Simple Summary: Horse grazing may benefit biodiversity. This study compared the effect of horses grazing year-round to that of mowing on pasture quality in a forest-grassland landscape in Sweden. Twelve Gotlandsruss stallions were kept in three enclosures ( $\sim .35$ horse/hectare) without supplementary feeding for 2.5 years. Each enclosure contained three exclosures where pasture was not grazed, but mown monthly. Horse grazing increased the diversity of pasture nutrient content. Moreover, energy and protein concentrations and grass availability increased in areas grazed by horses, but decreased where grass was mown. This indicates that year-round grazing can be used to increase biodiversity, a suggestion supported by botanical observations. Nutrient content in horses' droppings was found to correlate with nutrient content in pasture, so analysis of droppings may be used to roughly estimate the quality of pasture consumed by horses. Under the conditions studied, pasture protein content was sufficient to meet horse requirements year-round, while energy content and pasture availability may have been limited in winter. Monthly data presented here on the nutritive value of pasture can help guide the management of year-round grazing systems in the Nordic countries.

\begin{abstract}
Horse grazing may benefit biodiversity, but the impact of year-round grazing on nutrient dynamics has not been evaluated previously. This study compared pasture quality in a forest-grassland landscape grazed year-round by horses with that in exclosed mown areas. Twelve Gotlandsruss stallions were kept without supplementary feeding in three enclosures $(\sim 0.35$ horse/ha) outside Uppsala, Sweden, from May 2014 to September 2016. Each enclosure contained three mown exclosures, where grass sward samples were collected monthly and analyzed for chemical composition and vegetation density. Fecal grab samples were collected and analyzed for crude protein $(\mathrm{CP})$ and organic matter $(\mathrm{OM})$ content. There were no differences in exclosure pasture energy or $\mathrm{CP}$ content between enclosures $(p>0.05)$. In grazed areas, there were differences in grass energy and $\mathrm{CP}$ content $(p>0.05)$ between enclosures. During the three summers studied, energy and CP content increased in the enclosures, but decreased in the exclosures. By the end, biomass content/ha was greater in the enclosures than in the exclosures. Fecal $\mathrm{OM}$ and $\mathrm{CP}$ content showed moderate to strong correlations with pasture nutrient content $(r=0.3-0.8, p<0.05)$. Thus, in contrast to monthly mowing, horse grazing diversified pasture chemical composition and increased its nutritive value.
\end{abstract}

Keywords: pasture; horse nutrition; crude protein; exclosures 


\section{Introduction}

Year-round grazing by cattle, sheep, and horses is common in many European countries, but not in Sweden. To our knowledge, the effects on pasture quality and quantity of keeping horses year-round on extensive grazing have not been evaluated previously in the Scandinavian countries. Reasons for this might include the comparatively short growing season, the need for shelter to meet animal welfare legislation, and expected low nutrient content of pasture during winter. Lack of validated methods for monitoring horse nutrient intake on pasture may be another reason. However, studies in Germany have shown that the nutrient content of pastures grazed year-round can meet or exceed the requirements of adult cattle and horses, even in winter [1]. In contrast, a study on year-round grazing horses in France indicated that crude protein intake was very low six months per year, and that adult maintenance requirement was met only in April-September [2]. This estimation was based on fecal analyses of crude protein and an observed positive correlation between dietary and fecal crude content. The use of fecal crude protein analysis to monitor pasture crude protein content and intake needs, however, to be further validated.

Year-round grazing systems may have the potential to reduce feed costs, but may also support horses' natural behaviors and contribute to increased biological diversity. Abandonment of natural and semi-natural grasslands and forest encroachment, induced by lack of large herbivores in open landscapes, has caused loss of flora and fauna biodiversity in Sweden [3]. Studies in European countries, including Sweden, indicate that grazing horses can be used instead of cattle and sheep to promote biological diversity [4-9]. Horses remove more vegetation per unit body mass than cattle [10], create mosaic patches of short and tall grass, and leave more broad-leaved plants than cattle [10]. Horses prefer grasses [2], but their intake of forbs and shrubs may increase during periods of intense grazing in winter and spring [11,12], and they may also perform bark-stripping [13]. Use of horses in a year-round grazing system could therefore have great impacts on the landscape and biological diversity [14].

The overall aim of this study was to describe the seasonal and land-to-land variation in pasture quality in a Swedish forest-grassland landscape grazed year-round by horses, and compare it with that in adjacent exclosure areas mown monthly. A second aim was to investigate fecal sampling as a measure of pasture quality. The results are discussed in relation to whether the fodder quality was acceptable to meet energy and protein requirements in horses, and to the possible impact on pasture diversification. The hypotheses tested were that pasture energy and protein content can meet animal requirements but with differences between land areas; that horse grazing alters pasture energy and nutrient composition compared with mowing; and that fecal crude protein $(\mathrm{CP})$ content is correlated with pasture nutrient concentration.

\section{Materials and Methods}

The study was carried out between May 2014 and September 2016 in Krusenberg, Uppsala, Sweden $\left(59^{\circ} 44^{\prime} 8^{\prime \prime} \mathrm{N}, 17^{\circ} 38^{\prime} 58^{\prime \prime} \mathrm{E}\right)$. During the 15 years preceding the study, mean daily temperature April-October was $12.4 \pm 5.0^{\circ} \mathrm{C}( \pm \mathrm{SD})$ and mean precipitation was $1.7 \pm 4.3 \mathrm{~mm} /$ day, while in November-March the values were $-0.6 \pm 5.4{ }^{\circ} \mathrm{C}$ and $1.4 \pm 2.7 \mathrm{~mm} /$ day, respectively (Swedish Meteorological and Hydrological Institute (SMHI) weather station Uppsala Aut, https://www.smhi.se/klimatdata).

In our study, the summer was defined to start after the first four consecutive days with mean temperature $>+5^{\circ} \mathrm{C}$ in spring and to end after the first four days with $<+5{ }^{\circ} \mathrm{C}$ in fall, which defined the start of winter. Based on this definition, the summer season started on 11 April 2015 and on 30 March 2016, while the winter season started on 9 November 2014 and on 10 October 2015. The study was approved by Uppsala animal welfare ethics committee (license number: C28/14). Data on daily temperature and monthly precipitation during the study period were retrieved from the Department of Earth Sciences, Uppsala University, Sweden (www.geo.uu.se). 


\subsection{Horses and Management}

Twelve one-year old Gotlandsruss stallions (mean body weight $185 \pm 21 \mathrm{~kg}$ at the start) from six different breeders were used in the study. Gotlandsruss is a native Swedish horse breed that has been present on the island of Gotland from at least the seventeenth century [15] and probably the thirteenth century. The horses were divided into three groups of four and allocated to three enclosures at the start of the experiment on 21 May 2014. The horses were kept without supplementary feeding throughout the study. To avoid the grazing preferences of an individual horse or group affecting pasture composition, the groups were rotated between the enclosures on 27 May 2015 and 20 May 2016, i.e., each group grazed each enclosure for one growing season. In January 2016, one individual was excluded from the study due to an injury. Each enclosure contained a $16 \mathrm{~m}^{2}$ shelter (Figure 1). Water was offered in automatic water troughs, located in the forest, during summer, spring, and fall. During winter, when the temperature was below $0{ }^{\circ} \mathrm{C}$, water was offered once/day in plastic troughs. In all enclosures, water was also available in streams in the forest, even during winter. A salt block with trace minerals (May 2014-August 2014: Ab Hansson \& Möhring, Halmstad, Sweden, content (mg/kg): Zinc 300, manganese 200, copper 80, iodine 50, selenium 20, cobalt 12; August 2014-September 2016: Standard, KNC, Netherlands, content (mg/kg): Zinc 810, copper 220, iodine 100, selenium 20) was provided in all enclosures. Horses were dewormed five times during the study period, using Banminth (Pyrantel, Zoetis Finland Oy, Helsinki, Finland), Equimax (Ivermectin and Praziquantel, Sofarimex Indústria Química e Farmacêutica Ltd., Cacém, Portugal), or Cydectin (Moxidectin, Zoetis Manufacturing \& Research Spain, Gerona, Spain). Once per month, fresh grab sample (approximately $300 \mathrm{~g}$ ) of faces were collected immediately after defecation from a minimum of two horses/enclosure (in total a minimum of six samples). These samples were stored at $-20^{\circ} \mathrm{C}$ until analysis.

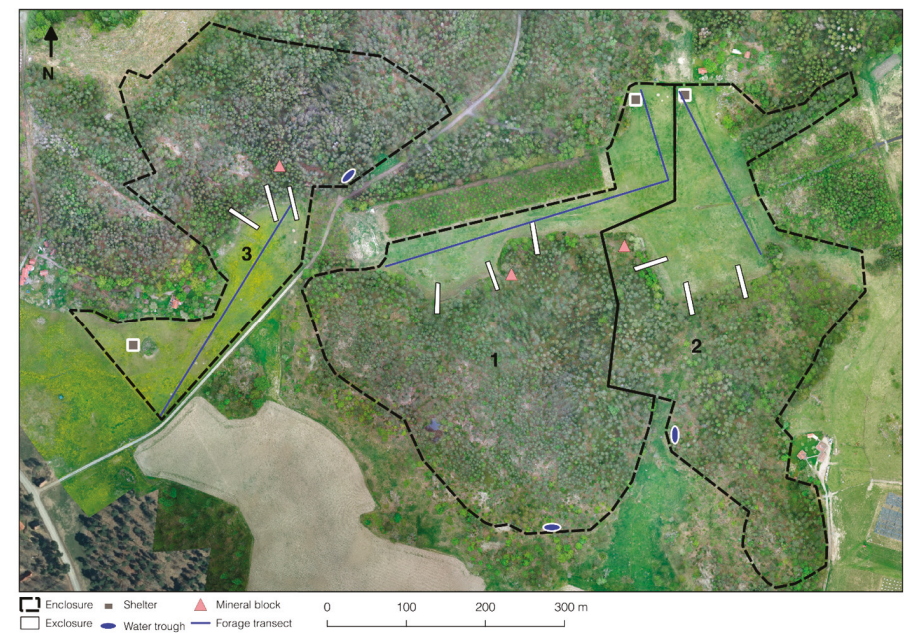

Figure 1. Aerial view of the three enclosures (1,2, and 3) used in the study, showing position of shelters, water troughs, mineral blocks, exclosures, and pasture transects. Photo taken on 24 May 2016 at $150 \mathrm{~m}$ altitude.

\subsection{Enclosures and Exclosures}

The three enclosures (En1-En3) were 13, 11, and 10 ha in size, respectively, and consisted of approximately $1 / 3$ fields and $2 / 3$ forest (Table 1 ). Each was surrounded by electric fencing. Dominating vegetation types, according to the classification used by the Swedish land survey (lantmateriet.se), were recorded in plots $15 \mathrm{~m}^{2}$ placed at $35 \mathrm{~m}$ spacing in a grid and located with GPS [16]. The vegetation was then merged into three different vegetation classes: grassland, forest, and semi-forest. Forest was 
defined as forested areas with $>30 \%$ crown coverage and semi-forest with $10-30 \%$ crown coverage, while grassland had $<10 \%$ crown coverage. In addition, plant species and species coverage were recorded in a $20 \times 20 \mathrm{~cm}$ square in the plots (Table 1). The fields had not been grazed by horses for at least 10 years, but En1 and En2 had been grazed by cattle and En 3 had been used for production of conserved forage.

In each enclosure, three exclosures each measuring $42.5 \mathrm{~m} \times 5 \mathrm{~m}$ were fenced off using electric fencing (Figure 1). All exclosures were placed in the edge zone between forest and open field, with $20 \mathrm{~m}$ of the exclosure in the forest and $22.5 \mathrm{~m}$ in the open field.

Table 1. Area (ha) of vegetation types within each enclosure and dominant plant species identified in a vegetation inventory performed in all three enclosures in May 2014 (study start).

\begin{tabular}{|c|c|c|c|}
\hline Vegetation Type, ha & Enclosure 1 & Enclosure 2 & Enclosure 3 \\
\hline Grassland & 2.7 & 3.3 & 2.7 \\
\hline Forest & 10.7 & 5.8 & 6.8 \\
\hline Semi-forest ${ }^{a}$ & 0 & 1.3 & 0.2 \\
\hline Total area & 13.4 & 10.3 & 9.7 \\
\hline \multicolumn{4}{|l|}{$\begin{array}{c}\text { Dominant Plant Species in } \\
\text { Grassland, \% }\end{array}$} \\
\hline Grasses & 60 & 57 & 26 \\
\hline Yarrow (Achillea millefolium) & 10 & 14 & \\
\hline Dandelion (Taraxacum spp.) & 7 & 10 & 47 \\
\hline Hempnettle (Galeopsis tetrahit) & & 6 & \\
\hline White clover (Trifolium repens) & & & 5 \\
\hline \multicolumn{4}{|l|}{$\begin{array}{c}\text { Dominant Ground Cover in } \\
\text { Forest, } \%\end{array}$} \\
\hline Mosses & 46 & 29 & 55 \\
\hline Grasses & 11 & 26 & 12 \\
\hline Bilberry (Vaccinium myrtillus) & 12 & 7 & 10 \\
\hline Lingonberry (Vaccinium vitis-idaea) & 5 & 4 & 3 \\
\hline
\end{tabular}

\subsection{Pasture Sampling}

The pasture in the open field areas was sampled in the second week of each month all year round, except when the ground was covered with snow (0-29 cm, December 2014-March 2015, January 2016, and March 2016). Four types of sample were collected: Forage, volume, graze, and exclosure.

Forage samples were collected by clipping a grab sample of vegetation $5 \mathrm{~cm}$ from the ground every $10 \mathrm{~m}$ along a transect crossing the open fields. In En2 and En3, samples were collected along that one transect, but due to the shape of En1, the sampling line was L-shaped and longer, and samples were collected every $20 \mathrm{~m}$ to retrieve the same amount of samples representing the approximate same size of grassland.

Volume samples were taken along the same transects as the forage samples, but every $50 \mathrm{~m}(100 \mathrm{~m}$ in En1), collecting all vegetation $5 \mathrm{~cm}$ from the ground within a $30 \mathrm{~cm} \times 30 \mathrm{~cm}$ square $\left(0.09 \mathrm{~m}^{2}\right)$. The volume samples were placed in plastic bags and weighed later for determination of pasture quantity.

Graze samples were collected in the area where horses were grazing at the time of sampling. Vegetation was cut close to the ground, i.e., the height at which the horses were assumed to graze.

Exclosure samples were taken within a $50 \mathrm{~cm} \times 50 \mathrm{~cm}$ quadrat $\left(0.25 \mathrm{~m}^{2}\right)$ in the open field part of the exclosures, $2 \mathrm{~m}$ from the fence (Figure 1). All vegetation above $5 \mathrm{~cm}$ from the ground within the quadrat was collected by mowing with a scissor. Grassland production was assessed by weighing the Exclosure samples, determining the dry matter (DM) content, and calculating the amount of DM per hectare.

In February and April 2016, only graze samples were collected, due to small sample size/no sample for the other three sample types. At all sampling sites except those for the graze samples, grass height was measured using a herbometer (Herbometre, AGRO-Systémes, La membrolle sur Chosille, 
France), with a $30 \mathrm{~cm} \times 30 \mathrm{~cm}$ square plate placed on top of the vegetation. On occasion, horses were observed eating bilberry plants (Vaccinium myrtillus L.) and in December 2014, random samples of bilberry, without berries or leaves, were collected at the time of grazing/browsing. All samples were stored at $-20^{\circ} \mathrm{C}$ until analysis.

\subsection{Analyses of Chemical Composition}

The exclosure samples from the three exclosures within each enclosure were pooled to one sample before analysis of nutrient content. To determine DM content, pasture and feces samples were dried at $60^{\circ} \mathrm{C}$ for $24 \mathrm{~h}$ and milled in a $1 \mathrm{~mm}$ hammer mill (Kamas, Slagy $200 \mathrm{~B}$, Malmö, Sweden). A $2 \mathrm{~g}$ subsample was then dried at $103^{\circ} \mathrm{C}$ for $16 \mathrm{~h}$. Ash content was determined by incinerating a $2 \mathrm{~g}$ sample at $550{ }^{\circ} \mathrm{C}$ for $3 \mathrm{~h}$, after which the residue was cooled and weighed. Organic matter (OM) content was calculated by subtracting the content of ash from the DM content. Digestibility coefficient of organic matter (VOS) and metabolizable energy (ME) content were determined in vitro according to Lindgren 163 [17]. The ME content is, however, based on the ME for ruminants, so was adjusted for horses using the following equation derived by Jansson et al. [18]:

$$
\mathrm{ME}_{\text {horse }}=1.12\left(\mathrm{ME}_{\text {ruminant }}\right)-1.1
$$

The concentration of neutral detergent fiber (NDF) was determined according to Chai and Uden [19]. Analysis of CP was performed according to Kjeldahl [20], where ammonia nitrogen concentration was determined by direct distillation with a Kjeltec 2460 analyser (Foss, Hilleröd, Denmark) and $\mathrm{N}$ content was multiplied by 6.25 to give the $\mathrm{CP}$ content. To estimate the amount of digestible $\mathrm{CP}(\mathrm{dCP})[19]$, the following equation used was:

$$
\mathrm{dCP}=0.939-31.1 / \mathrm{g} \mathrm{CP} \mathrm{kg} / \mathrm{DM}
$$

The ratio between digestible CP and ME (RdCPME) was also calculated, since this is an established measure of horse feed quality in Sweden [18]. In samples retrieved in June 2016 (see Table S1), macronutrient concentrations were analyzed by inductively coupled plasma-atomic emission spectroscopy (ICP-AES) using Spectro Flame equipment (SPECTRO Analytical Instruments, Kleve, Germany). Due to small sample size, values for exclosures in En2 and En3 in October 2014 are missing.

\subsection{Statistical Analyses}

All statistical analyses were performed in Statistical Analysis Systems package 9.4 (SAS Institute Inc., Cary, NC, USA). Differences were considered significant at $p<0.05$. Values presented are least square means (LSmeans) \pm standard error (SE).

To study if climate differed significantly between years during the study period, effects of year on air temperature and precipitation were estimated in a mixed model including an interaction between season and year.

Test of differences in pasture nutrient content between samples retrieved in exclosures and the samples retrieved in the enclosures, as well as possible differences between the different enclosure sample types (Forage, Volume, and Graze), were performed using a mixed model, with enclosure as repeated measurement and an effect of interaction between enclosure and time period (year and month). When the $p$-value for the interaction effect between enclosure and time period was $<0.1$, a separate analysis without the interaction effect was run. If no interaction effect is reported, values refer to the latter analysis. As analysis of differences in pasture nutrient content showed no significant difference between forage and volume samples, these were pooled before further analysis.

To test if different land areas, i.e., enclosures, responded differently in terms of nutrient content, as well as pasture quantity on horse grazing and mowing, a mixed model with enclosure as repeated measurement was used. The same model was also used to test if season (summer/winter) and year 
affected the nutritional content and pasture quantity. An analysis including the effect of interaction between year and season was also performed.

\section{Results}

Mean air temperature and precipitation did not differ between the three study years $(p>0.05)$. During summer, mean temperature was $13.3 \pm 5.8^{\circ} \mathrm{C}$ and mean precipitation was $1.8 \pm 4.3 \mathrm{~mm} / \mathrm{day}$. During winter, the corresponding values were $1.3 \pm 5.1^{\circ} \mathrm{C}$ and $1.0 \pm 2.2 \mathrm{~mm} /$ day.

\subsection{Variation in Pasture Nutrient Content Between Exclosures and Enclosures, and Between Sample Types}

The exclosure samples showed lower DM and higher CP and ME contents than the forage and volume samples from the enclosures, but there was no difference in NDF content (Table 2). The graze samples showed higher nutrient contents than the other three sample types (with the exception of energy content in exclosure samples, which was similar) (Table 2). There was a significant interaction between sample type and time period for ME per kg OM and CP as a percentage of OM $(p<0.05)$, where ME and CP remained at a high concentration in the period May-September in the graze samples, while decreasing from August onwards in the other sample types.

The bilberry shrubs sampled in the forest had the following composition: DM 45\%, CP 7\% of DM, digestible CP $32 \mathrm{~g} / \mathrm{kg}$ DM, ME 3.2 MJ/kg DM, and OM 97\% of DM.

Table 2. Content of dry matter (DM), metabolizable energy (ME) per kg organic matter (OM), crude protein $(\mathrm{CP})$ as \% of $\mathrm{OM}$, and neutral detergent fiber (NDF) as \% of OM in three different types of pasture samples collected in three enclosures grazed by horses, and in three exclosures per enclosure, monthly between May 2014 and September 2016, except for December 2014-March 2015 and January-April 2016.

\begin{tabular}{cccccc}
\hline Sample & \multicolumn{3}{c}{ Enclosures } & \multirow{2}{*}{ Exclosures } \\
\cline { 2 - 4 } & Forage & Volume & Graze & \\
\hline ME, MJ/kg OM & $10.0 \pm 0.2^{\mathrm{a}}$ & $10.0 \pm 0.2^{\mathrm{a}}$ & $10.9 \pm 0.2^{\mathrm{b}}$ & $10.5 \pm 0.2^{\mathrm{b}}$ & 0.0002 \\
CP, \% of OM & $11.9 \pm 0.4^{\mathrm{a}}$ & $11.6 \pm 0.5^{\mathrm{a}}$ & $17.0 \pm 0.4^{\mathrm{b}}$ & $13.7 \pm 0.4^{\mathrm{c}}$ & $<0.0001$ \\
$\mathrm{NDF}, \%$ of OM & $57.2 \pm 0.7^{\mathrm{a}}$ & $56.7 \pm 0.9^{\mathrm{a}}$ & $51.0 \pm 0.7^{\mathrm{b}}$ & $56.8 \pm 0.8^{\mathrm{a}}$ & $<0.0001$ \\
DM, \% & $34 \pm 1^{\mathrm{a}}$ & $34 \pm 1^{\mathrm{a}}$ & $29 \pm 1^{\mathrm{b}}$ & $27 \pm 1^{\mathrm{b}}$ & $<0.0001$ \\
\hline
\end{tabular}

$\mathrm{a}, \mathrm{b}, \mathrm{c}$ Different superscript letters indicate significant differences within rows $(p<0.05)$.

\subsection{Variation in Pasture Quantity}

Mean grass sward height was lower and DM and ME content/ha were higher in enclosures compared with exclosures, but there were also differences between the enclosures (Table 3). During the summer in 2016, grass sward height decreased in both enclosures and exclosures compared with in 2015, but DM and ME content/ha only decreased in exclosures (Table 4).

Table 3. Mean grass sward height and content of dry matter (DM) and metabolizable energy (ME) in the enclosures grazed by horses and in the exclosures within each enclosure mown monthly from May 2014 to September 2016. Exclosures were mown at the same spots as sward height measurements were made.

\begin{tabular}{|c|c|c|c|c|c|c|c|c|c|}
\hline & \multicolumn{4}{|c|}{ Enclosures } & \multicolumn{4}{|c|}{ Exclosures } & \multirow{2}{*}{$p$ Means } \\
\hline & En1 & En2 & En3 & Mean & En1 & En2 & En3 & Mean & \\
\hline $\begin{array}{l}\text { Grass sward } \\
\text { height, cm }\end{array}$ & $5.5 \pm 0.1^{\mathrm{a}}$ & $7.7 \pm 0.2^{b}$ & $5.5 \pm 0.2^{\mathrm{a}}$ & $5.3 \pm 0.1$ & $4.3 \pm 0.4^{\mathrm{a}}$ & $4.9 \pm 0.4^{\mathrm{a}, \mathrm{b}}$ & $6.0 \pm 0.4^{b}$ & $5.6 \pm 0.4$ & $<0.05$ \\
\hline $\mathrm{DM}, \mathrm{kg} / \mathrm{ha}$ & $957 \pm 114^{\text {a }}$ & $1393 \pm 114^{b}$ & $741 \pm 114^{a}$ & $886 \pm 73$ & $525 \pm 111$ & $487 \pm 111$ & $721 \pm 111$ & $326 \pm 76$ & $<0.0001$ \\
\hline ME, MJ/ha & $8494 \pm 895^{a}$ & $11,204 \pm 928^{b}$ & $7351 \pm 895^{\mathrm{a}}$ & $7470 \pm 636$ & $5208 \pm 1171$ & $4912 \pm 1171$ & $7760 \pm 1171$ & $3048 \pm 701$ & $<0.0001$ \\
\hline
\end{tabular}


Table 4. Mean summer season grass sward height and content of dry matter (DM) and metabolizable energy (ME) per year in the enclosures grazed by horses and in the exclosures within each enclosure mown monthly from May 2014 to September 2016. Exclosures were mown at the same spots as sward height measurements were made.

\begin{tabular}{ccccccc}
\hline & \multicolumn{5}{c}{ Enclosures } & \multicolumn{3}{c}{ Exclosures } \\
\cline { 2 - 6 } & $\mathbf{2 0 1 4}$ & $\mathbf{2 0 1 5}$ & $\mathbf{2 0 1 6}$ & $\mathbf{2 0 1 4}$ & $\mathbf{2 0 1 5}$ & $\mathbf{2 0 1 6}$ \\
\hline $\begin{array}{c}\text { Grass sward } \\
\text { height, } \mathbf{~ c m}\end{array}$ & $8.9 \pm 0.21^{\mathrm{a}}$ & $5.9 \pm 0.2^{\mathrm{b}}$ & $5.2 \pm 0.2^{\mathrm{c}}$ & - & $7.1 \pm 0.4^{\mathrm{a}}$ & $5.4 \pm 0.4^{\mathrm{b}}$ \\
\hline $\mathrm{DM}, \mathbf{~ k g} / \mathbf{h a}$ & $1560 \pm 160^{\mathrm{a}}$ & $863 \pm 176^{\mathrm{b}}$ & $770 \pm 176^{\mathrm{b}}$ & $714 \pm 96^{\mathrm{a}}$ & $760 \pm 105^{\mathrm{a}}$ & $260 \pm 105^{\mathrm{b}}$ \\
\hline ME, MJ/ha & $13,858 \pm 1293^{\mathrm{a}}$ & $8133 \pm 1416^{\mathrm{b}}$ & $8176 \pm 1466^{\mathrm{b}}$ & $7201 \pm 1044^{\mathrm{a}}$ & $7869 \pm 1144^{\mathrm{a}}$ & $2810 \pm 1144^{\mathrm{b}}$ \\
\hline \multicolumn{3}{c}{${ }^{\mathrm{a}, \mathrm{b}, \mathrm{c}}$ Different superscript letters indicate significant differences between years $(p<0.05)}$. \\
\end{tabular}

\subsection{Variation in Pasture Nutrient Content between Enclosures}

In exclosure samples, there was no general effect of the different enclosures on any of the nutritional parameters analyzed (Table 5). In the pooled forage + volume samples and in graze samples, the content of ME, CP, and NDF/ $\mathrm{kg}$ OM showed differences $(p<0.05)$ between enclosures (Table 5 ).

Table 5. Content of dry matter (DM), metabolizable energy (ME) per kg organic matter (OM), crude protein $(\mathrm{CP})$ as $\%$ of $\mathrm{OM}$, and neutral detergent fiber (NDF) content as \% of OM in four types of pasture samples collected in three enclosures (En1-En3) grazed all year round by Gotlandsruss and in three exclosures per enclosure. Samples were collected monthly between May 2014 and September 2016, except for December 2014-March 2015 and January-April 2016. LSmeans \pm SE, $p$-values indicate the general effect of enclosure.

\begin{tabular}{|c|c|c|c|c|}
\hline Sample Type & En1 & En2 & En3 & $p$ \\
\hline \multicolumn{5}{|l|}{ Exclosure } \\
\hline $\mathrm{ME}, \mathrm{MJ} / \mathrm{kg} \mathrm{OM}$ & $10.8 \pm 0.2$ & $10.9 \pm 0.2$ & $11.2 \pm 0.2$ & 0.2925 \\
\hline $\mathrm{CP}, \%$ of $\mathrm{OM}$ & $14.9 \pm 0.4$ & $14.3 \pm 0.4$ & $13.9 \pm 0.4$ & 0.1955 \\
\hline $\mathrm{NFD}, \%$ of $\mathrm{OM}$ & $55.0 \pm 1.1^{\mathrm{a}}$ & $54.7 \pm 1.1^{\mathrm{a}, \mathrm{b}}$ & $51.8 \pm 1.1^{b}$ & 0.0924 \\
\hline $\mathrm{DM}, \%$ & $27 \pm 1$ & $29 \pm 1$ & $26 \pm 1$ & 0.2722 \\
\hline \multicolumn{5}{|l|}{ Enclosure Graze } \\
\hline $\mathrm{ME}, \mathrm{MJ} / \mathrm{kg} \mathrm{OM}$ & $10.4 \pm 0.2^{\mathrm{a}}$ & $10.7 \pm 0.2^{\mathrm{a}}$ & $11.5 \pm 0.2^{b}$ & 0.0029 \\
\hline $\mathrm{CP}, \%$ of $\mathrm{OM}$ & $16.9 \pm 0.8^{\mathrm{a}, \mathrm{b}}$ & $16.0 \pm 0.8^{\mathrm{a}}$ & $18.8 \pm 0.8^{b}$ & 0.0427 \\
\hline $\mathrm{NFD}, \%$ of $\mathrm{OM}$ & $52.7 \pm 1.4^{\mathrm{a}}$ & $53.9 \pm 1.3^{\mathrm{a}}$ & $45.6 \pm 1.3^{b}$ & 0.0001 \\
\hline $\mathrm{DM}, \%$ & $30 \pm 1^{\mathrm{a}, \mathrm{b}}$ & $31 \pm 1^{\mathrm{a}}$ & $27 \pm 1^{\mathrm{b}}$ & 0.0159 \\
\hline \multicolumn{5}{|c|}{ Enclosure Forage + Volume } \\
\hline $\mathrm{ME}, \mathrm{MJ} / \mathrm{kg} \mathrm{OM}$ & $10.1 \pm 0.1^{\mathrm{a}}$ & $9.3 \pm 0.1^{b}$ & $10.6 \pm 0.1^{\mathrm{c}}$ & $<0.0001$ \\
\hline $\mathrm{CP}, \%$ of $\mathrm{OM}$ & $11.5 \pm 0.4^{\mathrm{a}}$ & $11.9 \pm 0.4^{\mathrm{a}, \mathrm{b}}$ & $12.5 \pm 0.4^{b}$ & 0.1405 \\
\hline $\mathrm{NFD}, \%$ of $\mathrm{OM}$ & $54.7 \pm 1.1^{\mathrm{a}}$ & $59.9 \pm 1.1^{\mathrm{b}}$ & $54.2 \pm 1.1^{\mathrm{a}}$ & 0.0007 \\
\hline $\mathrm{DM}, \%$ & $34 \pm 1^{\mathrm{a}, \mathrm{b}}$ & $37 \pm 1^{\mathrm{a}}$ & $31 \pm 1^{\mathrm{b}}$ & 0.0083 \\
\hline
\end{tabular}

$\mathrm{a}, \mathrm{b}, \mathrm{c}$ Different superscript letters within rows indicate significant differences $(p<0.05)$ between enclosures (En1, En2, En3).

\subsection{Variation in Pasture Quality Between Years, Seasons, and Months}

As pasture was not sampled in all months throughout the year, only differences within seasons between years are presented (Figure 2). During the study period, summer pasture NDF concentration decreased in the enclosures, while ME and CP concentrations increased (Figure 2). In the exclosures, summer pasture CP remained unchanged between years, while ME concentration increased and NDF concentration showed a decrease. 


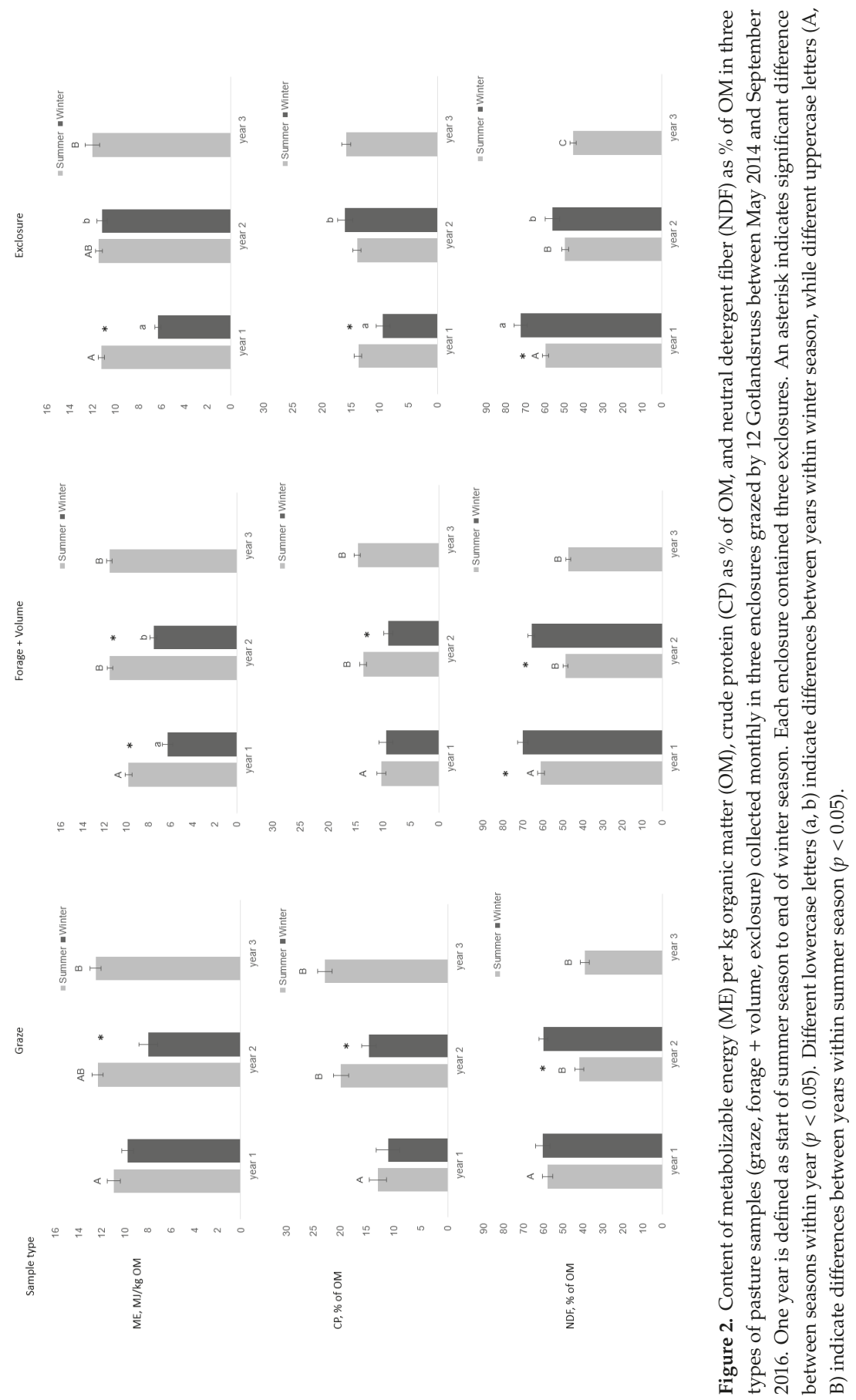


Mean monthly nutrient composition and RdCPME in forage + volume and graze samples in all three enclosures during the whole study period are shown in Tables S2 and S3. Mean ME content ranged from $4.9 \pm 0.5$ to $12.0 \pm 0.6 \mathrm{MJ}$ per $\mathrm{kg} \mathrm{DM}$, mean $\mathrm{CP}$ content ranged from $7 \pm 1 \%$ to $24 \pm 3 \%$, mean digestible CP per $\mathrm{kg}$ DM ranged from $37 \pm 12 \mathrm{~g}$ to $190 \pm 26 \mathrm{~g}$, and mean RdCPME ranged from $6.4 \pm 1.1$ to $15.9 \pm 2.6$ (Table S2).

\subsection{Fecal Composition and Correlation with Pasture Nutrient Content}

The $\mathrm{OM}$ and $\mathrm{CP}$ content in feces, but not the DM content, were dependent on the individual horse, but overall the OM content in feces was lower in En3 than in En1 and En2 (Table 6). Content of CP, both as \% of OM and as \% of DM, was lowest in En1 and highest in En3 (Table 6). Concentrations of $\mathrm{CP}$ in feces were lower in winter than in summer (Figure 3). Within season, fecal CP concentration increased with year.

Table 6. Content of dry matter (DM), organic matter (OM), and crude protein (CP) as \% of DM and as $\%$ of $\mathrm{OM}$ in feces from Gotlandsruss, divided equally between three enclosures (En1-En3) and grazing all year round.

\begin{tabular}{ccccc}
\hline & En1 & En2 & En3 & $p$ \\
\hline DM, \% & $20 \pm 0.3^{\mathrm{a}}$ & $19 \pm 0.3^{\mathrm{b}}$ & $21 \pm 0.3^{\mathrm{a}}$ & $<0.0001$ \\
OM, \% & $79 \pm 0.5^{\mathrm{a}}$ & $80 \pm 0.5^{\mathrm{a}}$ & $75 \pm 0.5^{\mathrm{b}}$ & $<0.0001$ \\
$\mathbf{C P}, \%$ of DM & $8.4 \pm 0.2^{\mathrm{a}}$ & $9.1 \pm 0.2^{\mathrm{b}}$ & $9.7 \pm 0.2^{\mathrm{c}}$ & $<0.0001$ \\
$\mathbf{C P}, \%$ of $\mathbf{O M}$ & $10.8 \pm 0.3^{\mathrm{a}}$ & $11.5 \pm 0.3^{\mathrm{b}}$ & $13.1 \pm 0.3^{\mathrm{c}}$ & $<0.0001$ \\
\hline
\end{tabular}
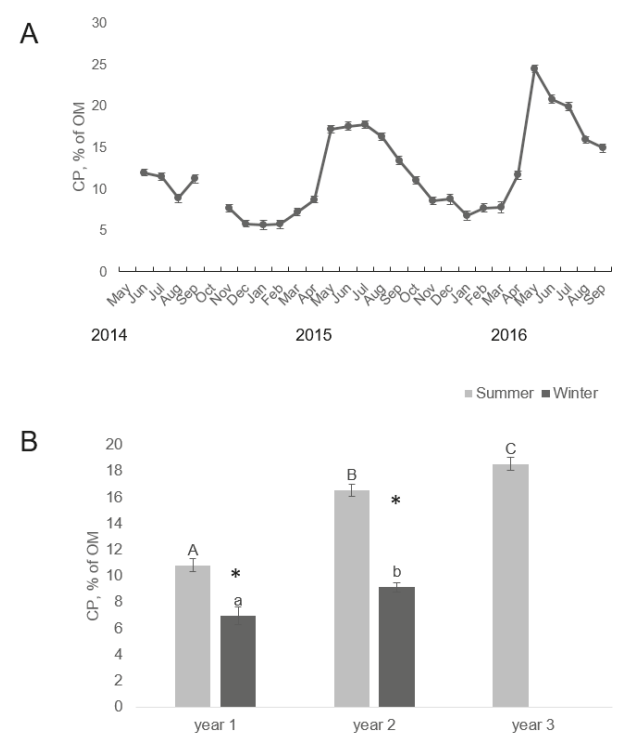

Figure 3. (A) Monthly variation and (B) seasonal and between-year variation in crude protein (CP) content (LSmeans $\pm \mathrm{SE}$ ) as \% of organic matter (OM) in feces from Gotlandsruss grazing without supplementary feeding from May 2014 to September 2016. One year is defined as start of summer season to end of winter season.

The content of DM, OM, and CP in feces showed moderate to strong correlations with the DM, $\mathrm{NDF}, \mathrm{OM}$, and $\mathrm{CP}$ concentrations in graze samples and in forage + volume samples (Tables 7 and 8). 
Table 7. Correlation coefficient ( $r, p$-value) between nutrient concentrations in graze samples and in fecal samples from 12 Gotlandsruss kept in three enclosures between May 2014 and September 2016 without supplementary feeding. $\mathrm{DM}=$ dry matter, $\mathrm{OM}=$ organic matter, $\mathrm{CP}=$ crude protein, VOS = digestibility coefficient of organic matter, NDF = neutral detergent fiber.

\begin{tabular}{|c|c|c|c|c|c|}
\hline \multirow{2}{*}{ Graze Samples } & & \multicolumn{4}{|c|}{ Fecal Samples } \\
\hline & & DM & OM & $\mathrm{CP}, \%$ of DM & $\mathrm{CP}, \%$ of $\mathrm{OM}$ \\
\hline \multirow{2}{*}{$\mathrm{DM}$} & $r$ & 0.37703 & \multirow[b]{2}{*}{ ns } & -0.30271 & -0.28796 \\
\hline & $p$ & 0.0032 & & 0.0198 & 0.0270 \\
\hline \multirow{2}{*}{ VOS } & $r$ & -0.58502 & -0.32107 & 0.62955 & 0.64978 \\
\hline & $p$ & $<0.0001$ & 0.0132 & $<0.0001$ & $<0.0001$ \\
\hline \multirow{2}{*}{ NDF } & $r$ & 0.36083 & 0.53560 & -0.69221 & -0.75195 \\
\hline & $p$ & 0.0050 & $<0.0001$ & $<0.0001$ & $<0.0001$ \\
\hline \multirow{2}{*}{$\mathrm{OM}$} & $r$ & -0.41346 & 0.36627 & \multirow{2}{*}{ ns } & \multirow{2}{*}{ ns } \\
\hline & $p$ & 0.0011 & 0.0043 & & \\
\hline \multirow{2}{*}{$\mathrm{CP}, \%$ of $\mathrm{DM}$} & $r$ & -0.35722 & -0.48196 & 0.60511 & 0.66090 \\
\hline & $p$ & 0.0055 & 0.0001 & $<0.0001$ & $<0.0001$ \\
\hline \multirow{2}{*}{$\mathrm{CP}, \%$ of $\mathrm{OM}$} & $r$ & \multirow{2}{*}{ ns } & -0.55235 & 0.49911 & 0.57349 \\
\hline & $p$ & & $<0.0001$ & $<0.0001$ & $<0.0001$ \\
\hline \multirow{2}{*}{$\mathrm{NDF}, \%$ of $\mathrm{OM}$} & $r$ & 0.48350 & 0.46697 & -0.75952 & -0.80312 \\
\hline & $p$ & 0.0001 & 0.0002 & $<0.0001$ & $<0.0001$ \\
\hline
\end{tabular}

Table 8. Correlation coefficient ( $r, p$-value) between nutrient concentrations in forage + volume samples and in fecal samples from 12 Gotlandsruss kept in three enclosures between May 2014 and September 2016 without supplementary feeding. $\mathrm{DM}=$ dry matter, $\mathrm{OM}=$ organic matter, $\mathrm{CP}=$ crude protein, VOS = digestibility coefficient of organic matter, NDF = neutral detergent fiber.

\begin{tabular}{|c|c|c|c|c|c|}
\hline \multirow{2}{*}{ Volume + Forage Samples } & \multicolumn{5}{|c|}{ Fecal Samples } \\
\hline & & DM & $\mathrm{OM}$ & $\mathrm{CP}, \%$ of $\mathrm{DM}$ & $\mathrm{CP}, \%$ of $\mathrm{OM}$ \\
\hline \multirow{2}{*}{ DM, \% } & $r$ & 0.58646 & \multirow{2}{*}{ ns } & -0.45184 & -0.44157 \\
\hline & $p$ & $<0.0001$ & & 0.0003 & 0.0005 \\
\hline \multirow{2}{*}{ VOS } & $r$ & -0.62653 & -0.44629 & 0.75445 & 0.76465 \\
\hline & $p$ & $<0.0001$ & 0.0004 & $<0.0001$ & $<0.0001$ \\
\hline \multirow{2}{*}{$\mathrm{NDF}, \%$} & $r$ & 0.57023 & 0.48945 & -0.84249 & -0.86310 \\
\hline & $p$ & $<0.0001$ & $<0.0001$ & $<0.0001$ & $<0.0001$ \\
\hline \multirow{2}{*}{$\mathrm{OM}, \%$} & $r$ & \multirow{2}{*}{ ns } & \multirow{2}{*}{ ns } & \multirow{2}{*}{ ns } & \multirow{2}{*}{ ns } \\
\hline & $p$ & & & & \\
\hline \multirow{2}{*}{$\mathrm{CP}, \%$ of $\mathrm{DM}$} & $r$ & -0.38627 & -0.43487 & 0.64359 & 0.67240 \\
\hline & $p$ & 0.0025 & 0.0006 & $<0.0001$ & $<0.0001$ \\
\hline \multirow{2}{*}{$\mathrm{CP}, \%$ of $\mathrm{OM}$} & $r$ & -0.38872 & -0.42891 & 0.64552 & 0.67353 \\
\hline & $p$ & 0.0023 & 0.0007 & $<0.0001$ & $<0.0001$ \\
\hline \multirow{2}{*}{$\mathrm{NDF}, \%$ of $\mathrm{OM}$} & $r$ & 0.56563 & 0.50105 & -0.84228 & -0.86426 \\
\hline & $p$ & $<0.0001$ & $<0.0001$ & $<0.0001$ & $<0.0001$ \\
\hline
\end{tabular}

\section{Discussion}

The results obtained in this three-year study showed that horse grazing altered pasture nutrient composition and diversified pasture chemical composition (between enclosures) to a greater extent than mowing. This indicates that horses can manage pasture and are therefore suitable for year-round grazing in Sweden, as a means to increase pasture diversity. To our knowledge, this is the first study at Nordic latitudes to evaluate the effect on pasture chemical composition of year-round grazing by horses without supplementary feeding. Year-round grazing is currently not practiced in the region because of the lack of vegetation growth in winter (i.e., temperatures below $5{ }^{\circ} \mathrm{C}$ for more than four days). However, the study area is within a zone suggested to be suitable with respect to climate conditions for rewilding of horses, although local biotic factors, land cover, and soil type may influence 
the degree of suitability [21]. The study was conducted between 2014 and 2016, under temperature and precipitation conditions typical for the region, and the results are therefore of general relevance for this form of horse management.

\subsection{Pasture Quality and Effects of Sample Type}

One likely explanation for the diversified nutrient content of grazed pasture is the grazing behavior of horses. Horses perform selective grazing [22,23], and also create mosaic landscape patterns [24], as some areas are frequently grazed close to the ground while others are avoided. In the present study, this was reflected in the higher content of ME and CP and lower content of NDF in the graze samples, compared with the forage and volume samples, indicating an earlier botanical stage. An additional explanation for the altered nutrient content may be the change in botanical composition reported previously for the study area [4]. For example, grazing favored prostrate plant species (low plant height at maturity).

The three enclosures all had different qualities. En1 and En2 showed a different response to En3 with respect to sward height and nutrient content, for example. The reason is unclear, but En3 had previously been cultivated (forage production) and En1 and En 2 had been grazed by cattle. En2 was also the enclosure with the lowest grazing pressure, as it had a larger grass area (3.3 ha, compared with 2.7 ha in En1 and En3), and the plant composition differed (Table 1). Mowing of the exclosures was performed without selection, creating similar plant stress between enclosures, which might have evened out initial differences in species and chemical composition. Horses, on the other hand, graze selectively [22,23] and might have favored different species and areas in the three enclosures, as well as putting more stress on the plants by grazing them shorter than mowing (i.e., $<5 \mathrm{~cm}$ ). In addition, the trampling effect of horses might have affected the botanical composition and, therefore, also the nutrient content.

Compared with the exclosure areas, from which grazing horses were excluded, grazed pasture showed both lower (volume and forage samples) and higher (graze samples) concentrations of CP, depending on sample type. The difference in composition between sample types may be due to the forage + volume samples and the exclosure samples including only plant parts $>5 \mathrm{~cm}$. These plant parts may be of a later botanical stage [25], as reflected by the higher content of NDF compared with graze samples collected close to the ground. Both the graze and forage + volume samples showed relatively high correlations with fecal NDF and CP content, indicating that they may both be valid sampling options when measuring the nutrient content of pasture consumed by horses.

Observations from Sweden indicate that heavily grazed grasses may have higher CP and energy content in October than grasses subjected to lower grazing pressure [26]. This is likely due to old biomass being replaced by new, nitrogen-rich leaves as grazing increases defoliation [27], and is presumably the reason for the higher nitrogen content in the graze samples in the present study. During summer seasons, $\mathrm{ME}$ and $\mathrm{CP}$ increased in graze and forage + volume samples, while they were unchanged in exclosure samples and remained high in the graze samples for longer than in the other sample types. These results are in accordance with observations in sheep pastures that frequent grazing during the vegetation period improves nutrient quality compared with mowing [28]. The results confirm that grazing managed at the right intensity can enhance the quality of pasture [29].

\subsection{Pasture Quantity}

Pasture dry matter production in the study area was within the range reported for other horse and ruminant year-round grazed pastures in Germany [1], and also similar to that reported for natural pastures in Sweden grazed by cattle and sheep [30]. In addition, based on the 10-year mean for forage harvest from cultivated grassland, the years included in the study seem to be representative for the region [31].

The pasture quantity values determined in the exclosures could be regarded as a measure of overall pasture production, while the volume samples collected in the enclosures could be considered a measure of the amount of pasture available to the horses. The exclosures were mown at the same 
sites as the exclosure samples were taken. In contrast, the volume samples were collected by walking along a straight line, and with this method, sampling sites may have varied slightly between sampling occasions. Comparisons of pasture and energy quantity between enclosures and exclosures should therefore be made with caution. However, the lack of differences in grass sward height between enclosures and exclosures implies that mowing to $5 \mathrm{~cm}$ every month resulted in a similar rate of vegetation removal as horse grazing within the enclosures.

Pasture quantity decreased over the study years in both enclosures and exclosures (2015 and 2016). This may therefore be an effect of annual variation, rather than an effect of horse grazing, on pasture production. To evaluate the long-term impact of horse grazing on pasture production, much longer studies are required.

\subsection{Ability of Pastures to Meet the Nutritional Requirements of Horses}

Despite the cold winters in the region, $\mathrm{CP}$ content during winter (7-11\% of DM) was within the range reported for other European winter pastures [1]. Assuming a maximum DM intake capacity of $3 \%$ of body weight [32-34], a $250 \mathrm{~kg}$ adult stallion with a CP requirement of $432 \mathrm{~g} /$ day [35] would, in theory, manage with a $\mathrm{CP}$ concentration in pasture of $6 \%$ of $\mathrm{DM}$, which is just below the lowest value recorded in the present study. However, as found for other European pastures [1], the amount of pasture available and the ME content during winter were insufficient to maintain body condition in horses. In addition, a snow layer of $>10 \mathrm{~cm}$ covered the ground for 14-31 days/winter in our study, making the pasture more difficult to access. At the beginning of winter, when snow was still absent, the mean energy content of the pasture was estimated to be $6200 \mathrm{MJ} \mathrm{ME} / \mathrm{ha}$ in the grasslands. Assuming a winter season lasting five months, and that all vegetation sampled here could be consumed by the horses, this would supply each horse with $10 \mathrm{MJ}$ ME/day, which represents $30 \%$ of the estimated daily requirements [35]. However, in reality the samples would probably contain plants generally not consumed by the horses and the energy requirement of the horses may have been higher during cold spells.

The insufficient levels of energy and $\mathrm{CP}$ in the pasture were reflected in loss of body weight and body condition in the horses during the winter months (unpublished data). On the other hand, during the growing season, pasture provided a surplus of energy great enough for the horses to store body fat, compensating for energy deficiency in winter. En2 was the only enclosure where no horse at any time would have required supplementary feeding to maintain a functional body condition. An energy content in pasture of at least 12,000 MJ ME/ha in November therefore seems sufficient to avoid horses becoming underweight at the given animal density (approximately $1000 \mathrm{~kg}$ horse on 3 ha of grassland and 7 ha forest) and summer conditions. However, the lack of need for supplementary feeding in En2 could also be due to this enclosure containing a rather large area $(1.3 \mathrm{ha})$ of semi-forest with some grass in the understory.

Interestingly, during wintertime, horses spent more time in the forest (unpublished data). Therefore, tree materials, some grass, and bilberry plants probably comprised a greater proportion of the horses' diet during winter. The chemical analysis of bilberry plants showed rather low contents of ME and CP. However, it should be noted that the analytical methods used are designed for grasses and legumes, and may be less relevant for shrubs.

\subsection{Correlation of Pasture Quality and Fecal Composition}

The correlations between fecal and pasture concentrations of CP (as \% of DM and OM) were moderate to strong $(r=0.57-0.67)$. These were similar to correlations reported for stabled horses fed a forage-only diet [36]. The fairly high correlation implies that a fecal grab samples could be used to give a rough estimate of $\mathrm{CP}$ intake in grazing horses. However, the method may not apply if the horses are growing or mares are lactating, as their nutrient requirements are higher than those of adult horses [35].

The trend for fecal CP concentration to be correlated with season is similar to that reported for bachelor horses in Camargue [2] and feral horses in Canada [37]. However, the seasonal variation in the present study was greater, ranging from $5.6 \%$ of DM in January to $17.0 \%$ of DM in May. The 
increment in fecal CP content with year reflected the pasture composition, as CP content in pasture vegetation was also higher in the second and third summer than at the start of the study.

Surprisingly, the correlation with fecal CP concentration was slightly stronger with forage + volume samples than with graze samples. The highest CP values were observed in Graze samples and the CP content was periodically much higher than the requirement. However, this was not reflected in higher CP content in feces compared with the forage + volume samples, probably because more of the easily digestible nitrogen was excreted with urine and not with feces [38]. The intention with collecting the graze samples was to get a more accurate estimate of the nutritional composition of the pasture actually consumed by the horses. However, both the graze samples and the grab sample of the feces were spot-samples taken at random times and the graze samples represented conditions at those times, while fecal samples would consist of digesta ingested hours to days before sampling [38]. This may be another reason why the $\mathrm{CP}$ content of forage + volume samples correlated better with $\mathrm{CP}$ concentration in feces.

\subsection{Practical Implications}

Our study provides practical data on the quality and quantity of Swedish pasture grazed year-round by horses. The area of semi-natural pastures in Sweden is decreasing [39]. At the same time, the number of horses in Sweden is increasing, from 85,000 in 1970 [40] to now approaching 355,000, which makes horses more common than dairy cows [31]. There is, thus, great potential for using horses in landscape conservation in Sweden. However, most horses are stabled for most of the year and the main roughage fed is hay or haylage harvested from cultivated leys. The results in the present study indicate that pasture grazed year-round south of latitude $60^{\circ} \mathrm{N}$ in Sweden can have a sufficient energy and nutrient content to meet the nutritional recommendations of adult horses for at least 10 months per year (Table S3, no data for January and March) and that the amount of pasture may be a limitation. The results presented here could be used as the basis for recommendations on utilization of semi-natural pastures by horses even outside the growing season, as an alternative to feeding hay or haylage, for example. Compared with feeding conserved forage, pasture provides increased opportunities for horses to express their natural behavior and requires less resources than harvesting, conservation, and transportation of hay/haylage. The low content of energy in shrubs such as bilberry means that forest pastures could be suitable to meet the feeding behavior requirement of obese horses, although this would require further evaluation. Increased grazing of semi-natural pastures would also increase biological diversity [4] and help preserve agricultural landscapes. Moreover, our data on the nutrient composition of Swedish semi-natural pastures support the suggestion [21] that they could be suitable for future rewilding of horses at this latitude.

\section{Conclusions}

Compared with mowing, year-round grazing by horses in Sweden increased pasture nutrient quality and diversity. This indicates that year-round grazing by horses in Sweden could be used as a general tool to increase biodiversity. Pasture sampling method affected the pasture quality results but, overall, CP content was sufficient to meet the horses' requirements year-round, while the energy content and pasture availability may be a limitation during winter. Fecal grab samples proved to give a fairly good estimate of CP intake in grazing horses, but should be complemented with analysis of pasture quality for pregnant, lactating, and young horses with high CP requirements.

Supplementary Materials: The following are available online at http://www.mdpi.com/2076-2615/9/8/500/s1: Table S1. Content of macronutrients in pasture; Table S2. Yearly variation in pasture nutrient content in forage + volume samples; Table S3. Yearly variation in pasture nutrient content in graze samples.

Author Contributions: S.R. contributed to the methodology, validation, formal analysis, investigation, data curation, and original draft manuscript preparation. A.S. contributed to the methodology, investigation, review and editing, and visualization. A.J. contributed to the conceptualization, methodology, formal analysis, investigation, resources, reviewing and editing, project administration, and funding acquisition. 
Funding: This work was supported by the Swedish World Wildlife Fund, the Helge Ax:on Johnsson Foundation, the Swedish University of Agricultural Sciences, and contributors to a crowd-funding campaign carried out in 2016 by the Swedish University of Agricultural Sciences.

Acknowledgments: We would like to thank our colleague Carl-Gustaf Thulin for contributing to the conceptualization and for commenting on the manuscript, and students Oceane Martinét, Elin Mattsson, and Karin Näslund for contributing to data collection. We also thank staff at the feed laboratory, Department of Animal Nutrition and Management, SLU.

Conflicts of Interest: The authors declare no conflict of interest. The funders played no role in the design of the study; in the collection, analyses, or interpretation of data; in writing the manuscript; or in the decision to publish the results.

\section{References}

1. Gilhaus, K.; Hoelzel, N. Seasonal variations of fodder quality and availability as constraints for stocking rates in year-round grazing schemes. Agric. Ecosyst. Environ. 2016, 234, 5-15. [CrossRef]

2. Duncan, P. Horses and grasses: The nutritional ecology of equids and their impact on the Camargue. Ecol. Stud. 1991, 87, 1-287.

3. Gärdenfors, U.; Simán, S.; Lundkvist, K. Rödlistade arter i Sverige 2005; ArtDatabanken i samarbete med Naturvårdsverket: Uppsala, Sweden, 2005.

4. Garrido, P.; Mårell, A.; Öckinger, E.; Skarin, A.; Jansson, A.; Thulin, C.G. Experimental rewilding enhances grassland functional composition and pollinator habitat use. J. Appl. Ecol. 2019, 56, 946-955. [CrossRef]

5. Loucougaray, G.; Bonis, A.; Bouzille, J.-B. Effects of grazing by horses and/or cattle on the diversity of coastal grasslands in western France. Biol. Conserv. 2004, 116, 59-71. [CrossRef]

6. Öckinger, E.; Eriksson, A.K.; Smith, H.G. Effects of grassland abandonment, restoration and management on butterflies and vascular plants. Biol. Conserv. 2006, 133, 291-300. [CrossRef]

7. Osoro, K.; Ferreira, L.; García, U.; García, R.R.; Martinez, A.; Celaya, R. Grazing systems and the role of horses in heathland areas. In Forages and Grazing in Horse Nutrition; Wageningen Academic Publishers: Wageningen, The Netherlands, 2012; pp. 137-146.

8. Putman, R.; Pratt, R.; Ekins, J.; Edwards, P. Food and feeding behaviour of cattle and ponies in the New Forest, Hampshire. J. Appl. Ecol. 1987, 24, 369-380. [CrossRef]

9. Yunusbaev, U.; Musina, L.; Suyundukov, Y.T. Dynamics of steppe vegetation under the effect of grazing by different farm animals. Russ. J. Ecol. 2003, 34, 43-47. [CrossRef]

10. Menard, C.; Duncan, P.; Fleurance, G.; Georges, J.Y.; Lila, M. Comparative foraging and nutrition of horses and cattle in European wetlands. J. Appl. Ecol. 2002, 39, 120-133. [CrossRef]

11. Gudmundsson, O.; Dyrmundsson, O. Horse grazing under cold and wet conditions: A review. Livest. Prod. Sci. 1994, 40, 57-63. [CrossRef]

12. Pratt-Phillips, S.E.; Stuska, S.; Beveridge, H.L.; Yoder, M. Nutritional quality of forages consumed by feral horses: The horses of Shackleford Banks. J. Equine Vet. Sci. 2011, 31, 640-644. [CrossRef]

13. Kuiters, A.; Van der Sluijs, L.; Wytema, G. Selective bark-stripping of beech, Fagus sylvatica, by free-ranging horses. For. Ecol. Manag. 2006, 222, 1-8. [CrossRef]

14. Helmer, W.; Saavedra, D.; Sylvén, M.; Schepers, F. Rewilding Europe: A New Strategy for an Old Continent. Rewilding European Landscapes. Available online: https://link.springer.com/content/pdf/10.1007\%2F978-3-31912039-3.pdf (accessed on 20 March 2019).

15. Linné, C.V. Öländska och Gotländska Resa, Faximil Edition Produced 1940; AB Malmö.Ljustrycksanstalt: Malmö, Sweden, 1745.

16. Skarin, A. Habitat use by semi-domesticated reindeer, estimated with pellet-group counts. Rangifer 2005, 27, 121-132. [CrossRef]

17. Lindgren, E. Vallfodrets näringsvärde bestämt in vivo och med olika laboratoriemetoder; Dep of Animal Nutrition and Management: Uppsala, Sweden, 1979.

18. Jansson, A.; Lindberg, J.; Rundgren, M.; Müller, C.; Connysson, M.; Kjellberg, L.; Lundberg, M. Utfodringsrekommendationer för häst; Swedish University of Agricultural Sciences: Uppsala, Sweden, 2011.

19. Chai, W.H.; Uden, P. An alternative oven method combined with different detergent strengths in the analysis of neutral detergent fibre. Anim. Feed Sci. Technol. 1998, 74, 281-288. [CrossRef] 
20. Kjeldahl, J. A new method for the determination of nitrogen in organic matter. Z. Anal. Chem. 1883, 22, 366-382. [CrossRef]

21. Naundrup, P.J.; Svenning, J.-C. A geographic assessment of the global scope for rewilding with wild-living horses (Equus ferus). PLoS ONE 2015, 10, e0132359. [CrossRef] [PubMed]

22. Carson, K.; Wood-Gush, D.G.M. Equine behaviour: II. A review of the literature on feeding, eliminative and resting behaviour. Appl. Anim. Ethol. 1983, 10, 179-190. [CrossRef]

23. Fleurance, G.; Duncan, P.; Fritz, H.; Cabaret, J.; Gordon, I.J. Importance of nutritional and anti-parasite strategies in the foraging decisions of horses: An experimental test. Oikos 2005, 110, 602-612. [CrossRef]

24. Carpenter, D.; Hammond, P.M.; Sherlock, E.; Lidgett, A.; Leigh, K.; Eggleton, P. Biodiversity of soil macrofauna in the New Forest: A benchmark study across a national park landscape. Biodivers. Conserv. 2012, 21, 3385-3410. [CrossRef]

25. McDonald, P. Animal Nutrition; Pearson Education: London, UK, 2002.

26. Andersson, A. Näringsvärde i betesgräs från naturliga betesmarker; Swedish University of Agricultural Sciences: Uppsala, Sweden, 1999.

27. Holland, E.A.; Detling, J.K. Plant response to herbivory and belowground nitrogen cycling. Ecology 1990, 71, 1040-1049. [CrossRef]

28. Kleinebecker, T.; Weber, H.; Hoelzel, N. Effects of grazing on seasonal variation of aboveground biomass quality in calcareous grasslands. Plant Ecol. 2011, 212, 1563-1576. [CrossRef]

29. Bilotta, G.S.; Brazier, R.E.; Haygarth, P.M. The Impacts of Grazing Animals on the Quality of Soils, Vegetation, and Surface Waters in Intensively Managed Grasslands. Adv. Agrono. 2007, 94, 237-280.

30. Steen, E.; Matzon, C.; Svensson, C. Avkastning På Naturbeten; Markväxt, Lantbrukshögskolan: Uppsala, Sweden, 1972.

31. Swedish Board of Agriculture. Jordbruksstatistisk sammanställning 2017. Available online: http: //www.jordbruksverket.se/omjordbruksverket/statistik/statistikomr/jordbruksstatistisksammanstallning/ jordbruksstatistisksammanstallning2017.4.695b9c5715ce6e19dbbaacb1.html (accessed on 20 March 2019).

32. Cymbaluk, N.F.; Christison, G.I.; Leach, D.H. Energy uptake and utilization by limit-fed and adlibitum-fed growing horses. J. Anim. Sci. 1989, 67, 403-413. [CrossRef] [PubMed]

33. Cymbaluk, N.F.; Christison, G.I. Effects of diet and climate on growing horses. J. Anim. Sci. 1989, 67, 48-59. [CrossRef] [PubMed]

34. LaCasha, P.A.; Brady, H.A.; Allen, V.G.; Richardson, C.R.; Pond, K.R. Voluntary intake, digestibility, and subsequent selection of Matua bromegrass, coastal bermudagrass, and alfalfa hays by yearling horses. J. Anim. Sci. 1999, 77, 2766-2773. [CrossRef] [PubMed]

35. NRC. National Research Council Committee Nutrient Requirements of Horses; National Academies Press: Washington, DC, USA, 2007.

36. Ringmark, S.; Jansson, A. Effects of crude protein content in forage-only diets fed to horses. In Proceedings of the 5th Nordic feed Science Conference, Uppsala, Sweden, 10-11 June 2014.

37. Salter, R.E.; Hudson, R.J. Feeding ecology of feral horses in western Alberta. J. Range Manag. 1979, 32, 221-225. [CrossRef]

38. Connysson, M.; Muhonen, S.; Lindberg, J.E.; Essen-Gustavsson, B.; Nyman, G.; Nostell, K.; Jansson, A. Effects on exercise response, fluid and acid-base balance of protein intake from forage-only diets in Standardbred horses. Equine Vet. J. 2006, 38, 648-653. [CrossRef] [PubMed]

39. Swedish Board of Agriculture. Jordbruksmarkens användning 2015. Available online: https://www.jordbruksverket.se/webdav/files/SJV/Amnesomraden/Statistik,\%20fakta/Arealer/JO10/ JO10SM1601/JO10SM1601_ikortadrag.htm (accessed on 10 June 2019).

40. Dyrendahl, S. Från arbetshäst i jordbruk och skogsbruk till sport- och rekreationshäst. K. Skogs. Lantbr. Akad. Tidskr. 1988, 20, 239-262.

(C) 2019 by the authors. Licensee MDPI, Basel, Switzerland. This article is an open access article distributed under the terms and conditions of the Creative Commons Attribution (CC BY) license (http://creativecommons.org/licenses/by/4.0/). 


\title{
Answers to the Frequently Asked Questions Regarding Horse Feeding and Management Practices to Reduce the Risk of Atypical Myopathy
}

\author{
Dominique-Marie Votion ${ }^{1}$, Anne-Christine François ${ }^{2, *}$, Caroline Kruse ${ }^{3}$, Benoit Renaud ${ }^{2}$, \\ Arnaud Farinelle ${ }^{4}$, Marie-Catherine Bouquieaux ${ }^{1}$, Christel Marcillaud-Pitel ${ }^{5}$ and Pascal Gustin ${ }^{2}$ \\ 1 Equine Pole, Fundamental and Applied Research for Animals \& Health (FARAH), Faculty of Veterinary \\ Medicine, University of Lieège, 4000 Liège 1 (Sart Tilman), Belgium; dominique.votion@uliege.be (D.-M.V.); \\ mcbouquieaux@uliege.be (M.-C.B.) \\ 2 Department of Functional Sciences, Faculty of Veterinary Medicine, Pharmacology and Toxicology, \\ Fundamental and Applied Research for Animals \& Health (FARAH), University of Liège, 4000 Liège \\ 1 (Sart Tilman), Belgium; benoit.renaud@uliege.be (B.R.); p.gustin@uliege.be (P.G.) \\ 3 Department of Functional Sciences, Faculty of Veterinary Medicine, Physiology and Sport Medicine, \\ Fundamental and Applied Research for Animals \& Health (FARAH), University of Liège, 4000 Liège \\ 1 (Sart Tilman), Belgium; caroline.kruse@uliege.be \\ 4 Fourrages Mieux asbl, 6900 Marloie, Belgium; farinelle@fourragesmieux.be \\ 5 Réseau d'Epidémio-Surveillance en Pathologie Équine (RESPE), 14280 Saint-Contest, France; \\ c.marcillaud-pitel@respe.net \\ * Correspondence: acfrancois@uliege.be
}

Received: 1 February 2020; Accepted: 14 February 2020; Published: 24 February 2020

Simple Summary: Equine atypical myopathy is a severe intoxication of grazing equids resulting from the ingestion of samaras or seedlings of trees from the Acer species. The sycamore maple (Acer pseudoplatanus) is involved in European cases whereas the box elder (Acer negundo) is recognized as the cause of this seasonal pasture myopathy in the Unites States of America. In Europe, young and inactive animals with a thin to normal body condition and no feed supplementation, except for hay in autumn, are at higher risk. The risk is also associated with full time pasturing in a humid environment. Indeed, dead leaves piling up in autumn as well as, the presence of trees and/or woods presumably exposes the horses to the sycamore maple. This manuscript answers the most frequently asked questions arising from the equine field about feeding and management of equines to reduce the risk of atypical myopathy. All answers are based on data collected from 2006 to 2019 by the "Atypical Myopathy Alert Group" (AMAG, Belgium) and the "Réseau d'épidémiosurveillance en Pathologie équine" (RESPE, France) as well as on a review of the most recent literature.

\begin{abstract}
In 2014, atypical myopathy (AM) was linked to Acer pseudoplatanus (sycamore maple) in Europe. The emergence of this seasonal intoxication caused by a native tree has raised many questions. This manuscript aims at answering the five most frequently asked questions (FAQs) regarding (1) identification of toxic trees; reduction of risk at the level of (2) pastures and (3) equids; (4) the risk associated with pastures with sycamores that have always been used without horses being poisoned and (5) the length of the risk periods. Answers were found in a literature review and data gathered by AM surveillance networks. A guide is offered to differentiate common maple trees (FAQ1). In order to reduce the risk of AM at pasture level: Avoid humid pastures; permanent pasturing; spreading of manure for pasture with sycamores in the vicinity and avoid sycamore maple trees around pasture (FAQ2). To reduce the risk of AM at horse level: Reduce pasturing time according to weather conditions and to less than six hours a day during risk periods for horses on risk pasture; provide supplementary feeds including toxin-free forage; water from the distribution network; vitamins and a salt block (FAQ3). All pastures with a sycamore tree in the vicinity are at risk (FAQ4). Ninety-four percent of cases occur over two 3-month periods, starting in October and in March, for cases resulting from seeds and seedlings ingestion, respectively (FAQ5).
\end{abstract}


Keywords: equine atypical myopathy; Acer spp.; risk factors; environment

\section{Introduction}

Equine atypical myopathy (AM) is a severe pasture-associated intoxication that may occur in autumn and spring following the ingestion of certain species of maple (Acer) seeds and seedlings, respectively. This environmental intoxication is linked to Acer pseudoplatanus (sycamore maple) in Europe and Acer negundo (box elder) in the US [1,2]. These trees may contain several toxins [3]. The ingestion of samaras or seedlings of the incriminated trees goes with the ingestion of two cyclopropylamino acids, hypoglycin A (HGA) and methylenecyclopropylglycine (MCPG) [4]. These toxins have been confirmed to be implicated in European AM cases. Long before the discovery of the cause of AM, Fowden and Pratt (1973) [3], reported the presence of cyclopropyl derivates in seeds of the different representatives of the Acer's species. Both Acer pseudoplatanus and Acer negundo seeds have been found to contain HGA and MCPG. On the contrary, other maple trees commonly found in Europe as Acer platanoides (Norway maple) and Acer campestre (field maple) tested negative for these compounds [3].

In fact, HGA and MCPG are not toxic per se but need to be converted into their active metabolites, i.e., methylenecyclopropylacetyl-CoA (MCPA-CoA) and methylenecyclopropylformyl-CoA (MCPF-CoA), respectively $[4,5]$. Both MCPA-CoA and MCPF-CoA inhibit enzymes that participate in $\beta$-oxidation and thus energy production from lipid metabolism $[5,6]$. The typical sign of intoxication is an acute rhabdomyolysis syndrome unrelated to exercise. This clinical picture may be seen on several horses within a group [7-10]. In more than $50 \%$ of the cases, the following clinical signs were observed: Weakness, recumbency, myoglobinuria, full bladder, stiffness, depression, muscle tremors or fasciculation, reluctance to move, sweating, normothermia, and congested mucous membranes [10-12] Atypical myopathy has a high mortality rate (i.e., $74 \%$ ) that varies between countries and years (from $43 \%$ [11] to $97 \%$ [13]). The overall mortality rate of $74 \%$ average data among countries included in the study of van Galen et al., (2012) and does not take into account the different sources of variability [11]. For example, a study reports a lower mortality rate (i.e., 44\%) in hospitalized animals [14]. It is hypothesized that less critical cases are driven to a hospital where appropriate symptomatic treatment is easier to provide. These two factors may contribute to the higher survival rate in an equine hospital than in the field. In any case, only the administration of vitamins and antioxidants has proven to be beneficial for survival [12,15].

In 2004, an alert group named "Atypical Myopathy Alert Group" (AMAG) was launched to warn horse practitioners and owners of the risk peaks. The alerts are released following case declarations and the AMAG regularly updates its data with the latest number of cases. Additionally, to its disease surveillance role, AMAG collects epidemiologic data about AM that has emerged in several European countries since 2006. French cases are gathered in close collaboration with the Réseau d'Épidémio-Surveillance en Pathologie Équine (RESPE) which monitors equine diseases through a network of French sentinel practitioners. Thanks to the European surveillance network, we now know that several Père David's deer (Elaphurus davidianus) have succumbed from this intoxication in different zoos in Germany. This indicates that ruminants pasturing in the vicinity of sycamore trees may also be intoxicated [16].

In light of the high mortality rate and the absence of specific treatment, prevention is the key to avoid intoxication of animals. Before discovering the cause of AM, epidemiological studies revealed risk factors associated with management practices of horse and pasture $[15,17]$ In 2014 , the cause of AM was discovered and linked to Acer pseudoplatanus in Europe [1]. Despite the cause of the intoxication being known, outbreaks have continued to occur. The development of a condition caused by a native tree has raised many questions among all actors attached to the equine sector. 
The most frequently asked question (FAQ) concerns the identification of toxic trees. Other commonly-asked questions involve the feeding and management practice of equids in order to reduce the risk of intoxication. These main FAQs can be summarized as being: (FAQ1) "Which maples are toxic? Is this tree a maple and if so, is it toxic?"; (FAQ2) "How can AM be prevented (at pasture level)?"; (FAQ3) “How can AM be prevented (at horse level)?"; (FAQ4) "Our pasture is surrounded by sycamore maple trees, but no case of AM ever occurred in our grazing horses. Does this mean the pasture is safe for our animals?" and (FAQ5), "When does the risk of AM start and stop in autumn and spring?".

This manuscript answers to these FAQs regarding horse nutrition and management practices in order to prevent AM both by reviewing the most recent literature and by analyzing epidemiological data gathered since 2006 .

\section{Materials and Methods}

\subsection{Literature Review}

A systematic review was performed using on the electronic databases PubMed and Scopus with « atypical myopathy » AND « horse » as keywords. In addition, abstracts of proceedings of meetings dedicated to horses were consulted (e.g., AAEP-American Association of Equine Practitioners Annual Convention, AVEF-Association des Vétérinaires Équins Français, BEPS-Belgian Equine Practitioners Society Study Days, BEVA—British Equine Veterinary Association and, WEVA—World Equine Veterinary Association Congress).

\subsection{Epidemiological Data}

Information regarding AM cases in Europe over a 13-year period (2006-2019) was collected via standardized questionnaires available on the AMAG (http://www.myopathie-atypique.be) and the RESPE (https://respe.net) websites. These forms were completed via email or phone contact with the owners or veterinarian whenever possible. Additionally, cases were also gathered by direct contact via mail or phone between owner/veterinarian and the principal investigator of this study. Information about the management and environment of diseased equines was obtained from the animals' owners whereas clinical data was collected from veterinary surgeons. Cases occurring between the 1 September to the end of February were classified as "autumnal cases" and those from the 1 March up to the end of August as "spring cases".

\section{Results}

\subsection{Literature Review}

Among 68 records identified in PubMed, five were rejected as they did not concern AM. From the search in Scopus, 514 results were obtained that were refined by selecting only research articles. From the 82 remaining studies, 63 were out of the scope and were discarded. In total, more than 127 documents (research articles and abstracts) were obtained.

\subsection{Epidemiological Data}

Epidemiologic data from 3039 cases were recorded in 14 different countries from autumn 2006 to 30 November 2019 (Figure 1, Table 1). This data set includes all cases communicated to the surveillance networks with a tentative diagnosis of AM. During this period, 14 autumnal outbreaks were encountered with a mean ( \pm S.D.) of $164.6 \pm 153.3$ (median 79.5) reported cases. For spring, 12 outbreaks were recorded with a mean ( \pm S.D.) of $56.5 \pm 77.3$ (median 24.0) diseased horses per outbreak. For all outbreaks together, the mean ( \pm S.D.) number of cases is $112.5 \pm 132.4$ (median 41). Parts of these data $(n=824)$ have already been analyzed to define risk (Table 2) and protective (Table 3) factors on cases in Belgium [17], in the UK [12] and at a European level [11,15]. Equines particularly at risk for AM were found to be young (i.e., less than 3 years of age) and inactive animals 
with normal body condition score and receiving hay in autumn [17]. The risk of intoxication was also associated with full time pasturing in a humid environment where dead leaves pile up in autumn, with the presence of trees and/or woods and thus presumably exposed to the above-mentioned maple trees $[12,15,17]$. During the ten years that have passed since the last epidemiological study performed at an European level [11,15], 2433 new cases have been reported, reaching a total number of 3039 cases available for the current study. The whole database (i.e., 2006-2019) was cleaned by removing all equids that were not at pasture at the onset of clinical signs or within the week preceding these signs, equids that were diagnosed with another disease as well as equids having a low probability of intoxication (e.g., no pigmenturia and serum creatine kinase activities $<10.000 \mathrm{IU} / \mathrm{L}$; normal values 50-200: IU/L) according to van Galen et al., 2012 [11]. As opposed to the study of van Galen et al., 2012 [11], cases too poorly documented to make a definitive diagnosis have been retained in the study group. A total of 2371 cases was included in this study. The age distribution of these cases over the years are presented in Figure 2. The weekly occurrence of AM during the spring and autumnal seasons may be found in Figure 3a,b, respectively.
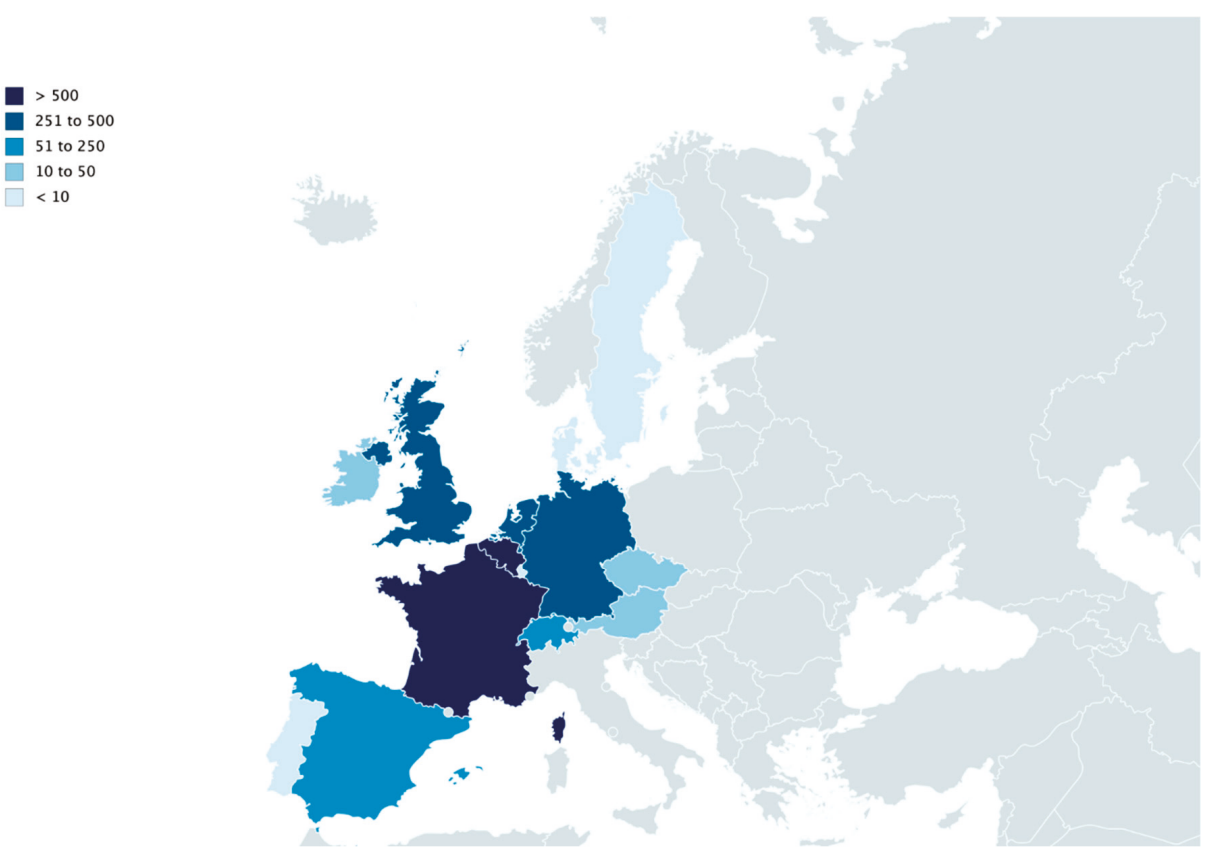

Figure 1. European distribution of atypical myopathy cases notified to the disease surveillance networks from autumn 2006 to November 2019. 


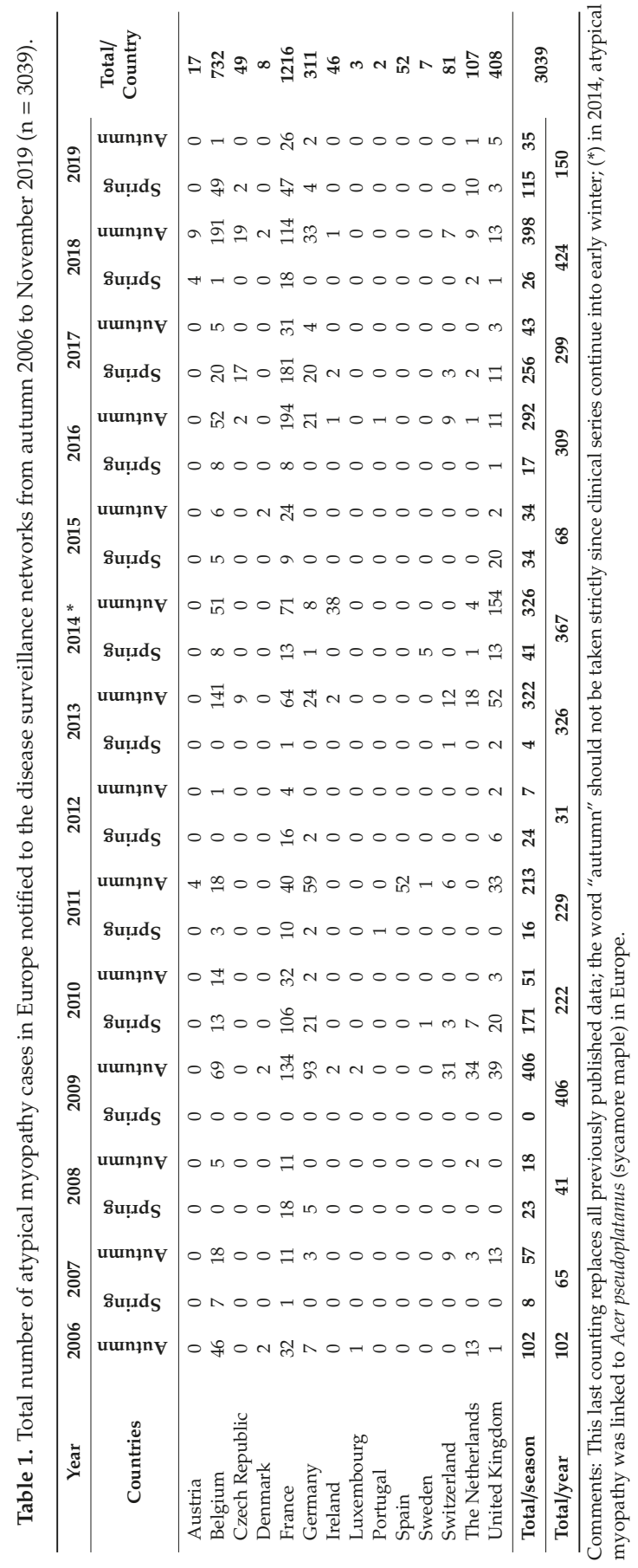




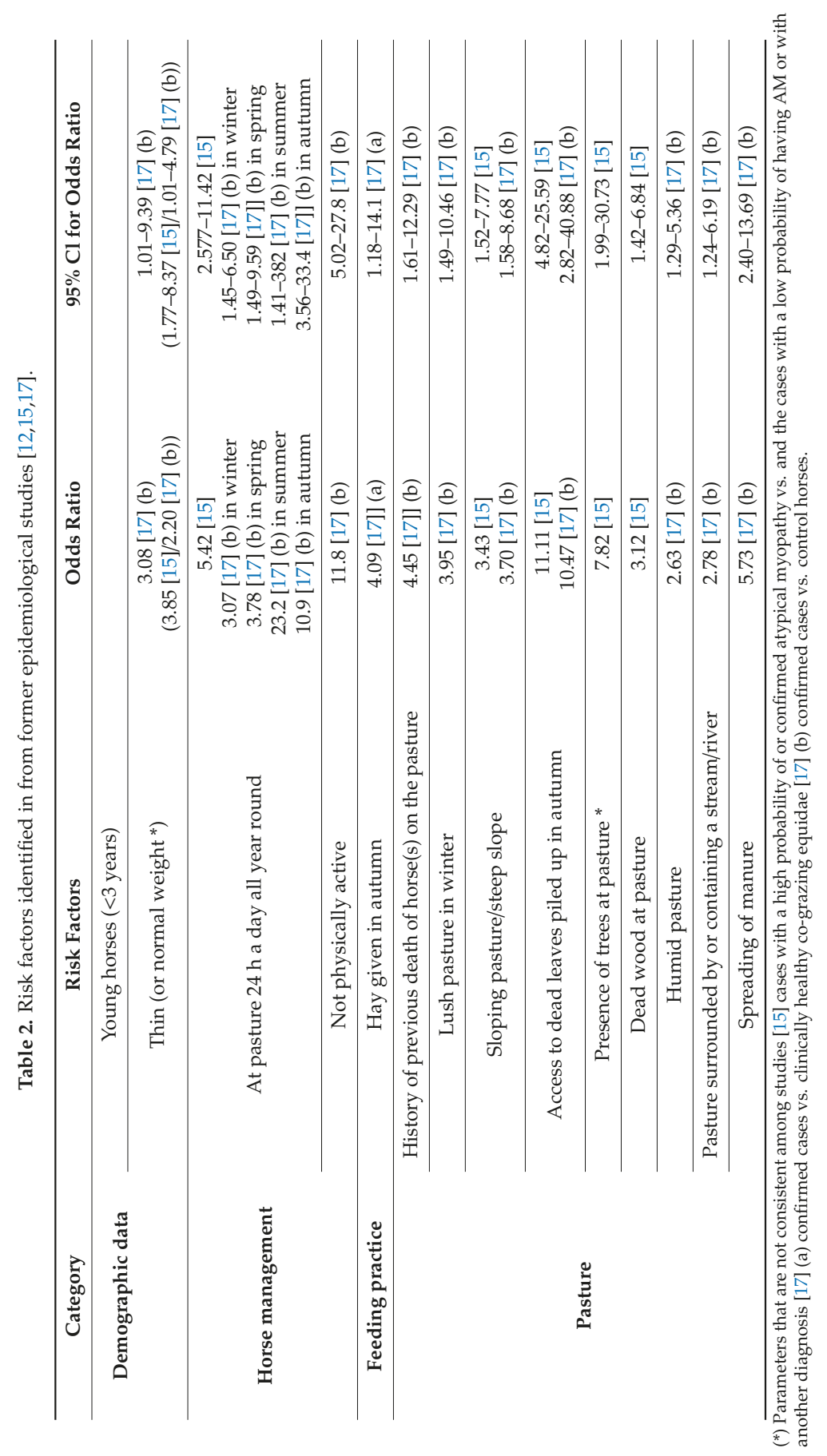




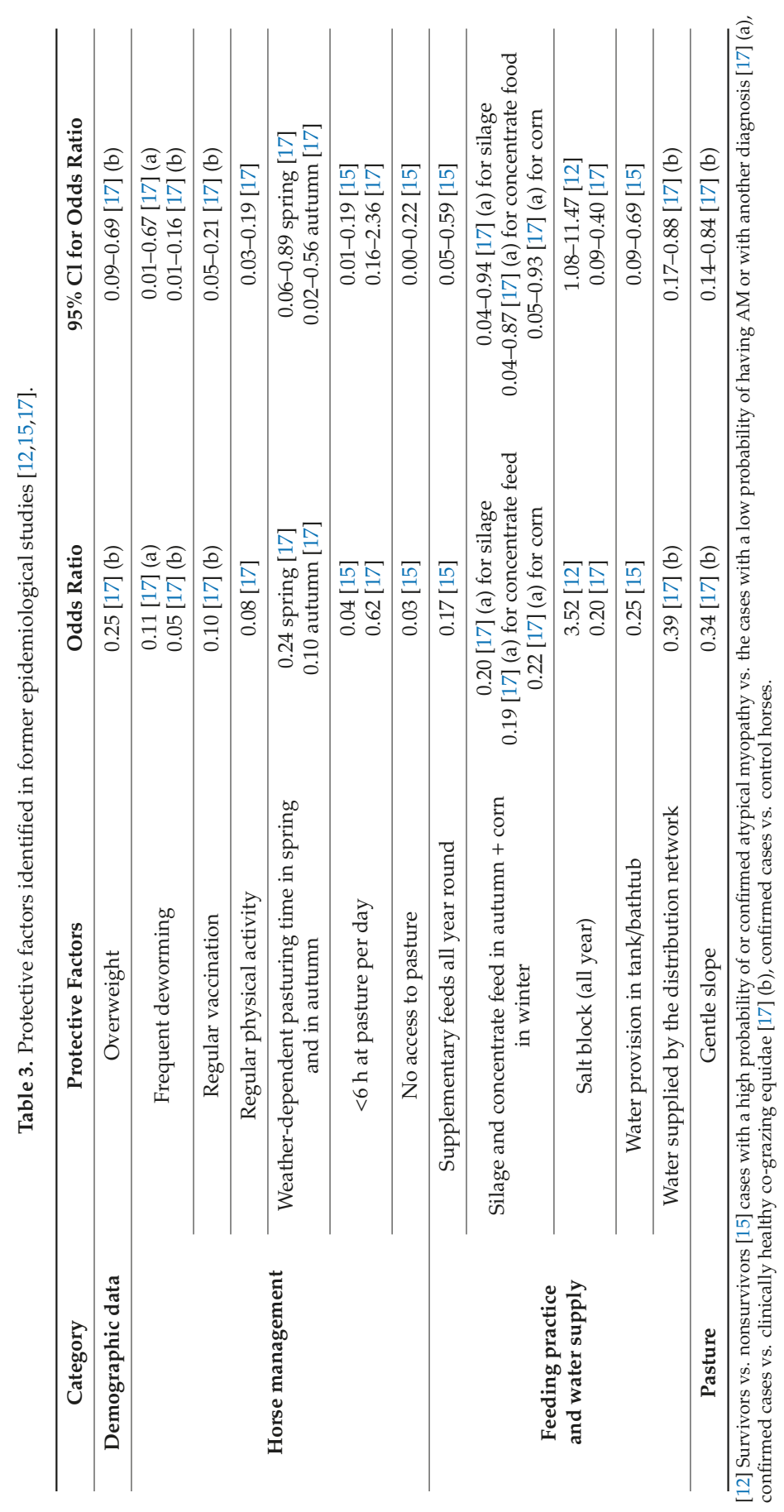




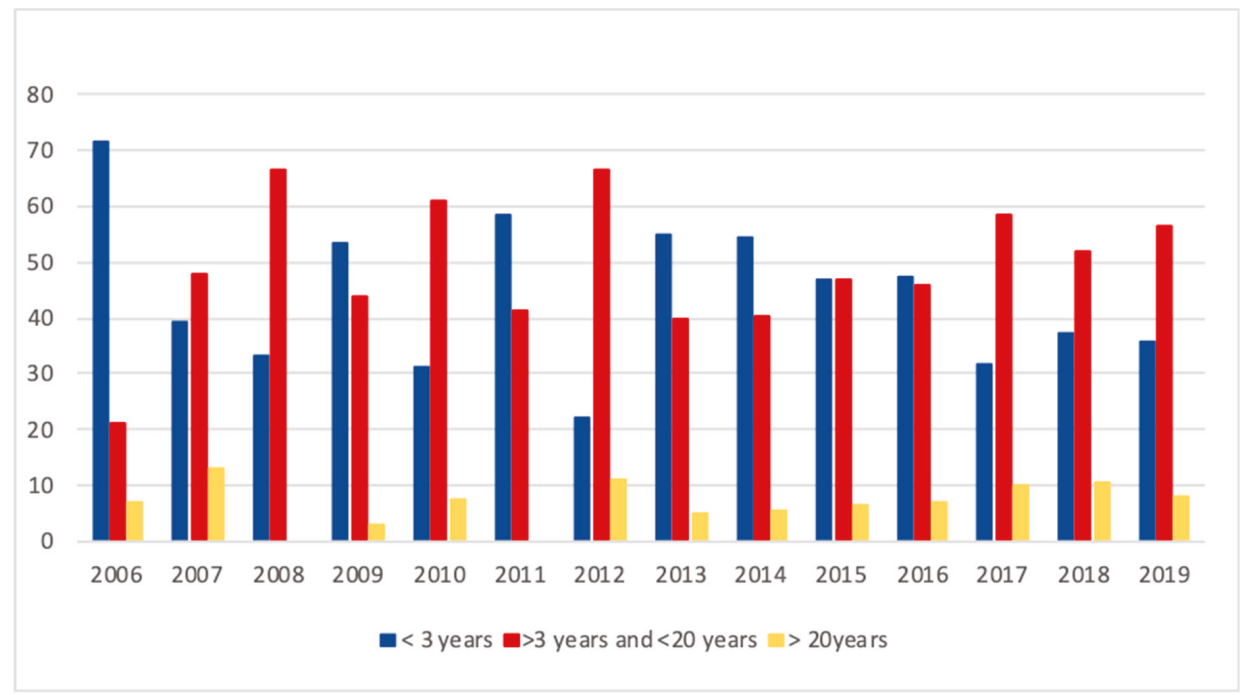

Figure 2. Frequency distribution of equids with age categories: $<3$ years, $>3$ years and $<20$ years and $>20$ years old $(n=1510)$ over the study period $(2006-2019)$.

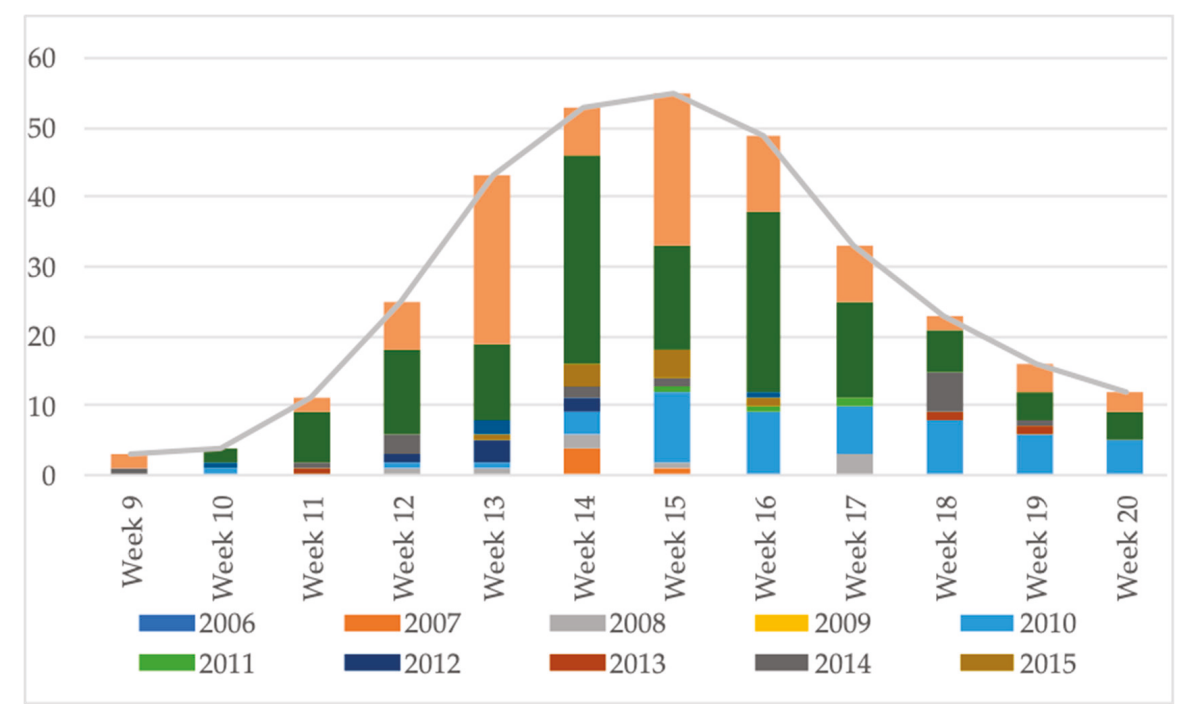

(a)

Figure 3. Cont. 


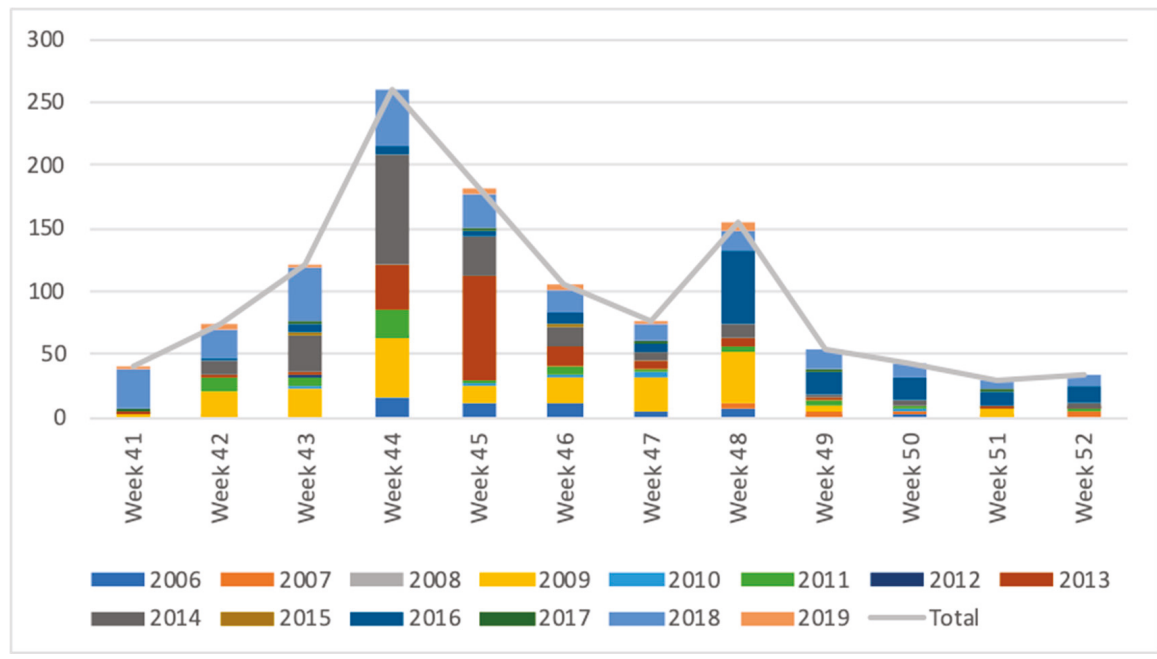

(b)

Figure 3. (a). Spring cases: weekly occurrence of atypical myopathy cases from week 9 (1 March) up to week 20 (31 May) over the study period (2006-2019); (b). Autumnal cases: weekly occurrence of atypical myopathy cases from week 41 (1 October) up to week 52 (31 December) over the study period (2006-2019).

\section{Discussion}

The origin of the results consists of previous epidemiological studies modified and completed by the analysis of the newest data. The results contribute to answer the FAQs regarding horse feeding and management practices to reduce the risk of AM.

\subsection{FAQ1: "Which Maples Are Toxic? Is this Tree a Maple and If So, Is It Toxic?"}

The question about which maple trees are toxic is often associated with a request to identify trees on the pasture. The database consultation indicates that $99 \%$ of pastures contain or are directly bordered by tree. However, looking at the data from 2014 up to now, it is observed that 20\% (92/456) of AM horse owners could not answer if seeds and/or seedlings of sycamore trees were present in their meadow. Despite the educational material available on the Internet (https://en.wikipedia.org), horse owners and veterinarians are still struggling to recognize the different maple species (personal observation). This phenomenon is accentuated due to the numerous erroneous descriptions in the literature [18]. A guide from Renaud et al., (2019) is available [19], helping the different actors to differentiate the three Acer species commonly found in European pastures where cases have been declared [20].

The maple genus includes approximately 561 species [21]. Some of them are extensively planted as ornamental trees because of their autumnal color. As a result, there is not only a demand to distinguish non-toxic trees (Acer platanoides (Norway maple) and Acer campestre (Field maple)) from Acer pseudoplatanus, but also many questions regarding the potential toxicity of other maple species. Even though up to now, not all maple trees have been tested, it is one of note that almost 50 years before the discovery of the cause of AM, the incriminated toxins had already been tested in many Acer species [3]. Among the tested species, the following species have tested positive for HGA and/or MCPG (non-exhaustive list): Acer palmatum, Acer japonicum, Acer macrophyllum, Acer spicatum, Acer saccharinurn, and Acer saccharum. These exotics species may be found in ornamental gardens and may 
spread to the neighboring regions [22]. Therefore, these Acer species might ultimately represent a risk of intoxication for equids.

\subsection{FAQ2: "How Can AM Be Prevented (at Pasture Level)?"}

Atypical myopathy occurs seasonally with outbreaks starting in autumn that may continue in early winter. On the contrary, spring outbreaks usually cease before summer. At pasture level, the risk can be decreased (1) by avoiding contact with toxic plant material and (2) by favoring low-risk meadows for pasturing during autumn and spring.

\subsubsection{Avoid Contact with Toxic Plant Materials}

Former epidemiological studies identified access to dead leaves piled up in autumn, the presence of trees and dead wood on pastures as risk factors for AM [15,17]. This observation is presumably due to the presence of Acer pseudoplatanus and the ingestion of samaras and seedlings in autumn and spring, respectively [23-25]. It is therefore important to be able to recognize Acer pseudoplatanus, its samaras and seedlings. When in doubt, professional expertise should be sought to identify the tree (botanists and/or forestry agents might be of help). Recently, it has been suggested that flowers falling from sycamore trees after heavy rainfall and/or wind could be an additional source of intoxication [26].

Depending on weather conditions, samaras of Acer species may be able to spread their seeds up to several hundred meters [27]. Therefore, pasture contamination with seeds or seedlings is not necessarily linked to the presence of a tree on the pasture. In early autumn, especially after windy weather has dispersed sycamore samaras, it is recommended to equids' owners to identify contaminated areas in their pasture. The removal of seeds may help to prevent AM [28]. However, when samaras are too abundant and/or too widely dispersed within the premise, grazing in the affected area must be prohibited. Another way to limit grazing to areas free of fallen seeds and/or flowers and/or seedlings is to create parcels within the pasture [26].

Additionally, the spreading of manure and/or harrowing of pastures was found to increase the risk of AM [17]. This practice might favor the dispersal of the toxic material throughout the pasture and subsequent intoxication of horses.

Regarding prevention at the pasture level, there is growing interest in the disposal of seedlings. It is worth noting that seedlings still contain HGA after herbicidal spraying or mowing [29]. These techniques are therefore ineffective regarding the destruction of toxic material.

\subsubsection{Use or Create Low-Risk Pastures}

Permanent pasturing was found to be a risk factor. This is most probably due to the associated decrease in grass quantity, which leads equids to ingest the etiological agent $[12,15,17]$. Our database indicates that, in $64 \%$ of our cases, the pasture grass was bare or absent of grass. This observation correlates with previous epidemiological studies [11]. A good pasture management (for example pasture rotation) is advised in order to offer lush pastures. Indeed, a green meadow will limit the ingestion of seeds and seedling by horses allowing them to eat mainly grass [11,17].

Pastures particularly at risk for AM have Acer pseudoplatanus in their vicinity. Grazing on these meadows should be avoided during the risky seasons (see FAQ4). Furthermore, humid pastures are of particular risk for AM and grazing should therefore also be avoided on these pastures [17]. HGA is a water-soluble toxin that may pass from plants to water by direct contact [26,30]. This solubility might explain the risk associated with humidity and the protective factor linked to drinking water provided via the distribution network. For this reason, only pastures that do not contain rivers and/or freestanding water should be used during the risky seasons.

\subsection{FAQ3: "How Can AM Be Prevented (at Horse Level)?"}

All type of equids were affected by AM including donkeys (1.6\% of the cases) and zebras (3 cases from zoological parks) with no highlighted risk factor associated with any species. The first 
epidemiological study highlighted that young horses, especially those $<3$ years of age were the primary affected group [17]. Later on, van Galen et al. (2012) [11] found that all age groups were represented. Our data suggest a gradual change in age distribution of cases over the years (Figure 2). In 2006, 71\% of affected equids were less than 3 years old, whereas now this age group represents only $36 \%$ of individuals. This finding is unlikely to be explained by acquisition of immunity to the toxins since some survivors of AM did succumb to a second episode of the disease (unpublished data). An explanation could be that the population at risk is increasing because toxic pressure has increased over the years. The practical usefulness of this information is that all equids must be considered at risk, whatever their age. At the animal level, the risk can be decreased by (1) management and (2) feeding practices.

\subsubsection{Management of Grazing Time}

The intoxication is intimately linked to pasturing as van Galen et al., (2012) reported that $98 \%$ of affected horses were at pasture at onset of clinical signs [11]. Our data confirms this information with $99.8 \%$ of horses being at pasture when clinical signs declared. The few remaining cases had been stabled for less than a week which implies these animals may have been in contact with the toxin before. Up to now, not a single case of our database has been confirmed in horses that had no access to pasture and/or paddock based on HGA and MCPA-carnitine detection (unpublished data). Thus, it is advised to stable horses during autumn and spring outbreaks if seeds or seedlings are, or may be, present at pasture [26]. However, keeping a horse in the stable day and night may be difficult and is not considered as good practice in animal welfare [31,32]. Interestingly, the limitation of grazing time to less than six hours a day was found to be a protective factor [15]. Consistent with a previous study of UK cases [12], 97.5\% of equids of our database had spent more than six hours per day at pasture. This observation suggests that the length of exposure to the toxins appears to be a determining factor in the risk of AM.

Specific weather conditions have been linked with AM outbreaks $[9,10,33,34]$ whereas weather-dependent pasturing time (i.e., stabling horses when inclement weather is forecast) reduces the risk of AM [17]. Reducing pasturing time according to weather conditions was not a recommendation implemented by owners in our cases since less than $1 \%$ of them were in compliance with this preventive measure. Our data reinforces the value of this preventive measure.

\subsubsection{Feed and Water Supply}

Receiving supplementary feeds (hay, straw, complete mix, oats, barley, and/or corn) throughout the year decreases the risk of AM [17]. Atypical myopathy results from an energetic imbalance subsequent to HGA and MCPG poisoning. Feed provides energy substrates (especially carbohydrates) that supports the energetic metabolism and also vitamins and antioxidants known to increase the chance of survival [15]. The mitochondrial enzymes inhibited by HGA are flavin adenine dinucleotide (FAD) dependent. This cofactor originates from riboflavin (vitamin B2) suggesting that it would be useful to give this vitamin [35]. Alfalfa is an excellent natural source of riboflavin as well as, to a lesser extent, the hay from common grass [36]. In addition, well-nourished horses might be less tempted to ingest samaras and/or seedlings. Among horses receiving supplementary feeds in their daily diet $(64 \% ; n=665)$, our data indicates that $61 \%$ received concentrated feed (complete mix, oats, and/or barley) and 50\% had access to a salt block providing minerals. However, a salt block did not prevent these animals to be intoxicated.

Giving hay in autumn was identified as a risk factor [17] (and 40\% of our cases receiving supplementary feed were fed with hay only). Indeed, hay may contain seeds and seedlings with detectable HGA concentration after several months [29] and even years of storage [30]. Gonzales et al. (2019) suggests that AM might occur in stabled horses [29] but this hypothesis is not sustained by our data since, as above-mentioned, not a single case has been confirmed by blood testing in equids with no access to pasture and/or paddock. However, we do agree that giving hay produced from contaminated pasture would increase the risk of AM in horses kept at pasture. It is probably wise not to produce 
hay/haylage and/or silage from pasture areas in the vicinity of sycamore trees [29]. Providing hay in autumn is controversial. Indeed, this practice was found to be a risk factor in a case-control study [17] but that appears nevertheless as a protective factor when comparing management practice in pasture of cases versus pastures of controls [15]. From this result, we can suggest that forages free from toxins should be given at libitum, but hay should neither be placed on the ground, nor under sycamore trees, since both practices could increase the risk of ingesting toxic material.

\subsubsection{Drinking Water}

Water supplied by the distribution network [17] or stored in a tank or in an bathtub [15] are protective factors. These observations suggest that water from other sources may be contaminated by the toxins. This hypothesis is reinforced by the study of Renaud et al., (2019) [30], which showed that HGA is released by stagnant flowers or seeds from Acer pseudoplatanus in contact with water. On the other hand, when water is dripping off flowers, no HGA is detected in collected water. However, this latest observation can be modulated by the fact that (1) the concentration of HGA can be below the limit detection threshold of the quantification method or (2) that HGA might be degraded in water. To the authors knowledge, there is no published study about the stability of HGA in water.

\subsection{FAQ4: "Our Pasture Is Surrounded by Sycamore Maple Trees, but No Case of AM ever Occured in Our Grazing Horses. Does this Mean the Pasture Is Safe for Our Animals?"}

Our data and former epidemiological studies indicate that unexplained sudden deaths of horse(s) had been noted on $22 \%$ of the pastures where cases were grazing [11]. In other words, $80 \%$ of cases were grazing in pastures that had no history of previous death of equid(s) (regardless of the suspected cause). Atypical myopathy is an emerging disease and a pasture surrounded by sycamore trees should not be considered as safe for pasturing horses.

\subsection{FAQ5: "When Does the Risk of AM Start and Stop in Autumn and Spring?"}

As previously reported, cases of AM occur more frequently in autumn $(76 \% ; n=1801)$ than in spring $(24 \% ; n=570)$. The expressions "autumn" and "spring" should not be taken stricto senso, since the autumnal clinical series are continuing in early winter and some spring cases are occurring after the 21 June. It is worth noting that $94 \%$ of "spring" cases occurred between the 1 March and the 31 May and $94 \%$ of "autumnal" cases occurred between the 1 October up to the 31 December (Figure 3a,b).

The cause of autumnal outbreaks cessation is not precisely known. Before discovering the etiology of AM, it was hypothesized that severe frost might destroy the etiological agent since outbreaks tend to cease after several days of deep freezing [10]. Now that HGA has been described as incriminated toxin, this hypothesis can be refuted since laboratory investigation showed that HGA is unaltered after several freeze-thaw cycles [37]. In our laboratory (unpublished data), we have collected samaras from the environment on a weekly basis since 2016 from now and, with very few exceptions, HGA has always been detected in seeds of sycamore tree. However, clinical series of AM usually fully stop in winter and resume with the germination of the samaras (personal observation). The analysis of HGA concentration over time in samaras fallen on the ground showed a high variability from tree to tree and from week to week thus impeding an easy interpretation of the evolution of toxicity. These field studies were complicated by the fact that the samaras collected on the ground had fallen at very different times. Therefore, the cause of the ceasing "autumnal" outbreaks in winter is not known but could result from a reduction in accessibility (e.g., adheration to the ground following rain and frost) and/or a decrease in toxins' concentration).

Regarding spring outbreaks, horse owners wonder if the case series stops because the seedlings have lost in toxicity. Actually, the end of spring outbreaks may not be explained by the disappearance of the toxicity since the seedlings remain toxic [26]. It is however hypothesized that spring outbreaks cease following a relative decrease in risk of intoxication by grazing. This reduced risk of intoxication might result from (1) a lusher meadow, (2) the observed decrease in toxicity of seedlings with their 
growth [26], (3) a decrease in palatability of older plants [26], (4) less frequently encountered weather conditions favoring toxicity and (5), a significant natural disappearance of seedlings. Regarding the latter, only a small percentage $(<20 \%)$ of seedlings recorded in early spring on heavily contaminated pastures are still present in early summer (unpublished data). This observation added to the fact that herbicidal spraying do not reduce HGA concentration in sycamore seedlings [29] questions the benefit of herbicide treatments.

\section{Conclusions}

As there is no specific treatment for AM yet, prevention is the key. The risk of developing AM results from the combinations of protective and risk factors. In order to reduce the risk of AM, it is advised to avoid humid pastures, permanent pasturing, spreading of manure, and contact with sycamore plant material. During the risky periods pasturing time should be modulated according to weather conditions and limited to less than six hours a day. Grazing equids should receive supplementary feeds, with preferences for feeds containing riboflavin. When hay or silage are fed, it is necessary to exercise caution ensuring the forages are toxin-free. Also, it is advised to supply a salt block and provide drinking water from the distribution network. It is worth noting that AM is an emerging disease and equids of any age and all pastures with a sycamore tree in the vicinity must be considered at risk. These preventive measures should be implemented for a period of 3 months twice yearly, starting in March for "spring cases" then again in October to prevent "autumnal cases". As mentioned before, these are the critical seasons and samaras or seedlings are likely to be present on the pasture. A French version of this paper with additional illustrations can be found in supplementary materials (Supplementary S1).

Supplementary Materials: The following are available online at http:/www.mdpi.com/2076-2615/10/2/365/s1, Supplementary S1: A French version of this paper with additional illustrations.

Author Contributions: Data curation, M.-C.B.; Funding acquisition, D.-M.V.; Investigation, D.-M.V.; Resources, A.F. and C.M.-P.; Supervision, D.-M.V. and P.G.; Writing-original draft, D.-M.V. and A.-C.F.; Writing-review and editing, B.R. and C.K. All authors have read and agreed to the published version of the manuscript.

Funding: The study was supported by the la Wallonie agriculture SPW (Service public de Wallonie; Belgique), $l^{\prime \prime \prime I n s t i t u t ~ f r a n c ̧ a i s ~ d u ~ c h e v a l ~ e t ~ d e ~ l ' e ́ q u i t a t i o n ~(I f c e) " ~ o f ~ F r a n c e ~ a n d ~ b y ~ " L e s ~ F o n d s ~ S p e ́ c i a u x ~ p o u r ~ l a ~ R e c h e r c h e ~}$ (FSR)" of Liege University (Belgium).

Acknowledgments: The authors thank all communicating veterinarians and owners of affected horses for their collaboration.

Conflicts of Interest: The authors declare no conflict of interest.

\section{References}

1. Votion, D.M.; Van Galen, G.; Sweetman, L.; Boemer, F.; De Tullio, P.; Dopagne, C.; Lefère, L.; Mouithys-Mickalad, A.; Patarin, F.; Rouxhet, S.; et al. Identification of methylenecyclopropyl acetic acid in serum of European horses with atypical myopathy. Equine Vet. J. 2014, 46, 146-149. [CrossRef]

2. Valberg, S.J.; Sponseller, B.T.; Hegeman, A.D.; Earing, J.; Bender, J.B.; Martinson, K.L.; Patterson, S.E.; Sweetman, L. Seasonal pasture myopathy/atypical myopathy in North America associated with ingestion of hypoglycin A within seeds of the box elder tree. Equine Vet. J. 2013, 45, 419-426. [CrossRef]

3. Fowden, L.; Pratt, H.M. Cyclopropylamino acids of the genus Acer: Distribution and biosynthesis. Phytochemistry 1973, 12, 1677-1681. [CrossRef]

4. Bochnia, M.; Sander, J.; Ziegler, J.; Terhardt, M.; Sander, S.; Janzen, N.; Cavalleri, J.M.; Zuraw, A.; Wensch-Dorendorf, M.; Zeyner, A. Detection of MCPG metabolites in horses with atypical myopathy. PLoS ONE 2019, 14, e0211698. [CrossRef]

5. Von Holt, C.; Chang, J.; von Holt, M.; Böhm, H. Metabolism and metabolic effects of hypoglycin. Biochim. Biophys. Acta 1964, 0, 611-613. [CrossRef]

6. Melde, K.; Jackson, S.; Bartlett, K.; Stanley, H.; Sherratt, H.; Ghisla, S. Metabolic consequences of methylenecyclopropylglycine poisoning in rats. Biochem. J. 1991, 274, 395-400. [CrossRef] 
7. Westermann, C.M.; de Sain-van der Velden, M.G.M.; van der Kolk, J.H.; Berger, R.; Wijnberg, I.D.; Koeman, J.P.; Wanders, R.J.A.; Lenstra, J.A.; Testerink, N.; Vaandrager, A.B.; et al. Equine biochemical multiple acyl-CoA dehydrogenase deficiency (MADD) as a cause of rhabdomyolysis. Mol. Genet. Metab. 2007, 91, 362-369. [CrossRef] [PubMed]

8. Palencia, P.; Rivero, J.L.L. Short Communications Atypical myopathy in two grazing horses in northern Spain. Vet. Rec. 2007, 161, 346-348. [CrossRef] [PubMed]

9. Finno, C.J.; Valberg, S.J.; Wünschmann, A.; Murphy, M.J. Seasonal pasture myopathy in horses in the midwestern United States: 14 cases (1998-2005). J. Am. Vet. Med. Assoc. 2006, 229, 1134-1141. [CrossRef]

10. Votion, D.M.; Linden, A.; Saegerman, C.; Engels, P.; Erpicum, M.; Thiry, E.; Delguste, C.; Rouxhet, S.; Demoulin, V.; Navet, R.; et al. History and clinical features of atypical myopathy in horses in Belgium (2000-2005). J. Vet. Intern. Med. 2007, 21, 1380-1391. [PubMed]

11. Van Galen, G.; Marcillaud Pitel, C.; Saegerman, C.; Patarin, F.; Amory, H.; Baily, J.D.; Cassart, D.; Gerber, V.; Hahn, C.; Harris, P.; et al. European outbreaks of atypical myopathy in grazing equids (2006-2009): Spatiotemporal distribution, history and clinical features. Equine Vet. J. 2012, 44, 614-620. [CrossRef] [PubMed]

12. Gonzalez-Medina, S.; Ireland, J.L.; Piercy, R.J.; Newton, J.R.; Votion, D. Equine atypical myopathy in the UK: Epidemiological characteristics of cases reported from 2011 to 2015 and factors associated with survival. Equine Vet. J. 2017, 49, 746-752. [CrossRef] [PubMed]

13. Brandt, K.; Brandtt, K.; Hinrrchs, U.; Schulze, C.; Landes, E. Atypische Myoglobinurie der Weidepferde. Pferdeheilkunde 1997, 13, 27-34. [CrossRef]

14. Dunkel, B.; Ryan, A.; Haggett, E.; Knowles, E.J. Atypical myopathy in the South-East of England: Clinicopathological data and outcome in hospitalised horses. Equine Vet. Educ. 2018, 1-6. [CrossRef]

15. Van Galen, G.; Saegerman, C.; Marcillaud Pitel, C.; Patarin, F.; Amory, H.; Baily, J.D.; Cassart, D.; Gerber, V.; Hahn, C.; Harris, P.; et al. European outbreaks of atypical myopathy in grazing horses (2006-2009): Determination of indicators for risk and prognostic factors. Equine Vet. J. Vol. 2012, 44, 621-625. [CrossRef]

16. Bunert, C.; Langer, S.; Votion, D.M.; Boemer, F.; Muller, A.; Ternes, K.; Liesegang, A. Atypical myopathy in Pere David's deer (Elaphurus davidianus) associated with ingestion of hypoglycin A. J. Anim. Sci. 2018, 96, 3537-3547. [CrossRef]

17. Votion, D.M.; Linden, A.; Delguste, C.; Amory, H.; Thiry, E.; Engels, P.; Van Galen, G.; Navet, R.; Sluse, F.; Serteyn, D.; et al. Atypical myopathy in grazing horses: A first exploratory data analysis. Vet. J. 2009, 180, 77-87. [CrossRef]

18. Westermann, C.M.; van Leeuwen, R.; van Raamsdonk, L.W.D.; Mol, H.G.J. “Hypoglycin A Concentrations in Maple Tree Species in the Netherlands and the Occurrence of Atypical Myopathy in Horses. J. Vet. Intern. Med. 2016, 30, 880-884. [CrossRef]

19. Renaud, B.; François, A.-C.; Dopagne, C.; Rouxhet, S.; Gustin, P.; Votion, D. Identification of the Maple Tree Responsible for Atypical Myopathy. Available online: http://hdl.handle.net/2268/242221 (accessed on 12 December 2019).

20. Van Galen, G.; Dopagne, C.; Rouxhet, S.; Pitel, C.; Votion, D. Etiologie de la myopathie atypique: Conditions de toxicité de l'agent causal-Étude préliminaire. In 40ème Journée de la Recherche Equine; Institut français du cheval et de l'équitation (IFCE): Paris, France, 2014; pp. 101-109.

21. Search Results_-The Plant List. Available online: http://www.theplantlist.org/tpl/search?q=Acer\&_csv=on (accessed on 12 December 2019).

22. Hulme, P.E.; Bacher, S.; Kenis, M.; Klotz, S.; Kühn, I.; Minchin, D.; Nentwig, W.; Olenin, S.; Panov, V.; Pergl, J.; et al. Grasping at the routes of biological invasions: A framework for integrating pathways into policy. J. Appl. Ecol. 2008, 45, 403-441. [CrossRef]

23. Unger, L.; Nicholson, A.; Jewitt, E.M.; Gerber, V.; Hegeman, A.; Sweetman, L.; Valberg, S. Hypoglycin A Concentrations in Seeds of Acer Pseudoplatanus Trees Growing on Atypical Myopathy-Affected and Control Pastures. J. Vet. Intern. Med. 2014, 28, 1289-1293. [CrossRef]

24. Baise, E.; Habyarimana, J.A.; Amory, H.; Boemer, F.; Douny, C.; Gustin, P.; Marcillaud-Pitel, C.; Patarin, F.; Weber, M.; Votion, D.M. Samaras and seedlings of Acer pseudoplatanus are potential sources of hypoglycin A intoxication in atypical myopathy without necessarily inducing clinical signs. Equine Vet. J. 2016, 48, 414-417. [CrossRef] [PubMed] 
25. Zuraw, A.; Dietert, K.; Kühnel, S.; Sander, J.; Klopfleisch, R. “Equine atypical myopathy caused by hypoglycin A intoxication associated with ingestion of sycamore maple tree seeds. Equine Vet. J. 2016, 48, 418-442. [CrossRef] [PubMed]

26. Votion, D.M.; Habyarimana, J.A.; Scippo, M.L.; Richard, E.A.; Marcillaud-Pitel, C.; Erpicum, M.; Gustin, P. Potential new sources of hypoglycin A poisoning for equids kept at pasture in spring: A field pilot study. Vet. Rec. 2019, 184, 740. [CrossRef] [PubMed]

27. Katul, G.G.; Porporato, A.; Nathan, R.; Siqueira, M.; Soons, M.B.; Poggi, D.; Horn, H.S.; Levin, S.A. Mechanistic analytical models for long-distance seed dispersal by wind. Am. Nat. 2005, 166, 368-381. [CrossRef] [PubMed]

28. Votion, D. Atypical myopathy: An update. Practice 2016, 38, 241-246. [CrossRef]

29. Gonzalez-Medina, S.; Montesso, F.; Chang, Y.-M.; Hyde, C.; Piercy, R.J. Atypical myopathy-associated hypoglycin A toxin remains in Sycamore seedlings despite mowing, herbicidal spraying or storage in hay and silage. Equine Vet. J. 2019, 51, 701-704. [CrossRef]

30. Renaud, B.; Francois, A.C.; Marcillaud-Pitel, C.; Gustin, P.; Votion, D. Myopathie atypique: Les différentes sources d'intoxication. Comment gérer le risque? In Journées Sciences et Innovations Équines; Institut français du cheval et de l'équitation (Ifce): Saumur, France, 2019; p. 9.

31. Cooper, J.J.; Mason, G.J. The identification of abnormal behaviour and behavioural problems in stabled horses and their relationship to horse welfare: A comparative review. Equine Vet. J. Suppl. 1998, 30, 5-9. [CrossRef]

32. Cooper, J.J.; Albentosa, M.J. Behavioural adaptation in the domestic horse: Potential role of apparently abnormal responses including stereotypic behavior. Livest. Prod. Sci. 2005, 92, 177-182. [CrossRef]

33. Hosie, B.D.; Gould, P.W.; Hunter, A.R.; Low, J.C.; Munro, R.; Wilson, H.C. Acute myopathy in horses at grass in east and south east Scotland. Vet. Rec. 1986, 119, 444-449. [CrossRef]

34. Harris, P.; Whitwell, K. Atypical myoglobinuria alert. Vet. Rec. 1990, 15, 603.

35. Westermann, C.M.; Dorland, L.; Votion, D.M.; De Sain-van der Velden, M.G.M.; Wijnberg, I.D.; Wanders, R.J.A.; Spliet, W.G.M.; Testerink, N.; Berger, R.; Ruiter, J.P.N.; et al. Acquired multiple Acyl-CoA dehydrogenase deficiency in 10 horses with atypical myopathy. Neuromuscul. Disord. 2008, 18, 355-364. [CrossRef] [PubMed]

36. Rooney, D.K. Applied nutrition. In Equine Internal Medicine; Sellon, D.C., Reed, S.M., Bayly, W.M., Eds.; W.B. Saunders: Philadelphia, PA, USA, 2004; pp. 235-272.

37. Gonzalez-Medina, S.; Hyde, C.; Lovera, I.; Piercy, R.J. Detection of equine atypical myopathy-associated hypoglycin A in plant material: Optimisation and validation of a novel LC-MS based method without derivatisation. PLoS ONE 2018, 13, 13-15. [CrossRef] [PubMed]

(C) 2020 by the authors. Licensee MDPI, Basel, Switzerland. This article is an open access article distributed under the terms and conditions of the Creative Commons Attribution (CC BY) license (http://creativecommons.org/licenses/by/4.0/). 


\title{
Differential Defecation of Solid and Liquid Phases in Horses-A Descriptive Survey
}

\author{
Katrin M. Lindroth ${ }^{1, *}$, Astrid Johansen ${ }^{2}$, Viveca Båverud ${ }^{3}$, Johan Dicksved ${ }^{1}$, \\ Jan Erik Lindberg ${ }^{1}$ and Cecilia E. Müller ${ }^{1}$ \\ 1 Department of Animal Nutrition and Management, Swedish University of Agricultural Sciences, \\ P.O. Box 7024, 75007 Uppsala, Sweden; Johan.Dicksved@slu.se (J.D.); jan.erik.lindberg@slu.se (J.E.L.); \\ cecilia.muller@slu.se (C.E.M.) \\ 2 NIBIO, Norwegian Institute of Bioeconomy Research, P.O. Box 115, 1431 Ås, Norway; astrid.johansen@nlr.no \\ 3 National Veterinary Institute, 75189 Uppsala, Sweden; viveca.baverud@sva.se \\ * Correspondence: katrin.lindroth@slu.se; Tel.: +46-1867-1781
}

Received: 30 October 2019; Accepted: 28 December 2019; Published: 1 January 2020

Simple Summary: Free faecal liquid is a condition in horses where faeces are voided in one solid and one liquid phase. The presence of free faecal liquid may cause management problems in equine husbandry and is potentially contributing to impaired equine welfare. Causes of free faecal liquid are not known, but nutritional factors such as the feeding of specific forages have been suggested to be of importance. Characterization of horses showing free faecal liquid and their feeding and management was, therefore, performed via an internet-based survey in order to map the condition further. Results showed that horses with free faecal liquid included a large variety of different breeds, ages, disciplines, coat colours, housing systems and feeding strategies, meaning that almost any type of horse could be affected. Horses that were reported to show free faecal liquid did so with all types of feeding strategies, but changes from wrapped forage to hay, to pasture, or to another batch of wrapped forage often resulted in diminished signs of free faecal liquid. Horses were also reported to have a comparably high incidence of colic in relation to published data for other horse populations. The results indicated that more detailed studies are required for a further understanding of the underlying cause of free faecal liquid.

\begin{abstract}
Free faecal liquid (FFL) is a condition in horses where faeces are voided in one solid and one liquid phase. The liquid phase contaminates the tail, hindlegs and area around the anus of the horse, resulting in management problems and potentially contributing to impaired equine welfare. The underlying causes are not known, but anecdotal suggestions include feeding wrapped forages or other feed- or management-related factors. Individual horse factors may also be associated with the presence of FFL. This study, therefore, aimed to characterize horses showing FFL particularly when fed wrapped forages, and to map the management and feeding strategies of these horses. Data were retrieved by a web-based survey, including 339 horses with FFL. A large variety of different breeds, ages, disciplines, coat colours, housing systems and feeding strategies were represented among the horses in the study, meaning that any type of horse could be affected. Respondents were asked to indicate if their horse had diminished signs of FFL with different changes in forage feeding. Fifty-eight percent $(n=197)$ of the horse owners reported diminished signs of FFL in their horses when changing from wrapped forages to hay; $46(n=156)$ of the horse owners reported diminished signs of FFL in their horses when changing from wrapped forages to pasture; $17 \%(n=58)$ reported diminished signs of FFL when changing from any type of forage batch to any other forage. This indicated that feeding strategy may be of importance, but cannot solely explain the presence of FFL. The results also showed that the horses in this study had a comparably high incidence of previous colic $(23 \%, n=78)$ compared to published data from other horse populations. In conclusion, the results showed that FFL may affect a large variety of horse types and that further studies should include detailed data on
\end{abstract}


individual horse factors including gastrointestinal diseases as well as feeding strategies, in order to increase the chance of finding causes of FFL.

Keywords: colic; equine; free faecal liquid; faecal water syndrome; feed changes; nutrition

\section{Introduction}

Free faecal liquid (FFL) is a condition in horses where faeces are voided in two physical phases; one solid and one liquid phase. The solid phase can be typical equine faecal balls, or more watery and similar to cowpat faeces. The liquid phase is a brown-coloured liquid that can be voided separately or together with the solid phase. The condition has previously been referred to as free faecal water and/or free faecal water syndrome (FWS), and cases have been described in Germany [1-3], Denmark [4] and Italy [5], but the overall incidence of FFL is not known. Horse owners in Sweden and Norway have anecdotally reported cases of FFL in horses, and have referred to the condition as "haylage intolerance" due to an assumed association with feeding wrapped forages (including grass conserved as silage and/or haylage with dry matter concentrations from 300-840 g per kg [6-8]). During the latest 25 years, wrapped forages such as grass silage and haylage have partially or totally replaced hay in equine feed rations in Nordic countries [9-11].

Horses affected with FFL may show discomfort when voiding faeces and/or faecal liquid, such as nervous trampling with hindlegs and extensive tail swishing, but no symptoms of disease have been described [1,5]. The faecal liquid may, however, cause lesions in the skin around the anus and on the inside of the hindlegs, as well as dirty tail and hindlegs of affected horses. The causes of FFL are unknown, but feeding wrapped forages instead of hay, feeding high amounts of alfalfa, being over 20 years of age, having poor dentition and endoparasitic infections have been suggested [1]. In a German study [1], associations between the presence of FFL and intrinsic horse factors such as being a gelding, paint-coloured and low in the social hierarchy in a group of horses were found. Improvement of the condition have been reported in association to changes in the diet in a one-horse case study [5] and after faecal transplantation performed in a study including 10 horses with FFL and twelve horses assessed to be clinically healthy [4]. However, no clear associations to feed- or management-related factors $[1,3,12]$ has been reported. Systematic collection of data on horse characteristics as well as on feeding and management of horses affected with FFL is scarce in the scientific literature. The aim of the present study was, therefore, to characterize horses showing FFL (when fed wrapped forages) and to map the feeding and management strategies of these horses. Such information is required for further studies of causes for the condition.

\section{Materials and Methods}

An online survey directed to owners and/or caretakers of horses showing FFL when fed wrapped forages was performed. The inclusion criteria were that horses should be $>2$ years old, showing FFL when fed wrapped forages and be located in Sweden or Norway (two countries in close proximity and with similar conditions for horse feeding and management). The inclusion criteria were given on the start page of the survey, and 3 questions in the survey were control questions ensuring that the inclusion criteria were met. The survey was created using the tool Netigate (Netigate, Stockholm) and was advertised through the website of the Department of Animal Nutrition and Management, SLU (http://www.slu.se/sv/institutioner/husdjurens-utfodring-vard/), Norsk hestesenter (http://www.nhest.no), Norwegian institute of Bioeconomy Research (http://www.nibio.no) and the website Hästsverige (http://www.hastsverige.se), a Swedish platform communicating equine research to the public. The full survey is available in Table S1 (Supplementary Materials). 


\subsection{Data Collection}

The survey was open from March 2016 to March 2017 and was available in both Swedish and Norwegian language. Respondents were instructed to give information about one horse per entry, even if they owned more than one horse showing FFL. If so, it was possible for the same respondent to answer the survey several times. The respondents were asked to answer questions about the horse, how it was kept and managed, current and previous feeding and history of gastrointestinal disturbances including FFL. The survey contained 50 questions in total, divided into horse characteristics (e.g., age, sex, breed, colour, body condition score [13] and temper as judged by the respondent); training (e.g., discipline, intensity); management (e.g., type of housing system, paddock use); current feeding (type and amount of feeds), feeding and watering strategies (e.g., number of feedings, time between feedings, how feed was offered in stable and paddock, type of water source and access to salt); presence of FFL (e.g., presence and symptoms of FFL, changes in faecal appearance due to feed changes, number of affected horses kept in the same housing system); and previous history of gastrointestinal tract (GIT) diseases.

\subsection{Data Treatment}

The data on horse breeds contained over 30 different breeds but with very few individuals in several breeds. Therefore, this variable was transformed to breed type. The reported breeds were divided into 4 breed groups; warmblood type horses (Appaloosa $(n=3)$, crossbred horses of warmblood type $(n=64)$, European warmblood riding horses $(n=82)$, Lusitano $(n=1)$, Standardbreds $(n=15)$, Paint horse $(n=2)$, Pura Raza Espaniola $(n=11)$ and Quarter horse $(n=2))$; cold-blood type horses (Ardennais $(n=4)$, Clydesdale $(n=1)$, Cold-blooded trotter $(n=13)$, crossbred horses of cold-blood type $(n=19)$, Dølehorse $(n=2)$, Friesian horse $(n=3)$, Haflinger $(n=3)$, North-Swedish draught horse $(n=8)$, Norwegian Fjord Horse $(n=12)$, Shire $(n=1)$ and Tinker $(n=1))$; Hot-blooded horses (Angloarabian $(n=1)$, Arabian $(n=8)$, and Thoroughbreds $(n=2)$ ); and native pony breeds (Connemara $(n=10)$, crossbred ponies $(n=25)$, Gotland pony $(n=6)$, Icelandic horse $(n=13)$, New Forest $(n=10)$, Shetland pony $(n=6)$, Welsh cob $(n=3)$ and Welsh pony $(n=8))$.

\subsection{Calculations and Statistical Analysis}

Statistical analysis was performed using SAS (Statistical Analysis System Institute Inc., Cary, NC, USA) version 9.4 for Windows. For continuous variables, minimum, maximum, quartiles (Q1, Q2 (median) and Q3), mean and standard deviation was calculated. The reported bodyweight (BW) of the horse and reported feeding levels were used to calculate the daily intake of feed ( $\mathrm{g}$ or $\mathrm{kg}$ ) per $100 \mathrm{~kg}$ BW and day. Descriptive analysis was performed using PROC FREQ. During data treatment, it was found that $23 \%(n=78)$ of the horses had a history of colic. The horses were, therefore, further divided into one colic and one non-colic group for comparisons of type of clinical signs during FFL episodes. Each clinical sign was compared separately between the groups using a Chi ${ }^{2}$-test (with expected model). Level of significance was set at $p<0.05$.

\section{Results}

In total, 780 responses to the survey were obtained. Out of these, 12 responses represented horses younger than 2 years of age, 234 responses were for horses that did not show FFL but other types of problems when fed wrapped forages, and 195 responses were incomplete. These 441 responses were excluded from the dataset, leaving 339 full responses for further evaluation. 


\subsection{Horses and Signs of Free Faecal Liquid}

The age of the horses in the study ranged from 2.5 to 28 years (average $11 \pm 5.9$ years). The majority of the horses were geldings $(57 \%, n=193)$ (Table 1$)$ and of warmblood breed type $(53 \%, n=180)$ (Figure 1). Thirty-seven percent $(n=123)$ of the horses had bay coat colour followed by chestnut $(19 \%, n=64)$, grey $(14 \%, n=47)$ and black $(8 \%, n=27)$. Body condition scores (BCS) ranged from 1 to 4 (on a scale of 0 to 5 [13]), with a normal distribution around BCS 3 as median $(55 \%, n=186)$ (Table 1). The most frequently reported disciplines horses were used for were leisure riding $(82 \%, n=278)$, dressage $(37 \%, n=125)$ and show jumping $(34 \%, n=115)$ (Figure 2). A majority of the horses $(63 \%, n=215)$ were reported to perform a low-intensity exercise (Table 1$)$. Extended information on horse characteristics is reported in Appendix A (Table A1). Twenty-nine percent $(n=98)$ of the horses were reported to show distinct irritation manifested by extensive tail swishing and nervous trampling of hindlegs while voiding faecal liquid and/or faeces, whereas 35\% $(n=118)$ did not show any signs other than FFL (Figure 3). A bloated abdomen was reported in 29\% $(n=98)$ of the horses during episodes of FFL (Figure 3). Fifty-two percent $(n=170)$ of the respondents reported that only their horse in the stable showed FFL, while $48 \%(n=159)$ of the respondents stated that there were more horses in the stable that showed FFL.

Table 1. Characteristics of horses showing free faecal liquid $(n=339)$.

\begin{tabular}{|c|c|c|}
\hline Item & No. of Horses & $\%$ of Horses \\
\hline \multicolumn{3}{|l|}{ Country (stabled in) } \\
\hline Sweden & 191 & 56 \\
\hline Norway & 148 & 44 \\
\hline \multicolumn{3}{|l|}{ Gender } \\
\hline Mare & 134 & 40 \\
\hline Gelding & 194 & 57 \\
\hline Stallion & 11 & 3 \\
\hline \multicolumn{3}{|l|}{ Coat colour } \\
\hline Bay & 123 & 37 \\
\hline Chestnut & 64 & 19 \\
\hline Grey & 47 & 14 \\
\hline Black & 27 & 8 \\
\hline Paint & 24 & 7 \\
\hline Palomino/Isabelline & 21 & 6 \\
\hline Cremello & 19 & 6 \\
\hline Other (Leopard pattern/buckskin) & 14 & 4 \\
\hline \multicolumn{3}{|l|}{ Body condition score ${ }^{1}$} \\
\hline$<3$ & 75 & 22 \\
\hline 3 & 188 & 55 \\
\hline$>3$ & 76 & 22 \\
\hline \multicolumn{3}{|l|}{ Training intensity } \\
\hline Low & 215 & 63 \\
\hline Medium & 63 & 19 \\
\hline High & 23 & 7 \\
\hline Breaking in & 23 & 7 \\
\hline No training ${ }^{2}$ & 15 & 4 \\
\hline
\end{tabular}

\footnotetext{
${ }^{1}$ According to the scale of Carroll and Huntington, 1988. ${ }^{2}$ No training includes horses kept as pets or for company.
} 


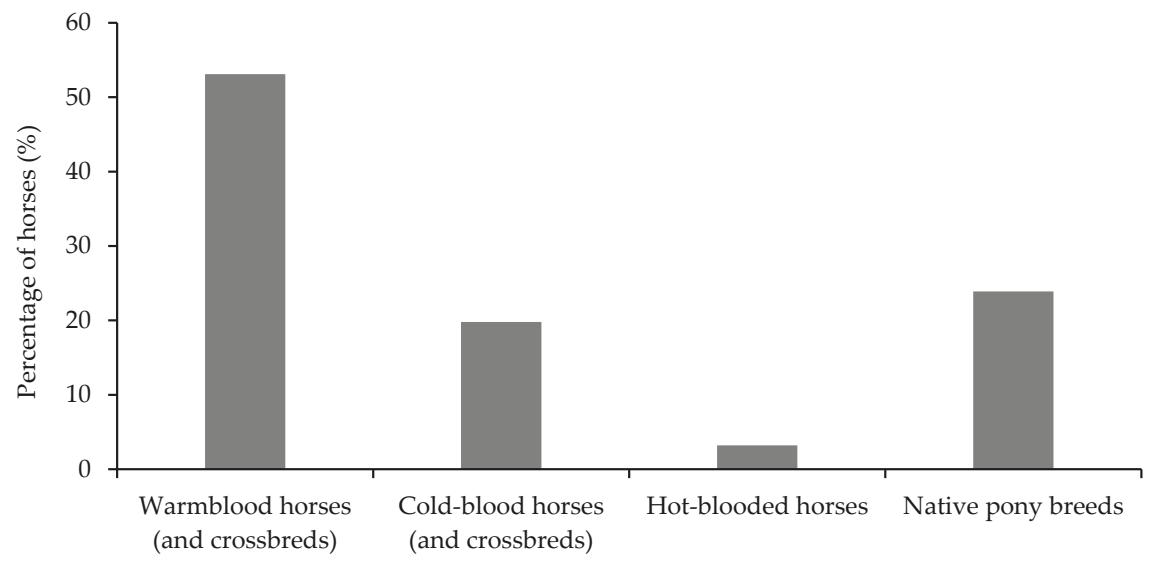

Breed types

Figure 1. Distribution of breed types for horses showing free faecal liquid $(n=339)$.

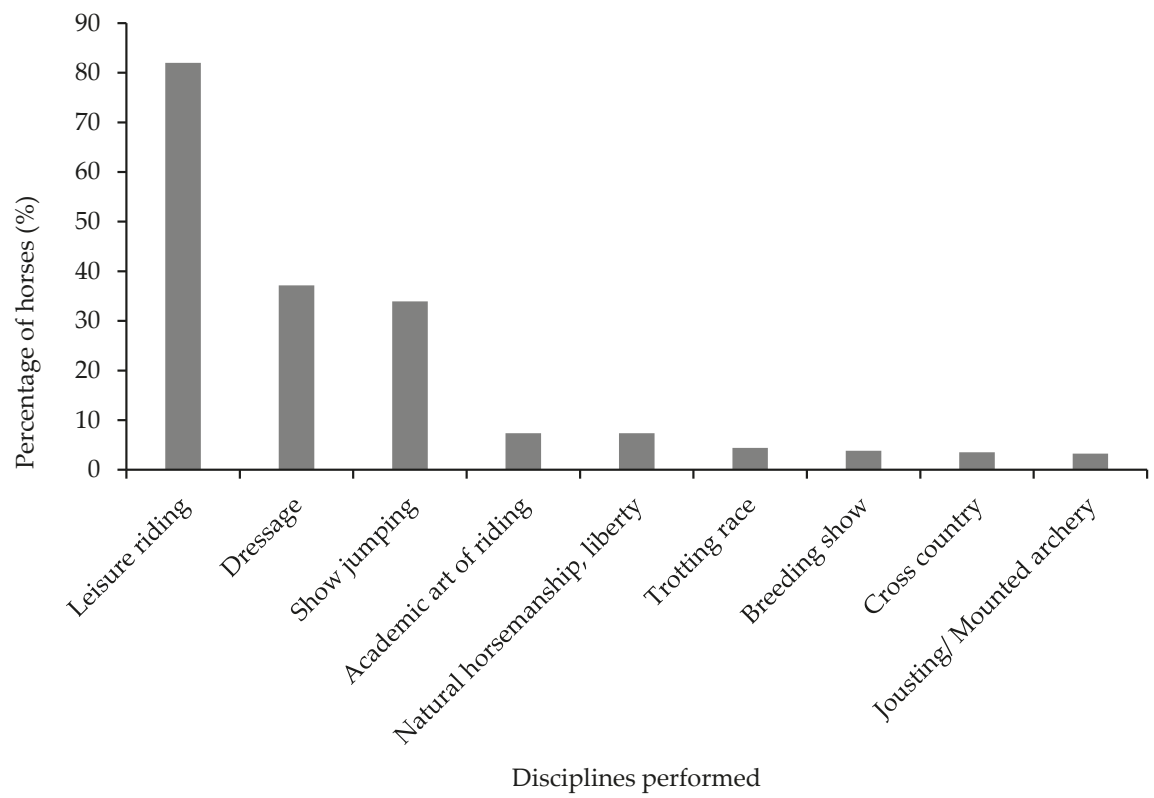

Figure 2. Distribution of disciplines performed by horses with free faecal liquid $(n=339)$, as reported by respondents. Multiple-choice question resulting in that the sum could exceed 100 percent. 


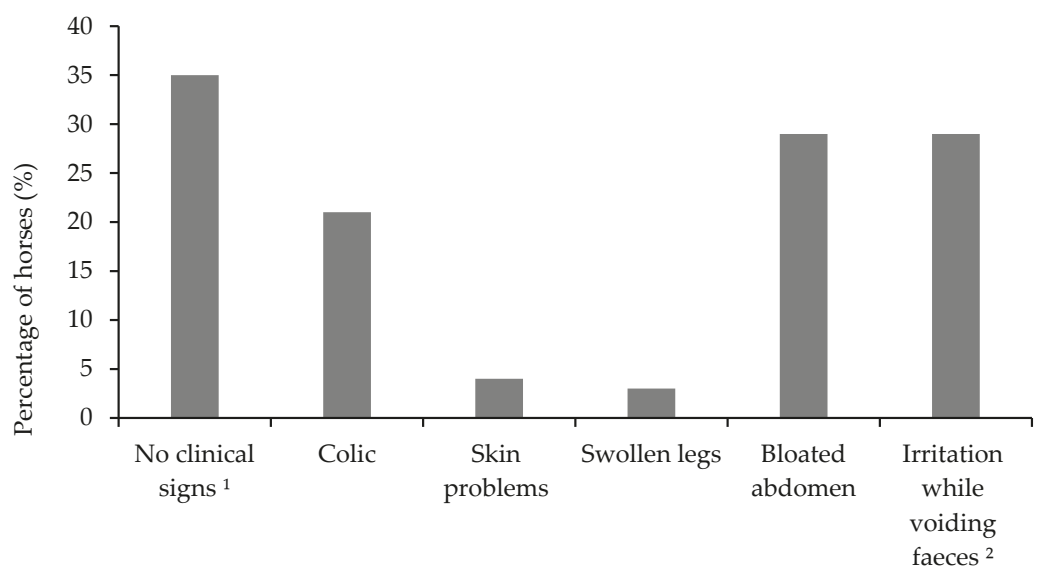

Figure 3. Percentage of horses showing different clinical signs associated with episodes of free faecal liquid, as reported by respondents $(n=339)$. Multiple-choice question resulting in a sum that could exceed $100 \% .{ }^{1}$ No clinical signs mean no signs other than free faecal liquid. ${ }^{2}$ Including extensive tail swishing and/or trampling with hindlegs while voiding faeces and/or faecal liquid.

\subsection{Management}

The majority of the horses $(79 \%, n=271)$ were kept in individual boxes at night and outside in paddocks during the daytime, while $19 \%(n=61)$ were kept in loose-housing systems (Table 2). The bedding materials used in stables and loose housing systems were a combination of straw and shavings $(37 \%, n=125)$, straw only $(20 \%, n=68)$ and shavings only $(17 \%, n=58)$ (Table 2$)$. Horses that spent their daytime in paddocks were generally kept outside for 8-12 h per day $(48 \%, n=163)$, while $29 \%(n=98)$ were kept outside for more than $12 \mathrm{~h}$ per day and $21 \%(n=71)$ were kept outside for less than $4 \mathrm{~h}$ per day (Table 2). The type of paddocks were soil paddocks $(39 \%, n=132)$, grass paddocks (old grass during winter) $(28 \%, n=94)$ or sand/gravel paddocks $(23 \%, n=78)$ (Table 2$)$. Forty-eight percent $(n=163)$ of the horses were kept on pasture for $9-12$ weeks, while $21 \%(n=71)$ were on pasture for $\leq 8$ weeks and $8 \%(n=27)$ were kept on pasture for $>12$ weeks (Table 2$)$. The majority $(55 \%, n=186)$ of the horses were dewormed if faecal egg counts showed sufficiently high numbers to indicate deworming according to national guidelines (www.sva.se) (Table 2). Other deworming procedures included regular deworming more than one time per year $(36 \%, n=122)$, dewormed if considered necessary $(7 \%, n=25)$ or not dewormed $(1 \%, n=4)$ (Table 2$)$. Horses were reported to have access to water by tubs, buckets or automatic waterers when kept in the stable, paddock and at pasture. At pasture, horses were also reported to have access to water by natural water sources (Table A1). Extended information on management factors is presented in Table A1 (Appendix A).

\subsection{Feeding}

The majority $(74 \%, n=250)$ of horses were fed forage in meals, while $26 \%(n=89)$ were fed forages ad libitum. Grass haylage (defined as in Table S1, Supplementary Materials) was offered to $95 \%(n=322)$ of the horses, whereas $5 \%(n=17)$ of the horses were fed grass silage (Figure 4$)$. Hay was fed to $50 \%(n=170)$ of the horses (Figure 4$)$. In general, horses were fed roughage-dominated feed rations with on average $90 \%$ roughage, and $7 \%$ concentrates in the daily feed ration (Table 3 ). Daily amounts of different feedstuffs are reported in Table 3. Most of the horses $(67 \%, n=227)$ fed forage in meals were fed forage 3 to 4 times daily, and the time between two forage feedings seldom exceeded $8 \mathrm{~h}$ (Table A1). Horses that were fed in their paddocks were served forage in tubs or haynets $(60 \%, n=204)$, or on the ground $(45 \%, n=153)$ (Table A1). Eight percent $(n=27)$ were not fed forage in their paddocks (Table A1). The majority $(66 \%, n=224)$ purchased their forage from a producer outside 
the farm, while the remaining proportion used forage produced on the farm (Table A1). About half $(48 \%, n=163)$ of the respondents stated that they did not know the forage nutritive contents (Table A1).

Table 2. Description of the management of horses showing free faecal liquid ( $n=339$, if not otherwise mentioned. Deviances in $\mathrm{N}$ were due to missing responses for that particular question).

\begin{tabular}{|c|c|c|}
\hline Item & No. of Horses & $\%$ of Horses \\
\hline \multicolumn{3}{|l|}{ Housing system $(n=337)$} \\
\hline Individual box & 271 & 79 \\
\hline Loose housing system & 64 & 19 \\
\hline Group housing & 2 & 1 \\
\hline \multicolumn{3}{|l|}{ Bedding $(n=336)$} \\
\hline Straw & 67 & 20 \\
\hline Shavings & 57 & 17 \\
\hline Combination of straw and shavings & 125 & 37 \\
\hline Sawdust & 40 & 12 \\
\hline Wood pellets & 26 & 8 \\
\hline Straw pellets & 11 & 3 \\
\hline Other (paper, mix of sawdust and peat, rubber mat, raw sawdust) & 10 & 3 \\
\hline \multicolumn{3}{|l|}{ Time spent per day in paddock during winter $(n=245)$} \\
\hline$<4 \mathrm{~h}$ & 5 & 2 \\
\hline $4-7 \mathrm{~h}$ & 67 & 20 \\
\hline $8-12 \mathrm{~h}$ & 163 & 48 \\
\hline$>12 \mathrm{~h}$ & 10 & 30 \\
\hline \multicolumn{3}{|l|}{ Paddock ground $(n=332)$} \\
\hline Grass (old grass during winter) & 94 & 28 \\
\hline Sand/Gravel & 79 & 24 \\
\hline Soil & 133 & 40 \\
\hline Other & 26 & 8 \\
\hline \multicolumn{3}{|l|}{ Annual time spent on pasture } \\
\hline$<4$ weeks & 5 & 2 \\
\hline 4-8 weeks & 67 & 20 \\
\hline 9-12 weeks & 163 & 48 \\
\hline$>12$ weeks & 100 & 30 \\
\hline No pasture & 4 & 1 \\
\hline \multicolumn{3}{|l|}{ Anthelmintic routines } \\
\hline Regularly dewormed $\geq 1$ times per year & 122 & 36 \\
\hline Dewormed due to high ${ }^{1}$ egg counts $\geq 1$ times per year & 154 & 45 \\
\hline Dewormed due to high ${ }^{1}$ egg counts $<1$ times per year & 34 & 10 \\
\hline Dewormed if considered necessary & 25 & 7 \\
\hline Not dewormed & 4 & 1 \\
\hline
\end{tabular}

${ }^{1}$ According to national guidelines (www.sva.se). 


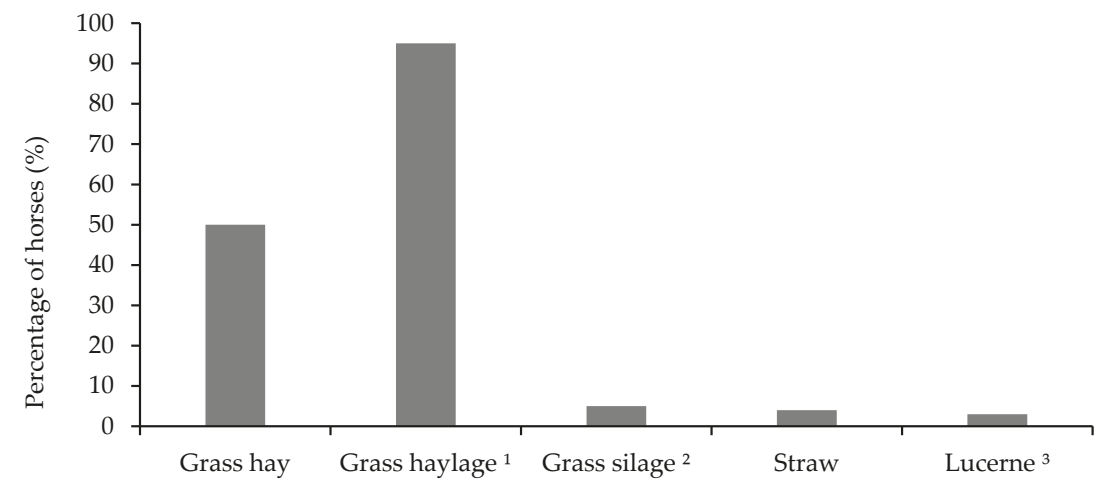

Roughage type

Figure 4. Different types of roughage fed to horses showing free faecal liquid $(n=339)$. Multiple roughages could be assigned in the survey, resulting in a sum of percentages exceeding $100 .{ }^{1}$ Wrapped forage with $\geq 50 \%$ DM. ${ }^{2}$ Wrapped forage with $<50 \%$ DM. ${ }^{3}$ Includes both pelleted lucerne and lucerne chaff in a dried format.

Table 3. Daily amounts of different feedstuffs ( $\mathrm{kg}$ per $100 \mathrm{~kg}$ bodyweight (BW) per day) and proportion $(\%)$ of roughage and concentrate in the diet offered to horses showing free faecal liquid $(n=339)$.

\begin{tabular}{|c|c|c|c|c|c|c|c|c|}
\hline Item & No. of Horses & Min & Q1 & Q2 & Q3 & Max & Mean & SD \\
\hline \multicolumn{9}{|l|}{$\begin{array}{l}\text { Roughage and concentrate feeding, } \mathrm{Kg} / 100 \mathrm{~kg} \\
\text { BW/ } / \mathrm{d}^{1}\end{array}$} \\
\hline Grass hay & 165 & 0.1 & 0.2 & 0.2 & 0.3 & 0.5 & 0.2 & 0.06 \\
\hline Grass haylage & 251 & 0.2 & 1.7 & 2.0 & 2.3 & 6.0 & 2.0 & 0.67 \\
\hline Grass silage & 4 & 1.2 & 1.2 & 2.9 & 3.8 & 4.7 & 2.9 & 1.73 \\
\hline Straw & 14 & 0.1 & 0.2 & 0.3 & 0.6 & 2.3 & 0.4 & 0.45 \\
\hline Lucerne $^{2}$ & 10 & 0.01 & 0.1 & 0.1 & 0.2 & 0.7 & 0.1 & 0.13 \\
\hline Total amount of roughage & 217 & 0.3 & 1.5 & 2.0 & 3.1 & 4.8 & 1.8 & 2.17 \\
\hline Total amount of concentrate & 190 & 0.01 & 0.1 & 0.2 & 0.3 & 1.0 & 0.2 & 0.18 \\
\hline Roughage proportion of total feed ration (\%) ${ }^{3}$ & 249 & 20 & 90 & 100 & 100 & 100 & 90 & 0.14 \\
\hline Concentrate proportion of total feed ration $(\%)^{3,4}$ & 107 & 0 & 1 & 5 & 10 & 80 & 7 & 0.14 \\
\hline Mineral supplementation, g/100 kg BW & 218 & 0.1 & 6.0 & 10.8 & 17.8 & 83.3 & 13.5 & 11.43 \\
\hline
\end{tabular}

\footnotetext{
${ }^{1}$ Horses reported to have ad libitum access to roughage, forage or having straw as bedding material were not included. ${ }^{2}$ Horses reported to have access to roughage ad libitum without concentrates in the diet were included. ${ }^{3}$ Horses reported to have access to roughage ad libitum without concentrates in the diet were included. ${ }^{4}$ Horses reported not to be fed concentrate were excluded. Min = Minimum value. Q1-Q3: First-, second- (=median) and third quartile. $\mathrm{Max}=$ Maximum value. $\mathrm{SD}=$ Standard deviation.
}

More than half of the horses $(56 \%, n=190)$ were fed concentrates, and the most common type was commercial concentrates $(n=118)$ followed by vegetable oil $(n=104)$ and molassed sugar beet pulp $(n=22)$ and (Table A1). Supplemental feeds were used for $84 \%(n=285)$ of the horses in the study and mostly comprised mineral and vitamin feed (Table A1). For horses reported to be fed concentrates, 217 horses were fed concentrates 1-2 times per day and the remaining proportion was fed concentrates more often (Table A1). The presence of FFL was reported to diminish when changing from wrapped forages to hay $(58 \%, n=197)$, from wrapped forage to pasture $(46 \%, n=156)$ and from one batch of wrapped forage to another batch $(17 \%, n=58)$ (Table 4$)$. However, not all horses showed any change in the presence of FFL with feed changes $(7 \%, n=24)$ and not all horses had been subjected to all feed changes $(2 \%, n=7)$ (Table 4$)$. 
Table 4. Changes in the presence of free faecal liquid in the horses in the study $(n=339)$ with diet changes as reported by respondents. "Less loose" refer to the absence and/or reduced amount of liquid phase in faeces compared to before the feed change, as reported by respondents. Not all respondents had tried all response alternatives.

\begin{tabular}{ccc}
\hline Item & $\begin{array}{c}\text { No. of } \\
\text { Horses }\end{array}$ & $\begin{array}{c}\% \text { of } \\
\text { Horses }\end{array}$ \\
\hline Faecal appearance less loose when changing from wrapped forage to hay & 198 & 58 \\
Faecal appearance less loose when changing from wrapped forage to pasture & 157 & 46 \\
Faecal appearance less loose when changing to another batch of wrapped forage & 56 & 17 \\
No change in faecal appearance with any change in feeding & 24 & 7 \\
Faecal appearance more loose in association to changing feeds & 20 & 6 \\
Faecal appearance less loose when changing from primary to regrowth harvest ${ }^{1}$ & 16 & 5 \\
Faecal appearance less loose when using feed additives ${ }^{2}$ & 8 & 4 \\
Have not tried any change in feeding & 5 & 2 \\
\hline
\end{tabular}

1 Wrapped forages. ${ }^{2}$ Feed additives reported included yeast, linseed, psyllium seed, thiamine and various types of commercial pro- and prebiotics.

\subsection{Gastrointestinal Health}

Eighty-seven percent $(n=295)$ of the horses in the study had not been treated for any gastrointestinal disease within the 3 previous months prior to responding to the survey. Twenty-two percent $(n=76)$ of the horses in the study were reported to have been examined for stomach ulcers, however, only 14 were reported to have been examined with gastroscopy. Of these, 9 were diagnosed with gastric ulcers. Nearly one-quarter of the horses in the study $(23 \%, n=78)$ were reported to have had a previous history of colic. Therefore, horses were divided into two groups, one with a previous history of colic and one with no previous history of colic, and compared within each type of symptom they were showing during episodes of FFL (Figure 5). For horses reported to show no clinical signs during episodes of FFL $(n=119)$, there was a higher proportion of horses with no previous history of colic $(74 \%, n=88)$ compared to horses with a previous history of colic $(26 \%, n=31)(p<0.001)$. For horses reported to show signs of colic during episodes of FFL ( $n=71)$ there was a higher proportion of horses with a previous history of colic $(87 \%, n=62)$ compared to horses with no previous history of colic $(13 \%, n=9)(p<0.001)$.

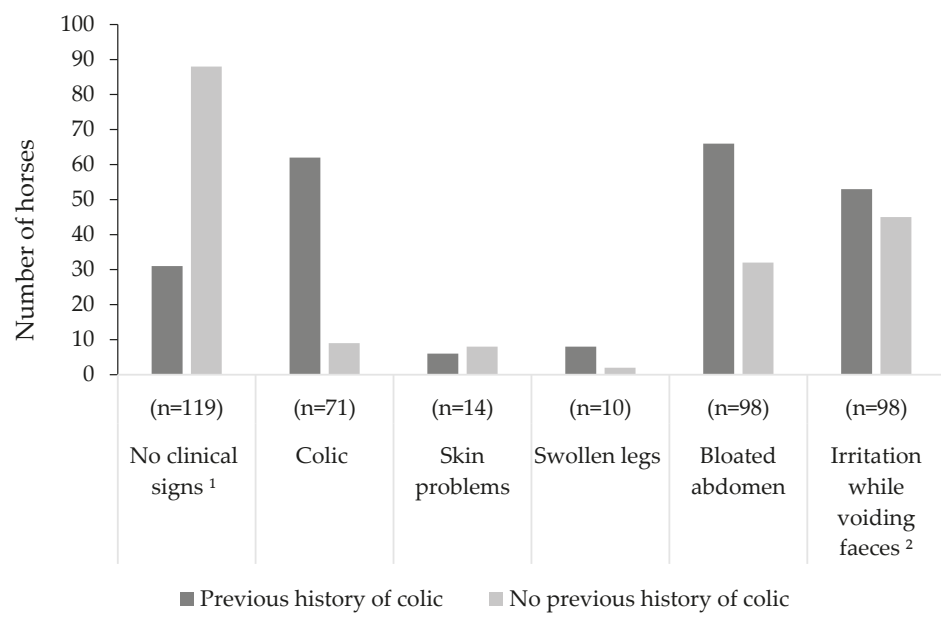

Figure 5. The horse owner reported clinical signs during episodes of free faecal liquid in horses with $(n=77)$ and without $(n=256)$ a previous history of colic. Multiple signs could be selected in the survey, resulting in the numbers of horses for all symptoms exceeding the total number of horses in the study. ${ }^{1}$ No clinical signs mean no signs other than FFL. ${ }^{2}$ Including extensive tail swishing and/or trampling with hindlegs. 
For horses reported to show a bloated abdomen $(n=98)$, there was a tendency $(p=0.08)$ for a higher proportion of horses with a previous history of colic $(67 \%, n=66)$ compared to horses with no previous history of colic $(33 \%, n=32)$.

\subsection{Stereotypic Behaviour}

Nineteen percent $(n=64)$ of the horses in the study were reported to show stereotypic behaviour. The reported stereotypic behaviours included crib biting (15\%,n=8), wind sucking $(4 \%, n=2)$, weaving $(7 \%, n=4)$, box walking $(11 \%, n=6)$, wood chewing $(60 \%, n=33)$ and tongue rolling $(7 \%, n=4)$.

\section{Discussion}

\subsection{Horses}

In the present study, the typical horse showing FFL was reported to be of warmblood type, have bay coat colour, be a gelding, on average 12 years old and be used for leisure riding, dressage or show jumping. A similar distribution of horse characteristics has been described within other horse populations in Sweden and Norway [14,15], which indicates that the population in the present study is a reflection of the normal horse population. As a large variety of breeds, ages and disciplines were represented in the population in the present study, it is evident that FFL could appear in almost any type of horse. The proportion of geldings was larger compared to the proportions of mares and stallions in the current study, which is in agreement with the findings in a previous study on FFL [1] where a larger proportion of geldings was found in the case group compared to controls. However, it may be more common to keep geldings as leisure horses [16,17], compared to mares and stallions, and this could explain the higher proportion of geldings in both studies. The reported BCS was in relation to what was expected. The majority of horses were reported to have a BCS of 3 (normal BCS), which is in agreement with previous descriptions of FFL $[1,5]$ where horses were not reported to show weight loss or loss of BCS. It has also been reported that horse owners are commonly underestimating the body condition score of their horses compared to a trained professional scorer [18]. This may indicate that the horses in the present study were not underweight or in lower than normal BCS. In a previous study, horses with the coat colour paint were over-represented $(29 \%, n=12)$ in a group of horses showing FFL compared to horses in two control groups, which comprised $10 \%(n=4)$ and $8 \%$ $(n=3)$ paint coloured horses, respectively) [1]. In the current study, the proportion of paint horses was lower than the proportions of the bay, chestnut, grey and black horses. Therefore, an association between the coat colour paint and the presence of FFL cannot be confirmed from the results in the current study. It has been suggested that grey horses may be more prone to show FFL due to the higher risk of melanoma [19], which may cause defecation difficulties, but no such association has been identified in the literature or in this study. Social stress has been suggested to play a role for the presence of FFL, as the majority of FFL-affected horses did not defend their feed against other horses and were judged as low in the hierarchy in a previous study [1]. However, in the same study [1], high ranked horses also showed FFL, indicating that stress from being low in the hierarchy is not a sole explanation for the presence of FFL.

\subsection{Management}

The majority of the horses in this study were kept outside in paddocks for $4-8 \mathrm{~h}$ in soil or sand/gravel paddocks and almost half the horses were fed forage on the ground. Feeding forage on the ground could lead to increased ingestion of soil and sand particles causing irritation of the intestinal mucosa, which has been associated with gastrointestinal conditions such as diarrhoea, including voiding of loose and watery faeces [20], and colic [21]. Whether or not this management factor plays a role in the presence of FFL remains to be further elucidated. 


\subsection{Feeding}

Despite the fact that about half of the horses were reported to have less loose faeces when feeding was changed from wrapped forages to hay $(58 \%)$ or to pasture $(46 \%)$, this was not the case for all horses in the study. In addition, about one-quarter of the horses improved by changing from one batch to another batch (including from primary to regrowth harvest) of wrapped forage. This indicates that the occurrence of FFL cannot be generally attributed to feeding wrapped forages. This finding is supported by results from a previous study in which horses displaying FFL predominantly were fed hay [1]. In addition, FFL has not been reported in controlled feeding studies with healthy horses fed silage, haylage and hay from the same grass sward and harvest [22,23]. As there may be individual variation in the gut microbiota of horses [24-26], it is possible that individuals respond differently to the same feed. Further study within this area is highly interesting and may provide more insight into factors contributing to the presence of both FFL and colic.

Although the forage conservation method may influence both chemical and microbial composition in forage [22], forages differ in a number of other factors as well. One important factor is plant maturity at harvest, which greatly influences overall digestibility in the equine GIT and the nutritive value of the forage [27]. Valle et al. [5] reported a horse with FFL to maintain a reduced or absent production of FFL with gradual changes in the nutritional plan to meet the theoretical nutritional requirements of the horse. Changes included reducing energy content in the feed ration by excluding concentrate feeds and decreasing the amount of forage and changing batch of forage in combination with increased exercise. However, simultaneously with the nutritional changes, the horse was treated with sulfasalazine, making it difficult to evaluate the effect of the changes in the feeding. Only half of the horse owners in the current study reported that they knew the nutritive content in their forage (through forage analytical reports), indicating that half of the horses may have been under- or overfed in relation to their nutritional requirements. Whether this is a factor of importance for the presence of FFL is currently not known.

The composition of the total feed ration and the ratio between forage and concentrate may be of importance for the physical appearance of faeces, as two-phase separation (liquid and solid phase) of both digesta and faeces has been reported in horses fed hay ad libitum with inclusion of grains ( $4.55 \mathrm{~kg}$ every $12 \mathrm{~h}$ ) but not when fed only the same hay ad libitum [28]. In horses fed hay only, a clear separation between solid and liquid phases was present in the contents of the right dorsal colon (RDC), but faecal balls were well-formed and with no separation in liquid and solid phases. No or minimal gas bubbles were present in RDC content when horses were fed hay [28]. When horses were fed hay with the inclusion of grains, RDC contents were more homogenous and foamy, with less separation of phases, and the liquid phase was more viscous than in horses fed hay only. Faeces of horses fed hay and grains were, however, less formed and had a clear separation, where the liquid phase had noticeable gas bubbles and was more viscous compared to faeces of horses fed hay only [28]. One explanation for this result could be differences in the hydrophilic properties of ingesta components, which may differ when horses were fed hay only or hay with grain inclusion. The hydrophilic properties of the ingesta have been suggested as a cause of osmotic diarrhoea [29,30]. In the current study, horses were fed much smaller proportions of concentrates compared to what was described by Lopes et al. [28]. However, smaller amounts of concentrates fed daily $(2.5-5 \mathrm{~kg})$ have been reported to increase the risk of colic [31-33] and may affect the ingesta and its transit as well. As horses displaying FFL seldom show clinical signs of disease, FFL may be a type of osmotic diarrhoea. Further insights in causes of FFL may be provided by investigations of forage and concentrate proportions in the total feed ration of horses with FFL.

\subsection{Gastrointestinal Health}

In previous studies, no symptoms of disease, such as fever or weight loss or loss of body condition has been described in horses with FFL [1,5]. Nine horses were reported to have been diagnosed with gastric ulcers, but overall very few horses $(n=14)$ had been examined for gastric ulcers with 
gastroscopy. From the results of the current study, it cannot be ruled out that gastric ulcers may be associated with the presence of FFL, even though the incidence of gastric ulcers was lower than what has been described in other studies of gastric ulcers in leisure horses (17\% to $58 \%$, [34-36]).

In the present study, almost one-quarter of the horses were reported to have had a previous history of colic. A colic incidence between $3.5 \%$ and $10.6 \%$ has been reported for general horse populations $[10,32,37,38]$ and of $4.8 \%$ within a German population of horses showing FFL [3]. This indicates that the incidence of colic was higher for Swedish and Norwegian horses showing FFL. In addition, in the present study, 55\% of the horses did not show any clinical signs other than faecal liquid during FFL episodes, whereas the remaining proportion of horses were reported to have one or a combination of several clinical signs including e.g., colic symptoms. The latter proportion also had a higher number of horses with a previous history of colic. This indicates that causes of FFL could differ among different horses, or that FFL is a generic symptom from several different conditions of a similar nature. The number of clinical signs during an FFL episode could also depend on the severity of the condition, which could not be assessed in this study. Further studies of FFL should preferably include detailed descriptions of duration, intensity and severity of FFL episodes as well as previous disturbances in the GIT of FFL-affected horses. It is possible that the hindgut microbiota of FFL-horses is responsible for the clinical signs. Transplantation of faecal microflora in affected horses has been reported to decrease the severity of FFL in a controlled study [4]. However, in the same study [4], horses were also treated with omeprazole and psyllium seeds in addition to faecal transplant, making it difficult to evaluate the effects.

\subsection{Stereotypic Behaviour}

The reported incidence of stereotypic behaviour among FFL horses in the study was $19 \%$ when wood chewing was included. Tree-wood chewing may not always be a stereotypy but could be related to low-fibre diets [39], and when excluded, the incidence of stereotypies was approximately $8 \%$, which is comparable to the previously reported incidence of 7.1-12.3\% [40-44] in other horse populations. Factors reported to be associated with an increased risk of stereotypic behaviour in previous studies include low levels of social interactions with other horses [44-46], low forage availability $[45,46]$ and low number of horses kept in the same and/or adjacent paddocks [45]. The majority of horses in the current study were kept in individual boxes when stabled and fed forage in predetermined portions during the day, which may have contributed to the incidence of stereotypic behaviour among horses in this study.

\subsection{Survey Response and Limitations of the Study}

The advantages of performing online surveys are the ease and low cost of data collection, the automation in data input and handling, which reduce errors, and the flexibility in survey design to make it easier for participants to respond to the questionnaire. The disadvantage includes the absence of an interviewer, and that data are reported by the horse owner, which could result in misinterpretations among respondents for some of the questions. Some of the variables have previously been shown to be difficult to estimate correctly for horse-owners, such as BCS [18]. It should be recognized that all conclusions drawn from this study were based on the perceptions of the respondents, which may vary in their knowledge of equine feeding and management.

In order to control that the respondents of the survey were within the intended group, control questions based on the inclusion criteria, such as the age of the horse, and if the horse had problems with FFL when fed wrapped forages, were asked. This resulted in the elimination of 441 responses to the present study, indicating that such controls could be of high importance to enhance the quality of data input in online surveys. 


\section{Conclusions}

There was a large variety of horse characteristics, including breed type, age and coat colour, in horses with FFL. Many, but not all horses in this study were reported to show less separation of solid and liquid phases in their faeces when changing from wrapped forages to hay, pasture or another batch of wrapped forage. Horses with FFL were also reported to have a higher incidence of a previous history of colic compared to reports from other horse populations. Further research on FFL in horses is of interest and should include details on feeding (such as forage nutritive values, feed ration composition), and gastrointestinal tract health and function (such as the presence of stomach ulcers, colic, gastrointestinal tract response to different feedstuffs), as well as detailed descriptions of severity and duration of FFL episodes.

Supplementary Materials: The following are available online at http://www.mdpi.com/2076-2615/10/1/76/s1, Table S1, The survey distributed to Swedish and Norwegian horse owners having horses showing FFL when fed wrapped forages. Modified (Translated from Swedish and Norwegian language) for the purpose of publication. Bulleted points indicate the response of the questions and different response alternatives are comma-separated. Space was provided for alternative answers where necessary.

Author Contributions: The authors have contributed to the following sections of this work: Conceptualization, K.M.L. and C.E.M.; data curation, K.M.L.; formal analysis, K.M.L., A.J., V.B., J.D., J.E.L., and C.E.M.; funding acquisition, A.J. and C.E.M.; investigation, K.M.L. and C.E.M.; methodology, K.M.L. and C.E.M.; project administration, K.M.L., A.J., and C.E.M.; writing-original draft preparation, K.M.L.; writing-review and editing, K.M.L., A.J., V.B., J.D., J.E.L., and C.E.M. All authors have read and agreed to the published version of the manuscript.

Funding: The Swedish-Norwegian Foundation funded this research for equine research, grant number H-15-47-063, 2015 and the Swedish University of Agricultural Science.

Acknowledgments: The authors would like to thank all horse-owners who contributed to the data. In addition, thanks to Professor Ulf Olsson, Biostokastikum, Department of Energy and Technology, Swedish University of Agricultural Sciences, for very valuable and helpful statistical support and advice.

Conflicts of Interest: The authors declare no conflict of interest. The funders had no role in the design of the study; in the collection, analyses, or interpretation of the data; in the writing of the manuscript, or in the decision to publish the results.

\section{Abbreviations}

The following abbreviations are used in this manuscript:

$\begin{array}{ll}\text { BCS } & \text { Body Condition Score } \\ \text { DM } & \text { Dry matter } \\ \text { FFL } & \text { Free faecal liquid } \\ \text { FMT } & \text { Faecal microbiota transplantation } \\ \text { GIT } & \text { Gastrointestinal tract } \\ \text { RDC } & \text { Right dorsal colon }\end{array}$

\section{Appendix A}

Horse owner responses to the survey for variables not presented in tables or figures in the main text. The number $(n)$ and proportion (\%) of horses presented are presented in Table A1. 
Table A1. Extended information on management factors and feeding strategies for horses with free faecal liquid $(n=339)$, as reported by respondents.

\begin{tabular}{|c|c|c|}
\hline Variables & Total Number of Horses & $\%$ of All Horses \\
\hline Horses showing FFL when fed wrapped forages & 339 & 100 \\
\hline \multicolumn{3}{|l|}{ Region of stable } \\
\hline Southern & 126 & 37 \\
\hline Central & 81 & 24 \\
\hline North & 39 & 12 \\
\hline Western ${ }^{1}$ & 23 & 7 \\
\hline Eastern $^{1}$ & 70 & 21 \\
\hline \multicolumn{3}{|l|}{ Horse imported } \\
\hline No & 253 & 75 \\
\hline Do not know & 6 & 2 \\
\hline Yes & 80 & 24 \\
\hline \multicolumn{3}{|l|}{ Ability of horse to keep desired BCS } \\
\hline Easy keeper & 97 & 29 \\
\hline Normal & 187 & 55 \\
\hline Hard keeper & 55 & 16 \\
\hline \multicolumn{3}{|l|}{ Type of water source in stable/loose housing system } \\
\hline Frostless waterer & 49 & 14 \\
\hline Frostless tub & 43 & 13 \\
\hline Waterer & 31 & 9 \\
\hline Tub & 31 & 9 \\
\hline Bucket & 78 & 23 \\
\hline Natural water source & 4 & 1 \\
\hline Combination of bucket and waterer & 103 & 30 \\
\hline \multicolumn{3}{|l|}{ Type of water source in paddock during winter } \\
\hline Frostless waterer & 34 & 10 \\
\hline Frostless tub & 80 & 24 \\
\hline Waterer & 4 & 1 \\
\hline Tub & 124 & 37 \\
\hline Bucket & 37 & 11 \\
\hline Natural water source & 5 & 1 \\
\hline Other (Combination of tub and bucket, bucket and waterer) & 55 & 16 \\
\hline \multicolumn{3}{|l|}{ Type of pasture } \\
\hline Pasture on arable land & 106 & 31 \\
\hline Natural pasture & 135 & 40 \\
\hline Forest & 6 & 2 \\
\hline No pasture & 30 & 9 \\
\hline Other (Combination of different pasture types) & 61 & 18 \\
\hline \multicolumn{3}{|l|}{ Type of water source on pasture } \\
\hline Frostless waterer & 45 & 13 \\
\hline Frostless tub & 12 & 4 \\
\hline Waterer & 10 & 3 \\
\hline Tub & 165 & 49 \\
\hline Bucket & 8 & 2 \\
\hline Natural water source & 33 & 10 \\
\hline Other (Combination of bucket and tub) & 66 & 19 \\
\hline \multicolumn{3}{|l|}{ Access to saltlick while on pasture } \\
\hline Yes & 220 & 65 \\
\hline No & 119 & 35 \\
\hline \multicolumn{3}{|l|}{ Saltlick in stable/loose housing system } \\
\hline Yes & 296 & 87 \\
\hline No & 43 & 13 \\
\hline
\end{tabular}


Table A1. Cont.

\begin{tabular}{|c|c|c|}
\hline Variables & Total Number of Horses & $\%$ of All Horses \\
\hline \multicolumn{3}{|l|}{ Time from last deworming } \\
\hline Not dewormed & 11 & 3 \\
\hline $0-3$ months ago & 75 & 22 \\
\hline 4-6 months ago & 126 & 37 \\
\hline $7-12$ months ago & 68 & 20 \\
\hline$>1$ year ago & 59 & 17 \\
\hline \multicolumn{3}{|l|}{ Origin of the forage } \\
\hline Bought & 226 & 67 \\
\hline Produced on farm, but not by the owner & 42 & 12 \\
\hline Produced on farm by the owner & 69 & 20 \\
\hline Other & 1 & 0 \\
\hline \multicolumn{3}{|l|}{ Forages analysis } \\
\hline Yes & 144 & 42 \\
\hline No & 163 & 48 \\
\hline Do not know & 37 & 9 \\
\hline \multicolumn{3}{|l|}{ Number of feedings of forage per day } \\
\hline 1 time & 1 & 0 \\
\hline 2 times & 14 & 4 \\
\hline 3 times & 122 & 36 \\
\hline 4 times & 108 & 32 \\
\hline$>4$ times & 33 & 10 \\
\hline Free access & 89 & 26 \\
\hline \multicolumn{3}{|l|}{ Storage of forage } \\
\hline Indoors & 223 & 66 \\
\hline Outdoors & 114 & 34 \\
\hline Outdoors, covered & 65 & 19 \\
\hline Outdoors, uncovered & 49 & 14 \\
\hline Hay indoors, wrapped forages outdoors uncovered & 1 & 0 \\
\hline Hay indoors, wrapped forages outdoors covered & 1 & 0 \\
\hline \multicolumn{3}{|l|}{ Maximum time between two feedings of roughage } \\
\hline $0-2 \mathrm{~h}$ & 2 & 1 \\
\hline $2-4 \mathrm{~h}$ & 35 & 10 \\
\hline $4-8 \mathrm{~h}$ & 115 & 34 \\
\hline $8-12 \mathrm{~h}$ & 101 & 30 \\
\hline$>12 \mathrm{~h}$ & 8 & 2 \\
\hline Don't know & 78 & 24 \\
\hline \multicolumn{3}{|l|}{ Feeding strategy for roughage in paddock ${ }^{2}$} \\
\hline Forage not fed in the paddock & 27 & 8 \\
\hline On the ground & 113 & 33 \\
\hline In the feeding rack & 79 & 23 \\
\hline In a haynet & 19 & 6 \\
\hline In a tub or similar & 62 & 18 \\
\hline Other (combination of ground and feeding rack/haynet) & 39 & 12 \\
\hline \multicolumn{3}{|l|}{ Type of concentrate fed ${ }^{2}$} \\
\hline Grains & 16 & 5 \\
\hline Molassed sugar beet pulp & 22 & 6 \\
\hline Linseed/Linseed cake & 4 & 1 \\
\hline Soybean meal & 14 & 4 \\
\hline Potato protein & 33 & 10 \\
\hline Wheat bran & 3 & 1 \\
\hline Vegetable oil & 104 & 31 \\
\hline No concentrate fed & 149 & 44 \\
\hline Commercial concentrate & 118 & 63 \\
\hline
\end{tabular}


Table A1. Cont.

\begin{tabular}{|c|c|c|}
\hline Variables & Total Number of Horses & $\%$ of All Horses \\
\hline \multicolumn{3}{|l|}{ Number of concentrate feedings per day } \\
\hline 0 times & 149 & 44 \\
\hline 1 time & 116 & 34 \\
\hline 2 times & 107 & 32 \\
\hline 3 times & 49 & 14 \\
\hline 4 times & 7 & 2 \\
\hline$>4$ times & 1 & 0 \\
\hline \multicolumn{3}{|l|}{ Type of supplemental feeds fed ${ }^{2}$} \\
\hline Mineral feeds & 237 & 70 \\
\hline Multivitamins & 58 & 17 \\
\hline B-vitamins (and Biotin) & 10 & 3 \\
\hline Selenium and Vitamin E & 9 & 3 \\
\hline Garlic & 13 & 4 \\
\hline Herbs & 8 & 2 \\
\hline Other (Yeast, magnesium) & 93 & 27 \\
\hline Not fed supplemental feeds & 51 & 16 \\
\hline \multicolumn{3}{|l|}{ Storage of concentrates } \\
\hline In covered/closed containers indoors & 255 & 66 \\
\hline In uncovered/open containers indoors & 11 & 3 \\
\hline In paper bags/original package indoors & 18 & 5 \\
\hline No concentrate & 51 & 15 \\
\hline Other & 4 & 1 \\
\hline \multicolumn{3}{|l|}{ Previous treatment of other gastro-intestinal diseases } \\
\hline No & 296 & 87 \\
\hline Don't know & 11 & 3 \\
\hline Yes & 32 & 9 \\
\hline
\end{tabular}

\section{References}

1. Kienzle, E.; Zehnder, C.; Pfister, K.; Gerhards, H.; Sauter-Louis, C.; Harris, P. Field study on risk factors for free fecal water in pleasure horses. J. Equine Vet. Sci. 2016, 44, 32-36. [CrossRef]

2. Ertelt, A.; Gehlen, H. Free fecal water in the horse-an unsolved problem. Pferdeheilkunde 2015, 31, 261-268. (In German) [CrossRef]

3. Zehnder, C. Field Study on Risk Factors for Free Faecal Water in Leisure Horses. Ph.D. Thesis, Ludwig-Maximilians-Universität München, Munich, Germany, 6 February 2009. (In German).

4. Laustsen, L.; Edwards, J.; Smidt, H.; van Doorn, D.; Luthersson, N. Assessment of faecal microbiota transplantation on horses suffering from free faecal water. In Proceedings of the 9th European Workshop on Equine Nutrition, Swedish University of Agricultural Science, Uppsala, Sweden, 16-18 August 2018.

5. Valle, E.; Gandini, M.; Bergero, D. Management of chronic diarrhea in an adult horse. J. Equine Vet. Sci. 2013, 33, 130-135. [CrossRef]

6. Gordon, C.H.; Derbyshire, J.C.; Wiseman, H.G.; Kane, E.A.; Melin, C.G. Preservation and feeding value of alfalfa stored as hay, haylage and direct-cut silage. J. Dairy Sci. 1961, 44, 129-131. [CrossRef]

7. Finner, M.F. Harvesting and handling low-moisture silage. Trans. ASAE 1966, 9, 377-381. [CrossRef]

8. Jackson, N.; Forbes, T.J. The voluntary intake by cattle of four silages differing in dry matter content. Anim. Sci. 1970, 12, 591-599. [CrossRef]

9. Enhäll, J.; Nordgren, M.; Kättström, H. Horses in Sweden; Report 2012:1; The Swedish Board of Agriculture: Jönköping, Sweden, 2012. (In Swedish)

10. Larsson, A.; Müller, C.E. Owner reported management, feeding and nutrition-related health problems in Arabian horses in Sweden. Livest. Sci. 2018, 215, 30-40. [CrossRef]

11. Vik, J.; Farstad, M. Horse, Horse Management and Feeding: The Status of Horse Husbandry in Norway; Norsk senter for Bygdeforskning: Trondheim, Norway, 2012. (In Norwegian) 
12. Gerstner, K.; Liesegang, A. Effect of a montmorillonite-bentonite-based product on faecal parameters of horses. J. Anim. Physiol. Anim. Nutr. (Berl.) 2018, 102, 43-46. [CrossRef]

13. Carroll, C.L.; Huntington, P.J. Body condition scoring and weight estimation of horses. Equine Vet. J. 1988, 20, 41-45. [CrossRef]

14. Heldt, T.; Macuchova, Z.; Alnyme, O.; Andersson, H. Socio-Economic Effects of the Equine Industry. Falun: Dalarna University. (Report 2018:04). Available online: https://hastnaringen-i-siffror.se/files/Hästnäringens_ samhällsekonomi_rapport2018_4_2.pdf (accessed on 5 November 2018). (In Swedish).

15. Hartmann, E.; Bøe, K.E.; Jørgensen, G.H.M.; Mejdell, C.M.; Dahlborn, K. Management of horses with focus on blanketing and clipping practices reported by members of the Swedish and Norwegian equestrian community. Anim. Sci. J. 2017, 95, 1104-1117. [CrossRef]

16. Ross, S.E.; Murray, J.K.; Roberts, V.L.H. Prevalence of headshaking within the equine population in the UK. Equine Vet. J. 2018, 50, 73-78. [CrossRef]

17. Wylie, C.E.; Ireland, J.L.; Collins, S.N.; Verheyen, K.L.P.; Newton, J.R. Demographics and management practices of horses and ponies in Great Britain: A cross-sectional study. Res. Vet. Sci. 2013, 95, 410-417. [CrossRef] [PubMed]

18. Wyse, C.A.; McNie, K.A.; Tannahil, V.J.; Love, S.; Murray, J.K. Prevalence of obesity in riding horses in Scotland. Vet. Rec. 2008, 162, 590-591. [CrossRef] [PubMed]

19. Hofmanová, B.; Vostrý, L.; Majzlík, I.; Vostrá-Vydrová, H. Characterization of greying, melanoma, and vitiligo quantitative inheritance in Old Kladruber horses. Czech J. Anim. Sci. 2015, 60, 443-451. [CrossRef]

20. Niinistö, K.E.; Määttä, M.A.; Ruohoniemi, M.O.; Paulaniemi, M.; Raekallio, M.R. Owner-reported clinical signs and management-related factors in horses radiographed for intestinal sand accumulation. J. Equine Vet. Sci. 2019, 80, 10-15. [CrossRef] [PubMed]

21. Kilcoyne, I.; Dechant, J.E.; Spier, S.J.; Spriet, M.; Nieto, J.E. Clinical findings and management of 153 horses with large colon sand accumulations. Vet. Surg. 2017, 46, 860-867. [CrossRef]

22. Müller, C.E. Equine digestion of diets based on haylage harvested at different plant maturities. Anim. Feed Sci. Technol. 2012, 177, 65-74. [CrossRef]

23. Müller, C.E. Silage and haylage for horses. Grass Forage Sci. 2018, 73, 815-827. [CrossRef]

24. Muhonen, S.; Julliand, V.; Lindberg, J.E.; Bertilsson, J.; Jansson, A. Effects on the equine colon ecosystem of grass silage and haylage diets after an abrupt change from hay. J. Anim. Sci. 2009, 87, 2291-2298. [CrossRef]

25. Daly, K.; Proudman, C.J.; Duncan, S.H.; Flint, H.J.; Dyer, J.; Shirazi-Beechey, S.P. Alterations in microbiota and fermentation products in equine large intestine in response to dietary variation and intestinal disease. Br. J. Nutr. 2012, 107, 989-995. [CrossRef]

26. Fernandes, K.A.; Kittelmann, S.; Rogers, C.W.; Gee, E.K.; Bolwell, C.F.; Bermingham, E.N.; Thomas, D.G. Faecal microbiota of forage-fed horses in New Zealand and the population dynamics of microbial communities following dietary change. PLoS ONE 2014, 9, e112846. [CrossRef] [PubMed]

27. Müller, C.E.; Von Rosen, D.; Udén, P. Effect of forage conservation method on microbial flora and fermentation pattern in forage and in equine colon and faeces. Livest. Sci. 2008, 119, 116-128. [CrossRef]

28. Lopes, M.A.; White, N.A., II; Crisman, M.V.; Ward, D.L. Effects of feeding large amounts of grain on colonic contents and feces in horses. Am. J. Vet. Res. 2004, 65, 687-694. [CrossRef] [PubMed]

29. Clarke, L.L.; Roberts, M.C.; Argenzio, R.A. Feeding and digestive problems in horses: Physiologic responses to a concentrated meal. Vet. Clin. N. Am. Equine Pract. 1990, 6, 433-450. [CrossRef]

30. Jones, S.L.; Spier, S.T. Pathophysiology of colonic inflammation and diarrhea. In Equine Internal Medicine; Reed, S.M., Bayly, W.M., Eds.; WB Saunders: Philadelphia, PA, USA, 1998; pp. 678-679.

31. Tinker, M.K.; White, N.A.; Lessard, P. Descriptive epidemiology and incidence of colic on horse farms: A prospective study. In Proceedings of the 5th Equine Colic Research Symposium, The University of Georgia, Athens, GA, USA, 26-28 September 1994.

32. Tinker, M.K.; White, N.A.; Lessard, P.; Thatcher, C.D.; Pelzer, K.D.; Davis, B.; Carmel, D.K. Prospective study of equine colic risk factors. Equine Vet. J. 1997, 29, 454-458. [CrossRef]

33. Hudson, J.M.; Cohen, N.D.; Gibbs, P.G.; Thompson, J.A. Feeding practices associated with colic in horses. J. Am. Vet. Med. Assoc. 2001, 219, 1419-1425. [CrossRef]

34. Luthersson, N.; Nielsen, K.H.; Harris, P.; Parkin, T.D. The prevalence and anatomical distribution of equine gastric ulceration syndrome (EGUS) in 201 horses in Denmark. Equine Vet. J. 2009, 41, 619-624. [CrossRef] 
35. Sandin, A.; Skidell, J.; Häggström, J.; Nilsson, G. Postmortem findings of gastric ulcers in Swedish horses older than age one year: A retrospective study of 3715 horses (1924-1996). Equine Vet. J. 2000, 32, $36-42$. [CrossRef]

36. Niedźwiedź, A.; Kubiak, K.; Nicpoń, J. Endoscopic findings of the stomach in pleasure horses in Poland. Acta Vet. Scand. 2013, 55, 45. [CrossRef]

37. Hillyer, M.H.; Taylor, F.G.R.; Proudman, C.J.; Edwards, G.B.; Smith, J.E.; French, N.P. Case control study to identify risk factors for simple colonic obstruction and distension colic in horses. Equine Vet. J. 2002, 34, 455-463. [CrossRef]

38. Traub-Dargatz, J.L.; Kopral, C.A.; Seitzinger, A.H.; Garber, L.P.; Forde, K.; White, N.A. Estimate of the national incidence of and operation-level risk factors for colic among horses in the United States, spring 1998 to spring 1999. J. Am. Vet. Med. Assoc. 2001, 219, 67-71. [CrossRef] [PubMed]

39. Normando, S.; Canali, E.; Ferrante, V.; Verga, M. Behavioral problems in Italian saddle horses. J. Equine Vet. Sci. 2002, 22, 117-120. [CrossRef]

40. Christie, J.L.; Hewson, C.J.; Riley, C.B.; McNiven, M.A.; Dohoo, I.R.; Bate, L.A. Management factors affecting stereotypies and body condition score in nonracing horses in Prince Edward Island. Can. Vet. J. 2006, 47, 136. [PubMed]

41. Normando, S.; Meers, L.; Samuels, W.E.; Faustini, M.; Ödberg, F.O. Variables affecting the prevalence of behavioral problems in horses. Can riding style and other management factors be significant? Appl. Anim. Behav. Sci. 2011, 133, 186-198. [CrossRef]

42. McGreevy, P.D.; French, N.P.; Nicol, C.J. The prevalence of abnormal behaviors in dressage, eventing and endurance horses in relation to stabling. Vet. Rec. 1995, 137, 36-37. [CrossRef] [PubMed]

43. Luescher, U.A.; McKeown, D.B.; Dean, H.A. Cross-sectional study on compulsive behaviour (stable vices) in horses. Equine Vet. J. 1998, 27, 14-18. [CrossRef]

44. McGreevy, P.D.; Cripps, P.J.; French, N.P.; Green, L.E.; Nicol, C.J. Management factors associated with stereotypic and redirected behaviour in the thoroughbred horse. Equine Vet. J. 1995, 27, 86-91. [CrossRef]

45. Bachmann, I.; Audige, L.; Stauffacher, M. Risk factors associated with behavioural disorders of crib-biting, weaving and box-walking in Swiss horses. Equine Vet. J. 2003, 35, 158-163. [CrossRef]

46. Redbo, I.; Redbo-Torstensson, P.; Odberg, F.O.; Henderdahl, A.; Holm, J. Factors affecting behavioural disturbances in racehorses. Anim. Sci. 1998, 66, 475-481. [CrossRef]

(C) 2020 by the authors. Licensee MDPI, Basel, Switzerland. This article is an open access article distributed under the terms and conditions of the Creative Commons Attribution (CC BY) license (http://creativecommons.org/licenses/by/4.0/). 
Article

\title{
Eye Blink Rates and Eyelid Twitches as a Non-Invasive Measure of Stress in the Domestic Horse
}

\author{
Katrina Merkies ${ }^{1,2, *}$, Chloe Ready ${ }^{1}$, Leanne Farkas ${ }^{1}$ and Abigail Hodder ${ }^{1}$ \\ 1 Department of Animal Biosciences, University of Guelph, Guelph, ON N1G 2W1, Canada \\ 2 Campbell Centre for the Study of Animal Welfare, University of Guelph, Guelph, ON N1G 2W1, Canada \\ * Correspondence: kmerkies@uoguelph.ca
}

Received: 12 July 2019; Accepted: 13 August 2019; Published: 15 August 2019

Simple Summary: Eye blink rate has been used as an indicator of stress in humans and, due to its non-invasive nature, could be useful to measure stress in horses. Horses exhibit both full and half blinks as well as eyelid twitches. We exposed 33 horses to stressful situations such as separation from herdmates, denied access to feed and sudden introduction of a novel object, and determined that full and half eye blinks decrease in these situations. Feed restriction was the most stressful for the horse as indicated by increased heart rate, restless behaviour and high head position. The decrease in eye blink rate during feed restriction was paralleled with an increase in eyelid twitches. There was no increase in eyelid twitches or heart rate with the other treatments indicating that the horses did not find these overly stressful, but they did focus their attention more during these situations. Observation of eye blinks and eyelid twitches can provide important information on the stress level of horses with a decrease in eye blinks and an increase in eyelid twitches in stressful environments.

\begin{abstract}
Physiological changes provide indices of stress responses, however, behavioural measures may be easier to determine. Spontaneous eye blink rate has potential as a non-invasive indicator of stress. Eyelid movements, along with heart rate (HR) and behaviour, from 33 horses were evaluated over four treatments: (1) control—horse in its normal paddock environment; (2) feed restriction-feed was withheld at regular feeding time; (3) separation-horse was removed from visual contact with their paddock mates; and (4) startle test-a ball was suddenly thrown on the ground in front of the horse. HR data was collected every five s throughout each three min test. Eyelid movements and behaviours were retrospectively determined from video recordings. A generalized linear mixed model (GLIMMIX) procedure with Sidak's multiple comparisons of least squares means demonstrated that both full blinks $\left(16 \pm 12^{\mathrm{b}}\right.$ vs. $15 \pm 15^{\mathrm{b}}$ vs. $13 \pm 11^{\mathrm{b}}$ vs. $26 \pm 20^{\mathrm{a}}$ full blinks/ 3 min \pm SEM; a,b differ $p<0.006)$ and half blinks $\left(34 \pm 15^{\mathrm{ab}}\right.$ vs. $27 \pm 14^{\mathrm{bc}}$ vs. $25 \pm 13^{\mathrm{c}}$ vs. $42 \pm 22^{\mathrm{a}}$ half blinks $/ 3$ $\min \pm$ SEM; $\mathrm{a}, \mathrm{b}, \mathrm{c}$ differ $p<0.0001$ ) decreased during feed restriction, separation and the startle test compared to the control, respectively. Eyelid twitches occurred more frequently in feed restriction $(p<0.0001)$ along with an increased HR $(p<0.0001)$. This study demonstrates that spontaneous blink rate decreases while eyelid twitches increase when the horse experiences a stressful situation.
\end{abstract}

Keywords: spontaneous blink rate; eyelid twitches; stress; horse; behaviour; welfare

\section{Introduction}

Stress is defined as the response of an organism to environmental stimuli that threatens its internal equilibrium [1]. As a prey species, the domestic horse (Equus caballus) has developed adaptive fear and flight responses when faced with external stressors [2]. However, modern husbandry practices routinely subject horses to aversive stimuli such as transportation, social isolation and medical intervention. 
Identifying indicators of stress in the horse is fundamental for the welfare of the animal itself and the safety of the handler [3].

Various physiological measures can be used to assess stress responses in animals including heart rate and heart rate variability [4], blood or salivary cortisol [5]. However, these measures have their limitations, including the increase in stress due to the invasive nature of drawing blood, for example [6]. As a result, researchers have explored behavioural indicators to augment physiological data. For example, horses exposed to various stressors demonstrate higher head carriage [7], focused orientation of the ears [8], increased vocalizations [9] and increased mouth movements [10]. Assessing stress responses in animals appears more accurate when using a combination of both behavioural and physiological indicators [11,12]. A novel scale developed to identify stress-related behaviours subjected 32 horses to known stressful husbandry practices including the sound of electric coat clippers, social isolation and grooming procedures [13]. Moderate to high levels of stress showed an increase in oral behaviours, flared nostrils and flattened or pinned ears which correlated with an increase in heart rate (HR) and salivary cortisol [13].

However, evidence of behaviours associated with stress in horses is conflicting. Horses subjected to two stressful handling tasks - walking across a tarpaulin and walking through streamers attached to an overhead pole-displayed an increase in heart rate variability and eye temperature [14]. The time taken or willingness to complete each task was not associated with physiological indicators, showing that the horses did experience stress even when not overtly displaying stress behaviours [14]. Further, horses undergoing a hair clipping procedure, a known aversive management practice, showed compliant behaviour while displaying an increase in HR, salivary cortisol and eye temperature [15]. These studies suggest that a horse's level of compliance and/or ability to tolerate stressors is not indicative of their level of arousal, and influences such as training may overshadow emotional responses [15].

Understanding the response of an animal to external stressors through valid behavioural indicators can be challenging and subjective, however behaviour is an easily observable and non-invasive measurement [16]. Identifying valid indicators of stress is essential to understanding the animal and ultimately improving welfare.

Eye-blink rate has been used as a non-invasive measure of arousal to predict stress levels in humans [17]. Blinking is defined as a quick movement of the eyelid that opens and closes the palpebral fissure and is composed of three different blinks: spontaneous, reflex and voluntary [18]. The levator palpebrae superioris muscle of the upper eyelid is primarily responsible for opening the eyelid, whereas the orbicularis oculi muscle encircling the palpebral fissure works to close the eyelid [19]. Upon close observation, different eyelid movements are noticeable, ranging from full blinks (complete closure of both eyelids with concomitant suppression of vision) to partial blinks (incomplete closure of the eyelids) and eyelid twitches (movement of the upper eyelid through innervation of the levator palpebrae superioris muscles with no movement of the orbicularis oculi muscles) [20]. Partial blinks have been observed in humans focused on computer terminal displays [21] and have been used as a diagnostic for dry eye disease [22]. Partials blinks have also been documented in both dogs [23] and cats [24]. Due to the large size and lateral placement of a horse's eyes, identifying eyelid movements is easily observable. Although little investigation has been done on half blinks in horses, it has been incorporated into the Equine Facial Action Coding System (EquiFACS) as its own action unit [25].

Spontaneous blinks are uniquely different from voluntary and reflexive blinks, as they can represent a range of information processing functions spanning attention and working memory [26]. Humans subjected to stressful stimuli through social and emotional recollection tests exhibited an increase in spontaneous blink rate and a similar trend has been demonstrated in guinea pigs that are in states of emotional arousal following handling [27]. Although an increase in spontaneous blink rate has been observed in humans subjected to stressful and neurologically-demanding stimuli, spontaneous blink rate has also been found to decrease when the subject is most attentive while performing demanding tasks or exposed to stressful visual stimuli $[28,29]$. This suggests that humans reduce their spontaneous blink rate when perceiving visual stimuli in order to maximize the amount 
of information entering the nervous system; thus, increased spontaneous blink rate potentially hinders attention in humans and the ability to perceive immediate stimuli [28]. Therefore, the influence of specific stressors such as visual stimuli, emotional anxiety and/or neurological levels of arousal that initiate a fight or flight response must be considered when investigating behavioural responses in horses $[17,28]$.

While spontaneous blink rate has been used as a non-invasive measure of stress in humans, little research has been applied to using spontaneous blink rate as a behavioural indicator in horses, and no research has differentiated between different eyelid movements. This study aims to investigate the use of spontaneous blink rate and eyelid movements as a non-invasive measure of stress in domestic horses (Equus caballus) in response to induced, external stressors. Based on the limited and contrasting evidence reviewed, sources of stressors including feed restriction and separation from herdmates were selected to induce social and neurological states of arousal. In comparison, the startle test was chosen to induce a stress response from visual stimuli. We hypothesized that spontaneous blink rates in horses would significantly increase during feed restriction and separation from conspecifics and decrease during the startle test in comparison to the control.

\section{Materials and Methods}

This project was approved by the University of Guelph's Animal Care Committee (AUP \#3143) in compliance with the Canadian Council on Animal Care guidelines for the use of animals in research.

\subsection{Subjects and Housing}

This study used 33 riding lesson horses (Equus caballus) from three different facilities in Eastern Ontario, Canada. The horses had a mean age of $11 \pm 6$ years, and all horses were in good health with no documented instances of digestive issues or ulcers that might impact the feed restriction treatment. As a variety of breeds were represented, they were categorized into four categories: Thoroughbred and Thoroughbred crosses $(n=10)$, warmbloods (e.g., Hanoverian; $n=8$ ), stock (e.g. Quarter Horse; $n=7$ ) and ponies (e.g., Welsh; $n=8$ ). Before and after each treatment, the horses were housed in their usual stalls and followed their regular regimes, including being turned out with their normal herdmates and maintaining their normal exercise routines. Their diets and feeding schedules remained the same throughout the study, with the exception of the feed restriction treatment when feed was withheld.

\subsection{Treatments}

Each horse was exposed to each of the four treatments in randomized order.

(i) Control: the horse was observed individually for three minutes in their normal turnout environment, with the exception of the presence of the handler and observer. The horse was surrounded by, or within sight of, their paddock mates. Observations occurred during quiet times at the facility with no expectation of predictable events such as riding or feeding.

(ii) Feed restriction: the horse was tied individually in their stall during their regular afternoon feeding time, and was observed while feed was withheld for three minutes, during which time the horse watched their neighbouring conspecifics being fed.

(iii) Separation: the horse was led individually from their normal environment to an isolated testing arena. Once there, the horse was asked to stand and was observed for three minutes. There was no visual contact with their conspecifics although auditory contact was still possible. Observations occurred during quiet times at the facility with no expectation of predictable events such as riding or feeding.

(iv) Startle test: the horse was led individually from their normal environment to an isolated testing arena where they were unable to see conspecifics although auditory contact was still possible. Once there, the horse was asked to stand while a ball was thrown suddenly on the ground $2 \mathrm{~m}$ in front of the horse (Figure 1), and the horse was observed for three minutes. Observations occurred during quiet times at the facility with no expectation of predictable events such as riding or feeding. 


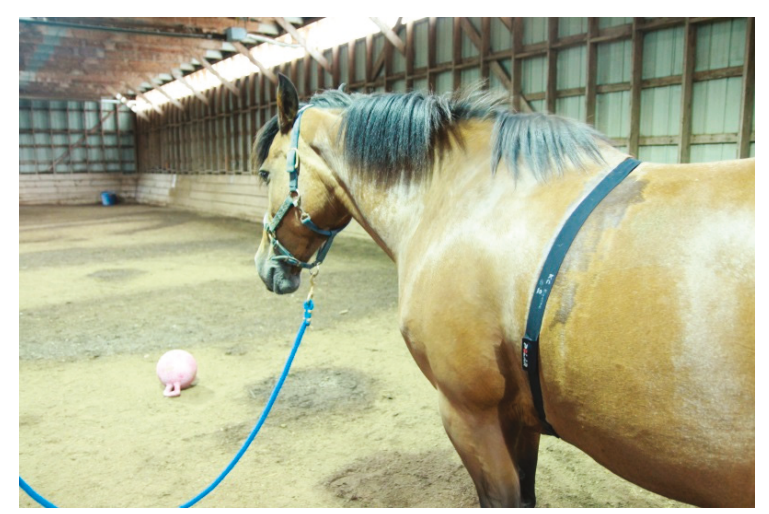

Figure 1. Horse with heart rate (HR) monitor (Polar RS800) during the startle test. The ball was tossed approximately $2 \mathrm{~m}$ in front of the horse. The handler maintained a fairly loose lead. The observer (not visible in this photo) was positioned about $3 \mathrm{~m}$ from the horse's right eye.

\subsection{Data Collection}

All data at any one facility were collected over two or three days, and all treatments for any one horse were tested on a single day. At least $10 \mathrm{~min}$ prior to each treatment, each horse was outfitted with a heart rate monitor (Polar RS800, Lachine, QC, USA; Figure 1) to allow them to acclimatize to the monitors. Heart rate (HR) was collected every five s throughout each treatment.

During each treatment, a handler held the horse by a lead rope attached to the halter, and the same handler was used throughout the study. The handler held the horse in place on a fairly loose lead $(1 \mathrm{~m})$, with just enough contact to maintain the head relatively still without restricting movement. A single observer was used throughout the study and maintained a position about $3 \mathrm{~m}$ perpendicular to the right eye of the horse. The observer videotaped all treatments using a Panasonic $2 \mathrm{MOS}$ video camera, with focus maintained on the right eye of the horse. One individual coded all the behaviours (Table 1) retrospectively from the videos using Observer XT (Version 12.0, Noldus, Leesburg, VA, USA). All occurrences of eye blinks and eyelid twitches were tallied, while the total duration of ear movement, head movement, mouth movement and restlessness was calculated over each 3 min treatment and reported as a percentage of total time.

\subsection{Data Analysis}

The data was exported from Observer XT to Microsoft Excel 2011 (Supplementary File SBrate data.xlsx). All statistical analyses were carried out using SAS (Version 9.4, Toronto, ON), and significance was considered to be $p<0.05$.

As there was no missing data, $n=33$ for all analyses. Residuals were graphically inspected to determine the fit of the model, and horse HRs were log transformed since they did not achieve a normal distribution (Kolmogorov-Smirnov test, $p<0.01$ ). A generalized linear mixed model procedure was used to analyse the effect of treatment on behaviour and HR, with location, age, breed and treatment as the independent variables and horse as the random factor. Sidak's methodology was used to test multiple comparisons of least squared means for each behaviour across treatments. 
Table 1. Ethogram of behaviours observed in horses $(n=33)$ during each of the four treatments—control, feed restriction, separation from conspecifics and the startle test. Adapted from $[13,25,30,31]$.

\begin{tabular}{|c|c|}
\hline Behaviour & Description \\
\hline Eye-full blink & The right eye becomes momentarily but completely closed \\
\hline Eye-half blink & $\begin{array}{l}\text { The right upper lid moves toward the lower lid of the eye but does not } \\
\text { cover the eye completely }\end{array}$ \\
\hline Eyelid—twitch & $\begin{array}{c}\text { Fine fibrillar movement of the skin involving the levator palpebrae } \\
\text { superioris muscle of the upper eyelid }\end{array}$ \\
\hline Ears-forward & The right ear points forward in an attentive manner \\
\hline Ears—sideways & The right ear is angled to the side \\
\hline Ears-back & The right ear is turned backward \\
\hline Head-above withers & The right eye level goes above the height of the withers \\
\hline Head-even with withers & The right eye is even with the height of the withers \\
\hline Head-below withers & The right eye level drops below the height of the withers \\
\hline Oral behaviour & $\begin{array}{c}\text { The lips are in motion, either with mouth shut, with the tongue licking } \\
\text { or coming out of the mouth, or chewing }\end{array}$ \\
\hline Restlessness & $\begin{array}{l}\text { Any movement made by the legs, including movement that causes the } \\
\text { horse to move out of view of the camera }\end{array}$ \\
\hline
\end{tabular}

\section{Results}

On average, horses performed full blinks 8-9 times/min in the absence of any stressors. This rate decreased to 5 blinks/min in the presence of any external stressors. Conversely, eyelid twitches increased from about $2 / \mathrm{min}$ in the control situation to 6/min during feed restriction. Full eye blinks occurred more often during control than during any other treatment $(\mathrm{F}(3,95)=9.88, p<0.0001$; Figure 2). Half blinks occurred most often during control and feed restriction treatments, and least often during separation or startle test $(\mathrm{F}(3,95)=10.65, p<0.0001$; Figure 2). Eyelid twitches were more evident during the feed restriction treatment than during any other treatment $(\mathrm{F}(3,95)=9.46, p<0.0001$; Figure 2).

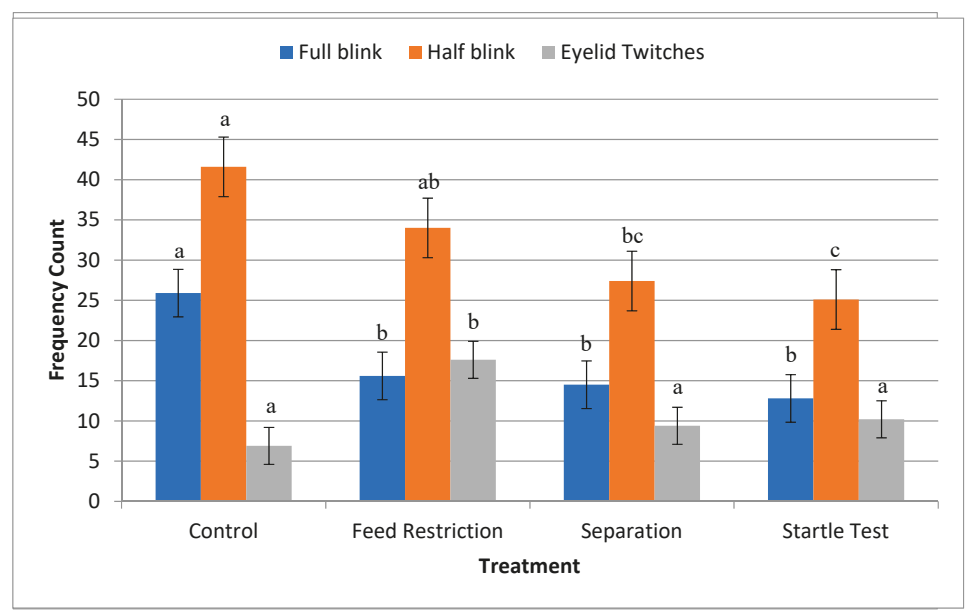

Figure 2. Total number of observations of full eye blinks, half blinks and eyelid twitches $( \pm \mathrm{SD})$ in horses $(n=33)$ over a $3 \mathrm{~min}$ observation period during control, feed restriction, separation from conspecifics or a startle test. a,b,c differ across treatments $p<0.0001$. 
Horse heart rate was higher during feed restriction $(44 \pm 13$ beats per minute $(\mathrm{bpm}))$ and lower during separation $(37 \pm 7 \mathrm{bpm})$ and the startle test $(37 \pm 8 \mathrm{bpm})$ compared to the control $(39 \pm 8 \mathrm{bpm})$ $(\mathrm{F}(3,92)=306.12, p<0.0001)$. There was no effect of facility $(p>0.05)$ on the behaviours or HR.

The horses' right ear was forward more often during separation and the startle test $(\mathrm{F}(3,95)=$ $8.29, p<0.0001$; Figure 3), whereas it was more often sideways during feed restriction and the control $(\mathrm{F}(3,95)=22.53, p<0.0001)$. There was no difference among treatments for the percentage of time the horses had their ears back $(\mathrm{F}(3,95)=0.82, p>0.49)$.

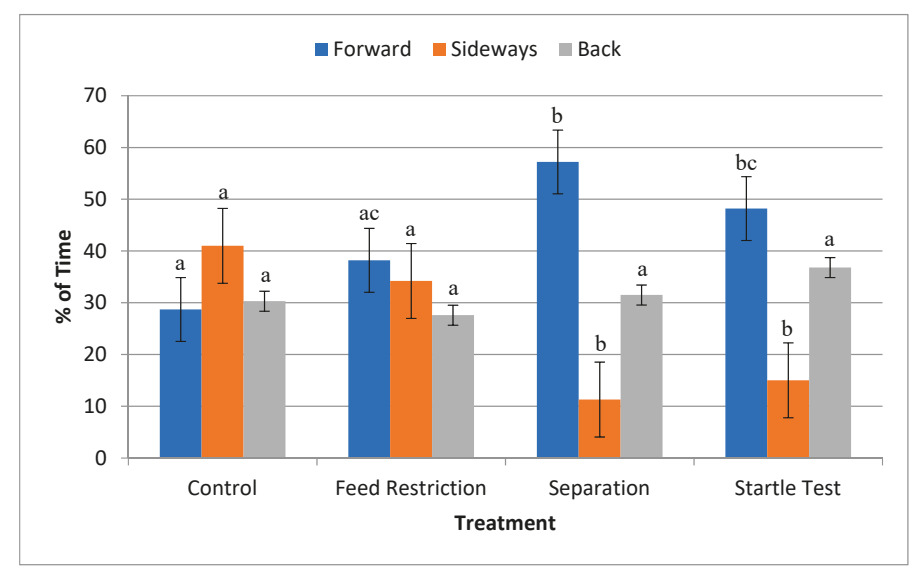

Figure 3. Percentage of time that horses' $(n=33)$ ears were forward, sideways or back $( \pm S D)$ over a 3 min observation period during feed restriction, separation from conspecifics, a startle test or control. $\mathrm{a}, \mathrm{b}, \mathrm{c}$ differ across treatments $p<0.0001$.

Horses held their head raised more frequently during feed restriction $(\mathrm{F}(3,95)=30.02, p<0.0001$; Figure 4) and held their head low more often during the control treatment and startle test $(\mathrm{F}(3,95)=$ $7.15, p=0.0002)$.

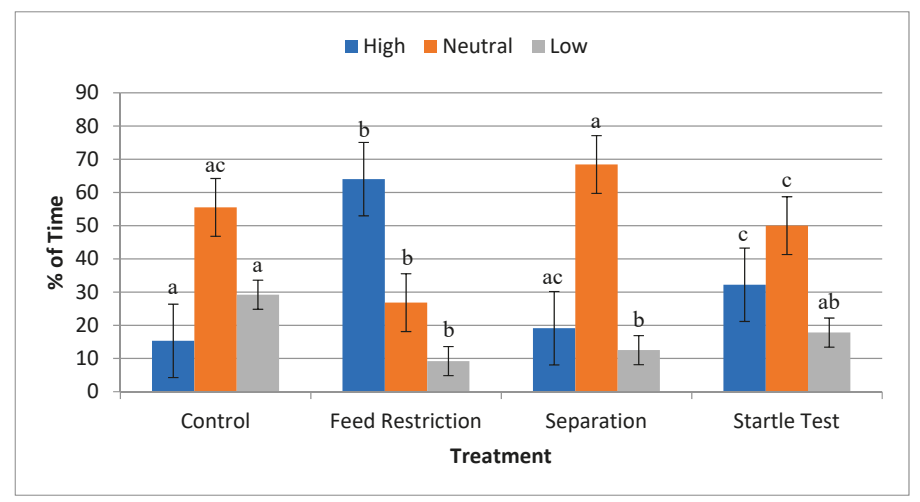

Figure 4. Percentage of time that horses' $(n=33)$ heads were held high, neutral or low $( \pm S D)$ over a 3 min observation period during feed restriction, separation from conspecifics, a startle test or control. $\mathrm{a}, \mathrm{b}, \mathrm{c}$ differ across treatments $p<0.0001$.

Oral behaviours were most evident during the feed restriction, with significantly fewer during separation and the startle test $(\mathrm{F}(3,95)=11.42, p<0.0001)$. Horses were more often restless during feed restriction than separation or the startle test $(\mathrm{F}(3,95)=6.78, p=0.0003)$. 


\section{Discussion}

The aim of this study was to determine changes in eyelid movement in horses during exposure to stressful stimuli. It was expected that spontaneous blink rate would increase during exposure to mental stressors such as feed restriction and separation from conspecifics and decrease during exposure to visual stimuli via the startle test. However, our results showed a decrease in both full and half blinks in response to each of the test situations.

Feed restriction was clearly the most stressful situation for the horse demonstrated by an increase in HR, restlessness, oral behaviours and percentage of time the head was held high. However, as HR increased only slightly, it may be concluded that this was only a mildly stressful situation. During separation from conspecifics and the startle test, horses had their right ear forward for more of the time, indicating focused attention in front of them that presumably maximized visual information processing. The horses may also have been attentive to sounds emanating outside of the test arena, although such sounds could come from any direction. Heart rate during these two situations was slightly decreased, showing that while attention was focused, physiologically the horses did not appear stressed. It could be that the presence of the human handler and observer may have had an appeasing effect on the horse, as Merkies et al. $[7,10]$ demonstrated a decrease in HR when any human was present rather than the horse being completely alone.

Like full blinks, half blinks were most evident in the control environment, with the lowest frequency in the startle test where visual stimulation is important for the horse to process information about their environment. Similarly, in humans, the number of both full and partial blinks decreased when they were asked to perform a reading test requiring visual concentration [32]. Also shown in guinea pigs, eye blink rate decreased during handling compared to the control, although this study did not verify the stressful effects of handling [27]. Conversely, both full and half blinks characterized in cats increased under conditions of induced fear [24].

A recent study investigating stress responses in horses observed a decrease in mean spontaneous blink rate only during the first minute of a $10 \mathrm{~min}$ sham clipping procedure [33]. This decline preceded the onset of a significant increase in spontaneous blink rate for the following nine min, suggesting that the initial reduction may be characteristic of a fight or flight response, allowing the horse to visually fixate on the stimulus before responding accordingly. In our current study, blink rate was calculated as a mean over three min. It could be that a longer time frame may have noted a subsequent increase in spontaneous blink rate similar to Mott et al.'s [33] study. It would have been interesting if Mott et al. [33] had collected data on differing eyelid movements.

Our results showed an increase in eyelid twitches during feed restriction, which the horses found stressful. Conversely, separation from conspecifics and the startle test did not evoke an increase in eyelid twitches, suggesting that eyelid twitches are more prevalent during stressful situations as the horses did not appear to find these two latter situations stressful.

Research investigating horse facial expressions led to the development of the equine Facial Action Coding System (EquiFACS) for use in determining behavioural indicators of a horse's emotional state [25]. In accordance with EquiFACS, the Equine Pain Face and Horse Grimace Scale (HGS) were created after observing changes in equine facial expressions when horses were subjected to painful procedures. These scales identified notable changes in eye expression associated with horses experiencing negative situations [31,34]. An angled eye was found to be indicative of stress by comparing the shape of the eye with the appearance of eye-white during treatments associated with negative arousal [35]. The appearance of "worry wrinkles", defined as a contraction of the levator anguli oculi medialis muscle and the corrugator supercilii muscle, are prominent during situations involving negative arousal such as food competition, in contrast to relaxed eyes during positive stimuli such as grooming [35]. These "worry wrinkles" may be similar to eyelid twitches that appear to increase under stressful situations. As Hintze et al.'s [35] study analysed photographs, what they may have witnessed was an eyelid twitch in a static moment. Furthermore, a more recent study showed that worry wrinkles could be assessed systematically regardless of horse sex, age or breed, with the 
exception of angle. In this instance, thoroughbred horses displayed less contraction of the eyelid muscles than ponies, with coldbloods displaying the strongest contraction [36].

In horses, an increase in spontaneous blink rate was associated with a more anxious temperament accompanied by more movement, while a decrease in spontaneous blink rate was associated with more docile behaviour [37]. The authors proposed that these differences in temperament may be directly related to striatal dopamine levels, with anxious horses having elevated dopamine while docile horses have lower levels of dopamine. In humans, spontaneous blink rate has been positively associated with striatal dopamine production. For example, it is well known that spontaneous blink rate is decreased in humans experiencing Parkinson's disease, an affliction that causes reduced functioning due to a decrease in dopamine production, whereas patients with schizophrenia (a hyperdopaminergic condition) exhibit increased anxiety and increased blink rate [38]. Additionally, Colzato et al. [39] demonstrated that both high and low spontaneous blink rates caused a decrease in performance in humans undergoing a start-stop task whereas those with average spontaneous blink rates performed best. These results emphasize the effect of tonic dopamine levels on spontaneous blink rate, which is an important baseline to understand changes in blink rates as a result of induced environmental stressors. It may be that a reduced spontaneous blink rate could indicate underlying pathologies such as depression, or alternatively that activity level may not necessarily reflect the level of arousal.

To our knowledge, this is the first report of the significance of eyelid twitches in horses. Blinking, and even more so eyelid twitches, are relatively easy measures to examine in horses, although the observer must be fairly close to the horse in question. Monitoring changes in blink rate, and in particular eyelid twitches, could alert the observer to changes in the level of arousal of the horse. A decrease in spontaneous blink rate concomitant with an increase in eyelid twitches may indicate a stressful situation for the horse, whereas a decrease in spontaneous blink unaccompanied by an increase in eyelid twitches may indicate an environment that is engaging but not stressful to the horse. Further research investigating specific eyelid movements in relation to level of arousal could give us insight into the emotional responses of horses. For example, in humans, facial electromyography has been successfully used to correlate facial muscle activation to positive or negative emotions. Since we cannot ask horses to self-report how they are feeling, physiological measures that differentiate between pleasant and unpleasant experiences may allow us to infer underlying emotions. Further investigation of changes in spontaneous blink rate and eyelid twitches over varying time spans is needed to identify patterns and temporal trends in response to stressful stimuli.

\section{Conclusions}

Horses exposed to stressful environments decrease their spontaneous eye blink rate and increase the frequency of eyelid twitches. However, if the environment is simply visually stimulating, eyelid twitches do not appear to increase even if eye blink rate decreases. Monitoring spontaneous blink rate is a sensitive metric of neural activity and differentiating eye blinks from eyelid twitches may provide insight on the level of arousal of the horse.

Supplementary Materials: The following are available online at http://www.mdpi.com/2076-2615/9/8/562/s1.

Author Contributions: Conceptualization, K.M.; methodology, K.M. and C.R.; formal analysis, K.M.; investigation, K.M., C.R. and L.F.; resources, K.M.; data curation, K.M. and L.F.; writing — original draft preparation, L.F. and A.H.; writing-review and editing, K.M.; supervision, K.M.; project administration, K.M.; funding acquisition, K.M.

Funding: This research received no external funding.

Acknowledgments: The authors would like to thank the three stables who volunteered the use of their school horses for data collection. Also, thanks to Amelia Garnett for coding many of the videos.

Conflicts of Interest: The authors declare no conflict of interest. 


\section{References}

1. Ramos, A.; Mormede, P. Stress and emotionality: A multidimensional and genetic approach. Neurosci. Biobehav. Rev. 1998, 22, 33-57. [CrossRef]

2. Budzynska, M. Stress reactivity and coping in horse adaptation to environment. J. Equine Vet. Sci. 2014, 34, 935-941. [CrossRef]

3. Yarnell, K.; Hall, C.; Royle, C.; Walker, S.L. Domesticated horses differ in their behavioural and physiological responses to isolated and group housing. Physiol. Behav. 2015, 143, 51-57. [CrossRef] [PubMed]

4. Von Borell, E.; Langbein, J.; Després, G.; Hansen, S.; Leterrier, C.; Marchant-Forde, J.; Marchant-Forde, R.; Minero, M.; Mohr, E.; Prunier, A.; et al. Heart rate variability as a measure of autonomic regulation of cardiac activity for assessing stress and welfare in farm animals-A review. Physiol. Behav. 2007, 92, $293-316$. [CrossRef] [PubMed]

5. Janczarek, I.; Wilk, I.; Stachurska, A.; Krakowski, L.; Liss, M. Cardiac activity and salivary cortisol concentration of leisure horses in response to the presence of an audience in the arena. J. Vet. Behav. 2019, 29, 31-39. [CrossRef]

6. Palme, R. Non-invasive measurement of glucocorticoids: Advances and problems. Physiol. Behav. 2019, 199, 229-243. [CrossRef]

7. Merkies, K.; Sievers, A.; Zakrajsek, E.; MacGregor, H.; Bergeron, R.; König von Borstel, U. Preliminary results suggest an influence of psychological and physiological stress in humans on horse heart rate and behaviour. J. Vet. Behav. 2014, 9, 242-247. [CrossRef]

8. McKinney, C.; Mueller, M.K.; Frank, N. Effects of therapeutic riding on measures of stress in horses. J. Equine Vet. Sci. 2015, 35, 922-928. [CrossRef]

9. Visser, E.K.; van Reenen, C.G.; Hopster, H.; Schilder, M.B.H.; Knaap, J.H.; Barneveld, A.; Blokhuis, H.J. Quantifying aspects of young horses' temperament: Consistency of behavioural variables. Appl. Anim. Behav. Sci. 2001, 74, 241-258. [CrossRef]

10. Merkies, K.; McKechnie, M.J.; Zakrajsek, E. Behavioural and physiological responses of therapy horses to mentally traumatized humans. Appl. Anim. Behav. Sci. 2018, 205, 61-67. [CrossRef]

11. Mason, G.; Mendl, M. Why is there no simple way of measuring animal welfare? Anim. Welf. Sci. 1993, 2, 301-319.

12. Hall, C.; Huws, N.; White, C.; Taylor, E.; Owen, H.; McGreevy, P. Assessment of ridden horse behavior. J. Vet. Behav. 2014, 8, 62-73. [CrossRef]

13. Young, T.; Creighton, E.; Smith, T.; Hosie, C. A novel scale of behavioural indicators of stress for use with domestic horses. Appl. Anim. Behav. Sci. 2012, 140, 33-43. [CrossRef]

14. Squibb, K.; Griffin, K.; Favier, R.; Ijichi, C. Poker Face: Discrepancies in behaviour and affective states in horses during stressful handling procedures. Appl. Anim. Behav. Sci. 2018, 202, 34-38. [CrossRef]

15. Yarnell, K.; Hall, C.; Billett, E. An assessment of the aversive nature of an animal management procedure (clipping) using behavioral and physiological measures. Physiol. Behav. 2013, 118, 32-39. [CrossRef]

16. Mendl, M.; Burman, O.H.P.; Paul, E.S. An integrative and functional framework for the study of animal emotion and mood. Proc. Biol. Sci. 2010, 277, 2895-2904. [CrossRef]

17. Giannakakis, G.; Pediaditis, M.; Manousos, D.; Kazantzaki, E.; Chiarugi, F.; Simos, P.G.; Mariasa, K.; Tsiknakis, M. Stress and anxiety detection using facial cues from videos. Biomed. Signal Process. Control 2017, 31, 89-101. [CrossRef]

18. Cruz, A.A.V.; Garcia, D.M.; Pinto, C.T.; Cechetti, S.P. Spontaneous eyeblink activity. Ocul. Surf. 2011, 9, $29-41$. [CrossRef]

19. Koo Lin, L. Eyelid anatomy and function. In Ocular Surface Disease: Cornea, Conjunctiva and Tear Film; Holland, E.J., Mannis, M.J., Lee, W.B., Eds.; Elsevier: Cambridge, UK, 2013; pp. 11-15. ISBN 978-1-4557-2876-3.

20. Blount, W.P. Studies of the movements of the eyelids of animals: Blinking. Exp. Physiol. 1927, 18, 111-125. [CrossRef]

21. Portello, J.K.; Rosenfield, M.; Chu, C.A. Blink rate, incomplete blinks and computer vision syndrome. Optom. Vis. Sci. 2013, 90, 482-487. [CrossRef]

22. Jie, Y.; Sella, R.; Feng, J.; Gomez, M.L.; Afshari, N.A. Evaluation of incomplete blinking as a measurement of dry eye disease. Ocul. Surf. 2019, 5. [CrossRef] 
23. Nakajima, S.; Takamatsu, Y.; Fukuoka, T.; Omori, Y. Spontaneous blink rates of domestic dogs: A preliminary report. J. Vet. Behav. 2011, 6, 95. [CrossRef]

24. Bennett, V.; Gourkow, N.; Mills, D.S. Facial correlates of emotional behaviour in the domestic cat (Feliscatus). Behav. Proc. 2017, 141, 342-350. [CrossRef]

25. Wathan, J.; Burrows, A.M.; Waller, B.M.; McComb, K. EquiFACS: The equine facial action coding system. PLoS ONE 2015, 10, e0131738. [CrossRef]

26. Rubin, M.; Denise, H.; Dipanjana, D.; Melara, R. Inhibitory Control under Threat: The Role of Spontaneous Eye Blinks in Post-Traumatic Stress Disorder. Brain Sci. 2017, 7, 16. [CrossRef]

27. Trost, K.; Skalicky, M.; Nell, B. Schirmer tear test, phenol red thread tear test, eye blink frequency and corneal sensitivity in the guinea pig. Vet. Ophthalmol. 2007, 10, 143-146. [CrossRef]

28. McIntire, L.K.; McKinley, R.A.; Goodyear, C.; McIntire, J.P. Detection of vigilance performance using eye blinks. Appl. Ergon. 2014, 45, 354-362. [CrossRef]

29. Weiner, E.A.; Concepcion, P. Effects of affective stimuli mode on eye-blink rate and anxiety. Clin. Psych. 1975, 31, 256-259. [CrossRef]

30. Lemasson, A.; Boutin, A.; Boivin, S.; Blois-Heulin, C.; Hausberger, M. Horse (Equus caballus) whinnies: A source of social information. Anim. Cognit. 2009, 12, 693-704. [CrossRef]

31. Gleerup, K.B.; Forkman, B.; Lindegaard, C.; Andersen, P. An equine pain face. Vet. Anaesth. Analg. 2015, 42, 103-114. [CrossRef]

32. Argilés, M.; Cardona, G.; Pérez-Cabré, E.; Rodríguez, M. Blink rate and incomplete blinks in six different controlled hard-copy and electronic reading conditions. Investig. Ophthalmol. Vis. Sci. 2015, 56, 6679-6685. [CrossRef]

33. Mott, R.; Hawthorne, S.; McBride, S. Spontaneous blink rate as a measure of equine stress. In Proceedings of the 14th Conference of the International Society for Equitation Science, Rome, Italy, 21-24 September 2018.

34. Dalla Costa, E.; Minero, M.; Lebelt, D.; Stucke, D.; Canali, E.; Leach, M.C. Development of the Horse Grimace Scale (HGS) as a pain assessment tool in horses undergoing routine castration. PLoS ONE 2014, 9, e92281. [CrossRef]

35. Hintze, S.; Smith, S.; Patt, A.; Bachmann, I.; Wurbel, H. Are eyes a mirror of the soul? What eye wrinkles reveal about a horse's emotional state. PLOS ONE 2016, 11, e0164017. [CrossRef]

36. Schanz, L.; Krueger, K.; Hintze, S. Sex and age don't matter, but breed type does-Factors influencing eye wrinkle expression in horses. Front. Vet. Sci. 2019, 6, 154. [CrossRef]

37. Roberts, K.; Hemmings, A.J.; Moore-Colyer, M.; Parker, M.O.; McBride, S.D. Neural modulators of temperament: A multivariate approach to personality trait identification in the horse. Physiol. Behav. 2016, 67, 125-131. [CrossRef]

38. Jongkees, B.J.; Colzato, L.S. Spontaneous eye blink rate as predictor of dopamine-related cognitive function-A review. Neurosci. Biobehav. Rev. 2016, 71, 58-82. [CrossRef]

39. Colzato, L.S.; van den Wildenberg, W.P.M.; van Wouwe, N.C.; Pannebakker, M.M.; Hommel, B. Dopamine and inhibitory action control: Evidence from spontaneous eye blink rates. Exp. Brain Res. 2009, 196, 467-474. [CrossRef]

(C) 2019 by the authors. Licensee MDPI, Basel, Switzerland. This article is an open access article distributed under the terms and conditions of the Creative Commons Attribution (CC BY) license (http://creativecommons.org/licenses/by/4.0/). 


\title{
Horse Transport to Three South American Horse Slaughterhouses: A Descriptive Study
}

\author{
Béke Nivelle ${ }^{1,2, *}$, Liesbeth Vermeulen ${ }^{3}$, Sanne Van Beirendonck ${ }^{4}$, Jos Van Thielen ${ }^{4,5}$ and \\ Bert Driessen ${ }^{1,2}$ \\ 1 Laboratory of Livestock Physiology, Department of Biosystems, KU Leuven, 3001 Heverlee, Belgium; \\ bert.driessen@dierenwelzijn.eu \\ 2 Dier\&Welzijn vzw, 3583 Paal, Belgium \\ 3 Westvlees NV, 8840 Westrozebeke, Belgium; liesbeth_vermeulen@westvlees.com \\ 4 Bioengineering Technology TC, KU Leuven, 2440 Geel, Belgium; \\ sanne.vanbeirendonck@kuleuven.be (S.V.B.); jos.vanthielen@kuleuven.be (J.V.T.) \\ 5 Thomas More, 2440 Geel, Belgium \\ * Correspondence: beke.nivelle@kuleuven.be
}

Received: 4 March 2020; Accepted: 30 March 2020; Published: 1 April 2020

Simple Summary: In the western world, the number of slaughtered horses is decreasing, but still about 5 million horses are slaughtered worldwide each year. The conditions in which horses are transported to the slaughterhouses are a topic of discussion. This study intended to investigate the circumstances of commercial slaughter horse transport and to detect possible risk factors for horse welfare. Therefore, 23 commercial horse transports to three South American slaughterhouses were monitored. During transport, a camera was mounted in each loading space so that horse behaviour could be analysed after transport. Fighting behaviour could not be explained by stocking density, environmental parameters, trailer characteristics, duration and distance of the journey. The temperature and relative humidity were recorded every five minutes in all loading spaces. Average temperatures exceeded the thermoneutral zone in six transports, but it is not clear if and to what extent horse welfare was impaired. Overall, loading and transporting of the horses went well, but the infrastructure of the loading area did not always promote smooth loading and can therefore be improved. At later visits, we noted that this issue was addressed.

\begin{abstract}
Between November 2016 and October 2017, 23 horse transports from 18 collection points to two slaughterhouses in Argentina and one in Uruguay were monitored. The goal of this study was to characterize the current practices in commercial horse transports and to detect potential threats to horse welfare. A total of 596 horses were transported over an average distance of $295 \pm$ $250 \mathrm{~km}$. Average transport duration was $294 \pm 153 \mathrm{~min}$. The infrastructure did not always promote smooth loading, but the amount of horses that refused to enter the trailers was limited. In each loading space, a camera was mounted to observe horse behaviour during the journey. Ambient temperature and relative humidity $(\mathrm{RH})$ were recorded every five minutes in each loading space. In 14 of the 23 transports, the maximum temperature rose above $25^{\circ} \mathrm{C}$ and the average temperature was over $25^{\circ} \mathrm{C}$ during six transports. The average temperature humidity index (THI) exceeded 72 during six transports. The average stocking density was $1.40 \pm 0.33 \mathrm{~m}^{2}$ per horse, or $308 \pm$ $53 \mathrm{~kg} / \mathrm{m}^{2}$. The degree of aggression differed between the front and rear loading space. Stocking density, environmental parameters, trailer characteristics, and transport duration and distance did not influence aggressiveness.
\end{abstract}

Keywords: horses; transport; slaughter 


\section{Introduction}

In the USA, Australia and Europe, the number of slaughtered horses is decreasing. In Belgium for example, the number of slaughtered horses decreased from 21,390 slaughtered horses in 2001 to only 5895 horses in 2018 [1]. Annually, about 5 million horses are slaughtered worldwide [2]. In 2018, China was the country that slaughtered the most horses worldwide-more specifically, about 1.59 million [2]. In the same year, 389,153 horses were slaughtered in South America [2]. However, to this day, the circumstances in which horses are transported give rise to discussion [3].

Animals should be handled as carefully as possible at all times, including during the transportation process to the slaughterhouse. The animals should undergo as little stress as possible, on the one hand for welfare reasons, but also to prevent any deterioration in the quality of the horse meat. Quality loss can occur as a result of excessive stress, bruises or injuries [4-7]. Suboptimal ambient parameters such as temperature, relative humidity, ammonia and carbon dioxide concentration in the air can cause stress, but also inappropriate infrastructure and psychological stressors. Examples of psychological stressors are the determination of dominance rank, and transport activities such as loading, unloading and the transport itself. In addition, activities that are part of the management of the animals, such as the weaning of young animals, weighing of animals or changing housing, can also cause stress [8].

The conditions of (non-commercial) transports of sport and company horses and the response of these horses to transport are well studied $[9,10]$. On the other hand, commercial transport of horses is studied to a lesser extent. Furthermore, most studies in which horses are transported untethered in groups involve healthy horses that are used to being transported [9,11-14]. Studies investigating slaughter horse transports or horses that were sold as slaughter horses are less numerous [13,15-19]. However, from those studies it is clear that a number of transport-related factors influence horse welfare. Journey distance and time [20,21], loading density [7,15,22,23], handling [7,24,25], new environments [24], potentially re-grouping or mixing with unfamiliar animals [24], fasting and deprivation of water [24], the myriad of trailer designs [7,23], driving behaviour [7], road type and quality $[7,22,24]$, traffic conditions [24], suspension systems and building materials of the trailers $[15,23]$, environmental conditions in the trailer [7,22], and weather conditions $[15,23,26]$ all affect horse welfare.

According to Morgan [27], the thermoneutral zone of a horse is on average between $5{ }^{\circ} \mathrm{C}$ and $25^{\circ} \mathrm{C}$. Another study defines the thermoneutral zone between $-1{ }^{\circ} \mathrm{C}$ and $24{ }^{\circ} \mathrm{C}$ [27]. The differences in estimation of the thermoneutral zone are, among other things, probably due to acclimatization, body condition and climate [28]. For example, the upper limit of the thermoneutral zone lowers with increasing humidity. At a relative humidity $(\mathrm{RH})$ of more than $50 \%$, it gets harder for the animals to dissipate heat to the environment [29]. The temperature humidity index (THI) is a useful parameter to estimate the thermal comfort of organisms [30].

Legislation involving animal welfare differs between countries. At the same time, meat is traded from countries with less stringent welfare requirements, like Argentina [31-33] and Uruguay [34], to countries with higher welfare requirements, like members of the European Union. The European Union (EU) sets welfare requirements at the time of killing for companies willing to export animal products to the EU (Council Regulation (EC) No 1099/2009) [35], but does not impose direct requirements on the transport of those animals to the slaughterhouses in third countries. The international Horse Meat Federation [36], on the other hand, expects its members to meet the requirements set in their "Manual for the Animal Welfare of horses during transport and slaughtering", which is based on existing legislation and international guidelines [36].

The first aim of this study was to characterize the current practices of the commercial horse transport from collection points to slaughterhouses in Argentina and Uruguay. Secondly, potential risk factors for horse welfare were detected.

\section{Materials and Methods}

Between November 2016 and October 2017, a total of 23 horse transports in Argentina and Uruguay were monitored from loading at a collection point to one of the three selected horse slaughterhouses. A 
total of 596 half-bred horses with an average weight of $415( \pm 38) \mathrm{kg}$ were picked up at 18 collection points and were transported to Lamar (Argentina), Frigorífico General Pico (Argentina) and Sarel (Uruguay). The transports were spread throughout a year, so that a number of transports were monitored in each season. A total of six transports took place in the spring (November 2016), six in the summer (March 2017), six in the fall (June 2017) and five in the winter (October 2017). Each season two transports per slaughterhouse were monitored, except for October 2017. At that time, only one transport to Frigorífico General Pico was followed up. The transports were carried out with different types of transport vehicles. In this study, three types of vehicles are distinguished, namely trucks, tractor-trailers and truck-trailers (Figure 1). A truck is a pulling vehicle with one inseparable loading space and is therefore a single unit. In the case of a tractor-trailer, the towing vehicle can be (dis)connected from the trailer via a fifth-wheel coupling. Finally, a truck-trailer is a truck, as defined above, with a trailer connected to it through a drawbar. This transport combination therefore exists of two separated loading spaces.

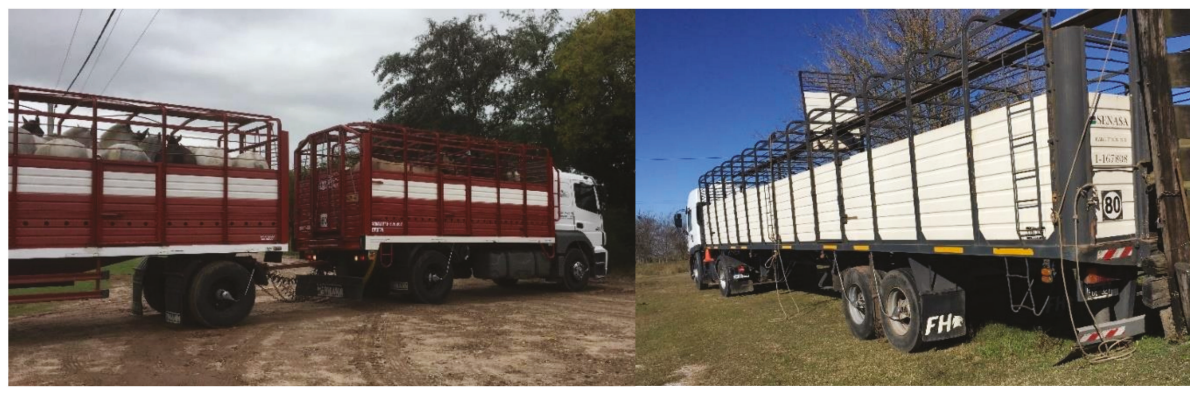

a

b

Figure 1. Example of different transport combinations. (a) A truck-trailer: a truck pulling a trailer and (b) A tractor-trailer: a pulling vehicle (without loading space) hauling a trailer through a fifth-wheel coupling.

The transports were monitored and supervised by the same researcher. The researcher also mounted the sensors and cameras in the trailers and recorded specific transport data. In each trailer the horses were filmed. The camera (Trophy Cam model 119437, Bushnell, China) filmed fragments of one minute at intervals of about 100 seconds. On average, 38.9\% $( \pm 3.8) \%$ of each transport was filmed. After the transports, the footage was viewed, and the behaviour and interactions of the horses were analysed. During the analysis of the videos, it was noted per trailer how many horses fell and whether the animals fought 'hardly or not', 'averagely' or 'a lot'. A fall was considered to be a loss of balance in which parts of the body other than the hooves touched the ground. If the horse could restore equilibrium without other body parts touching the ground, this was called stumbling. Furthermore, the temperature, relative humidity $(\mathrm{RH})$ and dew point were automatically recorded (EL-USB-2, Lascar Electronics, Wiltshire, UK) every five minutes in each loading space. These data were automatically written to an excel file. For the analysis of the environmental parameters, the thermoneutral zone used by Morgan [27], namely between $5{ }^{\circ} \mathrm{C}$ and $25^{\circ} \mathrm{C}$, is taken as the starting point. In addition, the temperature humidity index (THI) is calculated using the following formula [37], with T, temperature in ${ }^{\circ} \mathrm{C}, \mathrm{RH}$ expressed as a number between 0 and 1 :

$$
\mathrm{THI}=0.8 \mathrm{~T}+\mathrm{RH} \times(\mathrm{T}-14.4)+46.4
$$

The timing of various operations such as loading and unloading, the duration and distance of the transport, the number of intermediate stops for (police) checks, as well as the stocking density, dimensions and characteristics of the loading spaces were recorded. The observer noted what tools the drivers, which are the persons that handle the horses, used. Furthermore, the characteristics and 
dimensions of loading docks were registered. The openness of the side walls was categorised as 'open' when the surroundings could be seen easily through the wall, 'half open' when the view through the side walls was limited, and 'solid' when the horses could not see anything through the side walls of the loading dock. All the parameters that were considered during this investigation are listed in the Appendix A in Tables A1 and A2.

The data were processed using SAS Enterprise Guide and SAS 9.4. Averages and standard deviations were calculated using the PROC UNIVARIATE procedure. Correlations between the environmental parameters in the front and rear trailer were calculated using the regression (PROC REG) procedure. The frequency procedure (PROC FREQ) was used for all frequency calculations and generalized linear mixed models (PROC GLIMMIX) were used to identify which parameters influenced the degree of aggression and falling of horses during transport.

\section{Results}

\subsection{Loading Dock}

In 17 of the 18 collection points, a loading dock was present to facilitate the loading of the horses. From two collection points, horses were picked up more than once. However, only one loading dock was used for two transports. In one collection point, the loading dock did not have a slope, since the transport vehicle could be parked so that surface of the loading area was at the same level as the floor of the trailer. Therefore, this loading deck was excluded from the averages (Table 1). The slope of the loading docks was on average $17.4^{\circ}( \pm 3.6)^{\circ}$, which equals $31.5 \%( \pm 7.0) \%$ (Table 1$)$. Seven out of 21 loading docks had a slope steeper than $20.0^{\circ}(36.4 \%)$ and the slope of all but one loading dock was steeper than $10.0^{\circ}(17.6 \%)$. The length of the loading dock (measured on the surface of the loading dock) was $4.01( \pm 0.90) \mathrm{m}$ and the height was $1.18( \pm 0.17) \mathrm{m}$ (Table 1$)$.

Table 1. Dimensions and slope of the loading docks in the 18 collection points in degrees and in percentages.

\begin{tabular}{cccccc}
\hline Parameter & $\begin{array}{c}\text { Average } \pm \text { Standard } \\
\text { Deviation }\end{array}$ & N & Minimum & Maximum & Median \\
\hline Length $(\mathrm{m})$ & $4.01 \pm 0.90$ & 21 & 2.60 & 6.50 & 3.89 \\
Height $(\mathrm{m})$ & $1.18 \pm 0.17$ & 21 & 0.93 & 1.74 & 1.17 \\
Height side & $1.59 \pm 0.22$ & 19 & 1.16 & 1.94 & 1.60 \\
walls $(\mathrm{m})$ & $17.4 \pm 3.6$ & 21 & 9.3 & 23.6 & 17.1 \\
Slope $\left({ }^{\circ}\right)$ & $31.5 \pm 7.0$ & 21 & 16.4 & 43.6 & 30.7 \\
Slope $(\%)$ & & & & \\
\hline
\end{tabular}

The surface of the loading docks consisted of only soil (26.1\%), a combination of soil and wood $(26.1 \%)$, only wood $(13.0 \%)$, concrete (partly) covered with soil $(8.7 \%)$, a combination of soil and grit $(8.7 \%)$ or straw $(4.4 \%)$. The side walls of the loading docks were, on average, $1.59( \pm 0.22)$-m-high and constructed from wood-mostly planks $(82.6 \%)$, but round wooden beams $(4.3 \%)$ in one instance. The side walls of three (13.0\%) loading docks were categorised as 'open', seven (30.4\%) as 'half open' and 10 $(43.5 \%)$ as 'solid'. Of three $(13.0 \%)$ loading docks, the kind of side wall construction was not registered.

\subsection{Loading}

Loading the horses took an average of $12.2( \pm 7.1)$ minutes per transport and $0.49( \pm 0.27)$ minutes per horse (Table 2). Spread over three transports, five horses $(0.84 \%)$ had to be led into the trailer with a halter: three horses in one loading did not want to enter the trailer and twice one horse refused to enter the trailer. In the end, two of these horses could not be loaded at all. The trucks left the collection points $8.3( \pm 4.4)$ minutes after the loading process was completed. In total, $73.9 \%$ of the transports departed in the morning, on average at 11:15 a.m. ( \pm 1:31; between 9:25 a.m. and 3:20 p.m.). Figure 2 shows the arrival and departure times of the transports. 
Table 2. Duration of loading and standstill after loading before departure.

\begin{tabular}{cccccc}
\hline Parameter & $\begin{array}{c}\text { Average } \pm \text { Standard } \\
\text { Deviation }\end{array}$ & N & Minimum & Maximum & Median \\
\hline $\begin{array}{c}\text { Loading time } \\
\text { (minutes) }\end{array}$ & $12.2 \pm 7.1$ & 23 & 2.0 & 32.0 & 10.0 \\
$\begin{array}{c}\text { Loading time per horse } \\
\text { (minutes/horse) } \\
\text { Duration standstill } \\
\text { before departure } \\
\text { (minutes) }\end{array}$ & $0.49 \pm 0.27$ & 23 & 0.19 & 1.23 & 0.42 \\
\hline
\end{tabular}

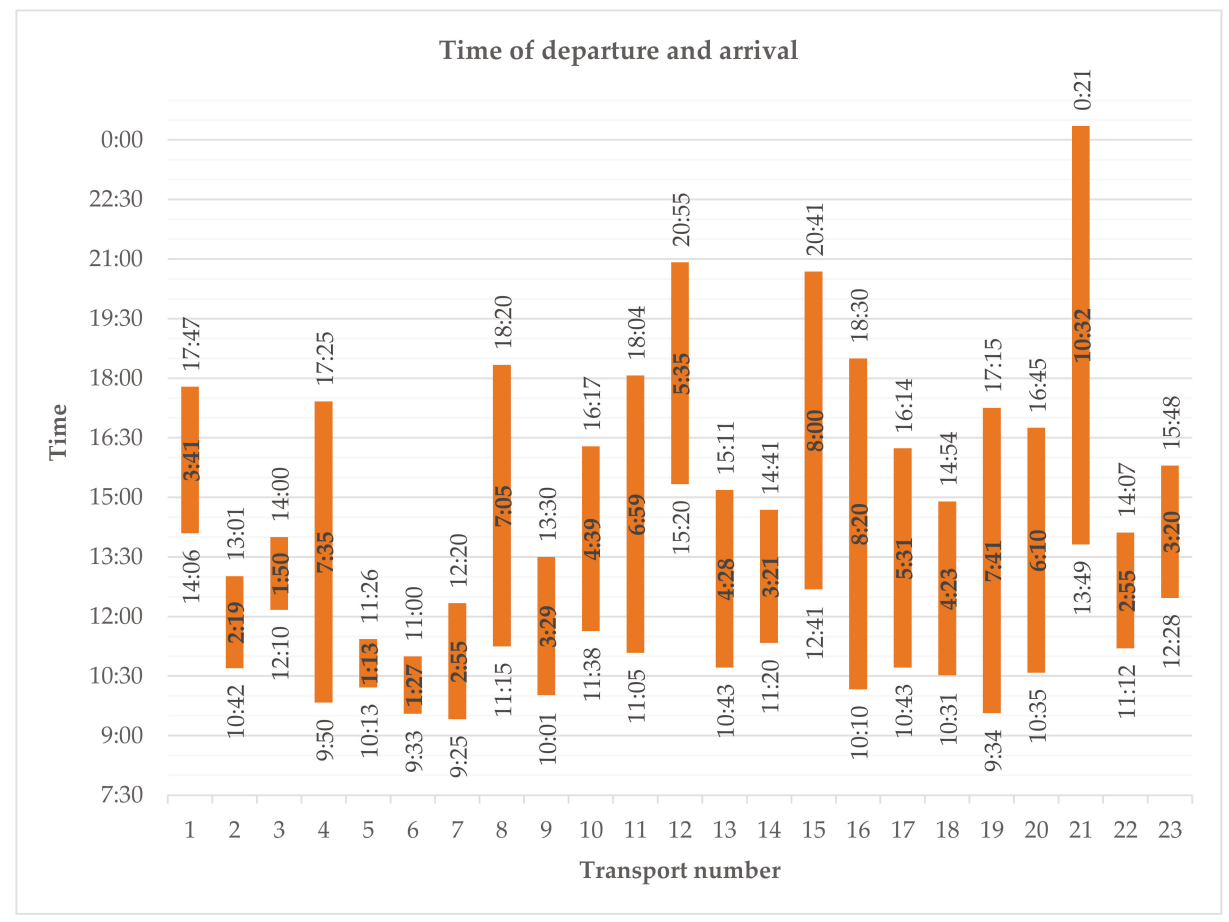

Figure 2. Arrival and departure times of the monitored transports. The duration of the transports is mentioned in the coloured bars. The transport numbers are the same as used in Tables A3 and A4 in the Appendix A.

Tools such as a flag, whip or stick were used to drive the horses on the trailers. We define a stick as a narrow, long and little or not flexible object to drive the horses with. A whip is a thin, not very flexible stick, with or without a handle on it. In this context, a flag is a stick with a piece or ribbons of textile or plastic, so that the movements of the object are more visible to the horses. Flags were used in $22(95.7 \%)$ of the 23 transports. Four times (17.4\%) a whip or a stick was used and three times $(13.0 \%)$ a rider on horseback drove the slaughter horses onto the trailer. The tools were not used to hit or poke animals on sensitive body parts, but to give visual signals. Occasionally, the horses were gently touched with the stick, whip or flag, but not to the extent that the touch could cause pain or discomfort.

Divided over 13 loads, a total of 23 (3.86\%) horses stumbled during loading, with a maximum of five horses during one loading. Five falling horses were noted, spread over three loadings. During a loading in which three horses stumbled, also three horses fell and during two other loads, in which respectively three and five horses stumbled, one horse fell each time. No falls were noted in other 
loadings. The falls were caused by pushing and/or fights among horses. One of the fallen horses was ran over by the other horses when the group abruptly turned around in the narrowing space towards the loading ramp. The abrupt turn of the group was caused by the directions of the drivers.

Horses enter the transport vehicles through trapdoors, which are guillotine-type doors. Internal doors were also trapdoors. During 13 of the 23 transports, at least one horse bumped its head against the trapdoor. In five transports, three or more horses (maximum eight) bumped their heads against the trapdoor. The height of the trapdoors where horses hit their heads varied between 1.51 and $1.81 \mathrm{~m}$.

\subsection{Environmental Parameters}

The lowest trailer temperature observed during transport was $6.0^{\circ} \mathrm{C}$, while the maximum temperature was $35.5^{\circ} \mathrm{C}$ (Table 3). In the trailers, the temperature never dropped below the lower limit of the thermoneutral zone, being $5.0^{\circ} \mathrm{C}$. The upper limit of the thermoneutral zone, $25.0^{\circ} \mathrm{C}$, was exceeded during 14 of the $23(60.9 \%)$ transports. During six $(26.1 \%)$ transports, the average temperature in the trailer was above $25.0{ }^{\circ} \mathrm{C}$ and during five $(21.7 \%)$ transports, the minimum temperature in the trailer exceeded $25.0^{\circ} \mathrm{C}$. For seven $(30.4 \%)$ transports, the maximum temperature was above or equal to $30.0^{\circ} \mathrm{C}$. There was a strong correlation between the front and rear load for both average, minimum and maximum temperatures (Table 4).

Table 3. The average, minimum and maximum temperature, $\mathrm{RH}$ and THI in the loading spaces. The average, minimum and maximum of each parameter was first calculated per transport and then per time period.

\begin{tabular}{cccccc}
\hline \multicolumn{2}{c}{ Parameter } & $\begin{array}{c}\text { Average } \pm \text { Standard } \\
\text { Deviation }\end{array}$ & $\mathbf{N}$ & Minimum & Maximum \\
\hline \multirow{2}{*}{ Temperature } & Spring & $22.0 \pm 5.0$ & 38 & 6.0 & 35.5 \\
& Summer & $24.4 \pm 3.7$ & 11 & 15.0 & 35.5 \\
& Autumn & $15.3 \pm 2.2$ & 11 & 17.5 & 32.5 \\
& Winter & $21.7 \pm 4.2$ & 9 & 6.0 & 26.0 \\
& & $57.4 \pm 13.5$ & 7 & 14.0 & 32.0 \\
$\mathrm{RH}$ & Spring & $52.6 \pm 14.9$ & 11 & 27.5 & 99.0 \\
& Summer & $59.9 \pm 12.9$ & 11 & 42.5 & 97.0 \\
& Autumn & $60.3 \pm 6.2$ & 9 & 43.5 & 80.0 \\
& Winter & $57.5 \pm 16.4$ & 7 & 31.5 & 99.0 \\
& & $67.8 \pm 6.5$ & 37 & 45.5 & 83.0 \\
& Spring & $72.0 \pm 4.6$ & 11 & 59.0 & 83.0 \\
& Summer & $71.4 \pm 2.7$ & 11 & 62.6 & 81.5 \\
& Autumn & $59.1 \pm 3.3$ & 9 & 45.5 & 72.8 \\
& Winter & $66.5 \pm 4.9$ & 6 & 57.3 & 78.0 \\
\hline
\end{tabular}

The RH varied between $28.0 \%$ and $99.0 \%$ (Table 3). There was a strong correlation between the front and rear loading space for both average, minimum and maximum humidity (Table 4). There was no correlation between temperature and $\mathrm{RH}$ within the same loading space.

Due to the lack of a reference framework with limit values for heat stress in horses $[38,39]$, the THI is tested against the values used for dairy cattle. A THI of 72-78 is labelled as mild heat stress, while a THI between 79 and 89 stands for severe heat stress in dairy cattle [40-42] (Appendix A, Figure A1). The THI ranged from 45.5-83.0 during transports (Table 3). In 13 (57\%) transports, the maximum THI exceeded 72 , which is the lower limit for mild heat stress in cattle. For six $(26 \%)$ transports, the average THI was above or equal to 72 and for four $(17.4 \%)$ transports, the minimum THI was at least equal to 72. During six (26.1\%) transports, the maximum THI value was between 78 and 89 , the standard for severe heat stress in cattle. However, the average THI value always remained below 78 . There was a strong correlation between the front and rear loading space for both average, minimum and maximum 
humidity (Table 4). The average temperature, $\mathrm{RH}$, dew point temperature and THI are shown per transport in Appendix A Table A4.

Table 4. Correlations between temperature $(\mathrm{T})$, relative humidity $(\mathrm{RH})$ and temperature humidity (THI) in front and rear loading space. The $p$-value of "a" is the $p$-value of the correlation coefficient. $\mathrm{T}_{\mathrm{AF}}=$ average temperature in the front loading space; $\mathrm{T}_{\mathrm{AR}}=$ average temperature in the rear loading space; $\mathrm{T}_{\mathrm{MinF}}=$ minimum temperature in the front loading space; $\mathrm{T}_{\mathrm{MinR}}=$ minimum temperature rear loading space; $\mathrm{T}_{\mathrm{MaxF}}=$ maximum temperature front loading space; $\mathrm{T}_{\mathrm{MaxR}}=$ maximum temperature rear loading space. $\mathrm{RH}_{\mathrm{AF}}=$ average $\mathrm{RH}$ front in front loading space; $\mathrm{RH}_{\mathrm{AR}}=$ average $\mathrm{RH}$ in rear loading space; $\mathrm{RH}_{\mathrm{MinF}}=$ minimum $\mathrm{RH}$ in front loading space; $\mathrm{RH}_{\mathrm{MinR}}=$ minimum $\mathrm{RH}$ in rear loading space; $\mathrm{RH}_{\mathrm{MaxF}}=$ maximum $\mathrm{RH}$ in front loading space; $\mathrm{RH}_{\mathrm{MaxR}}=$ maximum $\mathrm{RH}$ in rear loading space. $\mathrm{THI}_{\mathrm{AF}}=$ average $\mathrm{THI}$ in the front loading space; $\mathrm{THI}_{\mathrm{AR}}=$ average $\mathrm{THI}$ in the front loading space; $\mathrm{THI}_{\mathrm{MinF}}=$ minimum $\mathrm{THI}$ in the front loading space; $\mathrm{THI}_{\mathrm{MinR}}=$ minimum $\mathrm{THI}$ in the rear loading space; $\mathrm{THI}_{\mathrm{MaxF}}=$ maximum $\mathrm{THI}$ in the front loading space; $\mathrm{THI}_{\mathrm{MaxR}}=$ maximum $\mathrm{THI}$ in the rear loading space.

\begin{tabular}{|c|c|c|c|c|c|}
\hline Parameter & Equation $(Y=a X+b)$ & $\mathbf{N}$ & $\mathbf{r}^{2}$ & $p$-Value a & $p$-Value b \\
\hline $\mathrm{T}_{\mathrm{AF}}$ and $\mathrm{T}_{\mathrm{AR}}$ & $\mathrm{T}_{\mathrm{AF}}=1.01710 \times \mathrm{T}_{\mathrm{AR}}-0.26312$ & 14 & 0.9847 & $<0.0001$ & 0.7465 \\
\hline $\mathrm{T}_{\mathrm{MinF}}$ and $\mathrm{T}_{\mathrm{MinR}}$ & $\mathrm{T}_{\mathrm{MinF}}=1.04965 \times \mathrm{T}_{\mathrm{MinR}}-0.77318$ & 14 & 0.9840 & $<0.0001$ & 0.3104 \\
\hline $\mathrm{T}_{\mathrm{MaxF}}$ and $\mathrm{T}_{\mathrm{MaxR}}$ & $\mathrm{T}_{\mathrm{MaxF}}=0.85989 \times \mathrm{T}_{\mathrm{MiaxR}}+3.92441$ & 14 & 0.8111 & $<0.0001$ & 0.2244 \\
\hline $\mathrm{RH}_{\mathrm{AF}}$ and $\mathrm{RH}_{\mathrm{AR}}$ & $\mathrm{RH}_{\mathrm{AF}}=1.00838 \times \mathrm{RH}_{\mathrm{AR}}+0.22294$ & 14 & 0.9861 & $<0.0001$ & 0.9020 \\
\hline $\mathrm{RH}_{\mathrm{MinF}}$ and $\mathrm{RH}_{\mathrm{MinR}}$ & $\mathrm{RH}_{\mathrm{MinF}}=0.86383 \times \mathrm{RH}_{\mathrm{MinR}}+6.00346$ & 14 & 0.9246 & $<0.0001$ & 0.0668 \\
\hline $\mathrm{RH}_{\mathrm{MaxF}}$ and $\mathrm{RH}_{\mathrm{MaxR}}$ & $\mathrm{RH}_{\mathrm{MaxF}}=0.99305 \times \mathrm{RH}_{\text {MiaxR }}+0.78603$ & 14 & 0.9676 & $<0.0001$ & 0.8120 \\
\hline $\mathrm{THI}_{\mathrm{AF}}$ and $\mathrm{THI}_{\mathrm{AR}}$ & $\mathrm{THI}_{\mathrm{AF}}=1.01061 \times \mathrm{THI}_{\mathrm{AR}}-0.64323$ & 14 & 0.9878 & $<0.0001$ & 0.7704 \\
\hline $\mathrm{THI}_{\mathrm{MinF}}$ and $\mathrm{THI}_{\mathrm{MinR}}$ & $\mathrm{THI}_{\mathrm{MinF}}=1.04821 \times \mathrm{THI}_{\mathrm{MinR}}-3.03323$ & 14 & 0.9831 & $<0.0001$ & 0.2441 \\
\hline $\mathrm{THI}_{\mathrm{MaxF}}$ and $\mathrm{THI}_{\mathrm{MaxR}}$ & $\mathrm{THI}_{\mathrm{MaxF}}=0.92326 \times \mathrm{THI}_{\mathrm{MiaxR}}+5.81791$ & 14 & 0.8453 & $<0.0001$ & 0.4859 \\
\hline
\end{tabular}

\subsection{Trucks}

Different types of transport vehicles were used to carry out the 23 transports (see Materials and Methods). Some vehicles were used for multiple transports. Table A3 in the Appendix A shows the type of vehicle used for each transport and the frequency of use of the vehicle during the monitoring. Only one of the trucks had a roof consisting of a black sail. The average dimensions of the loading spaces are shown in Table A3 in the Appendix A. In 10 transports (43.5\%) the front loading space was divided into several compartments: eight times (34.8\%) into two compartments and twice (39.1\%) into three. The rear loading space was divided into two (six times; $40.0 \%$ ) or three (two times; $13.3 \%$ ) compartments in eight (53.3\%) of the 15 transports with two loading spaces.

The floor in all loading spaces was provided with wire mesh to prevent slipping of the horses. Different types of wire mesh could be distinguished. The most common were the standard wire mesh (Figure 3a), where the rods are on top of each other and the rods do not bend between the crossings. This type of wire mesh was used in 20 (87.0\%) transports. The curved wire mesh (Figure 3b), which is bent between the crossings, was used in two transports, just like the diamond-shaped wire mesh with connections in one plane (Figure 3c). In the Appendix A Table A3 shows which type of wire mesh was found per transport and per trailer. The average mesh size was $26.0 \pm 4.5 \mathrm{~cm}$ by $23.7 \pm 4.8 \mathrm{~cm}$. On average, the wire mesh was $1.29 \pm 0.38 \mathrm{~cm}$ thick and mounted at a height of $2.60 \pm 0.78 \mathrm{~cm}$. In our observations, both on the spot and afterwards, no shoed horses were detected in any of the transports. 


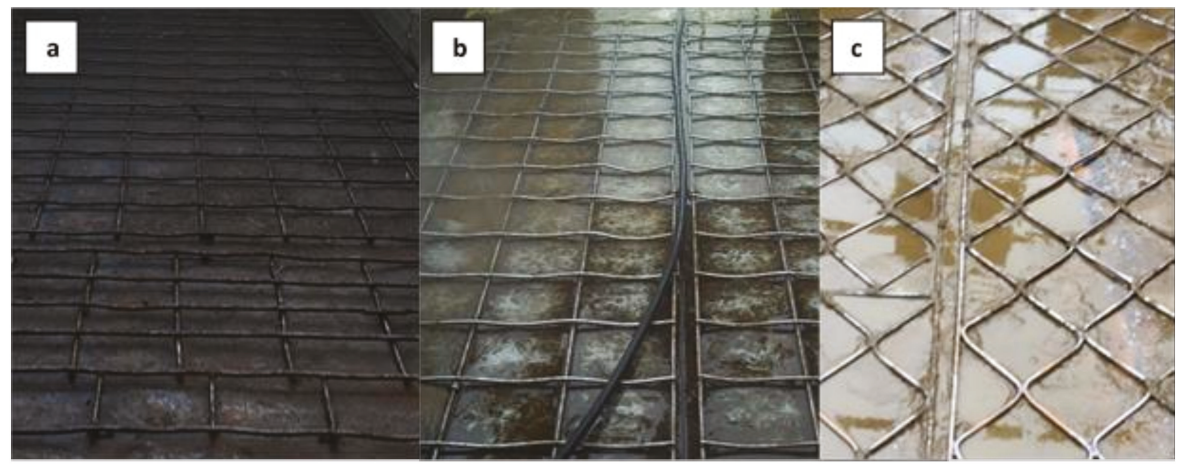

Figure 3. Different types of wire mesh that were used for the 23 observed slaughter horse transports. (a) Standard wire mesh-here addressed as "standard"; (b) standard wire mesh, which is curved between connection points-here called "curved"; (c) diamond shaped wire mesh, with connections in one plane-here called "diamond shaped".

\subsection{Trailer Density}

The average density of the trailers was $1.40( \pm 0.33) \mathrm{m}^{2} /$ horse or $308( \pm 53) \mathrm{kg} / \mathrm{m}^{2}$. Table 5 shows the average density in $\mathrm{m}^{2} /$ horse and $\mathrm{kg} / \mathrm{m}^{2}$ per trailer and per compartment. Average density varied between $0.94 \mathrm{~m}^{2} /$ horse and $2.45 \mathrm{~m}^{2} /$ horse. Stallions were not always separated from mares and geldings during transport. During at least five transports, one or more stallions were loaded. In at least two of these transports, the stallions were not separated from the other horses. Once, a stallion standing between mares was moved to another compartment before departure, because of his aggressive behaviour. In the other compartment however, the stallion was not separated from the other horses behind a fence or ropes either. To prevent further biting, a rope was tied tightly in the mouth. The stallion then stopped his aggressive behaviour. Several times a pony or a young horse was transported in the same compartment with significantly larger horses.

Table 5. Average available space per horse $\left(\mathrm{m}^{2} /\right.$ horse $)$ and average density $\left(\mathrm{kg} / \mathrm{m}^{2}\right) . \mathrm{T} 1=$ front loading space; $\mathrm{T} 2$ = rear loading space.

\begin{tabular}{|c|c|c|c|c|c|c|}
\hline Paramete & & $\begin{array}{l}\text { Average } \pm \\
\text { Standard } \\
\text { Deviation }\end{array}$ & $\mathbf{N}$ & Minimum & Maximum & Median \\
\hline $\begin{array}{l}\text { Surface area of loading } \\
\text { space }\left(\mathrm{m}^{2}\right)\end{array}$ & & $34.70 \pm 9.50$ & 23 & 13.50 & 41.91 & 39.45 \\
\hline \multicolumn{7}{|l|}{ Average density of full } \\
\hline $\begin{array}{l}\text { loading space } \\
\left(\mathrm{m}^{2} / \text { horse }\right)\end{array}$ & & $1.40 \pm 0.33$ & 23 & 0.94 & 2.45 & 1.38 \\
\hline \multirow[t]{4}{*}{ Density T1 (m²/horse) } & & $1.40 \pm 0.36$ & 23 & 0.80 & 2.45 & 1.33 \\
\hline & Compartment 1 & $1.52 \pm 0.53$ & 8 & 1.03 & 2.68 & 1.46 \\
\hline & Compartment 2 & $1.38 \pm 0.44$ & 7 & 0.97 & 2.25 & 1.33 \\
\hline & Compartment 3 & $1.25 \pm 0.35$ & 2 & 1.00 & 1.50 & 1.25 \\
\hline \multirow[t]{4}{*}{ Density T2 (m²/horse) } & & $1.38 \pm 0.22$ & 15 & 0.99 & 1.88 & 1.38 \\
\hline & Compartment 1 & $1.36 \pm 0.27$ & 6 & 1.06 & 1.74 & 1.36 \\
\hline & Compartment 2 & $1.53 \pm 0.49$ & 6 & 1.15 & 2.48 & 1.37 \\
\hline & Compartment 3 & $1.86 \pm 0.53$ & 2 & 1.49 & 2.23 & 1.86 \\
\hline $\begin{array}{l}\text { Average density } \\
\left(\mathrm{kg} / \mathrm{m}^{2}\right)\end{array}$ & & $308 \pm 53$ & 21 & 191 & 402 & 327 \\
\hline \multirow[t]{4}{*}{ Density T1 $\left(\mathrm{kg} / \mathrm{m}^{2}\right)$} & & $312 \pm 63$ & 21 & 191 & 473 & 308 \\
\hline & Compartment 1 & $283 \pm 65$ & 6 & 175 & 352 & 304 \\
\hline & Compartment 2 & $322 \pm 57$ & 6 & 208 & 365 & 338 \\
\hline & Compartment 3 & 362 & 1 & 362 & 362 & 362 \\
\hline \multirow[t]{4}{*}{ Density T2 $\left(\mathrm{kg} / \mathrm{m}^{2}\right)$} & & $309 \pm 42$ & 14 & 227 & 354 & 326 \\
\hline & Compartment 1 & $334 \pm 74$ & 5 & 253 & 446 & 344 \\
\hline & Compartment 2 & $291 \pm 67$ & 5 & 191 & 362 & 322 \\
\hline & Compartment 3 & 212 & 1 & 212 & 212 & 212 \\
\hline
\end{tabular}




\subsection{Aggression and Falling during Transport}

The degree of aggression was assessed per loading space during 22 transports, of which 15 transports with a truck-trailer, together accounting for 38 loading spaces. A loading space refers to the space in one transport component. A truck therefore has one loading space just like a tractor-trailer, while a truck-trailer has two loading spaces. In 13 (34.2\%) loading spaces, hardly any or no fights were registered. In 15 (39.5\%) loading spaces, an average amount of fights was recorded, and a lot of fights were recorded in $11(28.9 \%)$ loading spaces. No relation was found between the degree of aggression and the density (front loading space: $p=0.78$; rear loading space: $p=0.25$ ), the thickness of the wire mesh on the floor (front loading space: $p=0.23$; rear loading space: $p=0.20$ ), the transport duration (front loading space: $p=0.90$; rear loading space: $p=0.98$ ) or distance (front loading space: $p=0.93$; rear loading space: $p=0.78$ ), the average temperature (front loading space: $p=0.33$; rear loading space: $p=0.79$ ), the average dew point temperature (front loading space: $p=0.18$; rear loading space: $p=0.99$ ) and the average THI (front loading space: $p=0.28$; rear loading space: $p=0.80$ ). However, the degree of aggression differed between the front and rear loading spaces $(p=0.05)$. Splitting the rear loading space into two or more compartments resulted in less fighting than when the rear loadings spaces consisted of one compartment $(p=0.05)$. In the case of the front loading space (22 transports), no relation was found between compartmentalisation and the degree of fighting $(p=0.73)$. It should be noted, however, that the fighting behaviour in the rear loading space could only be monitored for 14 transports, since only 14 out of 15 truck-trailers had the rear loading spaces successfully filmed.

In only one journey did a horse fall twice. In the 22 other journeys, no horses fell, except once before departure. That horse was then removed from the truck and not taken to the slaughterhouse. No connection could be found between the degree of fighting and the falls of the horses, but this is likely due to the limited number of horses that fell during the journey.

\subsection{Transport Distance and Duration}

The transport distances from collection point to slaughterhouse ranged from $37-700 \mathrm{~km}$ (Table 6). The transport time varied from 73-632 min (Table 6). One transport lasted 480 min or eight hours, while two (8.7\%) other transports lasted longer, more specifically 500 and $632 \mathrm{~min}$. The horses were not unloaded during the journey and had no ability to eat or drink. The transport duration and distance were strongly correlated $\left(\mathrm{r}^{2}=0.94 ; p<0.0001\right)$ for the 23 observed transports: with increasing distance, the transport duration increased according to:

$$
\mathrm{Y}=49.7+0.8 \mathrm{X}
$$

(with $\mathrm{Y}=$ the transport duration in minutes and $\mathrm{X}=$ the distance in $\mathrm{km}$ )

Table 6. Average transport duration, distance and average number of stops and police checks per transport and per $100 \mathrm{~km}$. Duration of loading, unloading and standstill after loading and before unloading.

\begin{tabular}{|c|c|c|c|c|c|}
\hline Parameter & Average \pm Standard Deviation & $\mathbf{N}$ & Minimum & Maximum & Median \\
\hline Transport duration (minutes) & $296 \pm 150$ & 23 & 73 & 632 & 268 \\
\hline Distance $(\mathrm{km})$ & $295 \pm 177$ & 23 & 37 & 700 & 250 \\
\hline Number of stops per transport & $2.74 \pm 1.33$ & 23 & 0.0 & 5.0 & 3.0 \\
\hline Number of stops per $100 \mathrm{~km}$ & $1.14 \pm 0.90$ & 23 & 0.00 & 4.35 & 1.04 \\
\hline Number of police checks per transport & $0.87 \pm 1.00$ & 23 & 0.00 & 3.00 & 1.00 \\
\hline Number of police checks per $100 \mathrm{~km}$ & $0.39 \pm 0.58$ & 23 & 0.00 & 1.97 & 0.25 \\
\hline Standstill between arrival and unloading (minutes) & $14.8 \pm 12.6$ & 22 & 3.0 & 45.0 & 10.0 \\
\hline Duration of unloading (minutes) & $12.5 \pm 9.5$ & 20 & 2.0 & 36.0 & 9.0 \\
\hline Duration of unloading per horse (minutes/horse) & $0.473 \pm 0.285$ & 20 & 0.115 & 0.947 & 0.388 \\
\hline
\end{tabular}

An average of $2.74( \pm 1.33)$ stops were inserted per transport, of which an average of $0.87( \pm 1.00)$ were inserted for police checks (Table 6). 


\subsection{Unloading}

After arrival, transporters had to wait for an average of $14.8( \pm 12.6)$ minutes before unloading (Table 6). The unloading of the horses took on average $12.5( \pm 9.5)$ min per transport and $0.473( \pm 0.285)$ per horse (Table 6). There was no correlation between the duration of loading and unloading $\left(\mathrm{r}^{2}=0.11\right.$; $p=0.08)$.

\section{Discussion}

\subsection{Loading Docks}

Besides good handling, the professional federation of the international Horse Meat Sector (HoMeFe) [36] as well as the European Consortium of the Animal Transport Guides Project (CATGP) [7] stresses the importance of good loading dock design, construction and maintenance to minimize the risk of slipping, falling, injuries and stress to animals while (un)loading. Therefore, CATGP [7] sums up a number of 'good' and 'better' practices in its guidelines for transport of slaughter horses. The good practices are derived from the Council Regulation 1/2005 of 22 December 2004 on the protection of animals during transport and related operations $[7,43]$.

The loading area should be constructed in a way that prevents distress, excitement and injury as much as possible [7,36,43]. Good practices include that the slope of the loading dock does not exceed $36.4 \%$ (or $20.0^{\circ}$ ) $[7,36,43,44]$, better practices demand a maximum slope of no more than $10.0^{\circ}$ (17.3\%) [7]. When the slope is steeper than $10.0^{\circ}$ or $17.6 \%$, the loading dock must be equipped with some sort of system that improves passage of animals without the risk of slipping [36,43], such as stair steps or foot battens $[7,36,45]$. Argentinian legislation states that the slope of the loading dock should not exceed $30.0^{\circ}$ (57.7\%) and should be equipped with foot battens [33]. Good loading practices also include using a slip-resistant and anti-sliding surface on the loading ramp [7,36,43]. To prevent animals from falling off or escaping from the (un)loading dock, side walls should be provided [7,36,43]. Side walls which limit the view on the environment prevent animals from being distracted by what is happening around the loading dock and might thereby simplify (un)loading [7,36,44]. Grandin [46] also mentions that solid side walls are more efficient in preventing escape attempts due to the blocked vision of the animals.

\subsection{Loading and Unloading}

Loading duration is considered to be an indicator of the ease of loading. Since no loading times of slaughter horses are available for comparison, the observed loading durations can only be compared to these of beef cattle. María et al. [47] noted an average loading time of $1.20( \pm 0.86)$ minutes per beef bull. However, horses and cattle cannot be compared in terms of the leniency of their movements; these data support the observation that the loading of the horses in general went quite smoothly.

However, infrastructure did not always promote smooth loading. Horses regularly bumped their heads against trapdoors, clearly indicating that the trapdoors were too low. Furthermore, when stressed, for example due to rushed driving, horses carry their head higher [48] and thereby the chance of head-bumping is increased, especially when trapdoor height is rather low. Argentinian legislations states that the trapdoors should be at least $1.60 \mathrm{~m}$ high, which was not always the case, to prevent the horses from hurting their heads and backs [33].

In a total of seven loadings, the observing researcher noted that horses hesitated or reacted anxiously to specific elements of the infrastructure; for example, low or not fully opened trapdoors, a bar hanging too low over the passageway, a steep slope of a loading dock, or an uneven or muddy ground on or before the loading dock. Falling horses were only observed in loadings in which multiple horses stumbled. The falls were caused by pushing or fights between horses, which was clearly caused by the directions of the drivers in one instance. The directions of the drivers were not necessarily wrong in this case, but with a calmer approach the fall might not have happened. Furthermore, drivers must ensure that they do not give conflicting signals to the horses, for example by standing too 
close to the passageway of the horses when another driver is directing the horses to go there. These conflicting signals create confusion and thereby chaos. However, the presence of the investigators was probably - to a certain extent-an additional stress factor for the horses and loading crew.

For all transports, unloading went quite well. However, better communication between the slaughterhouse and the transporter may reduce the standstill before unloading the horses on arrival.

According to Friend [23], all horses experience stress during transport. Loading and unloading might even be more stressful to animals than the transport itself [47], but horses that were loaded before and did not have any negative experiences with loading experienced less stress than animals that were loaded for the first time [49]. It is not known whether the horses observed in this study had been loaded and transported before, and how any previous transports were perceived. It is possible that the horses that did not want to enter the trailer had had previously negative experiences during a transport, or had other bad experiences [13]. If the person who loads the horses has a good relationship with the horses, the stress level during loading decreases [49]. Since the horses do not have much contact with people during rearing, there is little evidence that there is a relationship of trust between the caretakers and the horses. Due to the lack of (positive) transport experiences of the horses and the absence of a trust relationship with the drivers, the importance of efficient and knowledgeable driving increases, in order to make loading as smooth as possible [49]. The authors of [47] state that education and training of the personnel is likely to be one of the most effective measures to improve horse welfare during loading and transport. HoMeFe demands that everyone involved in the transport of slaughter horses is trained regularly [36]. However, it is not clear whether or not the drivers and horse transporters of the observed transports had training in the handling and transporting of horses.

HoMeFe prohibits the use of electric driving aids, sticks and dogs [36]. As well as the World Organisation for Animal Health (OIE) [50], Grandin [51] mentions that the use of an electric prod should be avoided if possible, since the electric prod might cause the animals to become agitated and therefore sometimes dangerous. Furthermore, drivers should not scream, flap their arms or make sudden movements to keep the animals as calm as possible [36,50,51]. After all, besides their adverse effects on animal welfare, multiple studies demonstrate the adverse effects of the use of electric prods and incompetent handling on meat quality in pork and beef [52-54].

No electric prods were used and handlers stayed calm. Flags were used in all but one loading. Against the requirements of HoMeFe [36], a whip or stick was used in four loadings, but never to hit horses.

\subsection{Environmental Parameters}

About three-quarters of the transports left before noon, implying that the transports were often being carried out during the hottest moments of the day.

When the environmental temperature rises above the upper limit of the thermoneutral zone, the animal has to invest energy to keep its body temperature constant $[7,26]$; for example, by sweating, peripheral vasodilation, and by increasing the respiratory rate $[7,26]$. However, it is not clear from what point welfare is compromised. The temperature regularly rose above $25^{\circ} \mathrm{C}$, which is the upper limit of the thermoneutral zone of horses [27], and RH regularly increased above $50 \%$. Above $50 \%$, heat is dissipated less efficiently [29].

Based on the THI framework for producing dairy cows (Appendix A Figure A1) [42], mild and sometimes severe heat stress occurred during transports. However, THI must be interpreted carefully, since this parameter does not take solar load and wind speed into account [55]. Especially during transport in an open trailer, air displacement might enhance heat dissipation. On the other hand, the horses are standing close to each other during transport, which might limit heat dissipation. Moreover, the lack of a reference framework with limit values for heat stress in horses complicates interpretation.

Older horses are known to be more prone to heat stress than younger horses. When exposed to the same level of exercise, older horses overheat in a much shorter time than younger horses, indicating 
that their ability to dissipate excess heat is less compared to that of younger horses [56]. However, the age of the slaughter horses in this study was not known.

\subsection{Trucks and Trailer Density}

The floor of all transport vehicles was provided with wire mesh, as demanded by Argentinian legislation [33]. Different authorities and guidelines have determined the minimum and maximum density for horse transports, which explains the differences in thresholds. According to the CATGP [7], the density may vary between $1.00 \mathrm{~m}^{2}$ per horse and $1.75 \mathrm{~m}^{2}$ per horse, depending on the size and age of the horse (Appendix A Table A5). The available space per horse may deviate by a maximum of $10 \%$ from the directive, depending on the physical condition, the weather conditions and the probable transport time [7]. HoMeFe [36] has drafted guidelines in its specifications for the density during transport. The available space must be between $1.1 \mathrm{~m}^{2}$ per horse and $1.4 \mathrm{~m}^{2}$ per horse. Depending on the physical condition of the horses, the weather conditions, the travel time, the weight and the height of the horses, the actual density may deviate a maximum of $20 \%$ from the guidelines. This means that the available surface area per horse may vary between $0.88 \mathrm{~m}^{2}$ and $1.68 \mathrm{~m}^{2}$ [36]. In one or more compartments of six transports, the average surface area per animal deviated more than $20 \%$ from the HoMeFe guideline [36]: the surface area per animal was too large in five instances, and it was too small in one instance (Appendix A Table A6). It should be noted that the allowed stocking densities differ substantially between the CATGP [7] and HoMeFe [36] guidelines. However, comparing stocking densities expressed as surface area per horse is not evident, since adult horses can differ substantially in size. Two trailers with the same loading density expressed in $\mathrm{m}^{2} /$ horse can be, in reality, quite a different stocking density in $\mathrm{kg} / \mathrm{m}^{2}$ for these two loadings. On the other hand, determining the number of horses that can be loaded based on the estimated average weight of a group of horses might be prone to estimation errors.

Stull [57] compared some physiological parameters and the increase in injuries between horses transported at low (1.40-1.54 $\mathrm{m}^{2} /$ horse) and high stocking densities (1.14-1.31 $\mathrm{m}^{2} /$ horse). She concluded that it is better to provide at least $1.40 \mathrm{~m}^{2} /$ horse during transport, depending on the weight, conformation and size of the horses. Extra attention must be paid to the design of the trailer in order to prevent injuries to the horses [57].

A few times a pony or a young horse was transported in the same compartment with other, significantly larger horses. This is contrary to European Regulation EC 1/2005 [43] and the Argentinian Resolución 581/2014 [33], which states that animals of significantly different sizes or ages and sexually mature mares and stallions, must be handled and transported separately, unless the animals have been reared together, are accustomed to each other, or when the separation would cause distress. Similarly, mares accompanied by their dependent foals are not subject the above provisions. Finally, animals 'hostile to each other' and tied and untied animals should not be transported in the same compartment [43]. In at least five transports, one or more stallions were loaded. The stallions were not separated from the other horses in at least two transports, which is contrary to the abovementioned European Regulation [43], Argentinian legislation [33], and guidelines from HoMeFe [36]. One stallion that was not separated from the other horses was aggressive and was therefore placed in another compartment and had a rope tied tightly in the mouth. After putting on the rope, the stallion stopped behaving aggressively, but this was probably due to the inconvenience caused by the rope.

\subsection{Aggression and Falling during Transport}

In this study, no relationships could be demonstrated between environmental parameters and aggression. This suggests that the environmental parameters are not the most important factors that may or may not provoke aggression. As well as the current study (Appendix A Table A6), Iacono and colleagues [18] could not demonstrate a relationship between the degree of aggression and the density or fatigue of the horses during the transport of untied horses. According to the authors of [18], 
aggression is more likely to be a consequence of individual horses than stocking density. The current observations confirm this assumption (Appendix A Table A6).

\subsection{Transport Distance and Duration}

Argentinian legislation allows for a transport duration up to 36 hours without feeding, watering or rest [31]. In Uruguayan law, no maximum transport duration is mentioned [34]. According to the specifications of HoMeFe [36], a transport may take up to $12 \mathrm{~h}$. In exceptional cases, the transport may last up to $14 \mathrm{~h}$, for example if the destination can be reached by continuing the ride for a maximum of two hours [36]. This requirement differs substantially from the specifications of the European Regulation EC 1/2005 [43], that states that a transport may only take up to eight hours. In exceptional cases, the transport of trained horses may last up to $24 \mathrm{~h}$ if they are watered and fed every eight hours and if the transport vehicle meets some extra requirements for roof construction, presence and quality of litter, feeding and watering regime, partitions, ventilation, climate control and navigation system. However, for unbroken horses, the European Regulation does not allow any extension of the transport duration of eight hours, regardless of the transport vehicle in which the unbroken horses are transported [43].

Friend [14] claims that it is advisable to regularly provide the horses with water on the truck during long-distance transport in warm conditions, in order to reduce dehydration, stress and fatigue. CATGP [7] recommends to water horses every $4.5 \mathrm{~h}$, while the European Council Regulation EC 1/2005 [43] states that Domestic Equidae have to be watered every eight hours. Notwithstanding, Friend [14] also mentions that water consumption can be highly variable among different horses in the same situation [11]. Likewise, other studies question the watering of horses during transport [17,58]. After all, it often takes some time before the horses start drinking, about 20 min to an hour after the water is offered. Some horses did not drink, possibly for fear of the new water source or because of stress associated with the transport. Furthermore, the difference in weight loss between horses that did and did not drink suggested that the horses probably did not drink a large amount of water $[17,59]$. Therefore, it seems especially important that the horses are sufficiently hydrated before departure and have access to sufficient fresh water immediately after arrival $[14,36,60]$.

\section{Conclusions}

Our study identified the current practices of the commercial horse transport from collection points to slaughterhouses in Argentina and Uruguay. Some risk factors have been detected and could be improved. The loading and unloading of the horses generally went quite smoothly. Better training of drivers and optimized infrastructure (a level ground surface before and on the loading dock, sufficiently high trapdoors, steepness of the loading docks, provision of steps or foot battens on the loading dock, etc.) can prevent a lot of confusion and chaos for the horses, and thereby improve welfare. Driving aids were always used correctly. Most journeys started before noon, implying that the horses were often transported during the hottest moments of the day.

Still, on the one hand, interpretation of THI values is difficult because of a lack of reference framework for horses. On the other hand, not all parameters that affect thermal comfort are included in the THI. Therefore, it is not clear from what point on welfare is compromised. Stocking densities were not always according to relevant guidelines and significantly smaller horses or stallions were not always separated from the other horses. No influence of environmental parameters or transport characteristics on the degree of fighting behaviour could be demonstrated. On the contrary, the degree of aggression differed between the front and rear loading spaces of the same transport vehicle, suggesting that animal-specific factors, rather than environmental factors, determine the occurrence of aggressive behaviour. The willingness of all actors involved-slaughterhouses, transporters, loading crew, etc.- to conduct this study and to address shortcomings, underscores the growing awareness of animal welfare issues in Argentina and Uruguay. 
Author Contributions: Conceptualization, B.D.; methodology, B.D. and L.V.; formal analysis, L.V. and B.N.; investigation, L.V.; data curation, L.V. and B.N.; writing —original draft preparation, B.N. and B.D.; writing-review and editing, L.V., S.V.B. and J.V.T.; supervision, B.D. and J.V.T.; project administration, L.V and B.N. All authors have read and agreed to the published version of the manuscript.

Funding: This research received no external funding.

Acknowledgments: The staff of the slaughterhouses and all drivers are acknowledged for their collaboration.

Conflicts of Interest: The authors declare no conflict of interest.

\section{Appendix A}

Table A1. Observed parameters of the transport and transport vehicle.

\begin{tabular}{|c|c|}
\hline Parameter & Unit \\
\hline \multicolumn{2}{|l|}{ Transport date } \\
\hline \multicolumn{2}{|l|}{ Slaughterhouse } \\
\hline \multicolumn{2}{|l|}{ Date of slaughter } \\
\hline \multicolumn{2}{|l|}{ Address of the collection point } \\
\hline \multicolumn{2}{|l|}{ License plate of all parts of the transport combination } \\
\hline Presence of a roof on the loading spaces & Yes/no \\
\hline Does the roof cover the whole loading space?? & Yes/no \\
\hline \multicolumn{2}{|l|}{ Colour of the roof } \\
\hline Internal dimensions of the loading space & \\
\hline - length, width, height and height of the solid wall & $\mathrm{m}$ \\
\hline Surface area of the loading spaces & $\mathrm{m}^{2}$ \\
\hline \multicolumn{2}{|l|}{ Number of compartments in the front and rear loading space } \\
\hline $\begin{array}{c}\text { Dimensions of the compartments } \\
\text { - length and width }\end{array}$ & $\mathrm{m}$ \\
\hline $\begin{array}{c}\text { Loading density (averagely, per loading space and per } \\
\text { compartment) }\end{array}$ & $\begin{array}{c}\mathrm{m}^{2} / \text { horse } \\
\mathrm{kg} / \mathrm{m}^{2}\end{array}$ \\
\hline $\begin{array}{c}\text { Presence of tread plates in the front and rear loading space } \\
\text { Number of tread plates }\end{array}$ & Yes/no \\
\hline Length and width of the tread plates & $\mathrm{m}$ \\
\hline $\begin{array}{l}\text { Connecting method of the trailers: connected (yes) or not } \\
\text { connected (no). If the trailers are connected, both trailers can } \\
\text { be loaded through the hind gate. If trailers are not connected, } \\
\text { both trailers should be (un)loaded separately. }\end{array}$ & Yes/no \\
\hline $\begin{array}{l}\text { Dimensions of the gates to enter the vehicle, between loading } \\
\text { spaces, compartments or separate trailers (width and height) }\end{array}$ & $\mathrm{m}$ \\
\hline Presence of wire mesh on the floor of the loading spaces & Yes/no \\
\hline Type of wire mesh & $\begin{array}{c}\text { Standard; } \\
\text { Standard, bent; Diamond shaped }\end{array}$ \\
\hline $\begin{array}{l}\text { Mesh dimensions (length and width), height of the top of the } \\
\text { wire mesh and thickness of the wire mesh }\end{array}$ & 等 \\
\hline $\begin{array}{c}\text { Presence of fences in the loading space to create different } \\
\text { compartments }\end{array}$ & Yes/no \\
\hline
\end{tabular}


Table A2. Observed parameters during loading and unloading.

\begin{tabular}{|c|c|}
\hline Parameter & Unit \\
\hline \multicolumn{2}{|l|}{ Dimensions of the loading ramp } \\
\hline - length, height, width & $\mathrm{m}$ \\
\hline - slope & degrees \\
\hline \multicolumn{2}{|l|}{ Material that covers loading ramp (soil, wood, ... ) } \\
\hline \multicolumn{2}{|l|}{$\begin{array}{l}\text { Point of time on which loading and unloading started and ended (total, per } \\
\text { trailer and per compartment) }\end{array}$} \\
\hline Duration of loading and unloading (total, per trailer and per compartment) & Minutes \\
\hline \multicolumn{2}{|l|}{ Number of horses per transport, per trailer and per compartment } \\
\hline Hygiene of the loading space: is the loading space clean? & Yes/no \\
\hline \multicolumn{2}{|l|}{$\begin{array}{l}\text { Number of horses that bumped their head against the upside of the gates } \\
\text { while (un)loading }\end{array}$} \\
\hline \multicolumn{2}{|l|}{ Number of horses that stumbled during (un)loading } \\
\hline \multicolumn{2}{|l|}{ Number of horses that fell during (un)loading } \\
\hline \multicolumn{2}{|l|}{ Number of horses that had leg injuries at the moment of (un)loading } \\
\hline \multirow{2}{*}{\multicolumn{2}{|c|}{$\begin{array}{c}\text { Number of horses that had a belly injury at the moment of (un)loading } \\
\text { Number of horses that limped while (un)loading }\end{array}$}} \\
\hline & \\
\hline \multicolumn{2}{|l|}{ Number of horses that held the mouth opened while (un)loading } \\
\hline \multicolumn{2}{|l|}{$\begin{array}{c}\text { Number of horses that made noise while (un)loading (long and loud, } \\
\text { screamy whinnying) }\end{array}$} \\
\hline \multicolumn{2}{|l|}{ Number of horses that had the nostrils widely opened while (un)loading } \\
\hline \multicolumn{2}{|l|}{ Number of horses that fled back from the trailer during loading } \\
\hline \multicolumn{2}{|l|}{ Number of horses that had a head injury while (un)loading } \\
\hline \multicolumn{2}{|l|}{ Number of horses that heavily snort during (un)loading } \\
\hline \multicolumn{2}{|l|}{ Number of horses that sweat heavily during (un)loading } \\
\hline \multicolumn{2}{|l|}{ Number of horses that scrape the floor during (un)loading } \\
\hline \multicolumn{2}{|l|}{ Number of horses that fight during (un)loading } \\
\hline \multicolumn{2}{|l|}{ Colour of the flags (and other driving tools) at (un)loading } \\
\hline \multicolumn{2}{|l|}{ Material used for (un)loading the horses } \\
\hline \multicolumn{2}{|l|}{$\begin{array}{l}\text { Did the drivers leave the gate of the loading spaces opened when going } \\
\text { back to drive the other horses on the vehicle? }\end{array}$} \\
\hline Was the gate fully opened when (un)loading the horses? & Yes/no \\
\hline Were there any remarks during the (un)loading? & IEs/lio \\
\hline Weather conditions at (un)loading & \\
\hline - sunny & Yes/no \\
\hline - cloudy & Yes/no \\
\hline - rainy & Yes/no \\
\hline - windy & Yes/no \\
\hline - misty & Yes/no \\
\hline - moist & Yes/no \\
\hline - $\mathrm{CO}_{2}$-concentration & $\mathrm{ppm}$ \\
\hline - light intensity & $\operatorname{lux}$ \\
\hline $\begin{array}{l}\text { Point of time of departure, arrival, starting and finishing loading and } \\
\text { unloading (total, per trailer and per compartment) and point of time of the } \\
\text { end of weighing }\end{array}$ & \\
\hline $\begin{array}{l}\text { Duration of standstill before departure, standstill before unloading, } \\
\text { (un)loading (total, per loading space and per compartment) and weighing }\end{array}$ & minutes \\
\hline Distance of the transport & $\mathrm{km}$ \\
\hline Average speed & $\mathrm{km} / \mathrm{u}$ \\
\hline Duration of transport & minutes \\
\hline Number of stops during transport & \\
\hline Number of police controls during transport & \\
\hline Degree of aggression/fighting during transport (per loading space) & Not or barely, averagely or a lot \\
\hline Number of fallen horses during transport (per trailer) & \\
\hline $\begin{array}{l}\text { Temperature in the loading space during transport (measurement every five } \\
\text { minutes, calculated average, minimum and maximum) per loading space }\end{array}$ & ${ }^{\circ} \mathrm{C}$ \\
\hline $\begin{array}{l}\mathrm{RH} \text { in the loading space during transport (measurement every five minutes, } \\
\text { calculated average, minimum and maximum) per loading space }\end{array}$ & $\%$ \\
\hline $\begin{array}{c}\text { Dew point temperature in the loading space during transport (measurement } \\
\text { every five minutes, calculated average, minimum and maximum) per } \\
\text { loading space }\end{array}$ & ${ }^{\circ} \mathrm{C}$ \\
\hline Dimensions of the (un)loading ramp & \\
\hline - length, width, height & $\mathrm{m}$ \\
\hline - slope & degrees \\
\hline Is the gate completely opened when unloading? & Yes/no \\
\hline
\end{tabular}


Temperature

Relative humidity (\%)

${ }^{\circ} \mathrm{F}$

$\begin{array}{llllllllllllllllllll}0 & 5 & 10 & 15 & 20 & 25 & 30 & 35 & 40 & 45 & 50 & 55 & 60 & 65 & 70 & 75 & 80 & 85 & 90 & 95100\end{array}$

$72 \quad 22$.

$\begin{array}{lll}73 & 22.8\end{array}$

$\begin{array}{ll}74 & 23.3\end{array}$

$\begin{array}{ll}75 & 23.9\end{array}$

$\begin{array}{ll}76 & 24.4\end{array}$

$\begin{array}{ll}77 & 25.0\end{array}$

$\begin{array}{ll}78 & 25.6\end{array}$

$\begin{array}{ll}79 & 26.1\end{array}$

$80 \quad 26.7$

$81 \quad 27.2$

$\begin{array}{ll}82 & 27.8\end{array}$

$83 \quad 28.3$

$84 \quad 28.9$

$85 \quad 29.4$

$86 \quad 30.0$

$\begin{array}{ll}87 & 30.6\end{array}$

$88 \quad 31.1$

$\begin{array}{llllllllllllllllllllllll}90 & 32.2 & 72 & 73 & 74 & 75 & 76 & 77 & 78 & 79 & 79 & 80 & 81 & 82 & 83 & 84 & 85 & 86 & 86 & 87 & 88 & 89 & 90\end{array}$

$\begin{array}{lllllllllllllllllllllll}91 & 32.8 & 73 & 74 & 75 & 76 & 76 & 77 & 78 & 79 & 80 & 81 & 82 & 83 & 84 & 85 & 86 & 86 & 87 & 88 & 89 & 90 & 91\end{array}$

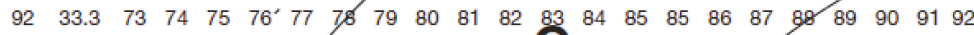

$\begin{array}{lllllllllllllllllllllll}93 & 33.9 & 74 & 75 & 76 & 77 & 78 & 79 & 80 & 80 & 81 & 82 & 83 & 84 & 85 & 86 & 87 & 88 & 89 & 90 & 91 & 92 & 93\end{array}$

$\begin{array}{lllllllllllllllllllllll}94 & 34.4 & 74 & 75 & 76 & 77 & 78 & 79 & 80 & 81 & 82 & 83 & 84 & 85 & 86 & 87 & 88 & 89 & 90 & 91 & 92 & 93 & 94\end{array}$

$\begin{array}{lllllllllllllllllllllll}95 & 35.0 & 75 & 76 & 77 & 78 & 79 & 80 & 81 & 82 & 83 & 84 & 85 & 86 & 87 & 88 & 89 & 90 & 91 & 92 & 93 & 94 & 95\end{array}$

$\begin{array}{lllllllllllllllllllllll}96 & 35.6 & 75 & 76 & 77 & 78 & 79 & 80 & 81 & 82 & 83 & 85 & 86 & 87 & 88 & 89 & 90 & 91 & 92 & 93 & 94 & 95 & 96\end{array}$

$\begin{array}{lllllllllllllllllllllll}97 & 36.1 & 76 & 76 & 78 & 79 & 80 & 81 & 82 & 83 & 84 & 85 & 86 & 87 & 88 & 89 & 91 & 92 & 93 & 94 & 95 & 96 & 97\end{array}$

$\begin{array}{lllllllllllllllllllllll}98 & 36.7 & 76 & 77 & 78 & 79 & 80 & 82 & 83 & 84 & 85 & 86 & 87 & 88 & 89 & 90 & 91 & 93 & 94 & 95 & 96 & 97 & 98\end{array}$

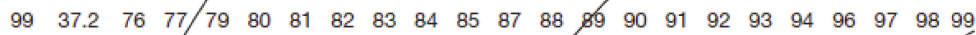

$\begin{array}{lllllllllllllllllllllll}100 & 37.3 & 77 & 78 & 79 & 80 & 82 & 83 & 84 & 85 & 86 & 87 & 88 & 90 & 91 & 92 & 93 & 94 & 95 & 97 & 98 & 99\end{array}$

$\begin{array}{lllllllllllllllllllll}101 & 38.3 & 77 & 79 & 80 & 81 & 82 & 83 & 86 & 86 & 87 & 88 & 89 & 90 & 92 & 93 & 96 & 95 & 96 & 97 & 99\end{array}$

$\begin{array}{llllllllllllllllllll}102 & 38.9 & 78 & 79 & 80 & 81 & 83 & 86 & 85 & 86 & 87 & 89 & 90 & 91 & 92 & 96 & 95 & 96 & 97 & 96\end{array}$

$\begin{array}{llllllllllllllllll}103 & 39.6 & 7 / 8 & 79 & 81 & 82 & 83 & 86 & 86 & 87 & 88 / 89 & 91 & 92 & 94 & 95 & 96 & 97\end{array}$

$\begin{array}{lllllllllllllllll}104 & 40.0 & 79 & 80 & 81 & 82 & 86 & 85 & 86 & 88 & 88 & 90 & 91 & 93 & 94 & 95 & 96\end{array}$

$\begin{array}{lllllllllllllllll}105 & 40.6 & 79 & 80 & 82 & 83 & 86 & 86 & 87 & 88 & / 89 & 91 & 92 & 93 & 96 & 96 & 97\end{array}$

$\begin{array}{lllllllllllllllll}106 & 41.1 & 80 & 81 & 82 & 86 & 85 & 86 & 88 & 89 & 90 & 91 & 93 & 94 & 95 & 97 & 98\end{array}$

$\begin{array}{lllllllllllllllll}107 & 41.7 & 80 & 81 & 83 & 86 & 85 & 87 & 88 & 89 & 91 & 92 & 94 & 95 & 96 & 98\end{array}$

$\begin{array}{lllllllllllllll}108 & 42.2 & 81 & 82 & 83 & 85 & 86 & 87 & 89 & 90 & 92 & 93 & 94 & 96 & 97\end{array}$

$\begin{array}{lllllllllllllll}109 & 42.3 & 81 & 82 & 86 & 85 & 87 & 88 & 89 & 91 & 92 & 94 & 95 & 96 & 98\end{array}$

$\begin{array}{llllllllllllll}110 & 43.3 & 81 & 83 & 86 & 86 & 87 & 88 & 90 & 91 & 92 & 94 & 96 & 97\end{array}$

$\begin{array}{llllllllllllll}111 & 43.9 & 82 & 83 & 85 & 86 & 88 & 89 & 91 & 93 & 94 & 95 & 96 & 98\end{array}$

$\begin{array}{llllllllllll}112 & 44.4 & 82 & 86 & 85 & 87 & 88 / 90 & 91 & 94 & 94 & 96 & 97\end{array}$

$\begin{array}{lllllllllllll}113 & 45.0 & 83 & 86 & 86 & 87 & 89 & 90 & 92 & 95 & 95 & 96 & 96\end{array}$

$\begin{array}{llllllllllll}114 & 45.4 & 83 & 85 & 86 & 88 & 89 & 91 & 92 & 94 & 96 & 97\end{array}$

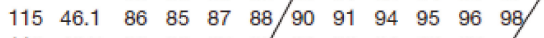

$\begin{array}{lllllllllll}116 & 46.7 & 86 & 86 & 87 & 89 & 90 & 92 & 94 & 95 & 97\end{array}$

$\begin{array}{lllllllllll}117 & 47.2 & 85 & 86 & 88 & 89 & 91 & 93 & 94 & 96 & 98\end{array}$

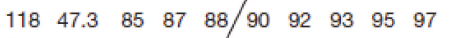

$\begin{array}{llllllllll}119 & 48.3 & 85 & 87 & 89 & 90 & 92 & 94 & 96 & 97\end{array}$

$\begin{array}{llllllllll}120 & 48.9 & 86 & 88 & 89 & 91 & 93 & 94 & 96 & 98\end{array}$

$\begin{array}{lllllllll}121 & 49.4 & 86 & 88 & 90 & 92 & 93 & 95 & 97\end{array}$

$\begin{array}{llll}\text { A } & <72 & \text { No stress } \\ \text { B } & 72-78 & \text { Mild stress } \\ \text { C } & 79-89 & \text { Severe stress } \\ \text { D } & 89-98 & \text { Very severe stress } \\ \text { E } & >98 & \text { Dead cows }\end{array}$

Figure A1. Temperature humidity index (THI) with classification in comfort zones for dairy cattle [42]. 


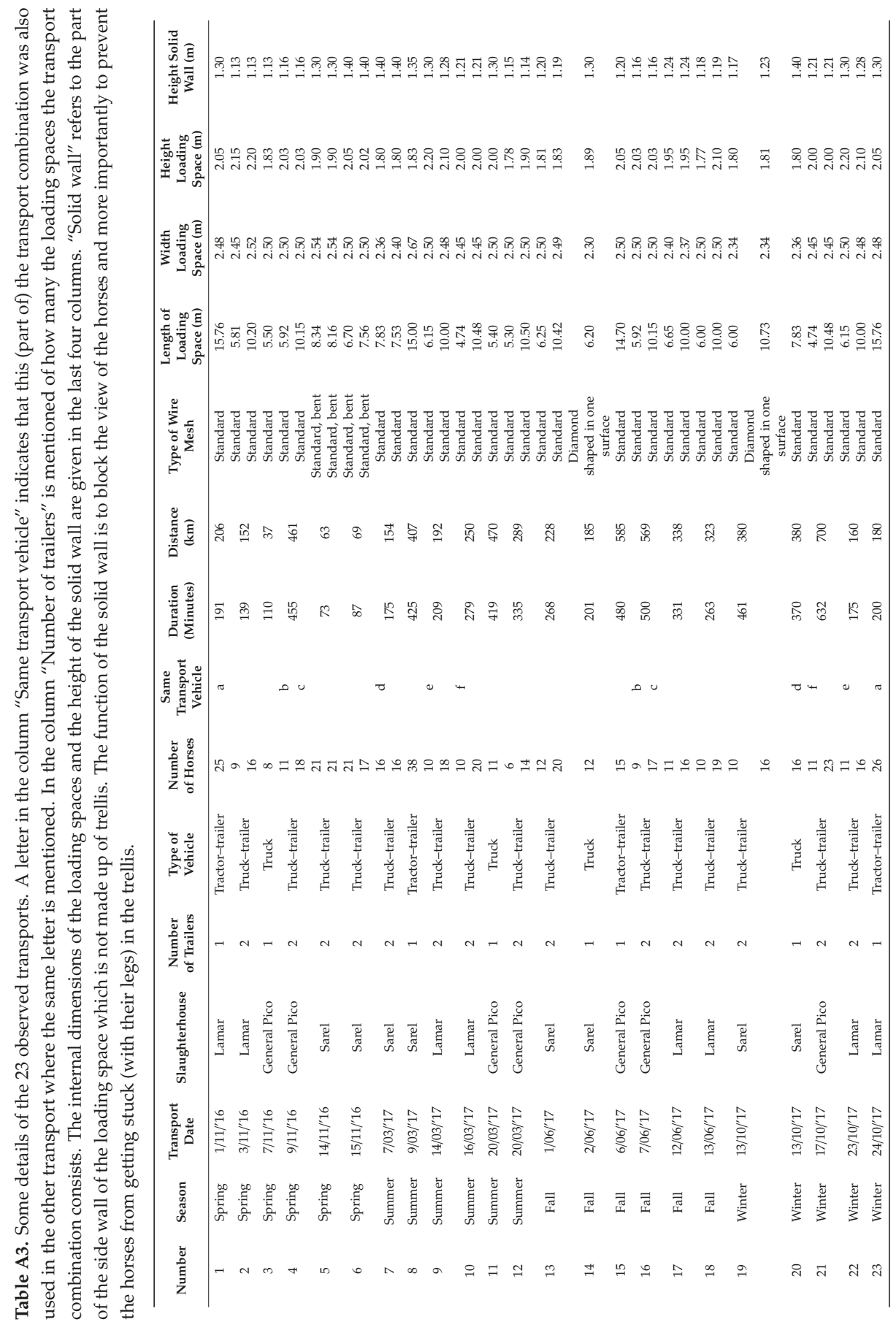




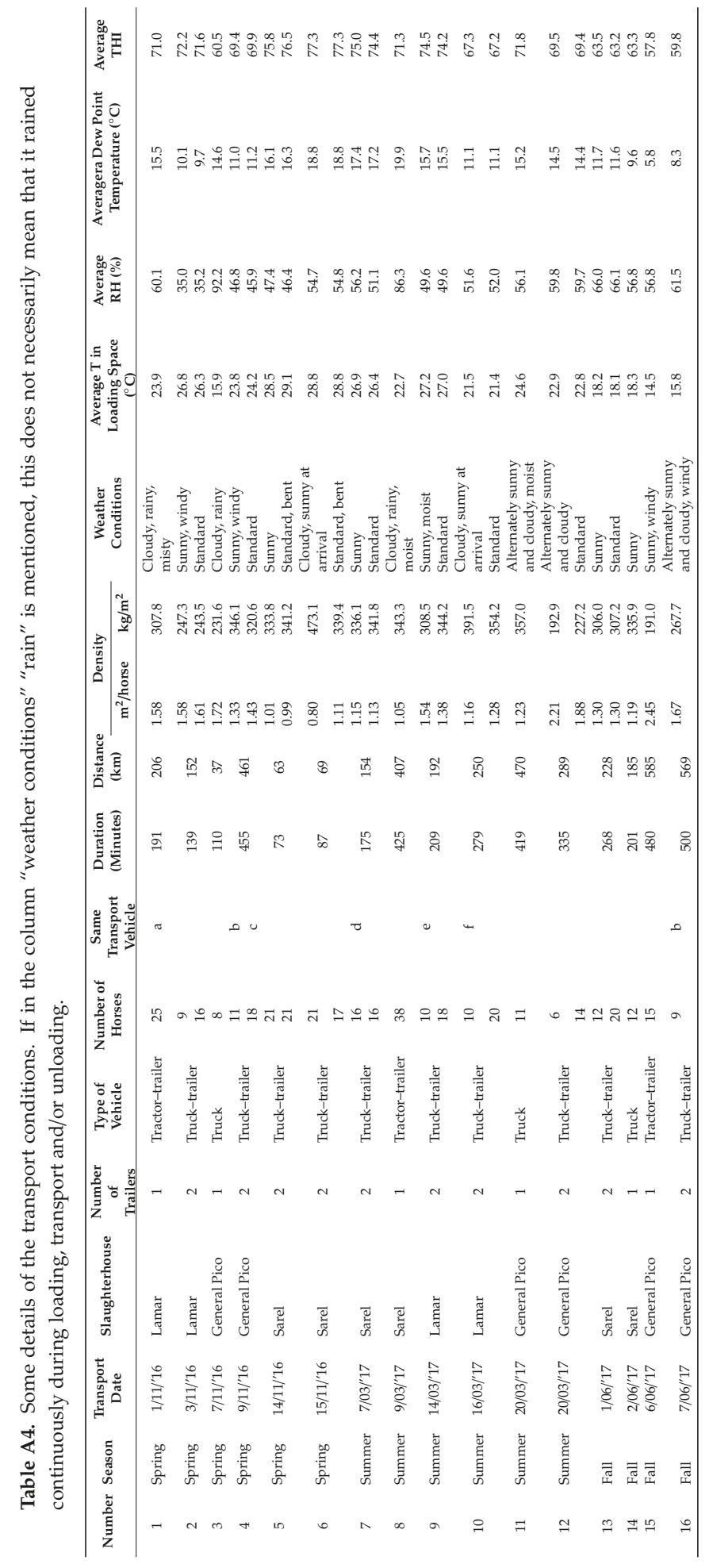


Table A5. Required space per horse for road transport in Europe [7,43].

\begin{tabular}{cc}
\hline Type of Horse & Available Space \\
\hline Adult horses & $1.75 \mathrm{~m}^{2}(0.7 \times 2.5 \mathrm{~m})$ \\
Young horses (6-24 months) (transport $<48$ hours) & $1.2 \mathrm{~m}^{2}(0.6 \times 2.0 \mathrm{~m})$ \\
Young horses (6-24 months) (transport $>48$ hours) & $2.4 \mathrm{~m}^{2}(1.2 \times 2.0 \mathrm{~m})$ \\
Ponies $(<1.44 \mathrm{~m})$ & $1.0 \mathrm{~m}^{2}(0.6 \times 1.8 \mathrm{~m})$ \\
Foals (0-6 months) & $1.4 \mathrm{~m}^{2}(1.0 \times 1.4 \mathrm{~m})$ \\
\hline
\end{tabular}

Table A6. Density per compartment of the transports with deviating density in one or more compartments. Densities in bold deviate from the norm. ${ }^{*}=$ unknown distribution. $\mathrm{T} 1=$ front loading space; $\mathrm{T} 2$ = hind loading space; $\mathrm{C} 1$ = first compartment; $\mathrm{C} 2$ = second compartment; C3 = third compartment.

\begin{tabular}{|c|c|c|c|c|c|c|}
\hline $\begin{array}{c}\text { Transport } \\
\text { Date }\end{array}$ & $\begin{array}{c}\text { Slaughter } \\
\text { Date }\end{array}$ & Slaughter-House & $\begin{array}{c}\text { Number of } \\
\text { Trailers }\end{array}$ & Compartment & $\begin{array}{c}\text { Density } \\
\left(\mathrm{m}^{2} / \text { Horse }\right)\end{array}$ & Fighting \\
\hline $7 / 11 / 2016$ & $8 / 11 / 2016$ & General Pico & 1 & $\mathrm{~T} 1$ & 1.72 & Average \\
\hline \multirow{3}{*}{$15 / 11 / 2016$} & \multirow{3}{*}{$16 / 11 / 2016$} & \multirow{3}{*}{ Sarel } & \multirow{3}{*}{2} & $\mathrm{~T} 1$ & 0.80 & Average \\
\hline & & & & $\mathrm{T} 2$ & 1.11 & High \\
\hline & & & & $\mathrm{T} 1^{*}$ & 1.54 & Barely or not \\
\hline \multirow{3}{*}{$14 / 3 / 2017$} & \multirow{3}{*}{$15 / 3 / 2017$} & \multirow{3}{*}{ Lamar } & \multirow{3}{*}{2} & $\mathrm{~T} 2, \mathrm{C} 1$ & 1.06 & \\
\hline & & & & $\mathrm{T} 2, \mathrm{C} 2$ & 2.48 & Average \\
\hline & & & & $\mathrm{T} 2, \mathrm{C} 3$ & 2.23 & \\
\hline \multirow{3}{*}{$20 / 3 / 2017$} & \multirow{3}{*}{$21 / 3 / 2017$} & \multirow{3}{*}{ General Pico } & \multirow{3}{*}{2} & $\mathrm{~T} 1$ & 2.21 & Barely or not \\
\hline & & & & $\mathrm{T} 2$ & 1.88 & Barely or not \\
\hline & & & & $\mathrm{T} 1$ & 2.45 & \multirow{3}{*}{ High } \\
\hline \multirow[t]{4}{*}{$6 / 6 / 2017$} & \multirow[t]{4}{*}{$8 / 6 / 2017$} & \multirow[t]{4}{*}{ General Pico } & \multirow[t]{4}{*}{1} & $\mathrm{~T} 1, \mathrm{C} 1$ & 2.68 & \\
\hline & & & & $\mathrm{T} 1, \mathrm{C} 2$ & 2.25 & \\
\hline & & & & $\mathrm{T} 1, \mathrm{C} 1$ & 1.46 & \multirow{2}{*}{ High } \\
\hline & & & & $\mathrm{T} 1, \mathrm{C} 2$ & 1.33 & \\
\hline \multirow[t]{3}{*}{$23 / 10 / 2017$} & \multirow[t]{3}{*}{$25 / 10 / 2017$} & \multirow[t]{3}{*}{ Lamar } & \multirow[t]{3}{*}{2} & $\mathrm{~T} 2, \mathrm{C} 1$ & 1.74 & \multirow{3}{*}{ High } \\
\hline & & & & $\mathrm{T} 2, \mathrm{C} 2$ & 1.49 & \\
\hline & & & & $\mathrm{T} 2, \mathrm{C} 3$ & 1.49 & \\
\hline
\end{tabular}

\section{References}

1. BESTAT. Statistics Belgium. Available online: https://bestat.statbel.fgov.be/bestat/crosstable.xhtml? datasource $=3488 \mathrm{f} 928-86 \mathrm{af}-4067-92 \mathrm{db}-4 \mathrm{fbe} 45 \mathrm{c} 9 \mathrm{a} 251$ (accessed on 26 February 2020).

2. FAOSTAT. Food and Agricultural Organization of the United Nations. Available online: http://www.fao.org/ faostat/en/\#data/QL (accessed on 26 February 2020).

3. Vermeulen, L.; Van Beirendonck, S.; Van Thielen, J.; Driessen, B. A review: Today's practices about the fitness for travel on land of horses toward the slaughterhouse. J. Vet. Behav. 2019, 29, 102-107. [CrossRef]

4. Poznyakovskiy, V.M.; Gorlov, I.F.; Tikhonov, S.L.; Shelepov, V.G. About the quality of meat with PSE and DFD properties. Foods Raw Mater. 2015, 3, 104-110. [CrossRef]

5. Pawshe, M.D.; Badhe, S.R.; Khedkar, C.D.; Pawshe, R.D.; Pundkar, A.Y. Horse meat. In Encyclopedia of Food and Health; Elsevier: Amsterdam, The Netherlands, 2016; pp. 353-356. [CrossRef]

6. Cruz-Monterrosa, R.G.; Reséndiz-Cruz, V.; Rayas-Amor, A.A.; López, M.; La Lama, G.C.M. Bruises in beef cattle at slaughter in Mexico: Implications on quality, safety and shelf life of the meat. Trop. Anim. Health Prod. 2017, 49, 145-152. [CrossRef] [PubMed]

7. Consortium of the Animal Transport Guides Project. Guide to Good Practices for the Transport of Horses Destined for Slaughter; Publications Office of the European Union: Luxembourg, 2018; pp. 1-66. Available online: http://animaltransportguides.eu/wp-content/uploads/2016/05/EN-Guides-Horses-final.pdf (accessed on 3 March 2020).

8. Gorlov, I.F.; Pershina, E.I.; Tikhonov, S.L. Identification and prevention of the formation of meat with PSE and DFD properties and quality assurance for meat products from feedstocks exhibiting an anomalous autolysis behavior. Foods Raw. Mater. 2013, 1, 15-21. [CrossRef] 
9. Marlin, D.; Kettlewell, P.; Parkin, T.; Kennedy, M.; Broom, D.; Wood, J. Welfare and health of horses transported for slaughter within the European Union Part 1: Methodology and descriptive data: Transport to slaughter. Equine Vet. J. 2011, 43. [CrossRef]

10. Leadon, D.; Waran, N.; Herholz, C.; Klay, M. Veterinary management of horse transport. Vet. Ital. 2008, 44, 16.

11. Friend, T.H.; Martin, M.T.; Householder, D.D.; Bushong, D.M. Stress responses of horses during a long period of transport in a commercial truck. J. Am. Vet. Med. Assoc. 1998, 15, 838-844.

12. Gibbs, A.E.; Friend, T.H. Horse preference for orientation during transport and the effect of orientation on balancing ability. Appl. Anim. Behav. Sci. 1999, 63, 1-9. [CrossRef]

13. Grandin, T.; McGee, K.; Lanier, J. Survey of Trucking Practices and Injury to Slaughter Horses (unpublished). Available online: https://www.grandin.com/references/horse.transport.html (accessed on 3 March 2020).

14. Friend, T.H. Dehydration, stress, and water consumption of horses during long-distance commercial transport. J. Anim. Sci. 2000, 78, 2568-2580. [CrossRef]

15. Collins, M.N.; Friend, T.H.; Jousan, F.D.; Chen, S.C. Effects of density on displacement, falls, injuries, and orientation during horse transportation. Appl. Anim. Behav. Sci. 2000, 67, 169-179. [CrossRef]

16. Gibbs, A.E.; Friend, T.H. Effect of animal density and trough placement on drinking behavior and dehydration in slaughter horses. J. Equine Vet. Sci. 2000, 20, 643-650. [CrossRef]

17. Iacono, C.M.; Friend, T.H.; Johnson, R.D.; Krawczel, P.D.; Archer, G.S. A preliminary study on the utilization of an onboard watering system by horses during commercial transport. Appl. Anim. Behav. Sci. 2007, 105, 227-231. [CrossRef]

18. Iacono, C.; Friend, T.; Keen, H.; Martin, T.; Krawczel, P. Effects of density and water availability on the behavior, physiology, and weight loss of slaughter horses during transport. J. Equine Vet. Sci. 2007, 27, 355-361. [CrossRef]

19. Werner, M.; Gallo, C. Effects of transport, lairage and stunning on the concentrations of some blood constituents in horses destined for slaughter. Livest. Sci. 2008, 115, 94-98. [CrossRef]

20. Tateo, A.; Padalino, B.; Boccaccio, M.; Maggiolino, A.; Centoducati, P. Transport stress in horses: Effect of two different distances. J. Vet. Behav. 2012, 7, 33-42. [CrossRef]

21. Padalino, B.; Hall, E.; Raidal, S.; Celi, P.; Knight, P.; Jeffcott, L.; Muscatello, G. Health problems and risk factors associated with long haul transport of horses in Australia. Animals 2015, 5, 1296-1310. [CrossRef]

22. Abbott, A. Physiological Responses of Horses in Transit and the Effect on Welfare. Available online: http://essays.cve.edu.au/sites/default/files/vein_essays/content_2607/Abbott.pdf (accessed on 3 March 2020).

23. Friend, T.H. A review of recent research on the transportation of horses. J. Anim. Sci 2001, 79, E32-E40. [CrossRef]

24. Šímová, V.; Večerek, V.; Passantino, A.; Voslářová, E. Pre-transport factors affecting the welfare of cattle during road transport for slaughter-A review. Acta Vet. Brno. 2016, 85, 303-318. [CrossRef]

25. Dai, F.; Dalla Costa, A.; Bonfanti, L.; Caucci, C.; Di Martino, G.; Lucarelli, R.; Padalino, B.; Minero, M. Positive reinforcement-based training for self-loading of meat horses reduces loading time and stress-related behavior. Front. Vet. Sci. 2019, 6, 350. [CrossRef]

26. Luz, C.S.M.; Fonseca, W.J.L.; Vogado, G.M.S.; Fonseca, W.L.; Oliveira, M.R.A.; Sousa, G.G.T.; Farias, L.A.; Sousa Júnior, S.C. Adaptative thermal traits in farm animals. J. Anim. Behav. Biometeorol. 2015, 4, 6-11. [CrossRef]

27. Morgan, K. Thermoneutral zone and critical temperatures of horses. J. Therm. Biol. 1998, 23, 59-61. [CrossRef]

28. National Research Council. Farm animals and the environment. In Effect of Environment on Nutrient Requirements of Domestic Animals; National Academies Press: Washington, DC, USA, 1981; ISBN 978-0-309-03181-3.

29. Stull, C.L.; Rodiek, A.V. Physiological responses of horses to 24 hours of transportation using a commercial van during summer conditions. J. Anim. Sci. 2000, 78, 1458-1466. [CrossRef] [PubMed]

30. Schlatter, T.W. Temperature-humidity index. In Climatology. Encyclopedia of Earth Science; Springer: Boston, MA, USA, 1987. [CrossRef]

31. Resolución N 97/1999. Créase el Registro Nacional de Medios de Transporte de Animales. Características Técnicas. Habilitación. Condiciones Para el Embarque y Transporte. Lavado y Desinfección. Disposiciones Generales. Available online: https://www.argentina.gob.ar/normativa/nacional/resoluci\%C3\%B3n-97-199955716/texto (accessed on 3 March 2020). 
32. Resolución $\mathrm{N}^{\circ}$ 25/2013 SENASA. Available online: http://www.senasa.gob.ar/resolucion-252013 (accessed on 3 March 2020).

33. Resolución $N^{\circ}$ 581/2014. Creación del Registro Nacional Sanitario de Medios de Transporte de Animales Vivos. Available online: http://www.senasa.gob.ar/sites/default/files/normativas/archivos/res_581-2014.pdf (accessed on 3 March 2020).

34. Ley $\mathrm{N}^{\circ}$ 18.471. Tenencia Responsable de Animales. Available online: https://legislativo.parlamento.gub.uy/ temporales/leytemp9528174.htm (accessed on 3 March 2020).

35. Council Regulation (EC) No 1099/2009 of 24 September 2009 on the Protection of Animals at the Time of Killing. Available online: https://eur-lex.europa.eu/eli/reg/2009/1099/oj (accessed on 3 March 2020).

36. Horse Meat Federation. Manual for the Animal Welfare of Horses during Transport and Slaughtering. Available online: http://www.respectfullife.com/wp-content/uploads/2016/09/160202-Homefe-Guidelinesanimal-welfare.pdf (accessed on 3 March 2020).

37. Kibler, H.H. Environmental physiology and shelter engineering. LXVII. Thermal effects of various temperature-humidity combinations on Holstein cattle as measured by eight physiological responses. Res. Bull. Mo. Agric. Exp. Stn. 1964, 862,1-42.

38. Hartmann, E.; Hopkins, R.J.; Von Brömssen, C.; Dahlborn, K. 24-h sheltering behaviour of individually kept horses during Swedish summer weather. Acta Vet. Scand. 2015, 57, 45. [CrossRef]

39. Snoeks, M. Schuilgedrag van Paarden op de Weide. Ph.D. Thesis, KU Leuven, Leuven, Belgium, July 2017.

40. Du Preez, J.H.; Giesecke, W.H.; Hattingh, P.J. Heat stress in dairy cattle and other livestock under Southern African conditions. I. Temperature-humidity index mean values during the four main seasons. Onderstepoort J. Vet. Res. 1990, 57, 77-86.

41. Gantner, V.; Mijić, P.; Jovanovac, S.; Raguž, N.; Bobić, T.; Kuterovac, K. Influence of temperature-humidity index (THI) on daily production of dairy cows in Mediterranean region in Croatia. In Animal Farming and Environmental Interactions in the Mediterranean Region; Casasús, I., Rogošiç, J., Rosati, A., Štokoviç, I., Gabiña, D., Eds.; Wageningen Academic Publishers: Wageningen, The Netherlands, 2012; pp. 71-78. ISBN 978-90-8686-741-7.

42. Moran, J. Appendix 1: Temperature humidity index. In Tropical Dairy Farming: Feeding Management for Small Holder Dairy Farmers in the Humid Tropics; Landlinks Press: Oxford, UK, 2008; pp. 275-291. Available online: https://www.publish.csiro.au/ebook/chapter/SA0501275 (accessed on 3 March 2020).

43. Council Regulation (EC) No 1/2005 of 22 December 2004 on the Protection of Animals During Transport and Related Operations and Amending Directives 64/432/EEC and 93/119/EC and Regulation (EC) No 1255/97. Available online: https://eur-lex.europa.eu/eli/reg/2005/1/oj (accessed on 3 March 2020).

44. Grandin, T. Designing meat packing plant handling facilities for cattle and hogs. Trans. ASAE 1979, 22, 912-917. [CrossRef]

45. Grandin, T. Design of loading facilities and holding pens. Appl. Anim. Behav. Sci. 1990, 28, $187-201$. [CrossRef]

46. Grandin, T. Behavioural principles of livestock handling. Prof. Anim. Sci. 1989, 5, 1-11. [CrossRef]

47. Maria, G.A.; Villarroel, M.; Chacon, G.; Gebresenbet, G. Scoring system for evaluating the stress to cattle of commercial loading and unloading. Vet. Rec. 2004, 154, 818-821. [CrossRef]

48. Draaisma, R. Tension shimmers through calming signals. In Language Signs and Calming Signals of Horses; CRC Press: Boca Raton, FL, USA, 2018; pp. 73-121.

49. Andronie, I.C.; Pârvu, M.; Andronie, V.; Ciurea, A. Risk assessment of welfare depreciation in horses during transport. In Proceedings of the XVth International Congress of the International Society for Animal Hygiene, Animal Hygiene and Sustainable Livestock Production, Vienna, Austria, 3-7 July 2011.

50. World Organisation for Animal Health. Terrestrial Animal Health Code (2019). Available online: https: //www.oie.int/en/standard-setting/terrestrial-code/access-online/ (accessed on 12 March 2020).

51. Grandin, T. Safe handling of large animals. Occup. Med. 1999, 14, 195-212.

52. Grandin, T. Livestock-handling quality assurance. J. Anim. Sci. 2001, 79, E239-E248. [CrossRef]

53. Correa, J.A.; Torrey, S.; Devillers, N.; Laforest, J.P.; Gonyou, H.W.; Faucitano, L. Effects of different moving devices at loading on stress response and meat quality in pigs. J. Anim. Sci. 2010, 88, 4086-4093. [CrossRef] [PubMed] 
54. Huertas, S.; Gil, A.; Piaggio, J.; Van Eerdenburg, F. Transportation of beef cattle to slaughterhouses and how this relates to animal welfare and carcase bruising in an extensive production system. Anim. Welf. 2010, 281-285.

55. Gaughan, J.B.; Mader, T.L.; Holt, S.M.; Lisle, A. A new heat load index for feedlot cattle. J. Anim. Sci. 2008, 86, 226-234. [CrossRef]

56. McKeever, K.H.; Eaton, T.L.; Geiser, S.; Kearns, C.F.; Lehnhard, R.A. Age related decreases in thermoregulation and cardiovascular function in horses: Ageing and thermoregulation. Equine Vet. J. 2010, 42, 220-227. [CrossRef] [PubMed]

57. Stull, C.L. Responses of horses to trailer design, duration, and floor area during commercial transportation to slaughter. J. Anim. Sci. 1999, 77, 2925. [CrossRef]

58. Mars, L.A.; Kiesling, H.E.; Ross, T.T.; Armstrong, J.B.; Murray, L. Water acceptance and intake in horses under shipping stress. J. Equine Vet. Sci. 1992, 12, 17-20. [CrossRef]

59. Nielsen, B.L.; Dybkjær, L.; Herskin, M.S. Road transport of farm animals: Effects of journey duration on animal welfare. Animal 2011, 5, 415-427. [CrossRef]

60. World Hore Welfare; FVE; EEVA; Animal Transportation Association; Animals' Angels; The Donkey Sanctuary. Practical Guidelines on the Watering of Equine Animals Transported by Road. 2014. Available online: http://www.animaltransportationassociation.org/Resources/Documents/Best\%20Practices/Wateringguidelines-equines\%2026June15.pdf (accessed on 3 March 2020).

(C) 2020 by the authors. Licensee MDPI, Basel, Switzerland. This article is an open access article distributed under the terms and conditions of the Creative Commons Attribution (CC BY) license (http://creativecommons.org/licenses/by/4.0/). 


\title{
Equine Milk Production and Valorization of Marginal Areas-A Review
}

\author{
Nicoletta Miraglia ${ }^{1}$, Elisabetta Salimei ${ }^{1, *}$ and Francesco Fantuz ${ }^{2}$ \\ 1 Dipartimento Agricoltura, Ambiente e Alimenti, Università degli Studi del Molise, Campobasso 86100, Italy; \\ miraglia@unimol.it \\ 2 Scuola di Bioscienze e Medicina Veterinaria, Università degli Studi di Camerino, Camerino MC 62032, Italy; \\ francesco.fantuz@unicam.it \\ * Correspondence: salimei@unimol.it; Tel.: +39-0874-404-850
}

Received: 3 December 2019; Accepted: 19 February 2020; Published: 22 February 2020

Simple Summary: The revaluation of equine milk for human consumption is showing an increased interest from a scientific point of view. As practical relapse of the peculiar characteristics of horse and donkey milk, and their potentialities as food products, the dairy equine enterprise is developing worldwide. The milk production can therefore contribute to the whole equine industry, but crucial factors still need to be elucidated. Aiming to promote advances of knowledge on the dairy equine enterprise, aspects of management of the dairy horse and donkey are reviewed in the frame of marginal areas, with a special focus on dam and foal feeding, and welfare, besides milk quality.

\begin{abstract}
The equine dairy chain is renewing the interest toward horse and donkey breeding for the production of milk with potential health promoting properties. The dairy equine chain for human consumption could contribute to the rural eco-sustainable development for the micro-economies of those areas threatened by marginalization. As a part of the whole equine industry, and its possible impact in the modern and future society, the main traits of the equine dairy enterprise are reviewed with a special focus on management of animals and milk. Equine milk compositional and nutritional peculiarities are described as also related to milk hygiene and health issues. Scientific and technical aspects of the feeding management are considered in the frame of the emerging dairy equine enterprise, where pasture is an essential element that allows to match production goals for horses and donkeys, biodiversity preservation, as well as landscape safeguard.
\end{abstract}

Keywords: equine milk; dairy equine chain; dairy equine management and feeding; biodiversity; landscape; pasture

\section{Introduction}

Equine breeding represents one of the most promising activities in rural development, which is considered a key strategy for restructuring the agriculture sector by means of diversification and innovation [1]. The equine species are involved not only in activities concerning their use for work and tourism, but also in niche activities related to the production of food and non-food products [2,3]. The high versatility of the equine species represents a strong argument for the conservation of endangered equine breeds and populations [4,5]. Many breeds occupy special niches and contribute to the biodiversity due to their own genetic characteristics, coming from adaptive mechanisms developed in centuries of evolution in specific local environments [6,7]. Consequently, policies for the safeguard of endangered equine breeds and autochthonous populations have been developed, also considering the recovery of the relationship among humans, animals, and territory, as a 'system integrator' of the rural eco-sustainable development $[8,9]$. The renewed interest toward equine milk and derivatives is today 
sustained by the emerging dairy equine enterprise, which is developing in France, Italy, Mongolia, China, Kazakhstan, Kirgizstan, Greece, Germany, and many other countries [10-12].

As a part of the whole equine industry and its potential impact in the modern and future society, the equine dairy enterprise is described in its main traits. Based on peculiarities of equine milk for human consumption, the essential features of management of animals and milk are reviewed in the context of marginal areas. Aspects of nutrition of the dairy equids are examined in the frame of those areas where pasture and natural meadows represent the main land use, as a further contribution to landscape safeguard.

\section{Equine Milk: Properties, Potentials, and Benefits}

The nutritional and therapeutic peculiarities of equine milk are known since ancient times, as Hippocrates [13] and Herodotus [14] described in the 5th century BC. Moreover, the consumption of koumiss (or airag), i.e., a traditional drink made in Central Asia, according to a nomads' recipe [15], is reported in literature, not only as an ingredient of the traditional "white diet" of the Mongolian steppes population [16], but also as a popular remedy for a variety of diseases [17,18]. The traditional use of donkey milk is also reported in China and South America for the treatment of many illnesses [19].

Recent scientific findings on the equine milk compositional peculiarities and their potential health promoting properties have increased interest toward its use for human consumption, especially for sensitive consumers, such as children with allergies to cow's milk protein, as well as immunocompromised or debilitated people $[10,20]$. In Europe, the dairy equine enterprise started up in France as part of a project on animal diversity preservation [21], and spread out in many marginal areas of the world where these monogastric herbivores are well adapted to difficult environments, with scarce availability of forages, often of poor-quality. Today, equine milk is mainly marketed for human consumption as raw, pasteurized, or freeze-dried [22], and as fermented derivatives [15]. In Italy, the price of donkey milk ranges from 9 to $15 € / \mathrm{L}$ of raw milk, 14 to $17.5 € / \mathrm{L}$ of pasteurized milk, and 27.5 to $36 € / 100 \mathrm{~g}$ of powdered milk, either spray dried or lyophilized [23,24]. Equine milk is also used in the non-food sector, as an ingredient in cosmetic products [25]. Data on the worldwide production of equine milk are not available, but equine milk has been reported to be consumed by 30 million people [26]. It should also be considered that consumer cognizance of equine milk and derivatives is so far limited, as well as common awareness of its local availability [18,27]. Besides communication gaps to be overcome, the emerging niche market of equine milk raises questions on appropriate management strategies of dam and foals, as mainly related to animal nutrition as well as environmental issues, besides food security and animal welfare.

\subsection{Equine Milk Compositional and Nutritional Features}

Table 1 summarizes the average horse and donkey milk gross composition and energy content from the recent literature. Values from human and cow milk are given for comparison. It should be considered that equine milk components are mainly affected by nutrition, length of lactation, and health status of the mammary gland, besides genetics. Equine milk has a high water content and shows a lower fat content than human and cow milk (Table 1). The milk fat globules diameter, likely related to lipid digestibility, is reported to be lower than in human and bovine milk [28].

Horse and donkey milk are closer to human milk in terms of both protein and lactose content than cow milk (Table 1). On this regard, it is worth noting that, although about $50 \%$ of the world population is lactose intolerant, the daily intake of $14 \mathrm{~g}$ of lactose is usually well-tolerated [28]. Moreover, the content of lactose is lower in fermented milk. From a nutritional point of view, it is also important to highlight the hypocaloric content (Table 1) that makes equine milk an inadequate food for infants, when not supplemented with vegetal oil (about $40 \mathrm{~g} \mathrm{~L}^{-1}$ ) [28]. 
Table 1. Average milk gross composition and energy content from different species ${ }^{1}$.

\begin{tabular}{ccccc}
\hline Item & Horse & Donkey & Human & Cow \\
\hline Total solids, $\mathrm{g} \mathrm{kg}^{-1}$ & 103.1 & 95.3 & 125 & 127 \\
Fat, $\mathrm{g} \mathrm{kg}^{-1}$ & 10.3 & 7 & 35 & 41 \\
Protein, $\mathrm{g} \mathrm{kg}^{-1}$ & 16.8 & 16 & 12 & 34 \\
${\text { Lactose, } \mathrm{g} \mathrm{kg}^{-1}}_{\text {Ash, g kg }}^{-1}$ & 63 & 66 & 64 & 48 \\
Gross energy, MJ kg & 4.2 & 4.1 & 1.9 & 7 \\
\hline
\end{tabular}

${ }^{1}$ Sources: [15,26,28-31].

The ash content of equine milk (Table 1), which is intermediate between human and cow milk, shows a decline throughout the lactation consistent with Ca and P concentrations in milk $[15,20]$. Although the absolute values of $\mathrm{Ca}$ and $\mathrm{P}$ in equine milk are reported variable, and in average higher than in human milk, the Ca:P ratio is reported to be in average 1.3 and 1.72, respectively, for donkey and horse milk, while it accounts for 1.7 and 1.23 in human and bovine milk, respectively [31-33]. As a further dietary consideration, the mineral content of milk is not reported to be influenced by the maternal diet in mammalians, except for Se and I [34,35].

Pieszka et al. [36] reviewed the level of fat-soluble vitamins (A, D, E) in mare milk and found them consistent with values reported for bovine milk. Donkey milk is reported to contain a higher level of vitamin D [37] but it displays very low contents of vitamins A and E, as probably related to the low-fat content [28]. Among the water-soluble vitamins, pyridoxine, pantothenic acid, cobalamin, and vitamin $C$ have so far been detected at high levels only in mare milk $[28,36]$.

After the first clinical evidences on the successful use of equine milk in children with multiple food allergies, reported in 1992 and 2000, respectively, for donkey and horse milk [38,39], donkey milk has mainly been the subject of numerous studies about its use in the diets of children affected by cow's milk protein allergy, thanks to its high palatability, due to the high lactose content, and low allergenicity, related to the nitrogenous components [28,40]. Equine milk with high hygiene characteristics, and properly supplemented from a nutritional point of view, has been confirmed as a promising alternative in the dietary treatment of children affected not only by Immunoglobulin E-mediated cow's milk protein allergy, but also by food protein-induced enterocolitis, occurring in the first six months of life $[40,41]$. However, findings on the efficacy of equine milk use in the fulfilment of nutrient requirements of children cannot be so far considered conclusive, as they need to be confirmed by larger studies [27]. For these reasons, the use of donkey milk is nowadays considered an ingredient in a solid-food diet, or after the first year of life for children [42].

In regards to the allergenicity of equine milk, the proteomic profile of equine milk has been extensively studied in recent years [43,44], and microheterogeneity is displayed due to genetic variants and post-translational modification [28]. A significant effect of the breed and stage of lactation on gene expression and milk composition, and the association among genetic polymorphisms, gene expression, and milk protein and fat contents have also been observed in mare milk [45-47]. This leads to the relevant role of the dairy equine enterprise in the survival of equine breeds, e.g., Lipizzan, Icelandic, German Warmblood, Akhal-Teke, Franches-Montagnes, Comtois, Italian Heavy Draught, Russian Heavy Draft, and Polish Coldblood among horses; and Poitou, Zamarano Leonés, Burro de Miranda, Ragusano, and Amiata among donkeys, and in the preservation of environment, landscape, and vegetal diversity of areas where they are adapted to live [2,24].

\subsection{Functional and Bioactive Compounds}

Milk, besides allergens, is a source of many bioactive and functional compounds, i.e. metabolites, enzymes, hormones, trophic, and protective factors that are involved in proper growth and nutrition in newborns [48], or in proper secretion of the mammary gland [49]. 
Among the bioactive and functional proteins detected in milk, there are enzymes active in protection against protozoa, bacteria, and viruses, e.g., lysozyme and lactoferrin [48]. Lysozyme accounts for $10.5 \%$ and $21 \%$ of whey proteins, respectively, in horse and donkey milk, but only $5.5 \%$ of whey protein in human milk; on the contrary, a higher level of lactoferrin ( $26.6 \%$ of whey protein) is detected. Lactoferrin in horse and donkey milk accounts, on average, for only $7 \%$ and $4.48 \%$ of whey protein, respectively $[11,50,51]$. Lysozyme activity was found unaffected by thermal treatment at $72{ }^{\circ} \mathrm{C}$ up to $3 \mathrm{~min}[52,53]$.

Other enzymes in milk are of technological relevance, such as alkaline phosphatase representing an index of pasteurization efficiency, with activity reported to be about $100 \mathrm{mU} \mathrm{L}^{-1}$ in thermal treated equine milk [22].

In mammalian milk, hormones and growth factors have also been detected and classified as bioactive peptides [54] derived from the maternal metabolism. Among them, there are leptin, insulin, ghrelin, Insulin-like growth factor 1 (IGF-1), and thyroid hormones that are involved in the central regulation of food intake and in the maintenance of energy balance. Their role in milk may be related to the regulation of growth, to the development and maturation of the neonatal gut, and of the immune and neuroendocrine system of the newborn [48]. Considering the species-specificity of many proteins, it is worth noting that leptin has been measured as human equivalent in both horse and donkey milk, and human-like ghrelin, IGF-1, and triiodothyronine (T3) were measured in donkey milk $[15,20]$. It is worth noting that the milk T3 content was affected by the diet in lactating donkeys [55]. The role of variations in the maternal hormone status of equids, as related to both physiological status, and how intensive husbandry strategies might interact with their adaptive capacities in the farming environment, deserves attention and needs to be further considered.

Bioactive peptides are also encrypted in the sequence of milk proteins and are released from them following enzymatic proteolysis, under gastrointestinal digestion or during fermentation. These dietary components exert health promoting, i.e., antimicrobial, antihypertensive, antioxidant, antithrombotic, immunomodulatory, antiproliferative, and opioid activities in the organism, beyond their nutritive value [56-59]. It should be noted, however, that technological treatments carried out to prolong milk shelf life could considerably affect structure, as well as the functional and nutritive properties of milk components, especially peptides and proteins, that might lead to a greater susceptibility to infection and/or the development of allergies [60].

In immunonutrition, the antioxidant properties of nutrients, such as alpha-tocopherol and beta-carotene are known, but increasing scientific evidence suggests the role of dietary lipids in the regulation of neonatal immune function and in the severity of symptoms of allergies [61]. Recent studies show the interesting free fatty acids profile of equine milk, with saturated fatty acids content $(50 \%)$ lower than that reported for goat and sheep milk, and a higher proportion of monounsaturated fatty acids and polyunsaturated fatty acids (PUFA) than ruminant milk [28]. A balanced ratio between n3PUFA and n6PUFA, respectively considered anti-inflammatory and pro-inflammatory nutrients, is reported for horse and donkey milk [62]. Moreover, in regards to the variability of the lipid fraction, Martini et al. [63] observed an increased content of oleic, palmitoleic, and vaccenic acids considered with a positive effect on human health, and a lowered concentration of stearic acid in donkey milk samples collected in the winter.

The atherogenic and thrombogenic indices, calculated on fatty acid composition, candidate equine milk as an interesting food for people with allergic and inflammatory conditions [28,64]. Moreover, the fatty acids profile detected after in vitro digestion shows significant differences depending on the milk sources, with a prevalence of saturated fatty acids released from both human and donkey milk [65]. Heat damages have been observed in donkey's milk on functional lipid compounds, which may also directly and indirectly influence gut environment and immunoinflammatory functions $[66,67]$.

The recent advances of knowledge on the claimed nutraceutical properties, here summarized, suggest that, when scientifically demonstrated, the added value of the equine milk should be properly exploited in the dairy equine enterprise. 


\section{Dairy Equine Management and Nutrition}

\subsection{Equine Milk Yield and Management of the Dairy Equine Enterprise}

The core of the dairy equine enterprise is related to the management of dams and foals, and of the milking practice, showing important differences from the conventional dairy species. Firstly, dams and foals live together until weaning, which occurs at 7 months (for foals) or later; dams won't start to be milked before $20 \mathrm{~d}$ from foaling [10,68]. Secondly, since the equine mammary gland is characterized by small volume, and milk is mainly alveolar [69], milk harvesting can be carried out many times per day. In the Steppes of Central Asia, mares are milked 4-5 times per day [70], while in more intensive dairy farms located in Europe, mares and jennies are frequently milked depending on consumer demand, up to eight times a day [10,62,71]. Milking is carried out at least 2 hours after foal separation from the mother [70,72]. This distinctive trait of the dairy equine enterprise introduced the neologism "milking session", i.e., the interval from foal separation up to the end of each milking [62]. It must be noted that milk ejection is not reported to be affected by the presence of the foal during milking in the dairy donkey farm [68], while it is recommended in the dairy horse farm for a complete oxytocin release [10]. In this regard, the selection for milkability of mares would greatly improve the milking routine, reducing the labor costs [73].

Milk harvested per milking session is reported to range within 500-2000 mL and 200-900 mL for mares and jennies, respectively [62,70,74-77], regardless of the milking technique used (mechanical or manual).

The available literature data on daily equine milk yield have been obtained under different methodological approaches, which partially explains the high variability of values reported in Table 2. The daily milk production is estimated to be $15-35 \mathrm{~g} \mathrm{~kg}^{-1}$ bodyweight $[10,29,78,79]$. However, literature data are inconclusive, as the value recently estimated for the dairy donkey, i.e., $12 \mathrm{~g}$ milk $\mathrm{kg}^{-1}$ body weight, shows [80]. Todini et al. [81] reported an average milk yield per milking of $2.68 \mathrm{~mL}$ $\mathrm{kg}^{-1}$ bodyweight.

Table 2. Daily milk yield ( $\mathrm{kg} / \mathrm{d})$ reported in literature for horse and donkey from d30 to d180 of lactation ${ }^{1}$.

\begin{tabular}{ccc}
\hline Item & Horse & Donkey \\
\cline { 2 - 3 } Mean value & 11.66 & 2.68 \\
s.d. $^{2}$ & 5.3 & 1.96 \\
Min & 3.9 & 0.72 \\
Max & 17.2 & 6 \\
\hline 1 Sources: Horse: $[15,80,82,83]$, Donkey: $[23,25,30,31,72,76-80,84] ;{ }^{2}$ standard deviation.
\end{tabular}

Milk yield is affected by many factors, including the farming system, nutrition and feeding, strategy and type of milking (manual or mechanical), individual milkability, stage of lactation, and size and body condition of animals, besides genetics [11]. Because of the lack of standardized methodologies in equine milking studies, the effect of the breed on dairy performances of mares and jennies is not currently defined. According to Doreau and Martin Rosset [10], any breed can be milked, provided the animals accept the milking procedure.

The farming system is a major cause of the observed variability in equine milk production, as reported for pastoralist areas of the Steppes of Central Asia [70,85], or for more intensive systems, described for both koumiss and dairy donkey farms. In the latter, shelters are available on pasture, and milking is usually carried out in dedicated areas or facilities [72,83]. Donkeys raised under temperate conditions are reported to need more protection in rainy and windy weather than horses, as the results of the adaptation of donkeys to semi-arid environments of Africa vs. continental climate, and Eurasian Steppe environments where horses evolved [86]. The grazed area must be close to the milking 
site $[70,79]$ so that the proximity of pasture represents a constraint in the dairy equine enterprise and management of milking influences the feeding strategy.

In intensive farming systems, the dairy mare and jenny are milked in ad hoc facilities equipped with sheep milking machines adapted to the equine mammary characteristics $[15,68]$. With trained animals and skilled operators, no difference was observed in the amount of milk harvested manually or mechanically per milking session, but milk microbial contamination can be reduced by the proper use of milking machine. This introduces a crucial aspect of the equine milk production and its commercialization, related to consumer safety.

\subsection{Equine Milk: Hygiene and Health Issues}

In Europe, equine milk is mainly commercialized at farm or by means of vending machines (raw milk), but it is also available at shops and supermarkets (pasteurized milk) or online (pasteurized and powdered milk) $[22,71,87,88]$.

The risk associated with equine milk consumption is considered reasonably low when compared to bovine milk. The presence of pathogens, such as Escherichia coli O157, Salmonella spp., Campylobacter spp., Yersinia enterocolitica, Brucella spp., Mycobacterium spp., Bacillus cereus, Cronobacter sakazakii, Streptococcus equi subsp. zooepidemicus, Rhodococcus equi, Streptococcus dysgalactiae subsp. equisimilis, Clostridium difficile, and Burkholderia mallei is reported to be low [87]. However, the variable level of microbial contamination of equine raw milk, ranging from 3.0 to $5.87 \log$ CFU mL $\mathrm{milk}^{-1}$, warns against ineffective sanitization of equipment and facilities, as well as packaging and storing conditions of milk, even after thermal treatments $[22,29,87]$.

For these reasons, while alternative processing for equine milk sanitation and shelf life extension are studied [22], thermal treatment is always recommended before consumption [87].

In regards to the mammary gland health status, the somatic cell count is reported to be below 50,000 cells $\mathrm{mL}^{-1}$ milk and mastitis is rarely observed in the dairy equine farm $[29,87,89]$. However, injuries or improper milking procedures reported for more intensive farming systems can affect the mammary health status [31,87].

Equine milk is gaining interest as an alternative food for sensitive consumers, so that high hygiene standards represents an important issue in the dairy equine enterprise, and it affects the labor costs for cleanliness of facilities, and areas frequented by the animals.

\subsection{Feeding the Dairy Equine and Pasture Management}

The nutritive value and the potential health-promoting properties of equine milk are related to the horse and donkey's metabolic utilization of the diet. These monogastric species and hindgut fermenter herbivores are reported to be better utilizers of metabolizable dietary energy than ruminants, at high levels of cell wall [90]. It is also well known that the dietary influence on milk composition is more direct in the equine species than in ruminants [10,90]. Regardless of the farming system, as already mentioned, the common denominator in the diet is the presence of forages and pasture, whose management is crucial for dairy equine production and welfare [71,72,74,91,92]. Because of the evolutionary history of the two equine species, their different feeding behavior and metabolism should also be considered in relation to nutrient requirements, management of feeding, and their impact on land preservation.

\subsubsection{Feeding the Dairy Horse}

According to Doreau and Martin-Rosset [10], no different approaches are required in feeding the dairy or nursing horse, as far as the energy and nitrogen requirements are concerned. The nutritional requirements of the lactating mare (600 kg body weight) are summarized in Table 3 [93]. To sustain the milk production, forages account on average for 50 to 80 percent of the dry matter of the diet, and they can supply 40 to 70 percent of the mare's annual nutritional requirements $[5,94]$. The dry matter intake of mares (Table 3) depends on the quality of the diet at foaling [93]. At the onset of lactation, the 
voluntary intake of mares is reported to be high (20-30 g dry matter per kg body weight). However, the dry matter intake is scarcely a limiting factor for the mare to meet nutritional requirements [93].

Table 3. Recommended nutrient requirements and intake for lactating mares (600 kg body weight) [93].

\begin{tabular}{|c|c|c|c|c|}
\hline $\begin{array}{l}\text { Lactation, } \\
\text { Month }\end{array}$ & $\begin{array}{l}\text { Milk Yield, } \\
\mathrm{kg} \mathrm{d}^{-1}\end{array}$ & $\begin{array}{l}\text { Horse Feed Units *, } \\
\qquad \mathrm{nd}^{-1}\end{array}$ & $\begin{array}{l}\text { Horse Digestible Crude } \\
\text { Protein }{ }^{* *}, \mathrm{~g} \mathrm{~d}^{-1}\end{array}$ & $\begin{array}{c}\text { Dry Matter Intake, } \\
\mathrm{kg} \mathrm{d}^{-1}\end{array}$ \\
\hline $1 s t$ & 18 & 10.1 & 1131 & $13.5-18.0$ \\
\hline 2 nd & 19.8 & 10.3 & 1091 & $15.0-19.0$ \\
\hline $3 \mathrm{rd}$ & 19.2 & 9.6 & 1030 & $15.0-19.0$ \\
\hline 4th & 17.4 & 9.1 & 844 & $13.5-18.0$ \\
\hline 5 th & 13.2 & 7.9 & 629 & $12.5-15.0$ \\
\hline 6th & 12 & 7.6 & 603 & $10.5-13.0$ \\
\hline
\end{tabular}

The diet composition varies according to quality and availability of pasture and forages. In case of good grassland conditions, dairy mare foals generally in spring, just before they turn out, and use natural or sown pasture during the grazing season [95]. They are generally dried up in autumn (early October), after 190-210 days of lactation. During winter (110-120 days), the mares are fed a limited amount of hay of medium quality (organic matter digestibility, OMD $=50-55 \%$ ) [93], and cereals, or a mixed diet based on straw, ad libitum, and hay of good quality (OMD = 55-60\%). In case of harsh conditions, mare foals generally in early spring, one month before turning out. They graze pastures of uplands. They are dried off in autumn (late October), and grazed resources meet the requirements of animals over 9 months of lactation. In case of low productive areas, mares graze for about $60-70 \%$ of the total grazing season. In late autumn and early winter, mares graze refusals of cattle and sheep in the lowlands [93].

In the dairy horse enterprise, the strategy of the feeding system is based on pasture availability throughout the year and consists, generally, in matching the highest requirements of the animals with the maximum biomass production [96]. It must also include provisions of preserved feedstuffs to be used in case of particularly adverse climatic conditions. The main aim of the feeding strategy, notwithstanding the horse breed, is that dairy mares gain body weight in early lactation to nurse adequately the foal and to be rebred as soon as possible, to achieve a 12-month interval between two subsequent foalings [94]. Foals live with their mothers at pasture and they are allowed to nurse when mares are not milked. Table 4 shows the nutrient requirements of foals ( $600 \mathrm{~kg}$ of adult body weight) performing an optimal or moderate growth rate.

Table 4. Recommended nutrient requirements and intake for foals (600 kg adult body weight) at 3-6 months of age with a growth rate optimal or moderate [93].

\begin{tabular}{|c|c|c|c|c|}
\hline $\begin{array}{c}\text { Body Weight, } \\
\text { kg }\end{array}$ & Gain, $\mathrm{g} \mathrm{d}^{-1}$ & $\begin{array}{l}\text { Horse Feed Units *, } \\
\qquad \mathrm{n} \mathrm{d}^{-1}\end{array}$ & $\begin{array}{l}\text { Horse Digestible Crude } \\
\text { Protein }{ }^{* *}, \mathrm{~g} \mathrm{~d}^{-1}\end{array}$ & $\begin{array}{l}\text { Dry Matter Intake, } \\
\qquad \mathrm{kg} \mathrm{d}^{-1}\end{array}$ \\
\hline 249 & $1000-1200$ & 6 & 647 & $6.0-8.0$ \\
\hline 207 & $800-900$ & 4.8 & 497 & $5.5-7.5$ \\
\hline
\end{tabular}

Mares should be managed at pasture with the aim to recover body weight and a proper body condition at drying off in late summer or fall, to ensure good nutritional conditions in pregnancy during winter [93]. Mares increase their body weight (+6-8\%) during the last three months of pregnancy, as they are usually fed from $100 \%$ to $120 \%$ of their energy requirements, and during the first month after foaling $(+3 \%)$ when they turn out in spring [93]. 
In extensive farming systems, grazing dairy mares should meet $80 \%$ of the total requirements over the 7-month lactation period. The animals use the vegetation regrowth from September until December. As already mentioned, in more intensive farming systems, hays or maize silage (30-35\% dry matter content, $0.80-0.84$ Horse Feed Unit per kg dry matter) and low concentrate supplementation are offered during winter.

\subsubsection{Feeding the Dairy Donkey}

Nutrient requirements and suggested allowances, nowadays available specifically for donkeys, are mainly devoted to working animals, i.e., used for transportation, small agricultural works, and equine therapy, and to animals at maintenance, i.e., companion animals, often castrated, hosted in international animal rescue charities, e.g., Donkey Sanctuary $[72,79,97,98]$. The available nutrient requirements of the dairy donkey are either based on results from one study on foal growth, or they are derived from domestic horse data, whose behavior and physiology are known to differ from those of the donkey. Consequently, they cannot be considered conclusive and need further investigation $[20,72,79,98,99]$. As reported by the US Research Council on equids, donkeys maximize their dry matter intake when good quality hay is offered [100]. For donkeys at maintenance, Raspa et al. [79] report a maximum dry matter intake per $\mathrm{kg}$ of body weight, declining from $32 \mathrm{to} 12 \mathrm{~g}$, with ad libitum diets based on either legume forages or barley straw. In order to prevent nutritional diseases, e.g., hyperlipemia and obesity, a diet high in fiber is suggested for companion donkeys at maintenance [99].

Because the mentioned lack of information in the specific literature on protein and energy requirements of lactating donkeys $[20,72,79,98]$, the common strategy is represented by ad libitum administration of forage-based diets associated to a monthly evaluation of the body condition score $[31,79]$.

In the dairy equine farming system, pasture should be always available for its positive effect on animal welfare and milk quality [79]; however, when jennies are milked, grazing time and quantiqualitative availability of grazed areas are limited, as also observed for dairy mares [70]. According to preliminary results on the grazing behavior of Miranda breed jennies in mountain pastures, Couto et al. [101] observed that the activities in searching and prehension lasted, on average, 16 hours per day with a preferential intake of herbaceous species. However, up to $30 \%$ of the intake was represented by shrubs, probably because of a low grass availability. This suggests the interesting role of these autochthonous donkeys in preserving the pasture areas from degradation and fire risks [101]. It is also worth considering that grazing time does not significantly affect the daily dry matter intake of donkeys at maintenance, when they also have free access to preserved forages [102].

Results of a survey carried out on 12 dairy donkey farms in Italy confirm the inclusion of pasture in the lactating donkey diets always associated to hay administration [72], likely due to the limited availability of pasture. Cereals and/or mixed feeds, commercial or not, are also administered to lactating donkeys, and diets are frequently salt supplemented [31,72].

Other data from on field studies about milk production report a high feed intake (30-32 g dry matter per kg body weight) of dairy jennies at the first 3-4 months of lactation. Moreover, diets are characterized on average (on a dry matter basis) by a 70:30 forage-to-concentrate ratio, a protein content of 10-13 g per $100 \mathrm{~g}$, and a digestible energy value of 8.5-10.0 MJ per kg [20].

After digestion, dietary fats, soluble carbohydrates, and proteins are mainly absorbed by the small intestine of equids. Due to the negligible biohydrogenation before absorption, the direct influence of the diet on the fatty acid composition of milk is expected. In this regard, the supplementation of the mares' diet in late pregnancy, and early lactation with eicosapentaenoic acid (EPA) and/or docosahexaenoic acid (DHA) did not affect the linoleic and linolenic milk content, but it increased the arachidonic acid, EPA, and DHA milk concentrations [103]. However, in jennies, the transfer of n3 polyunsaturated fatty acids (PUFAs) from blood to milk is reported to be more efficient than that of $\mathrm{n} 6$ PUFAs [20]. For a nutritionally correct ratio of n3:n6 PUFA in equine milk, dietary lipid sources should be evaluated with regard to the fatty acid profile. Dietary factors can also influence the palatability 
of donkey milk. 'Green' aromatic notes and related compounds have been identified in milk when jennies were fed fresh forage [20].

The survey by Dai et al. [72] reported that the diet always includes hay (100\% of farms) and pasture (about $92 \%$ farms) in non-lactating jennies. Concentrates and salt supplements are also administered, but in a lower percentage than during lactation [72]. Stallions, which are either grouped with females or housed individually, are mainly fed hay supplemented with mixed feeds, cereals, and salt or additives. Pasture availability is reported for about $70 \%$ of farms [72].

Nutrient requirements for foals are not defined and only rare data are available on growing rates in donkeys [104]. The administration of milk replacement formulas to foals is not common in the dairy donkey farm [72]. However, a highly digestible creep feed is usually distributed to nursing foals until one month of age, when dams are not milked [20]. Later, complementary feeds are administered to foals until weaning (7-12 months of age) [72]. Constant access to clean water and salt blocks is highly recommended for both foals and dams [20].

The welfare status of the animals needs to be constantly monitored by recommended indicators, such as body condition score, and hydration score [105]. Vaccinations and deworming are also recommended in all animals, along with regular hoof, dental, and health care treatments [105], even if they are not reported to be common practices in dairy donkey farms [72].

\subsection{Pasture in the Dairy Equine Enterprise}

Different systems of grazing management are possible: extensive vs. semi-extensive, associated or not with ruminants [106]. Depending on the grazing species and their nutrient requirements, the correspondence between animals and characteristics of the forage availability (in quality and quantity) is crucial for a sustainable use of the landscape [107]. As herbivore species, horses and donkeys have the ability to exploit large amounts of fibrous forages, often of low nutritive value in less favored areas, available for grazing and/or foraging. The ability of the equids to produce in high forage feeding systems is mainly explained by their distinctive features in selecting, consuming, and digesting forages and grazed resources [102], so that seasonal variations in grazing behavior and diet selection have been observed in mares [108]. In particular, equids show several adaptive abilities in harsh conditions when the total nutrient requirements can be achieved on a long-term period [102].

In free-ranging conditions, horses spend up to $70 \%$ of their time to consume available food resources and only $30 \%$ for other activities. This ingestive activity is usually distributed over several meals during the day and grazing also occurs during the night $[70,109]$. Moreover, grazing time can increase in autumn and in winter, and the length of grazing is in relation to the cell wall content of the sward [110].

In high forage systems, pasture is the major source of nutrients for dams and foals along the breeding cycle. Based on the type and composition of the grazing species, as well as on the carrying capacity of the pasture, the sustainable grazing period ranges from 100 to 130 days (Northern Europe), to 230 days (Central Europe) [5]. Especially in marginal areas, the most relevant management of horses and donkeys at pasture implies the evaluation of the nutritive value of forages available for the optimal animal response to match economic profits, technical feasibility, and ecological sustainability [107].

Pasture productivity varies according to the geographical zone and the climatic conditions. In Europe, the grazing period is usually limited in Northern countries by short summers. In countries of Central Europe, generally characterized by extensive grazing lands and high quality forages, long grazing periods are observed, while the grass growth is usually depressed by summer dryness in Southern Europe [5]. Table 5 shows the average chemical composition of pasture in selected areas of Europe. 
Table 5. Chemical components and estimated energy content of pasture in European areas. Values expressed on a dry matter basis [5,111].

\begin{tabular}{cccc}
\hline Country & Crude Protein, $\mathbf{~ g ~ k g}$ & Crude Fiber, $\mathbf{~} \mathbf{~ k g}$ & Horse Feed Units \\
* & $\mathbf{~} \mathbf{~ k g}^{-\mathbf{1}}$ \\
\hline Finland & $200-230$ & $180-200$ & $0.69-0.73$ \\
France, lowlands & $131-168$ & $244-276$ & $0.76-0.82$ \\
France, uplands & $111-166$ & $223-304$ & $0.66-0.92$ \\
Italy, lowlands & $85-159$ & $242-325$ & $0.67-0.90$ \\
Italy, uplands & $117-155$ & $285-345$ & $0.63-0.85$ \\
\hline
\end{tabular}

${ }^{*}$ Horse Feed Units (UFC) $=9.42$ MJ Net Energy.

In addition, it should be noted that climate changes may affect the forage population dynamics, its nutritive value, as well as the growing and grazing seasons, so that different approaches in the management of land, animals, and forage resources may be required [112]. The forage intake depends on the quality of plant resources and their ingestibility, the time of grazing, the grazing activity, and the stocking rate, especially in multispecies herding situations. On this purpose, practical and flexible models have been studied for the assessment of a grazing pressure compatible with the conservation of pasture in less favored areas [113]. Moreover, the adoption of appropriate strategies is also recommended, such as rotational grazing, control of infesting species, safeguard from parasites diffusion in the sward, and fertilization $\left(180 \mathrm{~kg} \mathrm{~N} \mathrm{ha}^{-1}\right)[107,108,114]$.

In extensive systems, characterized by low quality and poor productivity of natural pastures, the total requirements can be met using low grazing intensity, with a stocking rate of 0.3-0.7 animal $\mathrm{ha}^{-1}$, depending on the grass availability $[106,114]$. In more intensive systems of Central Europe, a concentrate supplementation is offered to horses, depending on their activity. Grass is plentiful until the beginning of July (beginning of the third vegetation cycle), then the production declines from mid-July to the end of August [94]. In Mediterranean regions, depending on the geographical area, the grazing season starts between April and May. A considerable reduction of the grass production is observed, depending on the variable rainfall in July, August, and early September. Then, up to the end of October, a regrowth of the grass can occur, offering the availability of fresh forages to foals in the weaning period [5].

The average growth of pasture grass during the grazing period in Italy is shown in Figures 1 and 2, respectively, for Central and Southern Italy pastures. It is interesting to note that in the pasture area located in Southern Italy, and in a mixed grazing system, including cattle, sheep goat, and horse, the sustainable stocking rate simulated in two subsequent years varied from 1.14 to 1.35 Adult Bovine Unit ha ${ }^{-1}$, due to different climatic conditions and carrying capacities of the pasture [107].

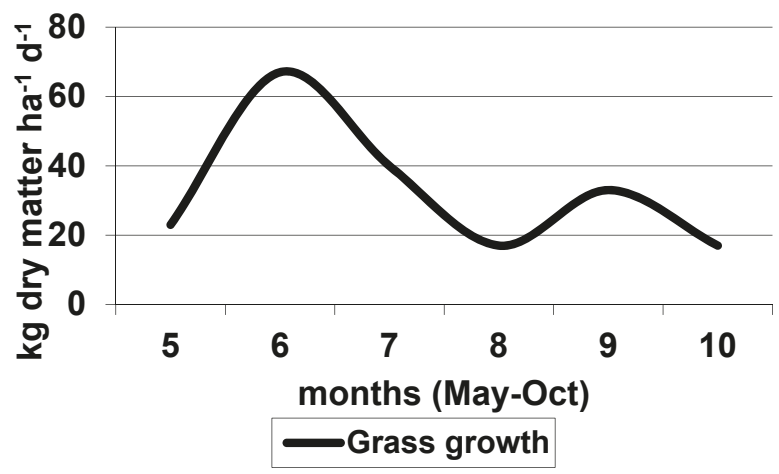

Figure 1. The average growth of pasture grass in Central Italy during the grazing period (modified from [94]). 


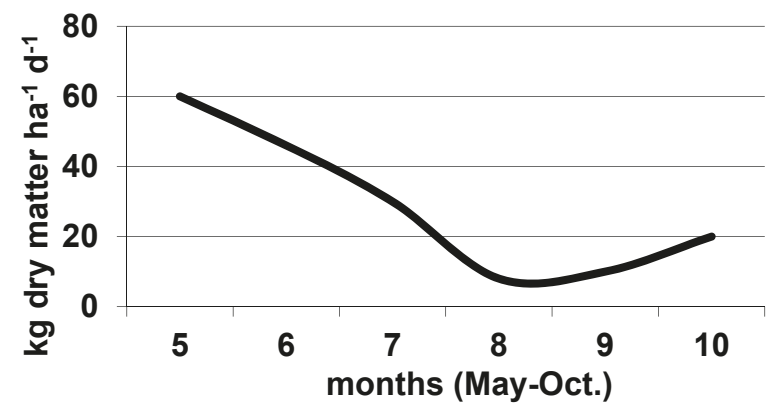

\section{Grass growth}

Figure 2. The average growth of pasture grass in Southern Italy (modified from [94]).

In order to achieve biodiversity and production goals in sustainable grazing systems of less favored areas, further management strategies include the reduction of the stocking rate, the periodic exclusion of the more degraded areas from grazing, the administration of complementary hay and concentrates, as well as the use of autochthonous breeds [115,116].

As a final consideration, the dairy equine enterprise, here described in its essential and promising traits, is the result of different environmental conditions, management strategies, and socio-economical aspects. Furthermore, no data on the evaluation of the economic impact of the dairy equine milk production are available in literature. However, besides labor, feeding, housing, and milking facilities, the evaluation of costs should also include those related to availability of infrastructures on pastures and marginal areas, and social costs of labor and bureaucracy, whose incidence can be relevant and different among countries [92]. Moreover, among the immaterial benefits, the impact of the dairy equine enterprise to environmental issues, such as landscape safeguard and biodiversity preservation, should also be included in a costs-to-benefits ratio evaluation [117], as also reported for horses used for tourism and work [3]. Alternatively, a price premium, based on environmental standards and labels, should be recognized to the products of the dairy equine enterprise.

\section{Conclusions}

The dairy enterprise involving equids, here discussed in its essential traits, represents a promising activity for the micro-economies of marginal areas around the world, because of its potentialities in human nutrition, biodiversity, and landscape preservation. Notwithstanding the advances of knowledge on milk nutritional and safety characteristics, as well as the improvement of technical skills in milk management, in depth studies are still required, especially in terms of animal nutrition and feeding. A better understanding on nutrient requirements of the dairy equid at pasture in heterogeneous and marginal areas will boost the interest toward endangered equine breeds, their milk, and their habitat. Positive relapses would in fact include the protection of plant diversity in the achievement of a productive and sustainable use of the landscape. Among the innovations for sustainable agriculture, the production of equine milk and derivatives with high nutritional value and health promoting properties should be therefore considered a promising extension of the equine industry for the modern and future society.

Author Contributions: Conceptualization, N.M., E.S. and F.F.; methodology, E.S., N.M. and F.F.; writing-original draft preparation, E.S., F.F. and N.M.; writing - review and editing, E.S. and F.F.; supervision, E.S., F.F. and N.M. All authors have read and agreed to the published version of the manuscript.

Funding: This research received no external funding.

Conflicts of Interest: The authors declare no conflict of interest. 


\section{References}

1. Martin-Rosset, W. Research, development and transfer in Equine Science. In EAAP Leroy Fellowship Award, Barcelona, Spain, 24-27 August 2009; Wageningen Academic Publishers: Wageningen, The Netherlands, 2009.

2. Miraglia, N. Sustainable development and equids in rural areas: An open challenge for the territory cohesion. In EAAP Scientific Series; Vial, C., Evans, R., Eds.; Wageningen Academic Publishers: Wageningen, The Netherlands, 2015; Volume 136, pp. 167-176. ISBN 978-90-8686-279-5.

3. Rzekec, A.; Vial, C.; Bigot, G. Green assets of equines in the european context of the ecological transition of agriculture. Animals 2020, 10, 106. [CrossRef] [PubMed]

4. Salimei, E.; Fantuz, F.; Coppola, R.; Chiofalo, B.; Polidori, P.; Varisco, G. Composition and characteristics of ass's milk. Anim. Res. 2004, 53, 67-78. [CrossRef]

5. Miraglia, N.; Saastamoinen, M.; Martin-Rosset, W. Role of pastures in mares and foals management in Europe. In Nutrition and Feeding of the Broodmare; Miraglia, N., Martin-Rosset, W., Eds.; Academic Publishers: Wageningen, The Netherlands, 2006; Volume 120, pp. 279-297.

6. Fleurance, G.; Duncan, P.; Mallevaud, B. Daily intake and the selection of feeding sites by horses in heterogeneous wet grasslands. Anim. Res. 2001, 50, 149-156. [CrossRef]

7. Edouard, N.; Fleurance, G.; Martin-Rosset, W.; Duncan, P.; Dulphy, J.P.; Dubroeucq, H.; Grange, E.; Baumont, R.; Perez-Barberia, F.J.; Gordon, I.J. Voluntary intake and digestibility in horses: effect of forage quality with emphasis for individual variability. Animal 2008, 2, 1526-1533. [CrossRef]

8. Van der Zijpp, A.; Boyazoglu, J.; Renaud, J.; Hoste, C. Research Strategy for Animal Production in Europe in the 21st Century; Wageningen Press: Wageningen, The Netherlands, 1993; Volume 64, p. 163.

9. Yachi, S.; Loreau, M. Biodiversity and ecosystem productivity in a fluctuating environment: The insurance hypothesis. Proc. Natl. Acad. Sci. USA 1999, 96, 1463-1468. [CrossRef]

10. Doreau, M.; Martin-Rosset, W. Animals that produce dairy foods - horse. In Encyclopedia of Dairy Sciences, 2nd ed.; Fuquay, J.W., Fox, P.F., McSweeney, P.L.H., Eds.; Elsevier Academy Press: London, UK, 2011; Volume 1, pp. 358-364.

11. Salimei, E.; Fantuz, F. Horse and donkey milk. In Milk and Dairy Products in Human Nutrition: Production, Composition and Health; Park, Y.W., Haenlein, G.F.W., Eds.; John Wiley \& Sons Ltd: Oxford, UK, 2013; pp. 594-613.

12. McLean, A.K.; Navas Gonzalez, F.J. Can scientists influence donkey welfare? Historical perspective and a contemporary view. J. Equine Vet. Sci. 2018, 65, 25-32. [CrossRef]

13. Adams, F. The Genuine Works of Hippocrates; The Sydenham Society: London, UK, 1849; Volume 1.

14. Mustoxidi, A. Le Nove Muse di Erodoto Alicarnasseo, 2nd ed.; Sonzogno Publisher: Milan, Italy, 1822.

15. Salimei, E.; Park, Y.W. Mare milk. In Handbook of Milk of Non-Bovine Mammals, 2nd ed.; Park, Y.W., Haenlein, G.F.W., Wendorff, W.L., Eds.; John Wiley \& Sons Ltd.: Oxford, UK, 2017; pp. 369-408.

16. Langlois, B. The history, ethnology and social importance of mare's milk consumption in Central Asia. J. Life Sci. 2011, 5, 863-872.

17. Bimbetov, B.; Zhangabylov, A.; Aitbaeva, S.; Benberin, V.; Zollmann, H.; Musaev, A.; Rakhimzhanova, M.; Esnazarova, G.; Bakytzhanuly, A.; Malaeva, N. Mare's milk: Therapeutic and dietary properties. Bull. Natl. Acad. Sci. Rep. Kazakhstan 2019, 3, 52-58. [CrossRef]

18. Romaniuk, K.; Majszyk-Świątek, M.; Kryszak, K.; Danielewicz, A.; Andraszek, K. Alternative use of mare milk. Folia Pomer. Univ. Technol. Stetin. 2019, 348, 121-130. [CrossRef]

19. Li, L.; Liu, X.; Guo, H. The nutritional ingredients and antioxidant activity of donkey milk and donkey milk powder. Food Sci. Biotechnol. 2018, 27, 393-400. [CrossRef]

20. Salimei, E. Animals that Produce Dairy Foods: Donkey. In Reference Module in Food Sciences, 1st ed.; Elsevier Academic Press: London, UK, 2016; pp. 1-10.

21. Drogoul, C.; Prevost, H.; Maubois, J.L. Le lait de juments un produit. Une filiere a developer? In Quoi de Neuf en Matiere d'Etudes de Recherches sur le Cheval, 18eme Journee d'Etude, 4 Mars; CEREOPA: Paris, France, 1992; pp. 37-51.

22. Giacometti, F.; Bardasi, L.; Merialdi, G.; Morbarigazzi, M.; Federici, S.; Piva, S.; Serraino, A. Shelf life of donkey milk subjected to different treatment and storage conditions. J. Dairy Sci. 2016, 99, 4291-4299. [CrossRef] [PubMed] 
23. Bordonaro, S.; Dimauro, C.; Criscione, A.; Marletta, D.; Macciotta, N.P.P. The mathematical modeling of the lactation curve for dairy traits of the donkey (Equus asinus). J. Dairy Sci. 2013, 96, 4005-4014. [CrossRef] [PubMed]

24. Camillo, F.; Rota, A.; Biagini, L.; Tesi, M.; Fanelli, D.; Panzani, D. The current situation and trend of donkey industry in Europe. J. Equine Vet. Sci. 2018, 65, 44-49. [CrossRef]

25. Cosentino, C.; Paolino, R.; Musto, M.; Freschi, P. Innovative use of jenny milk from sustainable rearing. In The Sustainability of Agro-Food and Natural Resource Systems in the Mediterranean Basin; Vastola, A., Ed.; Springer International Publishing: Cham, Switzerland, 2015; pp. 113-132.

26. Uniacke-Lowe, T.; Fox, P.F. Milk, Equid milk. In Encyclopedia of Dairy Sciences, 2nd ed.; Fuquay, J.W., Fox, P.F., McSweeney, P.L.H., Eds.; Elsevier Academy Press: London, UK, 2011; Volume 3, pp. 518-529.

27. Mansueto, P.; Iacono, G.; Seidita, A.; D'Alcamo, A.; Iacono, S.; Carroccio, A. Ass's milk in allergy to cow's milk protein: A review. J. Food Allergy 2012, 1, 181-191.

28. Fantuz, F.; Salimei, E.; Papademas, P. Macro- and micronutrients in non-cow milk and products and their impact on human health. In Non-Bovine Milk and Milk Products, 1st ed.; Tsakalidou, E., Papadimitriou, K., Eds.; Elsevier Academic Press: London, UK, 2016; pp. 209-261.

29. Kaić, A.; Luštrek, B.; Simčič, M.; Potočnik, K. Milk quantity, composition and hygiene traits of routinely machine milked Lipizzan mares. Slov. Vet. Res. 2019, 56, 115-123.

30. Aroua, M.; Jemmali, B.; Said, S.B.; Kbaier, H.B.H.; Mahouachi, M. Physicochemical properties of north African donkey milk. Agric. Res. Tech. Open Access J. 2019, 21, 1-3.

31. Malacarne, M.; Criscione, A.; Franceschi, P.; Bordonaro, S.; Formaggioni, P.; Marletta, D.; Summer, A. New insights into chemical and mineral composition of donkey milk throughout nine months of lactation. Animals 2019, 9, 1161. [CrossRef]

32. Fantuz, F.; Maglieri, C.; Lebboroni, G.; Salimei, E. Ca, Mg, Zn, Fe, Cu and Mn content of ass's milk. It. J. Anim. Sci. 2009, 8, 703-705. [CrossRef]

33. Fantuz, F.; Ferraro, S.; Todini, L.; Piloni, R.; Mariani, P.; Salimei, E. Donkey milk concentration of Calcium, Phosphorus, Potassium, Sodium and Magnesium. Int. Dairy J. 2012, 24, 143-145. [CrossRef]

34. Fantuz, F.; Ferraro, S.; Todini, L.; Mariani, P.; Piloni, R.; Salimei, E. Essential trace elements in milk and blood serum of lactating donkeys as affected by lactation stage and dietary supplementation with trace elements. Animal 2013, 7, 1893-1899. [CrossRef]

35. Fantuz, F.; Ferraro, S.; Todini, L.; Piloni, R.; Mariani, P.; Malissiova, E.; Salimei, E. Minor and potentially toxic trace elements in milk and blood serum of dairy donkeys. J. Dairy Sci. 2015, 98, 5125-5132. [CrossRef] [PubMed]

36. Pieszka, M.; Luszczyński, J.; Zamachowska, M.; Augustyn, R.; Dlugosz, B.; Hędrzak, M. Is mare milk an appropriate food for people?-A review. Ann. Anim. Sci. 2016, 16, 33-51. [CrossRef]

37. Martini, M.; Altomonte, I.; Licitra, R.; Salari, F. Short communication: Technological and seasonal variations of vitamin D and other nutritional components in donkey milk. J. Dairy Sci. 2018, 101, 1-5. [CrossRef] [PubMed]

38. Iacono, G.; Carroccio, A.; Cavataio, F.; Montaldo, G.; Soresi, M.; Balsamo, V. Use of ass's milk in multiple food allergy. J. Ped. Gastroent. Nutr. 1992, 14, 177-181. [CrossRef]

39. Businco, L.; Giampietro, P.G.; Lucenti, P.; Lucaroni, F.; Pini, C.; Di Felice, G.; Iacovacci, P.; Curadi, C.; Orlandi, M. Allergenicity of mare's milk in children with cow's milk allergy. J. Allergy Clin. Immunol. 2000, 105, 1031-1034. [CrossRef]

40. Sarti, L.; Martini, M.; Brajon, G.; Barni, S.; Salari, F.; Altomonte, I.; Ragona, G.; Mori, F.; Pucci, N.; Muscas, G.; et al. Donkey's milk in the management of children with cow's milk protein allergy: nutritional and hygienic aspects. It. J. Ped. 2019, 45, 102-110. [CrossRef]

41. Restani, P.; Ballabio, C.; Di Lorenzo, C.; Tripodi, S.; Fiocchi, A. Molecular aspects of milk allergens and their role in clinical events. Anal. Bioanal. Chem. 2009, 395, 47-56. [CrossRef]

42. Giovannini, M.; D'Auria, E.; Caffarelli, C.; Verduci, E.; Barberi, S.; Indinnimeo, L.; Dello Iacono, I.; Martelli, A.; Riva, E.; Bernardini, R. Nutritional management and follow up of infants and children with food allergy: Italian Society of Pediatric Nutrition/Italian Society of Pediatric Allergy and Immunology Task Force Position Statement. It. J. Ped. 2014, 40,1-9. [CrossRef]

43. Uniacke-Lowe, T.; Huppertz, T.; Fox, P.F. Equine milk proteins: chemistry, structure and nutritional significance. Int. Dairy J. 2010, 20, 609-629. [CrossRef] 
44. Cunsolo, V.; Saletti, R.; Muccilli, V.; Gallina, S.; Di Francesco, A.; Foti, S. Proteins and bioactive peptides from donkey milk: the molecular basis for its reduced allergenic properties. Food Res. Int. 2017, 99, 41-57. [CrossRef]

45. Cieslak, J.; Wodas, L.; Borowska, A.; Sadoch, J.; Pawlak, P.; Puppel, K.; Kuczynska, B.; Mackowski, M. Variability of lysozyme and lactoferrin bioactive protein concentrations in equine milk in relation to LYZ and LTF gene polymorphisms and expression. J. Sci. Food Agric. 2017, 97, 2174-2181. [CrossRef] [PubMed]

46. Wodas, Ł.; Maćkowski, M.; Borowska, A.; Pawlak, P.; Puppel, K.; Kuczyńska, B.; Czyżak-Runowska, G.; Wójtowski, J.; Cieślak, J. 5'-flanking variants of the equine $\alpha$-lactalbumin (LALBA) gene-relationship with gene expression and mare's milk composition. J. Anim. Feed Sci. 2018, 27, 317-326. [CrossRef]

47. Cieslak, J.; Wodas, L.; Borowska, A.; Pawlak, P.; Czyzak-Runowska, G.; Wojtowski, J.; Puppel, K.; Kuczynska, B.; Mackowski, M. 5'-flanking variants of equine casein genes (CSN1S1, CSN1S2, CSN2,CSN3) and their relationship with gene expression and milk composition. J. Appl. Genet. 2019, 60, 71-78. [CrossRef] [PubMed]

48. Ballard, O.; Morrow, A.L. Human milk composition: nutrients and bioactive factors. Pediatr. Clin. N. Am. 2013, 60, 49-74. [CrossRef]

49. Bonnet, M.; Delavaud, C.; Laud, K.; Gourdou, I.; Leroux, C.; Djiane, J.; Chilliard, Y. Mammary leptin synthesis, milk leptin and their putative physiological roles. Reprod. Nutr. Dev. 2002, 42, 399-413. [CrossRef]

50. Inglingstad, R.A.; Devold, T.G.; Eriksen, E.K.; Holm, H.; Jacobsen, M.; Liland, K.H.; Rukke, E.O.; Vegarud, G.E. Comparison of the digestion of caseins and whey proteins in equine, bovine, caprine and human milk by human gastrointestinal enzymes. Dairy Sci. Technol. 2010, 90, 549-563. [CrossRef]

51. Tidona, F.; Criscione, A.; Devold, T.G.; Bordonaro, S.; Marletta, D.; Vegarud, G.E. Protein composition and micelle size of donkey milk with different protein patterns: Effects on digestibility. Int. Dairy J. 2014, 35, 57-62. [CrossRef]

52. Martini, M.; Salari, F.; Licitra, R.; La Motta, C.; Altomonte, I. Lysozyme activity in donkey milk. Int. Dairy J. 2019, 96, 98-101. [CrossRef]

53. Yvon, S.; Schwebel, L.; Belahcen, L.; Tormo, H.; Peter, M.; Haimoud-Lekhal, D.A.; Eutamene, H.; Jard, G. Effects of thermized donkey milk with lysozyme activity on altered gut barrier in mice exposed to water-avoidance stress. J. Dairy Sci. 2019, 102, 7697-7706. [CrossRef]

54. Claeys, W.L.; Verraes, C.; Cardoen, S.; De Block, J.; Huyghebaert, A.; Raes, K.; Dewettinck, K.; Herman, L. Consumption of raw or heated milk from different species: an evaluation of the nutritional and potential health benefits. Food Control 2014, 42, 188-201. [CrossRef]

55. Todini, L.; Salimei, E.; Malfatti, A.; Ferraro, S.; Fantuz, F. Thyroid hormones in milk and blood of lactating donkeys as affected by stage of lactation and dietary supplementation with trace elements. J. Dairy Res. 2012, 79, 232-237. [CrossRef] [PubMed]

56. Brumini, D.; Criscione, A.; Bordonaro, S.; Vegarud, G.E.; Marletta, D. Whey proteins and their antimicrobial properties in donkey milk: A brief review. Dairy Sci. Technol. 2016, 96, 1-14. [CrossRef]

57. Fotschki, J.; Szyc, A.M.; Laparra, J.M.; Markiewicz, L.H.; Wróblewska, B. Immune-modulating properties of horse milk administered to mice sensitized to cow milk. J. Dairy Sci. 2016, 99, 9395-9404. [CrossRef] [PubMed]

58. Kushugulova, A.; Kozhakhmetov, S.; Sattybayeva, R.; Nurgozhina, A.; Ziyat, A.; Yadav, H.; Marotta, F. Mare's milk as a prospective functional product. Funct. Food Health Dis. 2018, 8, 537-543. [CrossRef]

59. Aspri, M.; Leni, G.; Galaverna, G.; Papademas, P. Bioactive properties of fermented donkey milk, before and after in vitro simulated gastrointestinal digestion. Food Chem. 2018, 268, 476-484. [CrossRef]

60. Roth-Walter, F.; Berin, M.C.; Arnaboldi, P.; Escalante, C.R.; Dahan, S.; Rauch, J.; Jensen-Jarolim, E.; Mayer, L. Pasteurization of milk proteins promotes allergic sensitization by enhancing uptake through Peyer's patches. Allergy 2008, 63, 882-890. [CrossRef]

61. Newburg, D.S.; Walker, W.A. Protection of the neonate by the innate immune system of developing gut and of human milk. Pediatr. Res. 2007, 61, 1-8. [CrossRef]

62. Salimei, E.; Fantuz, F. Equid milk for human consumption. Int. Dairy J. 2012, 24, 130-142. [CrossRef]

63. Martini, M.; Altomonte, I.; Manica, E.; Salari, F. Changes in donkey milk lipids in relation to season and lactation. J. Food Compos. Anal. 2015, 41, 30-34. [CrossRef]

64. Jirillo, F.; Magrone, T. Anti-inflammatory and anti-allergic properties of donkey's and goat's milk. Endocr. Metab. Immune 2014, 14, 27-37. [CrossRef] 
65. Santillo, A.; Figliola, L.; Ciliberti, M.G.; Caroprese, M.; Marino, R.; Albenzio, M. Focusing on fatty acid profile in milk from different species after in vitro digestion. J. Dairy Res. 2018, 85, 257-262. [CrossRef] [PubMed]

66. Laiho, K.; Ouwehand, A.; Salminen, S.; Isolauri, E. Inventing probiotic functional foods for patients with allergic disease. Ann. Allergy Asthma Immunol. 2002, 89, 75-82. [CrossRef]

67. Sorrentino, E.; Salimei, E.; Succi, M.; Gammariello, D.; Di Criscio, T.; Panfili, G.; Coppola, R. Heat treatment of ass's milk, a hypoallergenic food for infancy. In Technological Innovation and Enhancement of Marginal Products; Severini, C., DePilli, T., Giuliani, R., Eds.; Claudio Grezi Editore: Foggia, Italy, 2005; pp. 569-574.

68. Salimei, E. Animals that produce dairy foods - donkey. In Encyclopedia of Dairy Sciences, 2nd ed.; Fuquay, J.W., Fox, P.F., McSweeney, P.L.H., Eds.; Elsevier Academy Press: London, UK, 2011; Volume 1, pp. 365-373.

69. Dzidic, A.; Knopf, L.; Bruckmaier, R.M. Oxytocin release and milk removal in machine-milked mares. Milchwiss. Milk Sci. Int. 2002, 57, 423-424.

70. Bat-Oyun, T.; Ito, T.Y.; Purevdorj, Y.; Shinoda, M.; Ishii, S.; Buho, H.; Morinaga, Y. Movements of dams milked for fermented horse milk production in Mongolia. Anim. Sci. J. 2018, 89, 219-226. [CrossRef] [PubMed]

71. Naert, L.; Vandevyvere, B.; Verhoeven, G.; Duchateau, L.; De Smet, S.; Coopman, F. Assessing heterogeneity of the composition of mare's milk in Flanders. Vlaams Diergenskund. Tijds. 2013, 82, 23-30.

72. Dai, F.; Segati, G.; Dalla Costa, E.; Burden, F.; Judge, A.; Minero, M. Management practices and milk production in dairy donkey farms distributed over the italian territory. Mac. Vet. Rev. 2017, 40, 131-136. [CrossRef]

73. Brinkmann, J.; Jagannathan, V.; Drogenmuller, C.; Rieder, S.; Leeb, T.; Thaller, G.; Tetens, J. Genetic variability of the equine casein genes. J. Dairy Sci. 2016, 99, 5486-5497. [CrossRef]

74. Bayle-Labouré, J. Approche Technico-économique de l'opportunité de Développement d'une Filière "Lait de Jument Comtoise". Thesis Ingénieure Spécialité Agriculture, Éstablissement National d'Enseignement Supérieur Agronomique de Dijon (ENESAD), Dijon, France, 2007; p. 154.

75. Mazhitova, A.T.; Kulmyrzaev, A.A.; Ozbekova, Z.E.; Bodoshev, A. Amino acid and fatty acid profile of the mare's milk produced on Suusamyr pastures of the Kyrgyz Republic during lactation period. Procedia Soc. Behav. Sci. 2015, 195, 2683-2688. [CrossRef]

76. De Palo, P.; Maggiolino, A.; Albenzio, M.; Caroprese, M.; Centoducati, P.; Tateo, A. Evaluation of different habituation protocols for training dairy jennies to the milking parlor: effect on milk yield, behavior, heart rate and salivary cortisol. Appl. Anim. Behav. Sci. 2018, 204, 72-80. [CrossRef]

77. Salari, F.; Ciampolini, R.; Mariti, C.; Millanta, F.; Altomonte, I.; Licitra, R.; Auzino, B.; D’ Ascenzi, C.; Bibbiani, C.; Giuliotti, L.; et al. A multi-approach study of the performance of dairy donkey during lactation: Preliminary results. It. J. Anim. Sci. 2019, 18, 1135-1141. [CrossRef]

78. Centoducati, P.; Maggiolino, A.; De Palo, P.; Tateo, A. Application of Wood's model to lactation curve of Italian Heavy Draft horse mares. J. Dairy Sci. 2012, 95, 5770-5775. [CrossRef] [PubMed]

79. Raspa, F.; Cavallarin, L.; McLean, A.K.; Bergero, D.; Valle, E. A review of the appropriate nutrition welfare criteria of dairy donkeys: nutritional requirements, farm management requirements and animal-based indicators. Animals 2019, 9, 315. [CrossRef] [PubMed]

80. De Palo, P.; Maggiolino, A.; Centoducati, P.; Calzaretti, G.; Milella, P.; Tateo, A. Equid milk production: evaluation of Martina Franca jennies and IDH mares by Wood's model application. Anim. Prod. Sci. 2017, 57, 2110-2116. [CrossRef]

81. Todini, L.; Salimei, E.; Malfatti, A.; Brunetti, V.L.; Fantuz, F. Thyroid hormones in donkey blood and milk: correlations with milk yield and environmental temperatures. It. J. Anim. Sci. 2015, 14, 596-601. [CrossRef]

82. Akimbekov, A.R.; Baymukanov, D.A.; Yuldashbaev, Y.A.; Iskhan, K.Z. Productive qualities of the Seleti factory-type Kazakh horse of the toad. Bull. Natl. Acad. Sci. Rep. Kazakhstan 2017, 3, 100-110.

83. Iskhan, K.Z.; Akimbekov, A.R.; Baimukanov, A.D.; Aubakirov, K.A.; Karynbayev, A.K.; Rzabayev, T.S.; Mukhatai, G.; Dzhunusova, R.Z.; Apeev, K.B. Dairy productivity of the kazakh horse mares and their cross breeds with roadsters. Bull. Natl. Acad. Sci. Rep. Kazakhstan 2019, 3, 22-35. [CrossRef]

84. Muhatai, G.G.; Chen, L.; Rugoho, I.; Xiao, G.; Chen, G.; Hodge, S.; Zhou, S. Effect of parity, milking time and stage of lactation on milk yield of Jiangyue donkey (Equus asinus) in North West China. J. Dairy Res. 2017, 84, 23-26. [CrossRef]

85. Minjidgorj, N.; Baldorj, O.; Austbø, D. Chemical composition of Mongolian mare milk. Acta Agric. Scand. Sect. A-Anim. Sci. 2012, 62, 66-72. 
86. Proops, L.; Osthaus, B.; Bell, N.; Long, S.; Hayday, K.; Burden, F. Shelter-seeking behavior of donkeys and horses in a temperate climate. J. Vet. Behav. 2019, 32, 16-23. [CrossRef]

87. Colavita, G.; Amadoro, C.; Rossi, F.; Fantuz, F.; Salimei, E. Hygienic characteristics and microbiological hazard identification in horse and donkey raw milk. Vet. It. 2016, 52, 21-29.

88. Dai, F.; Dalla Costa, E.; Burden, F.; Judge, A.; Minero, M. The development of guidelines to improve dairy donkey management and welfare. It. J. Anim. Sci. 2019, 18, 189-193. [CrossRef]

89. Cieslak, J.; Mackowski, M.; Czyzak-Runowska, G.; Wojtowski, J.; Puppel, K.; Kuczynska, B.; Pawlak, P. Screening for the most suitable reference genes for gene expression studies in equine milk somatic cells. PLoS ONE 2015, 10, e0139688.

90. Van Soest, P.J. Nutritional Ecology of the Ruminant, 2nd ed.; Cornell University Press: Ithaca, NY, USA; London, UK, 1994; p. 476.

91. Cavallarin, L.; Giribaldi, M.; Soto-Del Rio, M.D.; Valle, E.; Barbarino, G.; Gennero, M.S.; Civera, T. A survey on the milk chemical and microbiological quality in dairy donkey farms located in NorthWestern Italy. Food Control 2015, 50, 230-235. [CrossRef]

92. Salimei, E.; Malissiova, E.; Papademas, P.; Colavita, G.; Galaverna, G.; Fletouris, D.; Manouras, A.; Habib, I.; Šarić, L.; Budak S.O.; et al. Donkey milk and dairy donkey farming in Mediterranean Countries: current situation, challenges and prospects. In Proceedings of the 7th IDF International Symposium on Sheep, Goat and Other Non-Cow Milk, Limassol, Cyprus, 23-25 March 2015.

93. INRA. Equine Nutrition. INRA Nutrient Requirements, Recommended Allowances and Feed Tables; Martin-Rosset, W., Ed.; Wageningen Academic Press: Wageningen, The Netherlands, 2015; p. 691.

94. Miraglia, N.; Burger, D.; Kapron, M.; Flanagan, J.; Langlois, B.; Martin-Rosset, W. Local animal resources and products in sustainable development: Role and potential of equids. In Product Quality Based on Local Resources Leading to Improve Sustainability; Rubino, R., Sepe, L., Dimitriadou, A., Gibon, A., Eds.; Wageningen Academic Publishers: Wageningen, The Netherlands, 2006; pp. 217-233.

95. Martin-Rosset, W.; Trillaud-Geyl, C.; Jussiaux, M.; Agabriel, J.; Loiseau, P.; Beranger, C. Exploitation du pâturage par le cheval en croissance ou à l'engrais. In Le Cheval. Reproduction, sélection, Alimentation, Exploitation; Jarrige, R., Martin-Rosset, W., Eds.; INRA: Paris, France, 1984; pp. 583-599.

96. Moulin, C. Le pâturage du cheval: questions posées par les pratiques d'éleveurs. (Grazing by horses: From farm practices to technical questions). Fourrages 1997, 149, 37-54.

97. Burden, F.; Thiemann, A. Donkeys Are Different. J. Equine Vet. Sci. 2015, 35, 376-382. [CrossRef]

98. Martin-Rosset, W. Donkey nutrition and feeding: Nutrient requirements and recommended allowances-A review and prospect. J. Equine Vet. Sci. 2018, 65, 75-85. [CrossRef]

99. Burden, F.A.; Bell, N. Donkey nutrition and malnutrition. Vet. Clin. Equine 2019, 35, 469-479. [CrossRef]

100. NRC. Donkeys and other equids. In Nutrient Requirements of Horses, 6th ed.; National Research Council, Ed.; National Academies Press: Washington, DC, USA, 2007; pp. 268-279.

101. Couto, M.; Santos, A.S.; Laborda, J.; Nóvoa, M.; Ferreira, L.M.; Madeira de Carvalho, L.M. Grazing behavior of Miranda donkeys in a natural mountain pasture and parasitic level changes. Livest. Sci. 2016, 186, 16-21. [CrossRef]

102. Wood, S.J.; Smith, D.G.; Morriss, C.J.; Oliver, J.; Cuddeford, D. The effect of pasture restriction on dry matter intake of foraging donkeys in the United Kingdom. In Forages and Grazing in Horse Nutrition; Saastamoinen, M., Fradinho, M.J., Santos, A.S., Miraglia, N., Eds.; Wageningen Academic Publishers: Wageningen, The Netherlands, 2012; pp. 163-176.

103. Kouba, J.M.; Burns, T.A.; Webel, S.K. Effect of dietary supplementation with long-chain n-3 fatty acids during late gestation and early lactation on mare and foal plasma fatty acid composition, milk fatty acid composition, and mare reproductive variables. Anim. Reprod. Sci. 2019, 203, 33-44. [CrossRef]

104. De Palo, P.; Maggiolino, A.; Milella, P.; Centoducati, N.; Papaleo, A.; Tateo, A. Artificial suckling in Martina Franca donkey foals: effect on in vivo performances and carcass composition. Trop. Anim. Health Prod. 2016, 48, 167-173. [CrossRef]

105. Awin Welfare Assessment Protocol for Donkeys, University of Milan (Italy) and Donkey Sanctuary (UK). Available online: https://air.unimi.it/retrieve/handle/2434/269100/384805/AWINProtocolDonkeys.pdf (accessed on 15 October 2019). 
106. Micol, D.; Martin-Rosset, W. Feeding systems for horses on high forage diets in the temperate zone. In Recent Developments in the Nutrition of Herbivores; Journet, M., Grenet, E., Farce, M.-H., Thériez, M., Demarquilly, C., Eds.; INRA Editions: Paris, France, 1995; pp. 569-584.

107. Fatica, A.; Circelli, L.; Dilorio, E.; Colombo, C.; Crawford, T.W.; Salimei, E. Stresses in pasture areas in South-Central Apennines, Italy, and evolution at landscape level. In Handbook of Plant E Crop Stress, 4th ed.; Pessarakli, M., Ed.; CRC Press Taylor and Francis Group: Boca Raton, FL, USA, 2019; pp. 271-291.

108. Ferreira, L.M.M.; Celaya, R.; Benavides, R.; Jáuregui, B.M.; García, U.; Santos, A.S.; García, R.R.; Rodrigues, M.A.M.; Osoro, K. Foraging behavior of domestic herbivore species grazing on heathlands associated with improved pasture areas. Livest. Sci. 2013, 155, 373-383. [CrossRef]

109. Doreau, M.; Moretti, C.; Martin-Rosset, W. Effect of quality of hay given to mares around foaling on their voluntary intake and foal growth. Ann. Zootech. 1990, 39, 125-131. [CrossRef]

110. Duncan, P. Horses and Grasses: The Nutritional Ecology of Equids and Their Impact on the Camargue; Springer: New York, NY, USA, 1992; p. 287.

111. Parrini, S. Caratterizzazione nutrizionale delle erbe dei pascoli naturali e impiego di metodi di valutazione innovativi. Ph.D. Thesis (28th cycle), Università degli Studi di Firenze, Florence, Italy, December 2015.

112. Hristov, A.N.; Degaetano, A.T.; Rotz, C.A.; Hoberg, E.; Skinner, R.H.; Felix, T.; Li, H.; Patterson, P.H.; Roth, G.; Hall, M.; et al. Climate change effects on livestock in the Northeast US and strategies for adaptation. Clim. Chang. 2018, 146, 33-45. [CrossRef]

113. Pulina, G.; Salimei, E.; Masala, G.; Sikosana, J. A computerised spreadsheet model for the assessment of sustainable stocking rate in semiarid and subhumid regions. Livest. Prod. Sci. 1999, 61, 287-299. [CrossRef]

114. Miraglia, N.; Polidori, M.; Salimei, E. A review on feeding strategies, feeds and management of equines in Central-Southern Italy. In Working Animals in Agriculture and Transport; Pearson, R.A., Lhoste, P., Saastamoinen, M., Martin-Rosset, W., Eds.; Wageningen Academic Publishers: Wageningen, The Netherlands, 2003; pp. 103-112.

115. Dumont, B.; Rook, A.J.; Coran, C.; Rover, K.U. Effects of livestock breed and grazing intensity on biodiversity and production in grazing systems. 2. Diet selection. Grass and Forage Sci. 2007, 62, 159-171. [CrossRef]

116. Dumont, B.; Garel, J.P.; Ginane, C.; Decuq, F.; Farruggia, A.; Pradel, P.; Rigolot, C.; Petit, M. Effect of cattle grazing a species-rich mountain pasture under different stocking rates on the dynamics of diet selection and sward structure. Animal 2007, 1, 1042-1052. [CrossRef]

117. Bele, B.; Norderhaug, A.; Sickel, H. Localized agri-food systems and biodiversity. Agriculture 2018, 8, 22. [CrossRef]

(C) 2020 by the authors. Licensee MDPI, Basel, Switzerland. This article is an open access article distributed under the terms and conditions of the Creative Commons Attribution (CC BY) license (http://creativecommons.org/licenses/by/4.0/). 


\title{
Review
}

\section{Green Assets of Equines in the European Context of the Ecological Transition of Agriculture}

\author{
Agata Rzekęć ${ }^{1}$, Céline Vial ${ }^{1,2, *}$ and Geneviève Bigot ${ }^{3}$ \\ 1 Research Unit MOISA (Marchés, Organisations, Instituts et Stratégies d'acteurs)-French National Research \\ Institute for Agriculture, Food and Environment (INRAE), CIHEAM-IAMM, CIRAD, Montpellier Supagro, \\ Univ Montpellier, 34060 Montpellier, France; agata.rzekec@gmail.com \\ 2 Pôle Développement, Innovation, Recherche-French Institute for Horse and Horse Riding (Ifce), \\ 61310 Exmes, France \\ 3 Université Clermont Auvergne, AgroParisTech, French National Research Institute for Agriculture, \\ Food and Environment (INRAE), VetAgro Sup, Research Unit Territoires, 63000 Clermont-Ferrand, France; \\ genevieve.bigot@irstea.fr \\ * Correspondence: celine.vial@inrae.fr
}

Received: 30 October 2019; Accepted: 2 January 2020; Published: 8 January 2020

Simple Summary: Equines have a peculiar place in our society. From livestock to sport, through to landscape managers and leisure partners, equines show a wide range of little-known environmental advantages and assets. Today's wake-up calls about the environment are progressively putting pressure on stakeholders of the agricultural sector, including the equine industry. This study focusses on the main environmental consequences of equine use and possession in Europe based on scientific and technical sources under the lens of five leading sectors where equines show unique impacts as green assets. Now, more than ever before, it is important to highlight the role of equines as a green alternative in political debates and management practices to give them the place equines deserve in the ecological transition of agriculture.

Abstract: Despite the decline of equine populations in the middle of the 20th century, the European horse industry is growing again thanks to economic alternatives found in the diversification of the uses of equines (sports, racing, leisure, etc.). Equines have many environmental advantages, but the fragmentation of the sector and the lack of synthetic knowledge about their environmental impacts do not enable the promotion of these assets and their effective inclusion in management practices and European policies. To highlight the equine environmental impacts, a literature review was carried out to cover the main European stakes. This work led to the identification of five "green assets", fields where equines show unique environmental advantages compared to other agricultural productions. These green assets are linked to the nature of equines (grazing and domestic biodiversity), to their geographical distribution (land use), and to their use by human beings (tourism and work). Today, when searching for sustainable solutions to modern environmental issues, the use of equines is a neglected green alternative. Better knowledge and use of equine green assets could partly respond to more ecological agricultural needs and contribute to the development of this animal industry, which has a place in regional development and in Europe's sustainable transition.

Keywords: equine; horse; environment; green assets; land use; equine grazing; domestic biodiversity; equine and equestrian tourism; equine work; multifunctional review

\section{Introduction}

In the European Union (EU), after World War II, equine numbers declined drastically because of the motorization of transport (estimates generally agree that horse numbers decreased approximately 
90\% in Europe by the 1950s [1]). For example, in France, the total number of equines was evaluated to be three million at the beginning of the 20th century but was less than half a million at the end of this century (Figure 1). Before 1950, horses were largely used for agriculture, transportation, and the army. This was particularly the case for heavy (or draft horses) (represented by the light color in Figure 1), but also for saddle horses (represented by the dark color in Figure 1). The European community was built after the Second World War to maintain peace and ensure the autonomy of its inhabitants regarding basic necessities, particularly food products. To this end, a Common Agricultural Policy (CAP) (which still exists today) was created to improve agricultural production, first to improve cereal yields and then to improve animal productions. However, equines were not included in the CAP's plans. In this post-war period, the market situation was geared toward productivism, where the disinterest in equines as a source of power and their absence in development policies led the European equine population to collapse. In France, the decline of heavy horses led to the construction of national programs in 1980 to develop meat production [2,3]. After 1970, saddle horses began to be used for other purposes (sport and leisure), which explains the progressive increase in their numbers (Figure 1). This trend was similar in Sweden. In 1920, there were 700,000 horses; then, their numbers decreased to around 95,500 in 1980 before increasing again [4]. However, today, the equine population is still lower (48\%) than it was in 1920 (362,700 heads in 2010) [5]. However, the recent increases in equine livestock have not been observed in Mediterranean countries: 87\% of horses were lost in Greece between 1983 and 2000, and 31\% and 36\% were lost in Spain and Portugal, respectively, between 1987 and 2000 [6]. This population decline could be linked to difficulties in national economies during this period.

Today, Europe has 88.4 million cattle, 150 million pigs, 86.8 million sheep, and 12.7 million goats to ensure the animal protein needs of the European population (Eurostat, 2017), but Europe has only six million equines [7], according to the European Horse Network (a non-profit network of stakeholders acting at the world, European, national, or regional level within the European equine sector).

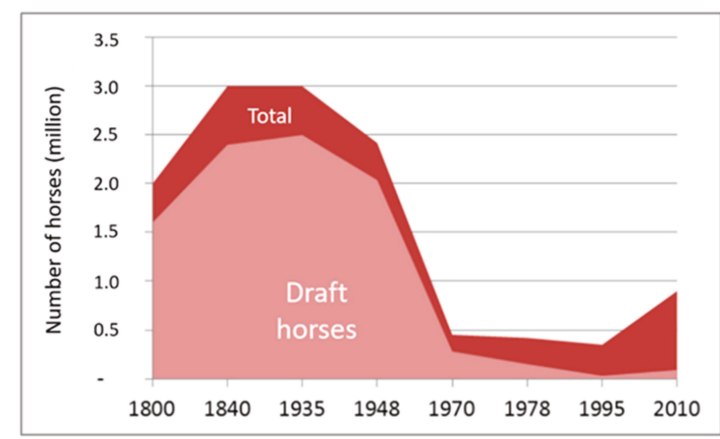

Figure 1. Evolution of the horse population in France from 1800 to 2010 (translated from French [8]).

Since the end of the 20th century, the equine industry has undergone significant evolutions linked to the diversification of equine uses: first, in terms of sports, racing, and leisure; and second, in terms of meat and milk productions, traction, therapy, and even companionship. This gave rise to debates on the status of equines (as a farm animal or pet) between European countries but also inside each country. For example, in the United Kingdom, horses are seen as companion animals, whereas in other European countries-France, Germany, or Sweden for example-equines are considered livestock [9].

These issues are particularly problematic because the European agricultural census could be a powerful tool to quantify the equine population at the European level, but today, this census underestimates the equine population because only equines kept by farmers are counted (EU Regulation (EC) No 1166/2008 19.11.2008), whereas, for example, in France, only half of the equine livestock was kept on farms in 2010 [10]. This problem is similar in other European countries (in Germany, for example) [11]. No other database exists at this scale, so the current official figures are misleading. 
To counter this, the European Union required the creation of a central national database for each Member State that would identify all equines. This requirement was presented in the EU Regulation (EC) No $262 / 20153.03 .2015$, and the creation of these databases remains a work in progress in some member states today [9]. This lack of data concerning equine numbers in Europe complicates descriptions about their importance and impacts.

At present, the diversity of equine uses leads to a large variety of impacts on the environment, especially when activities are exclusive to equines, such as sports or racing. This creates difficulties in listing and evaluating the environmental impacts of the entire equine industry. However, in today's European context, local authorities aim to maintain rural activities and to support agriculture in its sustainable transition. These terms, in the EU context, include all policies that search for the transformation of current societal systems to minimize negative effects on the environment and promote innovative projects [12]. A variety of new uses of equines could meet these challenges. In particular, the European Horse Network has expressed the need for a foundation of scientific resources to build arguments and promote equines in European policies and debates. Consequently, this study describes equines not only as animal producers, but also as ecosystem service providers, especially for land use and biodiversity conservation. This choice consolidates the fact that equines are not only seen as a source of agricultural goods (leisure diversification or meat production, for example), but generate a wide range of other externalities.

The aim of this review is to highlight the most important services provided by equines for the environment at the European level. In order to answer public and professional stakeholders' questions about the inclusion of equines in public policies according to priority, we first met with stakeholders to understand their main issues. Then, a literature review of the available knowledge on the green assets of equines was conducted. Consequently, this paper examines the environmental assets (and limits) of equines that appear to be most important in the context of European policies about agriculture and rural development.

\section{Choice and Definition of the Main Green Assets}

To achieve this goal, the reflection about equine environmental assets started with fifteen interviews among key stakeholders coming from various institutes at the French and European level: the European Commission, the European Parliament, the French Ministry of Agriculture, the International Federation of Equestrian Tourism, the French Permanent Representation in Brussels, and the European Federation of Working Horses. The aims of the interviews were also to estimate the main issues of the equine industry toward environmental challenges. The interviews were semi-directed and were conducted from May 2019 to July 2019. The choice of respondents was made in order to have a large panel of expertise scales (France or Europe) and professional functions (researchers, institutional stakeholders, and professional representatives). The distribution of these 15 interviews was as equal as possible in function and level of decision (Table 1). The high number of interviews from European institutional stakeholders was undertaken to have a better view of the diversity of the issues at this level. Put another way, it was not easy to find professional representatives concerned with the green assets of equines at the European level.

Table 1. Distribution of interviewees according to the scale of expertise and the function.

\begin{tabular}{cccc}
\hline Scale of Expertise/Function * & Researchers & Institutional Stakeholders & Professional Representatives \\
\hline France & 3 & 3 & 3 \\
Europe & 1 & 4 & 1 \\
\hline
\end{tabular}

* Respondents who answered questions about the French equine industry are counted in the group "Scale of expertise: France." Those who answered questions with a European point of view are counted in "Scale of expertise: Europe".

These interviews entailed a reflection based on sectors where equines have particular and specific impacts on the environment, here called "green assets". 
Globally, the most cited impact is grazing, which was described positively, e.g., in terms of pasture maintenance, complementarity with other livestock, and as a carbon sink, even if some respondents insisted on the destructive nature of equine grazing when mismanaged. Equine work and tourism were seen as green alternatives even if the dynamism of equine work was perceived quite negatively, at least in Western Europe. Another point was the key role of buildings and infrastructures related to equines. These buildings are, in most cases, made from wood, which is a renewable material with positive technical characteristics, e.g., isolation, and favorable effects on the landscape. Manure methanization was also mentioned. Indeed, recycling manure by producing energy is a promising way to improve the environmental image of the equine industry. More generally, according to the respondents, equines have quite a positive impact on the environment since they do not eject as much methane as cattle do, they graze, there is a very rich domestic biodiversity that permits a wide range of uses, even as alternatives for engines in agriculture, for example. Often, no negative effects were spontaneously mentioned by stakeholders when asked about environmental impacts.

This process led to an evaluation of the whole European equine industry that considered the current European context and challenges. Green assets were directly or indirectly linked to European rural policies: the maintenance of open areas through grazing, agritourism, and the maintenance of endangered breeds [7].

Green assets are generally directly linked to:

- The inherent nature of equines (as non-ruminant herbivores whose species presents a high biodiversity of breeds).

- The geographical repartition of equines and their particular land use.

- Their use by humans, which can offer environmental benefits. Even if all human activities with equines benefit from a green image linked to the use of an animal, only some of these uses have positive environmental impacts. Of course, the impacts of equine breeding, whatever the equine's future use, are considered when examining green assets for land use, breed biodiversity, and grazing. We decided to focus on two equine uses that generate specific environmental advantages: equine work and tourism.

This initial information was completed through a literature review of the newest sources possible to build the first state-of-the-art overview of this subject. This review mainly focused on Europe, even though some sources also concerned other continents. In addition to international references, many countries, especially in Europe, developed studies published only in their national language. Consequently, this study was supplemented by French-language references. From March 2019 until November 2019, we used two main databases, Web of Science and Google Scholar to search for articles and reports. To select documents, we searched for the terms "equid" ", "equine ${ }^{*}$, " "environment*," "horse*," and all words related to green assets, in both French and English.

This literature review highlighted key arguments for five green assets:

- Equine grazing: Equine grazing incidence is unique because of this animal's morphology and its physiology specificities, especially regarding ruminants (the main herbivores raised on grasslands). In particular, equine grazing is done on different patches made of lawns and high grasses.

- Domestic biodiversity: Human and environmental selection has led to a rich diversity of equine breeds all over the world. Some of these breeds are currently endangered and their conservation is an important issue, which could be introduced in European policies.

- Land use: Equines are present in various areas, especially where other livestock is presently absent. This land use is directly linked to the place of equines in society; as livestock, it is possible to find equines in farms and large areas, but as family pets, equines can be encountered near houses, sometimes on small plots of lands that are not usable for agriculture.

- Tourism: Equines can be used as a means of transport but also as travel companions to discover wild countries and landscapes. 
- Equine work: Equines are also used in tourism, cities, and agriculture as a source of energy, whereas other livestock are not, at least in Europe.

\section{State of the Current Scientific Knowledge Concerning the Five Equine Green Assets}

\subsection{How does the Inherent Nature of Equines Impact the Environment?}

Equines are non-ruminant herbivores. Equine grazing impacts pastures differently than cattle, sheep, or goat grazing thanks to the particular physiology and morphology of equines, who have a double row of incisors and a high capacity for ingestion linked to the absence of a rumen. They adapt their diet easily according to the available forage. Their behavior also differs from that of cattle in their feed preferences and greater movement when grazing (as there is no rumination rest). These differences induce various impacts on grasslands according to the whether horses graze alone or are associated with ruminants.

\subsubsection{Equine Grazing}

Grasslands in Europe and Their Maintenance

Meadows are lands covered by grasses and legumes and mainly aim to be a feed source for livestock through grazing or mowing. Meadows are known to be a carbon sink: they can stock 60 to 70 tons of carbon per hectare in temperate areas [13,14]. Moreover, the presence of legumes allows for the fixation of nitrogen from the air to the ground. There are different types of meadows: permanent grasslands (retained over 5 years, with possible reseeding after 5 years); semi-natural grasslands (a particular kind of permanent grassland because they exist for more than five years and are known to be among the most species-rich habitats in Europe [15]); cultivated grasslands (seeded each year (or more often than 5 years), and they are the most commonly used in current breeding systems [15]); and other less productive grasslands present in arid or rugged areas, which are called rangelands (shrub lands, steppes, alpine communities, marshes, tundras, etc.) [16]. In Europe, grasslands cover $21 \%$ of the agricultural land in the European Union, while croplands cover $22 \%$ and woodlands cover $38 \%$ (Eurostat, 2015). However, there is a decrease in permanent grasslands in Europe [15], while pastures are known to have different positive impacts: they are seen as pleasant and aesthetic [16] and provide multifunctional goods [15] that produce agricultural commodities and maintain biodiversity, soil, and water quality, even in suburban areas [17], in addition to meeting the needs of herbivorous productions. Animal grazing presents three general consequences: (1) it maintains a certain level of vegetal biomass [18] with the control of invasive species (through the intake of plants [19] and trampling [19]); (2) it has effects on plant metabolism (defence, resistance, and avoidance) [19]; and (3) it enables the creation of ecological niches [20].

\section{Equine Grazing Specificities}

Equines show specificities that are morphological, physiological, and behavioral. First, equines have two rows of incisors that allow them to graze on short grasses [16] lower than cattle are able to and reach young plants that are easily digestible [20]. This leads to a panel of feed preferences. Equines are graminoids feeders [16] and make less use of forbs and legumes than cattle [15]. Equines' preferences change when there is feed shortage. Equines move more easily toward less palatable grasses species than cattle [21], particularly in winter [16]. This may be explained by their physiology. The absence of rumination permits more time for feed intake [22]; less methane emissions compared to cattle (100 kg/ $\mathrm{CH}_{4} /$ dairy cow in Western Europe [23], more specifically: $117.9 \mathrm{~kg} \mathrm{CH} /$ dairy cow/year in France [24], and $18.0 \mathrm{~kg} \mathrm{CH}$ /horse/year in Western Europe [23] and $20.7 \mathrm{~kg} \mathrm{CH}_{4} / \mathrm{horse}_{\text {year in }}$ France [24]); and no limitation of intake capacity due to rumen volume [25]. Consequently, the global intake capacity of equines can be bigger than that of cattle [16] as equines graze longer than cattle [26]. Most equines (except high-performance horses like racehorses) do not need high-quality feed; instead, 
they are able to live on low-nutrition feed [27]. Moreover, their physiology explains their adaptation to a low starch diet because of the low activity of amylase [15]. They also seem not to be able to digest the secondary metabolites of some plants (such as shrubs) [26]. Because of this, there should be a lower control of shrubs when equines graze them compared to other herbivorous species. However, in extensive Mediterranean conditions with a low stocking rate, shrubs are controlled by local equines [16]. Equines do not appear to be affected by shrubs' defences, such as thorns [26].

As a consequence of these specificities, equines can adapt their intake through a reduction of feed resources during harsh environmental periods [16]. Some primitive equine breeds are better able to mobilize the bodily reserves they gain during summer to survive during the winter if grass is not sufficient [16] than some specialized equine breeds. For example, in Iceland, despite the cold climate, equine grazing occurs even during winter and is supplemented with the hay refused by cattle or sheep [16]. Likewise, equines can be raised in Camargue, where plants are halophilic and resources are scarce [16].

Equines impact pasture differently than other herbivores because their grazing behavior induces a particular heterogeneity of plant cover [28]. Some areas with high plants are not grazed by equines and could be used as latrines [15], but they could be grazed if there were a lack of resources [27]. Nevertheless, there is also the risk of overgrazing and soil erosion in equine pastures [15]. Equines can impact a pasture, for example, by trampling during periods of exercise [29] or if they are concentrated in small areas. Finally, gnawing on trees in semi-natural pastures was reported [20] due to the lack of minerals [15], but this can be reduced with supplementation [30].

Studies on exclusive equine grazing show the positive impacts on flora, including an increase of legumes in France [20], a control of competitive grass [15,20], and control of some shrub species in Camargue [20] (e.g., Vaccinium myrtillus by trampling [16,31]), alongside negative impacts, such as the limited control of fast forest regeneration in boreal conditions [15] and an increase of foams in Iceland [20]. In particularly harsh conditions, some lands are maintained by equines to decrease fire risks, for example, by reducing the aerial biomass of gorse in Galicia [16]). Equines are able to preserve and maintain pastoral biodiversity [15] by grazing in areas abandoned by agriculture. This process is identified as a specific threat to habitats and species by the European Union, as the invasion of some plants left non-grazed by livestock leads to landscape closure [25].

Equine grazing also impacts fauna:

- The populations of small herbivores increased due to high-quality vegetative regrowth

- Insectivorous birds, such as the spoonbill, appeared in pastures grazed by equines in the Netherlands (as with ducks in French wetlands) [20].

- The wolf population in Galicia, Spain, was maintained partly thanks to ponies bred in semi-natural conditions. These one were the preferential feed source of wolves [27], which consequently did not attack other livestock. As a result, farmers felt less disposed to shoot them down. Finally, ponies were an indirect way to conserve the wolf population.

Pastures can be grazed by equines only, by two or more herbivorous species, or mowed. All these types of pasture management methods allow animals to feed and exert their own effects on the environment (biomass, grassland evenness, and effects on butterflies) depending on the area (grazing seems to be a better option in Central Europe and mowing may be more suitable in Southern Europe) [32]. In boreal conditions, continuous equine grazing seems to be less beneficial to biodiversity than alternative grazing regimes (late grazing, years without grazing, and mowing) [15]. In Sweden, year-round equine grazing increased the pasture quality and diversity compared to mowing [28].

\section{The Impact of Cattle and Horse Mixed Grazing on Meadows}

The heterogeneity of plant cover may be beneficial for flora and fauna but can lead to pasture destruction when it is mismanaged. Indeed, non-grazed areas can be invaded by shrubs, while grazed areas can be overgrazed. To prevent this situation, mixed grazing with two herbivorous species could 
be a solution. Mixed grazing is "a practice of stocking two or more species of grazing or browsing animals on the same land unit, not necessarily at the same time but within the same grazing season" [16]. Cattle and equines graze preferentially in similar habitats, such as grasslands [26]. This can lead to a competition for resources but also complementarity because of their different foraging behaviors. A survey carried out on farmers who raised both (dairy and/or beef) cattle and horses in the French central mountains highlighted the equines' ability to exploit the grasses refused by cattle (total surveyed farmers: 25) [33]. In Massif Central (French mountains), when equines were introduced on cattle pastures, their nutritive value increased because of the development of higher nutritive plants (within the following conditions: $350-440 \mathrm{~kg}$ live weight per hectare and as many horses as cattle) $[16,20]$. When bred with cattle, equines could graze in poorer pastures not useable by cattle because of their low nutritive requirements [33]. Moreover, in winter, equines can remain on pastures and continue maintaining them while cattle are held in stables [16]. However, mixing cattle and equine grazing can generate problems, especially when increasing the number of animals in the pasture. For example, when the equine stocking rate is too high, cattle may be disadvantaged because they are unable to eat enough $[27,34]$. The main consequences of mixed grazing on grassland management are:

- A lower workload: Because their grazing behavior is different from and complementary to cattle, equine replace the use of machines for mowing grass refused by cattle and for crushing wastelands $[22,33]$. In the absence of equines, farmers would need to use the roller chopper more frequently [22].

- A decrease of the parasitic burden: This may be explained by different host sensitivities and improved nutritional status (intake of various plant species) [16,35].

- A better control of woody species: In Massif Central, woody species were better controlled when pastures were grazed by cattle and horses than by cattle only [20].

In France, equines are often raised with cattle in grassland areas [10]. A study of 51 farms located in the highlands, breeding cattle (for beef or milk production) and heavy horses together, highlighted the common practices and confirmed the preceding results about the advantages of mixed grazing [22]:

- Equine grazed mostly after dairy cattle but grazed simultaneously with suckling cows and heifers.

- Equine grazing helped to remove grasses refused by milked cows.

- Equine were present on small plots, fields far from stables, and on poor pastures.

In this survey, equines comprised on average about $10 \%$ of the total livestock in terms of livestock units. Heavy horses were bred for meat production mainly. This breeding process is seen as a complement to the production of cattle for use in grasslands but is not considered a significant source of income. On the other hand, thanks to equine pasture management, the mechanical maintenance of meadows decreased, which can be seen as an indirect contribution to the greater efficiency of forage systems in the highlands.

Beyond grazing specificities, the inherent nature of equines leads to another environmental asset: equine species present high biodiversity among their breeds, which is shaped by the environment and human beings.

\subsubsection{Domestic Biodiversity}

Several equine breeds are well adapted to poor grasslands and semi-wild breeding systems $[18,26,27]$ because their format and size seem to ease their growth in these specific areas [36].

For a long time, and still today, natural and human selection have affected breeds, including those that live in semi-natural or particularly harsh conditions [25]. Human beings selected the most suitable breeds for different uses (traction, meat production, racing, and sport), leading to a high variety of sizes, formats, and phenotypes of equines sorted into breeds. A breed may be defined as a breeding pool of individuals that share a common phenotype (which is typically purely morphological, i.e., coat color, height, etc.) [25]. Worldwide, in 2011, there were 397 equine breeds according to the Universal Equine 
Life Number (the international lifelong identification number for equine, www.ueln.net). Germany (46 breeds), France (37), and the United States (34) were the countries with the greatest numbers of breeds. Of all these breeds, three-quarters were saddle horses (sport, recreation, and ponies), $15 \%$ were heavy horses (France had the highest heavy breeds number with 9), and racing breeds represented only $5 \%$ of breeds [37]. Today, uses of equines are diversifying, and competition between studbooks is increasing because of the internationalization of the equine industry. Consequently, some equine populations collapse when they are not useful anymore. For example, worldwide, 60 donkey breeds are known, but only 28 have had their morphologies described [38]. Only one donkey breed out of 28 is considered to be not threatened by the Food and Agriculture Organization of the United Nations, as $80 \%$ of the donkey population disappeared over 20 years in Europe [ibid.].

Being part of a breed means being identified in a studbook, which is a book of genealogy where breed standards are established. A closed studbook does not allow foals whose parents are not identified in the book; this keeps the breed "pure." However, to improve the traits of interest, studbooks may be opened to some other breeds that will shape the breed. As an example, the pure-bred Arabian and thoroughbred breeds underlie $25 \%$ of the genetic variability of 500,000 saddle horses from 55 different breeds, born between 2002 and 2011 in Europe [39]. A consequence of this intensive direct selection is the specialization of breeds toward modern uses. This specialization is a threat to the versatile, multi-skilled, and generalized breeds. Conversely, these breeds can be seen as an emblem of a region that needs to find new approaches to remain competitive. Finding economically sustainable alternative activities in environmental conservation projects (e.g., animal traction, equestrian tourism, and meat and milk production) would be an interesting way to conserve local and endangered breeds.

European aids for endangered breeds help breeders maintain their activity, even if equine production is no longer economically competitive (Regulation (EU) 2016/1012 of the European Parliament and of the Council of 8 June 2016). This underlines a contradiction in common European programs that give funds based on a small number of animals to preserve animal biodiversity and not just their skills [40]. This kind of breed development is not sufficient to ensure economic viability [41]. However, these programs conserve invaluable environmental services and cultural heritage $[25,42]$.

Equines, because of their essential nature, directly impact the environment. Nevertheless, these impacts may differ depending on the location of the animals.

\subsection{How Does the Spatial Repartition of Equines Impact Land Use?}

Equines require forage areas for grazing and for preserved fodder harvesting. Equine grazing may lead to the maintenance of open areas and a possible improvement in the agronomic quality of grasslands [43]. Breeding farms, riding schools, racecourses, and trails are other kinds of indirect land uses by equines. A French region typology of equine farms highlighted that equines are present in $91 \%$ of all cantons (exclusive of Corsica) [44], which means that the equine industry extends to various areas. Equines are also present in suburban areas: $75 \%$ of equines are encountered in the most inhabited areas in Sweden, for example [45]. This is also the case in Scotland [46], Germany [47], France [48], and Belgium [17]. Equines are also present in Polish post-agricultural lands and forests [49], Spanish heathlands [27], and British grasslands [25]. Studies across Europe agree that equines, whatever their use, are located in various kinds of lands: (a) suburban areas, (b) rural areas, and (c) sensitive areas, such as mountains [17,44-48].

\subsubsection{Suburban Areas}

Pastures in suburban areas are seen as an extensive method of farming and a good way to conserve water quality; however, these pastures are disadvantageous for agriculture [30] because of their small available surface, the presence of housing and non-rural neighbors, and land conflicts. Equines are kept in suburban areas thanks to urban demand [47]; equines are not only seen as a source of agricultural income [50] but as a leisure activity [51] or even as a family "member" whose place is near the home [43]. As a link between urbanization and rurality [51], equines are present in transitional 
areas that have been abandoned by agriculture but have not yet been developed by urbanization [43]. This kind of "sub-agriculture" [43] may be called "soft urbanization" [17] because equines are a spatial and functional link between residential areas and agriculture, and are also of concern in land conflicts with other agricultural productions. In fact, these conflicts for land force equines to reach the edges of urban areas [43]. Nevertheless, equines remaining in these areas mobilize a large array of services, including veterinarians, feed industries, trainers, equipment sellers, and transporters [47].

Some studies quantify the presence of equines in suburban areas, underlying their growing importance. In France, research conducted on 49 municipalities showed that equines use between 1\% and $3.5 \%$ of suburban areas depending on the region [43]. In Sweden, it was shown that the density of equines can increase up to 6 horses $/ \mathrm{km}^{2}$ near urban areas but that specialized equine farms near suburban areas keep more equines than farms in rural areas [51].

In terms of environmental impacts, the presence of equines is comparable to the introduction of nature in the city, which improves landscapes [51]. Equines can graze on small plots near forests and gardens (for example, in Flanders (Belgium) and the Netherlands [17]). Their presence yields positive changes, such as positive land management, added landscape value, and job creation $[43,45]$. Equine grazing is perceived as being a positive element of landscape management in Belgian suburban areas [17] and in Sweden, where the terms used by inhabitants to describe the equine presence were globally positive: ecology, landscape managing, and useful [51]. The presence of equines in these areas opens the possibility to include equines in reflections about urban planning [43,51]. Nevertheless, the high density of equines in small areas could pose a threat to the environment [47] through problems, such as overgrazing, droppings concentration, and destruction of landscapes, because of the creation of mismanaged infrastructures (overgrazed paddocks, and horse-riding rings) [45]. Equines are also a source of odor, insects, and lack of safety [43,45], thereby leading to land conflicts. In Belgium, because of the population density of the country, farmers and equine owners fight for land [52]. Indeed, only $10 \%$ of land is considered to be rural (depending on the density of inhabitants) in this country, but agriculture is present in $45 \%$ of the total national area, and $1 / 3$ of grasslands are grazed by equines, underlying their high presence in suburban grasslands [17]. The presence of equines in these areas does not always imply grazing because equines can be fed with cereals and preserved forage. In some cases, the available area does not allow grazing, and equines are kept in small unproductive plots or stables [34]. For example, in the Berlin suburban region, there is no grazing in specialized and intensive farms [47]. This raises specific issues related to overgrazing and manure management. More studies about grazing in these specific areas are needed [17].

It is important to note that the presence of equines in suburban areas depends on urban sprawl (horse riding schools near cities), but sometimes urban sprawl depends on the presence of equines (owners who want to live closer to their horses) [43]. This kind of agriculture in suburban areas could respond to sustainable issues according to some authors [47], but communication actions should be deployed in order to raise awareness about the risks of overgrazing, droppings concentration, manure management, safety, and land laws.

\subsubsection{Rural Areas}

Rural areas are the main production areas for animal feed and for other derived products, such as straw. In France, equines use from $1.5-6 \%$ of the total rural areas. Equine numbers depend on the type of agriculture: the numbers are lower if there is more professional agriculture (e.g., if the lands are used for food production) and they are higher if non-professional agriculture prevails (e.g., retired persons or multi-active land owners) [43]. The presence of equines may be combined with other local agricultural production, thereby maintaining pastures even in intensive agricultural areas [44]. Farmers can experience benefits from the presence of equines on their land, such as selling equine feed, letting the equines graze on unproductive pastures, or receiving manure. 


\subsubsection{Sensitive Areas}

A sensitive area has a long-term capacity to maintain and enhance natural resources, such as soil and water quality, biodiversity, and the landscape. In such areas, agriculture is more constrained than in the lowlands. Mountains are part of this definition. Other kinds of sensitive areas include natural rangelands in harsh climates and abandoned agriculture areas invaded by shrub, wetlands, or heathlands.

Some sensitive areas produce difficulties when using machines because of the slope or soil depth. Consequently, in these areas, animal husbandry seems to be the most adapted solution to preserve landscapes and maintain economic activity. For example, in French plains, farms breed mostly saddle and race horses with high economic value [10], whereas few heavy horses are associated with cattle farming in the uplands, in an attempt to improve grassland management despite their low economic value [22]. In this study, up to $15 \%$ of farmers said that they would abandon some parcels of land if they did not possess equines [22]. In Poland, ponies named Konik Polski use forests and post-agricultural areas, exerting several impacts on them, including a reduction of shrubs and bushes through trampling, an increase in coprophagic insects, an increase in birds (thanks to greater food resource diversity and hiding place availability), and an increase in the interest and awareness of nature and ecology for tourists and local inhabitants [49]. In Galicia, Spain, where transhumance was abandoned, the presence of equines raised in semi-wild conditions helped to restore heathlands [16]. Heathlands and grasslands in the United Kingdom are usually grazed by sheep, but there have also been studies on the reintroduction of ponies to these areas, where the authors recognized the value of equines as conservation grazers [25]. Rewilding areas abandoned by agriculture with large mammalians, such as equines, are a proposed solution to maintain the important functional links between plants and pollinators in grassland ecosystems in Sweden [18]. Some releases of equines may be a threat to ecosystems, as sometimes breeds are not indigenous to the region. Specific attention should be given [25] to wisely choosing breeds that are to be introduced in natural areas, as well as the density of the released equines. In the "Parc des Volcans d'Auvergne" (an environmentally protected area in France), some authors prescribed the use of mixed grazing with equines and cattle to restore the area [53]. Rangelands are also affected by the definition of sensitive areas. Mediterranean zones show the possibility to access a diversity of pastures (salty pastures, marshes, and rice stubbles), which complement each other and permit local equine breeders to lengthen the grazing season [16]. In areas where the soil is fragile, like in low mountainous olive groves, donkeys are usually used to control grass growth because they weigh less than other heavy animals, such as cattle or horses [38].

In highlands, preserving natural biodiversity when maintaining human activity is possible through agriculture, and more specifically, through animal husbandry. Indeed, the maintenance of the open landscape is particularly interesting for its biodiversity, as explained above, to preserve vegetal resources in non-arable lands, but also to manage areas for human activities, such as hiking or skiing. Because of their slopes and peculiar climates, arable lands are scarce, and pasture meadows are favored as a source of food for livestock, thereby spearheading agricultural products, such as meat and milk.

To conclude, equines take part in the problems of land pressure but have complementarities to agriculture and urbanization in terms of their functionality for land use and maintenance [43]. Other environmental advantages of equines come from their use by humans for working or leisure activities.

\subsection{Animal Uses Serving Environmental Issues}

Equines have been used by humans since their domestication. Activities with equines are often seen as "natural." However, not every use of equines is environmentally virtuous; for example, horses travelling by plane for international competitions or races. According to our findings in the literature review, two uses present interesting environmental assets: equine work and tourism. 


\subsubsection{Equine Work}

In this study, a working equine refers to an equine who is used to work with humans; provides energy that can be substituted by other sources of energy, other machines, or types of transport; and generates earnings [54]. Sport and leisure horses, equines used for therapy, race horses, and equines bred for meat or milk productions are not affected by this definition. There exist four primary non-exclusive types of equine work: agriculture (mostly vineyards and market gardening in organic production systems), forests (logging), human transportation (such as equines drawing a carriage for tourists or schoolchildren), and public service missions (watering, garbage collection, and mounted police).

In the world, there are ten times more animals used as sources of traction energy than motorized tractors. In "developed" countries, $26 \%$ of the land area is managed by animal traction (versus $52 \%$ in "developing" countries) [54], especially in sensitive areas [55] or in mountains [56], where plot structures (slope and soil quality) make mechanization difficult. However, these numbers have decreased over time in Europe. For example, in Poland, the percentage of horses used in agriculture compared to all sources of energy decreased from $93.8 \%$ in 1950 to $1.73 \%$ in 2009 [57]. In the context of productivity gains in post-war Europe, it was necessary to work on bigger areas in less time. Machines seem to be more adapted to this aim than animals, as their use increases sowing, treatment, and harvesting speeds, along with work efficiency, as well as decreases the time dedicated to crops. Nevertheless, a full replacement of animals used in traction by machines may be perceived as a heritage loss [56] and a threat to the environment (soil quality, for example).

Equines as a Potential Source of Renewable Energy

Equines consume fodder, which is considered a renewable source of energy because it does not involve fossil energy in the narrowest sense (unlike fossil fuels or biofuels) [58]. In fact, biofuels may be considered, in some cases, to be a renewable source of energy, but they need the same arable lands as crops and are the focus of land conflict debates. Grasslands used to feed equines could be located in non-arable parts of the territory, as noted above. A one-day harvest allows for enough forage to feed an equine for one year in Switzerland [54]. A total of 0.6 ha of alfalfa, 0.5 ha of oats, and 0.5 ha of wheat for straw are enough to feed two horses working on 14 hectares for 140 days a year in Croatia; for the remainder of the year, these horses stay in stables, where they are fed the by-products of crops, or graze on roadside vegetation or in orchards [58]. Moreover, grasslands and areas worked with equines can be fertilized with their manure. In the case of biofuels, nitrogen must be imported or manufactured and is spread on plots where it evaporates into the atmosphere, providing the main source for $\mathrm{N}_{2} \mathrm{O}$ emissions [58]. The animals must be fed all year, whereas machines can be used occasionally and refuelled infrequently. Despite this disadvantage, equine work allows farmers to attain better feed and energy autonomy [54], to highlight a traditional vision, to be appreciated by urban inhabitants [58], and to maintain a diversified gene pool through the use of local equine breeds [55]. Finally, equine work is considered by some authors as a form of sustainable agriculture [58].

\section{On Arable Lands}

On arable lands, soil compaction is known to be the most severe form of degradation in conventional agriculture $[55,58]$. There is a difference between the paths made by machines (continuous, because of their tyres, with deep soil compaction) and equines (intermittent, because of their hooves, with superficial soil compaction) [58]. The soil porosity was higher after using donkeys or cattle compared to a motorized machine [55]. A comparison between the use of a donkey and a motorized machine for the ploughing, fertilization, and preparation of rapeseed in the context of the high hills in northern Italy was made thanks to the life-cycle assessment (LCA) approach for which inventory data were taken from the GaBi 4.0 database. All aspects related to the life spans of animals were considered, except the end of life: pregnancy, growing and maintenance (health care, feed, keep, and equipment), 
and work. For machines, material acquisition, manufacturing, utilization, transport, and disposal were considered. This information was acquired through interviews with animal owners, field measurements, and technical reports from manufacturers. The results showed that, for the same amount of carbon emissions $(1 \mathrm{~kg}$ eqCO 2$)$, a donkey was able to prepare $330.63 \mathrm{~m}^{2}$ of land, whereas the machine prepared only $18.69 \mathrm{~m}^{2}$ (three operational stages were considered on a $1000 \mathrm{~m}^{2}$ functional unit: ploughing, application of the fertilizer, and seedbed preparation (harrowing and opening seed furrows). Manure from donkeys was assumed to be applied as a fertilizer, so environmental impacts from fertilizer production were avoided in the case of animal traction) [56]. If the fossil fuel used for machines had been replaced by biofuels, the relative effects on the environment could have been $9 \%$ lower. When comparing classic machines and donkeys, these effects were 97\% lower [56]. In Ireland, yields were greater when animal traction was chosen after the long-term use of tractors [58]. It is important to note that equine traction is well adapted to small areas. Finally, there are not enough studies about equine work in mountainous areas, where they could have particular assets [55].

\section{In Forest Areas}

Equines are known to be more drivable than machines in forests, or on rugged or narrow fields. Thanks to this skill, there is less damage to residual trees [55] because machines need more space to access fields [55] and create disturbances [56]. Without counting trail development costs, the use of an equine was more profitable up to $50 \mathrm{~m}$ [55]. This distance increased up to $200 \mathrm{~m}$ when trail development costs were considered [55]. A comparison between the use of a mule and a motorized machine in a one-kilometer distant forest was made thanks to the LCA approach and showed that, for the same amount of carbon emissions ( $1 \mathrm{~kg}$ eqCO 2 ), a mule was able to bring $311.30 \mathrm{~kg}$ of wood, whereas the machine brought only $79.64 \mathrm{~kg}$ of wood (three stages were considered: (i) felling (individual cutting of trees), limbing (removing branches), and bucking (cutting into logs); (ii) yarding (collection of logs); and (iii) transport from the forest to the farm $(1 \mathrm{~km})$. The functional unit was set to $100 \mathrm{~kg}$ of wood at the warehouse. In the animal traction scenario, a mule was used in stages (ii) and (iii)) [56]. If the fossil fuel used for the machines was replaced by biofuels, the relative effects on the environment could have been $26 \%$ lower. When comparing a classic machine and a mule, these effects were $74 \%$ lower [56].

\section{Other Agricultural and Territorial Works}

Equines can also be used in:

- $\quad$ Old vineyards, because their drivability permits work in narrow rows and on terraced or steeped fields (Douro River Valley, Portugal; Bordeaux, France; Sibeira Sacra region, Spain [55]).

- Greenhouses, because their drivability allows for precise work [54] and can be highlighted in ecological production.

- Natural areas, where they are less noisy, degrade the soil less, and frighten local fauna less [54], thereby enabling them to work in protected and sensitive areas. It is possible to compare this to the consequences of equestrian tourism on wild fauna, which are perhaps less frightened by equines than by pedestrians or bikers [59]. Mules are still present in some European areas, such as national parks, where it is impossible or forbidden to use motorized tractors [38].

- Cities where they decrease the carbon footprint and are used as "city pacification" agents [60].

\subsubsection{Tourism}

According to the International Federation of Equestrian Tourism (FITE), the term "equestrian tourism," which emerged in the 1950s [61], concerns all outdoor activities with equines outside of residential areas. Indeed, it is necessary to distinguish between equestrian tourism and equine tourism:

- Equestrian tourism comprises itinerant journeys with a ridden or hitched equine or on foot supported by a pack equine. 
- $\quad$ Equine tourism concerns all activities devoted to equines, in their presence or not, that attract tourists, including sport events, cultural events, races, fairs, museums dedicated to these animals, riding courses, etc.

In addition, the two kinds of tourism linked to equines can be local (i.e., tourists move inside their region of origin) or non-local (inter-regional, international, etc.).

France is the third-largest country in terms of rider numbers in Europe (behind the United Kingdom and Germany), but is considered to be the leader in equestrian tourism and the first travel destination, with 60,000 kilometres of equestrian trails in 2011 [61]. Other countries highlighted in the European report on the equine industry in 2001 are Greece and Portugal, where donkeys are still used for tourism [62]. Equestrian tourism has expanded through farm diversification called agritourism, which is affected by the European development policies for 2014-2020 [36]. This kind of tourism can involve farmers who want to promote local breeds to preserve culture and tradition, as is the case of Camargue horses related to specific bull farming in marshes of the Rhone River estuary in the south of France (Figure 2) [61] or Icelandic ponies in Iceland [63], where tourists want to find a link between nature, animals, and local culture.

\begin{abstract}
In southern France, near the Mediterranean Sea, a regional park and nature reserve named "Camargue" houses particular flora and fauna adapted to saline conditions. This reserve is composed of marshes and wetlands of the Rhône Delta, spanning 150,000 hectares. Camargue horses live in semi-feral conditions in this area and are ridden by guardians/traditional breeders who raise Camargue bulls used in bullfighting. This traditional work is seen as a part of cultural heritage and is promoted during cultural events. This equine breed is also used in equestrian tourism to explore the Camargue region.
\end{abstract}

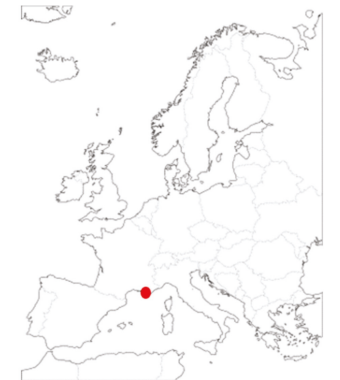

Figure 2. Presentation of the Camargue region and the use of the local equine breeds in this area.

\section{Impacts of Equestrian Tourism}

Equestrian tourism is a form of sustainable leisure [61], though there are very few studies on the direct impacts of using equines in tourism; these studies are mainly American (12 in total, as of 2019) and Australian (six in total, as of 2019) [64]. This is why it is important to contextualize the results presented below, as climate and cultural history are not the same in every region. Europe has always been a host to large mammals, whereas Australia never housed such animals before 1800 [64]. A comparison between hiking, cycling, and horse riding [64] shows that the impacts on the environment were the same between these means of transport but they differed in the degree of impact (e.g., soil compaction and erosion, loss of organic matter biomass, and biodiversity losses). The two most severe impacts of equestrian tourism are: (1) nitrification of rivers and soils because of the overconcentration of phosphor in poor soils, and (2) zoochory through fur and manure, which raises the risk of invasive plants being spread in protected areas [64]. On the other hand, this spread may be beneficial for the flora diversity of poor soils.

Equestrian tourism is also an illustration of soft roaming. Indeed, nature-based recreation activities impact wild fauna (most of them, even if non-motorized, have negative impacts on birds in terms of their metabolisms, behaviors, and habitat disturbances [59]). There are no studies concerning equestrian travel, but it is possible to consider a softer approach for wild fauna; wild animals are, perhaps, less frightened by horses than by pedestrians. In addition, the trails used for horse-riding are a softer way to adapt land to tourism than roads. Moreover, in sensitive and protected areas [61], horseback tourism also creates and maintains trails in a useful state for other users.

The negative impacts of equestrian tourism must also be mentioned. Infrastructures are not always adapted to equestrian tourism, and this shortfall can present destructive impacts on the environment. 
Indeed, during a long-term journey, a horse must rest every 20-40 kilometres but this is not always accomplished [65]. In Poland, for example, on the longest national equestrian trail (2100 km in 2012), there are only 36 liveries; this means one stable every $41 \mathrm{~km}$ [65]. When searching for a campsite or pasture, horse-riders can destroy sensitive or protected areas [64]. Moreover, from surveys carried out on equestrian tourists, security, comfort, and conviviality were more important when travelling than ecosystem conservation [64].

\section{Equine Activities and Tourism}

Because of the wide definitions of equine tourism, it is difficult to list all ecological effects of such tourism. However, some reflections about this issue can be highlighted. In France, for example, the professional organization of the horse industry provides awards to infrastructures that put efforts toward improving their environmental impacts, such as riding schools in Camargue [61] or the numerous stud farms and boarding stables all over the country, in the form of environmental labels (www.label-equures.com, accessed 27.11.2019). This is also the start for reflecting upon the environmental impacts of equestrian events (the transport of horses and persons, the use of natural resources, etc.) in France through an evaluation of the most impacting positions, like wash areas [66]. These efforts provide an early ecological wake-up call for all events, including equine-related ones, and need further research.

\section{Discussion}

\subsection{Links between Green Assets and Specific Issues}

The green assets highlighted above are not completely independent but are mostly linked to each other.

This fact can be first illustrated through the example of the Camargue horse, which plays a key role in land planning and tourist development. This equine breed is known to be a representative of local cultural heritage (Figure 3). Raised in the wetlands, Camargue horses are robust and largely participate in the maintenance of this sensitive area through shrub grazing. They are also hardy enough to be used to control and move cattle herds in these vast swamps. The Camargue region attracts tourists because of its particular fauna (such as flamingos, horses, bulls, etc.) and flora (halophilic plants). The Camargue equine breed is also well adapted to be ridden by tourists to discover the natural environment of this area. Finally, Camargue horses can also be found in suburban areas, such as in riding schools or pasture areas near houses.

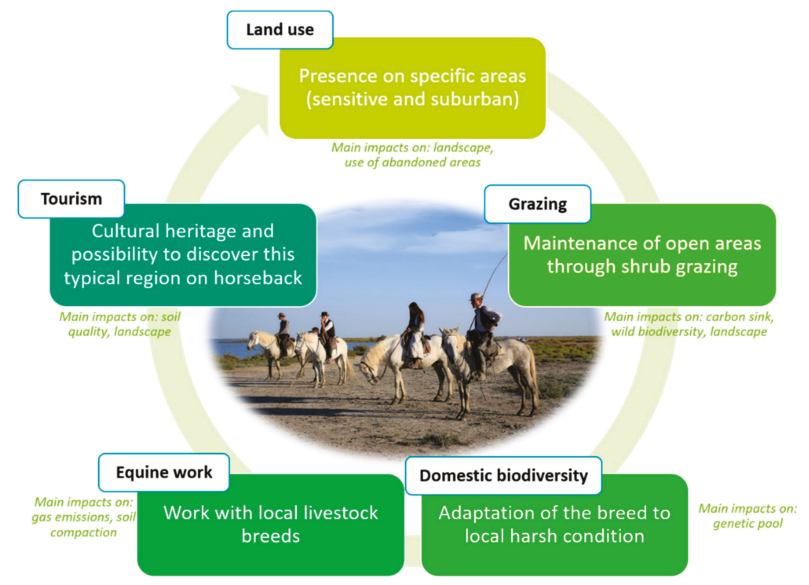

Figure 3. The Camargue horse breed as an image of the link between the five green assets. 
Each green asset has its own specificities and issues but some of these issues are common to several green assets. For example, because of the task intensity, animal traction sometimes must be assisted by another source of energy (in cities for example) [60]. To avoid soil compaction, innovative projects have emerged to improve machines, but the use of equines is not always proposed as a solution [58]. Finally, there is a need to improve the equipment for animal traction [55] and to inform stakeholders about this need. Presently, the use of equine work depends on the geographical and market opportunities created thanks to these animals [56]. These opportunities should also be developed for threatened breeds whose population have collapsed since the middle of the 20th century. Regardless of the species, these communities must face common challenges [41], such as how to ensure their competitiveness on the international market while maintaining the appearance of an iconic breed that is illustrative of regional culture and heritage, and how to conciliate the development programs and conservation programs for an already threatened breed. The uniqueness of some breeds is used to bring tourism into the breeds' native region, such as Icelandic ponies in Iceland [63], even if tourism may be a source of conflicts with other users and even sometimes a source of the deterioration of protected areas [61]. These conflicts may also appear in land use. Equine owners are often disadvantaged toward more "agricultural" productions [17]. In suburban areas, equines stand on transitional plots, which are rented or borrowed [43], within the urban network. This presence may lead to disturbances, such as smells and noises. However, in Sweden, a survey made in the suburban areas where equines were encountered showed that the inhabitants were less annoyed by equines than by other disturbances, such as noisy roads or mowers [51]. Urban planning does not consider the specificities of the equine industry. Equine owners want to keep their animals close to their houses and urban centers but are restrained because of land conflicts. If urban planning undertook a multifunctional approach for every activity [17], there would be fewer conflicts of interest [51]. Conversely, intensive equine holdings on small plots, as is often done in suburban areas, can be harmful to the landscape. This is why "horsiculture" is sometimes seen as degrading for the environment [45] as it is directly linked to the specificities of equine grazing that leave areas overgrazed if badly managed. In addition, in most cases, only broodmares and growing horses graze, while stallions or equines in training do not [22]. Moreover, the workload increases when horses and donkeys graze if they are trained daily because, sometimes, it is necessary to pick them up from distant plots [22].

Facing this context, each member state of the European Union has specificities concerning equines. Some countries orient their equine industry more toward sports and racing (e.g., England and Germany) and do not consider equines to be a source for rural development [67], whereas others highlight their equine sector through native breeds and tourism, such as Iceland [68]. Thus, impacts on the environment will be as diverse as the uses of equines and farming in each area. In some countries, equine husbandry is perceived as an intensive process (no grazing, many individuals on small plots, main outlet exported, etc.), for example, in Belgium, the Netherlands, or Luxembourg, because of the lack of available land. In other countries, equines are still used as a source of energy or entertainment, with grazing on large lands and sometimes in semi-wild conditions, such as in Poland [49]. In occidental Europe, land use by equines depends mainly on the type of area (rural, suburban, or sensitive), as discussed in the aforementioned studies. This grouping may be different in other countries, such as Romania, where horses are still used in agriculture [69]. Thus, the numbers of equines may still be anecdotal in suburban areas.

Consequently, it is important to determine how to best take advantage of the green assets of equines.

\subsection{How to Better Use Equine Green Assets}

\subsubsection{For Equine Keepers}

This knowledge is partially taught in agricultural training. Indeed, there is a lack of training courses and technical information for small equine owners to teach the specificities of equines' relationship to 
the environment. Difficulties arise from the atomization of horse owners and the diversity of horse keeping. Moreover, owners mostly raise horses in small areas with low productive value, so the technical improvements of pastures are difficult to apply. The risks of injury or escape have also been is raised by equine breeders, even if equine grazing itself is not to be feared. Advice for management practices needs to be adapted to the specific conditions of each horse keeper according to the type of meadow, the herd size, the physiological and nutritional needs of the equines, and welfare requirements. To improve this situation, communication and teaching about pasture management practices, related risks, and threats are necessary. Raising awareness and improving management practices could improve equine environmental impacts, highlight their green assets, and better use these assets in everyday practice. It is already possible to propose some examples of practical recommendations to equine owners:

- In order to avoid the overconcentration of manure in suburban areas, equine owners may build reliable partnerships with local farmers, who can use manure as fertilizer. Manure can also be recycled and rapidly composted to improve soils in city parks. Another solution is to transport manure to methanation firms for energy production [70].

- Equine grazing has interesting characteristics in pastures and shows complementarities with other herbivores, such as cattle. Thus, associating these animals could be a first step toward improving pasture quality and maintenance.

- When searching to buy an equine for leisure or tourism, looking for a native breed could be a good option if the future owner wants a hardy equine that is well adapted to the local climate. These breeds may value local feed resources better and more cheaply than other breeds. At the same time, this act would help to conserve threatened breeds, facilitating a cultural development of the region and maintaining the genetic diversity of equine species.

- When travelling on horseback, it is important to follow trails that are dedicated to horse riding, to avoid protected areas, and to take care of the paths.

- Equine work represents a diversification opportunity for riding schools. This diversification can be achieved using equines that are already present in the structures for maintenance tasks, either on site or in collaboration with local municipalities (service provision).

Despite these few examples, it is necessary to develop further recommendations for equine keepers in order to establish clear aims, build a reliable argument, and ensure adequate follow-up. These recommendations could be spread by local authorities, teaching centers, and the professional or public institutes responsible for the horse industry. As a contribution to advancing knowledge, this literature review is a first step that will need regular updates to enhance the advisors' arguments.

\subsubsection{For Institutional and Political Stakeholders}

Equines are often forgotten in political debates as they are seen as both livestock and pets. This duality is exacerbated by the large diversity of stakeholders responsible for the equine industry within Europe, including ministries of agriculture, sports, and tourism; technical institutes; research institutes; national and regional associations; breed associations; and equestrian federations. Moreover, there is a lack of practical information and courses on equine green assets that are usable by stakeholders. Promoting equine grazing and communicating about its benefits on the environment can improve different situations. This could also help integrate equines into political debates and help develop research on this topic. Hence, it is possible to propose some practical recommendations to institutional and political stakeholders:

- Equines are an interesting alternative for the maintenance of small abandoned lands in suburban areas that could be promoted by local authorities.

- In regions where grasslands or rangelands are important, local development policies could include aids in favor of the equine industry, for example, subsides for cattle farmers to also hold equines, or for the creation of numerous platforms to help horse owners meet farmers for feed purchases, pasture grazing, or the use of manure. 
- Regional subsidies could support the breeding and keeping of local breeds. These could also be integrated in local tourist events or as a vector for job-creation.

- The trails used for equestrian tourism and camping sites should be framed well to keep tourists from disturbing natural areas. Moreover, every trail should clearly indicate whether it is adapted for equines to ensure that equestrian tourists use the trails safely. Further, linking equestrian tourism stakeholders with stakeholders from the tourism sector or those in charge of protected areas could be an interesting way to develop collaborative actions to support sustainable regional development.

- When discussing new sustainable projects concerning ecological farming or public service missions in cities, equines could be included in the list of suggested alternatives based on the assets presented in this paper if all economic, social, and welfare conditions are fulfilled.

- The new 2020 CAP is in process. At a national level, its measures could better support the equine industry through new agri-environmental measures for equines, such as the use of animal traction, the practice of mixed grazing, the use of local threatened breeds, and the use of equines to maintain vacant suburban plots of land.

Finally, by gathering the available scientific knowledge about equine green assets, this paper offers some common reflections and issues about the place of equines in a sustainable regional development.

\section{Conclusions}

The equine industry is constantly evolving according to changes in society. One of the next steps is linked to the growing environmental awareness. This issue concerns citizens but also the political spheres, thereby putting pressure on the stakeholders of all economic sectors, including the equine industry. Indeed, in most European countries, environmental issues are not yet considered to be important enough by stakeholders in the equine industry. However, through their green assets, equines can have an active role in ecological transition and debates, both alone and as a complement to other economic productions and services. In the future, it could be interesting to support knowledge exchange in order to progress equine research, thus making this industry more visible and understandable, and to include equines in political debates about the environment and raise awareness about equine uses to avoid radical actions from animal activists. Creating and publishing all kinds of communication media, such as articles, photos, videos, websites, and podcasts, could be a way to reach a larger audience and make equine owners adapt their management practices to better use equine green assets.

From European organizations to society, everyone should be aware of the potential place of equines during the ecological and agronomic transition toward a greener future.

Author Contributions: Conceptualization, A.R.; investigation, A.R.; writing-original draft, A.R.; visualization, A.R.; supervision, C.V.; project administration, C.V.; writing-review and editing, C.V. and G.B.; validation, G.B. All authors have read and agreed to the published version of the manuscript.

Funding: This research was funded by the French Institute for Horse and Horse Riding (Ifce) and the European Horse Network (EHN).

Acknowledgments: The work has been carried out with the help of the National Research Institute for Environment and Agriculture (IRSTEA). The authors thank Pascale Heydemann, Amandine Julien, Agnès Orsoni, and Claire Cordilhac from IFCE and Florence Gras from EHN for their input in this study.

Conflicts of Interest: The authors declare no conflict of interest.

\section{References}

1. Evans, R. Introduction to the new equine economy in the 21st century. In EAAP Scientific Series; Vial, C., Evans, R., Eds.; Wageningen Academic Publishers: Wageningen, The Netherlands, 2015; Volume 136, pp. 11-18. ISBN 978-90-8686-279-5.

2. Leteux, S. L'hippophagie en France. La difficile acceptation d'une viande honteuse (archives) [Horse meat in France. Difficult acceptance of a shameful meat]. Terrains Trav. 2005, 9, 143-158. 
3. Rossier, E.; Coleou, J.; Blanc, H. Les effectifs de chevaux en France et dans le monde [Numberof horses in France and in the world]. In Le Cheval: Reproduction, Sélection, Alimentation, Exploitation [The horse: Breeding, selection, feeding, holding]; INRA: Paris, France, 1984.

4. Häggblom, M.; Rantamäki-Lahtinen, L.; Vihinen, H. Equine Sector Comparison between The Netherlands, Sweden and Finland; Equine Life; MTT Agrifood Research Finland: Jokioinen, Finland, 2008.

5. Swedish University of Agricultural Science; MTT Agrifood Research in Finland; Latvia University of Agriculture. Current Status of Equine Sector in the Central Baltic Region (Finland, Latvia and Sweden); Swedish University of Agricultural Science: Alnarp, Sweden, 2012; p. 47.

6. Vidal, C. Thirty years of agriculture in Europe: holdings with grazing livestock have followed different paths. Eurostat Stat. Focus 2002, 25, 8.

7. Liljenstolpe, C. Horses in Europe; Swedish University of Agricultural Sciences: Uppsala, Sweden, 2009; p. 32.

8. Jez, C.; Coudurier, B.; Cressent, M.; Méa, F.; Perrier-Cornet, P.; Rossier, E. La Filière Equine Française à L'Horizon 2030 [French Equine Industry in 2030]; INRA-IFCE: Paris, France, 2012.

9. Engelsen, A.; IFCE; EHN. What are the Laws for Equines in Europe? Synthèse; IFCE: Paris, France; Haras Nationaux: Le Pin-au-Haras, France, 2017; ISBN 978-2-915250-56-5.

10. Perrot, C.; Barbin, G.; Bossis, N.; Champion, F.; Morhain, B.; Morin, E. L'Élevage d'Herbivores au Recensement Agricole 2010. Cheptels, Exploitations, Productions. [Herbivore farming according to the Agricultural Census 2010.Livestock, farms, productions]; IDELE: Paris, France, 2013; p. 96.

11. Vial, C.; Bigot, G.; Heydemann, P.; Cordilhac, C. Les chiffres clés de la filière équine à l'international: Un essai de collecte d'informations [Key figures of the international equine sector: An attempt of data collection]. IFCE 2017, 6, 7.

12. Geels, F.; Turnheim, B.; Asquith, M.; Kern, F.; Kivimaa, P. European Environment Agency Sustainability Transitions: Policy and Practice; European Environment Agency: København, Denmark, 2019. [CrossRef]

13. Angers, D.A.; Arrouays, D.; Saby, N.P.A.; Walter, C. Estimating and mapping the carbon saturation deficit of French agricultural topsoils: Carbon saturation of French soils. Soil Use Manag. 2011, 27, 448-452. [CrossRef]

14. Soussana, J.-F.; Loiseau, P.; Vuichard, N.; Ceschia, E.; Balesdent, J.; Chevallier, T.; Arrouays, D. Carbon cycling and sequestration opportunities in temperate grasslands. Soil Use Manag. 2004, 20, 219-230. [CrossRef]

15. Saastamoinen, M.; Herzon, I.; Särkijärvi, S.; Schreurs, C.; Myllymäki, M. Horse Welfare and Natural Values on Semi-Natural and Extensive Pastures in Finland: Synergies and Trade-Offs. Land 2017, 6, 69. [CrossRef]

16. Jouven, M.; Vial, C.; Fleurance, G. Horses and rangelands: Perspectives in Europe based on a French case study. Grass Forage Sci. 2016, 71, 178-194. [CrossRef]

17. Bomans, K.; Dewaelheyns, V.; Gulinck, H. Pasture for horses: An underestimated land use class in an urbanized and multifunctional area. Int. J. Sustain. Dev. Plan. 2011, 6, 195-211. [CrossRef]

18. Garrido, P.; Mårell, A.; Öckinger, E.; Skarin, A.; Jansson, A.; Thulin, C. Experimental rewilding enhances grassland functional composition and pollinator habitat use. J. Appl. Ecol. 2019, 56, 946-955. [CrossRef]

19. Lefebvre, T.; Gallet, C. Impacts des grands herbivores sur la végétation des prairies et conséquences sur la décomposition de la litière [Impacts of large herbivores on plants: Consequences for litter decomposition]. INRA Prod. Anim. 2018, 30, 455-464. [CrossRef]

20. Fleurance, G. Impact du Pâturage Equin sur la Diversité Biologique des Prairies [Impacts of Equine Grazing on Biological Diversity of Pastures]. In Proceedings of the Sommet de l'Elevage, Clermont-Ferrand, France, 2-4 October 2008.

21. Orth, D. Impact sur la végétation ligneuse d'un troupeau mixte de bovins et d'équins en conditions de sous-chargement [Impacts of a mixed herd (cattle/equine) on shrubby vegetation in conditions of low stocking rate]. Fourrages 2011, 207, 201-209. Available online: https://prodinra.inra.fr/record/179486 (accessed on 8 January 2020).

22. Bigot, G.; Mugnier, S.; Brétière, G.; Gaillard, C.; Ingrand, S. Roles of horses on farm sustainability in different French grassland regions. In EAAP Scientific Series; Vial, C., Evans, R., Eds.; Wageningen Academic Publishers: Wageningen, The Netherlands, 2015; Volume 136, pp. 177-186. ISBN 978-90-8686-279-5.

23. U.S. Environmental Protection Agency. 14.4 Enteric Fermentation-Greenhouse Gases. In Compilation of Air Pollutant Emission Factors; U.S. Environmental Protection Agency: Washington, DC, USA, 1995; Volume 1.

24. De Cara, S.; Thomas, A. Évaluation des émissions de $\mathrm{CH} 4$ par les équins [Evaluation of $\mathrm{CH} 4$ emissions by equine]. In Projections des Missions/Absorptions de Gaz à Effet de Serre Dans Les Secteurs Forêt et Agriculture aux Horizons 2010 et 2020; INRA: Paris, France, 2008; pp. 146-148. 
25. Fraser, M.D.; Stanley, C.R.; Hegarty, M.J. Recognising the potential role of native ponies in conservation management. Biol. Conserv. 2019, 235, 112-118. [CrossRef]

26. López, C.L.; Celaya, R.; Ferreira, L.M.M.; García, U.; Rodrigues, M.A.M.; Osoro, K. Comparative foraging behaviour and performance between cattle and horses grazing in heathlands with different proportions of improved pasture area. J. Appl. Anim. Res. 2019, 47, 377-385. [CrossRef]

27. López-Bao, J.V.; Sazatornil, V.; Llaneza, L.; Rodríguez, A. Indirect Effects on Heathland Conservation and Wolf Persistence of Contradictory Policies that Threaten Traditional Free-Ranging Horse Husbandry: Threats to traditional horse husbandry. Conserv. Lett. 2013, 6, 448-455. [CrossRef]

28. Ringmark, S.; Skarin, A.; Jansson, A. Impact of Year-Round Grazing by Horses on Pasture Nutrient Dynamics and the Correlation with Pasture Nutrient Content and Fecal Nutrient Composition. Animals 2019, 9, 500. [CrossRef] [PubMed]

29. Bott, R.C.; Greene, E.A.; Koch, K.; Martinson, K.L.; Siciliano, P.D.; Williams, C.; Trottier, N.L.; Burk, A.; Swinker, A. Production and Environmental Implications of Equine Grazing. J. Equine Vet. Sci. 2013, 33, 1031-1043. [CrossRef]

30. Launay, F.; Genevet, E.; Jouven, M.; Auréjac, R.; IDELE. Les Parcours: Des Pâtures Intéressantes Pour les Equins Dans les Régions Méditéranéennes [Heathlands: Interesting Pastures for Equine in Mediterranean Regions]; IDELE, Oier-suamme: Paris, France; Montpellier SupAgro, CE LR: Montpellier, Occitanie, France, 2014; p. 15.

31. Fleurance, G.; Duncan, P.; Farruggia, A.; Dumont, B.; Lecomte, T. Impact du pâturage équin sur la diversité floristique et faunistique des milieux pâturés [Impacts of equine grazing on floral and animal diversity in grazed areas]. Fourrages 2011, 207, 189-199. Available online: https://afpf-asso.fr/revue/l-utilisation-desressources-prairiales-et-du-territoire-par-le-cheval?a=1848 (accessed on 8 January 2020).

32. Tälle, M.; Deák, B.; Poschlod, P.; Valkó, O.; Westerberg, L.; Milberg, P. Grazing vs. mowing: A meta-analysis of biodiversity benefits for grassland management. Agric. Ecosyst. Environ. 2016, 222, 200-212. [CrossRef]

33. Bigot, G.; Brétière, G.; Micol, D.; Turpin, N. Management of cattle and draught horse to maintain openness of landscapes in French Central Mountains. In Proceedings of the 17th Meeting of the FAO-CIHEAM Mountain Pasture Network, Pastoralism and Ecosystem Conservation, Trivero, Italy, 5-7 June 2013; pp. 72-75.

34. Morhain, B. Systèmes fourragers et d'alimentation du cheval dans différentes régions françaises [Forage and feed system for equine in different French regions]. Fourrages 2011, 207, 155-163. Available online: https: //afpf-asso.fr/revue/l-utilisation-des-ressources-prairiales-et-du-territoire-par-le-cheval?a=1844 (accessed on 8 January 2020).

35. Forteau, L.; Dumont, B.; Sallé, G.; Bigot, G.; Fleurance, G. Horses grazing with cattle have reduced strongyle egg count due to the dilution effect and increased reliance on macrocyclic lactones in mixed farms. Animal 2019, 1-7. [CrossRef]

36. Miraglia, N. Sustainable development and equids in rural areas: An open challenge for the territory cohesion. In EAAP Scientific Series; Vial, C., Evans, R., Eds.; Wageningen Academic Publishers: Wageningen, The Netherlands, 2015; Volume 136, pp. 167-176. ISBN 978-90-8686-279-5.

37. Institut Français du Cheval et de L'équitation. Les races d'équidés et leurs utilisations dans le monde [Equine breeds and uses in the world]. In Panorama Economique de la Filière Equine: Synthèse; Institut Français du Cheval et de L'équitation: Le Pin au Haras, France, 2011; pp. 34-35, ISBN 978-2-915250-19-0.

38. Camillo, F.; Rota, A.; Biagini, L.; Tesi, M.; Fanelli, D.; Panzani, D. The Current Situation and Trend of Donkey Industry in Europe. J. Equine Vet. Sci. 2018, 65, 44-49. [CrossRef]

39. Bigot, G.; Vial, C.; Fleurance, G.; Heydemann, P.; Palazon, R. Productions et activités équines en France: Quelles contributions à la durabilité de l'agriculture? [Equine production and activities in France: What contributions to the sustainability of agriculture?]. INRA Prod. Anim. 2018, 31, 37-50. [CrossRef]

40. Miraglia, N. Equids contribution to sustainable development in rural areas: a new challenge for the third millennium. In Forages and Grazing in Horse Nutrition; Saastamoinen, M., Fradinho, M.J., Santos, A.S., Miraglia, N., Eds.; Wageningen Academic Publishers: Wageningen, The Netherlands, 2012; pp. 439-452, ISBN 978-90-8686-755-4.

41. Lauvie, A.; Audiot, A.; Couix, N.; Casabianca, F.; Brives, H.; Verrier, E. Diversity of rare breed management programs: Between conservation and development. Livest. Sci. 2011, 140, 161-170. [CrossRef]

42. Leinonen, R.-M.; Dalke, K. National Treasure: Nationalistic Representations of the Finnhorse in Trotting Championships. In Equestrian Cultures in Global and Local Contexts; Adelman, M., Thompson, K., Eds.; Springer International Publishing: Cham, Germany, 2017; pp. 105-117, ISBN 978-3-319-55885-1. 
43. Vial, C. Le développement des activités équestres dans les campagnes françaises: Enjeux et conséquences pour les territoires ruraux et périurbains [Developpment of equine activities in French countryside: Issues and consequences for rural and suburban areas]. In Proceedings of the the Colloque de Cerisy: Les Chevaux de L'imaginaire Universel aux Enjeux Prospectifs pour les Territoires; Presses Universitaires de Caen, Cerisy-la-Salle, France, 17-22 May 2014;

44. Perret, É.; Turpin, N. Territoires et exploitations équines en France [Equine territories and holdings in France]. Écon. Rural. Agric. Aliment. Territ. 2016, 85-98. [CrossRef]

45. Elgåker, H.; Wilton, B.L. Horse farms as a factor for development and innovation in the urban-rural fringe with examples from Europe and Northern America. In Proceedings of the Nature and Landscape as an Asset to Development in Rural Areas, Copenhagen, Denmark, 8-10 March 2008; University of Copenhagen: Copenhagen, Denmark, 2008; Volume 27-2008, pp. 43-55.

46. Quetier, F.F.; Gordon, I.J. 'Horsiculture': How important a land use change in Scotland? Scott. Geogr. J. 2003, 119, 153-158. [CrossRef]

47. Zasada, I.; Berges, R.; Hilgendorf, J.; Piorr, A. Horsekeeping and the peri-urban development in the Berlin Metropolitan Region. J. Land Use Sci. 2011, 8, 199-214. [CrossRef]

48. Vial, C.; Evans, R. (Eds.) The New Equine Economy in the 21st Century; EAAP Publication; Wageningen Academic Publishers: Wageningen, The Netherlands, 2015; ISBN 978-90-8686-279-5.

49. Doboszewski, P.; Doktór, D.; Jaworski, Z.; Kalski, R.; Kułakowska, G.; Łojek, J.; Płąchocki, D.; Ryś, A.; Tylkowska, A.; Zbyryt, A.; et al. Konik polski horses as a mean of biodiversity maintenance in post-agricultural and forest areas: An overview of Polish experiences. Anim. Sci. Pap. Rep. 2017, 35, 333-347.

50. Bailey, A.; Williams, N.; Palmer, M.; Geering, R. The farmer as service provider: The demand for agricultural commodities and equine services. Agric. Syst. 2000, 66, 191-204. [CrossRef]

51. Elgåker, H.; Pinzke, S.; Lindholm, G.; Nilsson, C. Horse keeping in Urban and Peri-Urban Areas: New Conditions for Physical Planning in Sweden. Geogr. Tidsskr.-Dan. J. Geogr. 2010, 110, 81-98. [CrossRef]

52. De L'Escaille, T.; (European Land Owners, Bruxelles, Belgium). Personnal communication, 2019.

53. Bigot, G.; Perret, É.; Turpin, N. L'élevage équin, un atout pour la durabilité des territoire ruraux: Cas de la région Auvergne [Equine breeding, an asset for the sustainability of rural areas: case of Auvergne region]. In Proceedings of the Identité, qualité et compétitivité territoriale; Association de Science Régionale de Langue Française, Aoste, Italy, 20-22 September 2010; p. 15.

54. Reynaud, E.; von Niederhaüsern, R.; Ackermann, C. Le cheval de travail en Suisse, enquête 2017 [Working horse in Switzerland, survey 2017]. Agroscope Transf. 2018, 51. Available online: https://www.agroscope. admin.ch/agroscope/fr/home/publications/recherche-publications/agroscope-transfer.html (accessed on 8 January 2020).

55. Almeida, A.; Rodrigues, J. Animal Traction: New Opportunities and New Challenges. In Proceedings of the Farm Machinery and Processes Management in Sustainable Agriculture, IX International Scientific Symposium, Lublin, Poland, 20-24 November 2017; pp. 27-31.

56. Cerutti, A.K.; Calvo, A.; Bruun, S. Comparison of the environmental performance of light mechanization and animal traction using a modular LCA approach. J. Clean. Prod. 2014, 64, 396-403. [CrossRef]

57. Głębocki, B.; Główny Urząd Statystyczny. Produkcja zwierzęca-Rozwój i zmiany przestrzenne w latach 2002-2010-9.7 konie [Animal production—evolution and land development between 2002-2010-9.7 Horses]. In Zróżnicowanie Przestrzenne Rolnictwa: Powszechny Spis Rolny 2010: Praca Zbiorowa; Główny Urząd Statystyczny: Warszawa, Poland, 2014; pp. 402-409. ISBN 978-83-7027-556-3.

58. Gantner, R.; Baban, M.; Glavaš, H.; Ivanović, M.; Schlechter, P.; Šumanovac, L.; Zimmer, D. Indices of sustainability of horse traction in agriculture. In Proceedings of the 3. Međunarodni Znanstveni Simpozij Gospodarstvo Istočne Hrvatske-Vizija i Razvoj/3rd International Scientific Symposium Economy of Eastern Croatia-Vision and Growth, Osijek, Croatia, 22-24 May 2014; Volume 3, pp. 616-626.

59. Steven, R.; Pickering, C.; Guy Castley, J. A review of the impacts of nature based recreation on birds. J. Environ. Manag. 2011, 92, 2287-2294. [CrossRef] [PubMed]

60. Linot, O. La commission des chevaux territoriaux en France [The commission of territorial horses in France]. In Les Chevaux: De L'imaginaire Universel aux Enjeux Prospectifs pour les Territoires; Leroy du Cardonnoy, É., Vial, C., Eds.; Colloques de Cerisy; Presses Universitaires de Caen: Caen, France, 2017; pp. 161-171, ISBN 978-2-84133-864-1. 
61. Pickel-Chevalier, S. Can equestrian tourism be a solution for sustainable tourism development in France? Loisir Soc./Soc. Leis. 2015, 38, 110-134. [CrossRef]

62. EU Equus. The Horse Industry in the European Union; Department of Economics Swedish University of Agricultural Sciences: Skara/Solvalla, Sweden, 2001; p. 50.

63. Sigurðardóttir, I.; Helgadóttir, G. Riding High: Quality and Customer Satisfaction in Equestrian Tourism in Iceland. Scand. J. Hosp. Tour. 2015, 15, 105-121. [CrossRef]

64. Pickering, C.M.; Hill, W.; Newsome, D.; Leung, Y.-F. Comparing hiking, mountain biking and horse riding impacts on vegetation and soils in Australia and the United States of America. J. Environ. Manag. 2009, 91, 551-562. [CrossRef]

65. Kozak, M.W. Making Trails: Horses and Equestrian Tourism in Poland. In Equestrian Cultures in Global and Local Contexts; Adelman, M., Thompson, K., Eds.; Springer International Publishing: Cham, Germany, 2017; pp. 131-152, ISBN 978-3-319-55885-1.

66. Vial, C.; Gouget, J.-J.; Barget, E.; Clipet, F.; Caillarec, C. Manifestations Equestres et Développement Local [Equestrian Events and Local Development], 1st ed.; Synthèse; Institut Français du Cheval et de L'équitation: Arnac-Pompadour, France, 2016; ISBN 978-2-915250-45-9.

67. McCarthy, K.; Cosgrove, A.; Zelmer, A. A Study into the Business \& Skills Requirements of the UK Equine Industry; Lantra: Warwickshire, UK, 2011; p. 112.

68. Sigurðardóttir, I.; Helgadóttir, G. The new equine economy of Iceland. In EAAP Scientific Series; Vial, C., Evans, R., Eds.; Wageningen Academic Publishers: Wageningen, The Netherlands, 2015; Volume 136, pp. 223-236, ISBN 978-90-8686-279-5.

69. World Horse Welfare; Eurogroup for Animals. Removing the Blinkers: The Health and Welfare of European Equidae in 2015; World Horse Welfare: London, UK; Eurogroup for Animals: Brussels, Belgium, 2015; p. 122.

70. Bellino, R.; Affeltranger, B.; Battistini, B.; Evanno, S.; Le Pochat, S. Comparative environmental assessment of two systems of agronomic and energetic valorisation of horse manure. In Proceedings of the 2nd LCA Conference, Lille, France, 6-7 November 2012; p. 7.

(C) 2020 by the authors. Licensee MDPI, Basel, Switzerland. This article is an open access article distributed under the terms and conditions of the Creative Commons Attribution (CC BY) license (http://creativecommons.org/licenses/by/4.0/). 
MDPI

St. Alban-Anlage 66

4052 Basel

Switzerland

Tel. +41616837734

Fax +41 613028918

www.mdpi.com

Animals Editorial Office

E-mail: animals@mdpi.com www.mdpi.com/journal/animals

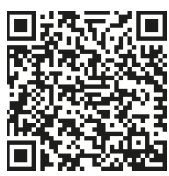



MDPI

St. Alban-Anlage 66

4052 Basel

Switzerland

Tel: +41 616837734

Fax: +41 613028918

www.mdpi.com 